\title{
Toward the Synthesis of the Fungal Metabolite (-)-TAN-2483B
}

by

Daniel Francis James Phipps

A thesis submitted to Victoria University of Wellington in partial fulfilment of the requirements for the degree of Master of Science in Chemistry 


\begin{abstract}
In the search of chemical species with potential therapeutic biological activity, synthetic chemists have looked to nature for inspiration. Molecules built by biological machinery often have structures predisposed for biological interaction.

(-)-TAN-2483B and the related compounds (-)-TAN-2483A, and waol A are fungal metabolites that display biological activity in kinase inhibition and parathyroid-induced bone resorption. Though total syntheses of (-)-TAN-2483A and waol A have been achieved, the established methodology does not afford access to (-)-TAN-2483B owing to the unique relative configuration about the ring system.
\end{abstract}

Derivatives of D-galactal have been synthesised, and functionalised at the C-1 and C-2 positions, laying the groundwork for a route to (-)-TAN-2483B and analogues. Using Dgalactal derivatives is advantageous as it circumvents some difficult transformations in the existing method for analogue synthesis.

The functionalities installed were halide and formyl groups at the C-2 position, and acetylenes at the $\mathrm{C}-1$ position. The synthesis of 2-haloglycals from tri- $O$-acetyl-D-galactal using $\mathrm{N}$ halosuccinimides was achieved in $32 \%$ and $<37 \%$ for the bromo- and iodo- variants respectively. Vilsmeier-Haack formylation was explored using per-benzylated and peracetylated galactals as substrates. Formylation of the per-benzylated species was achieved in $78 \%$ yield in accordance with literature values. Vilsmeier-Haack formylation on the peracetylated galactal has not been reported and the glycal was found to be a poor substrate for the formylation. Theories regarding the incompatibility of the per-acetylated species with Vilsmeier-Haack conditions were developed.

Ferrier-type alkynylation of the 2-halo/formylglycals was explored, with yields up to $17 \%$ and $13 \%$ for the bromo- and iodo- species (unoptimised), and $7 \%$ for 2 -formylglycal (after optimisation studies). The resulting 1-ethynyl-2-formyl/halo-2,3-unsaturated pyrans could be potential intermediates en route to the furanone ring of the target compound. 


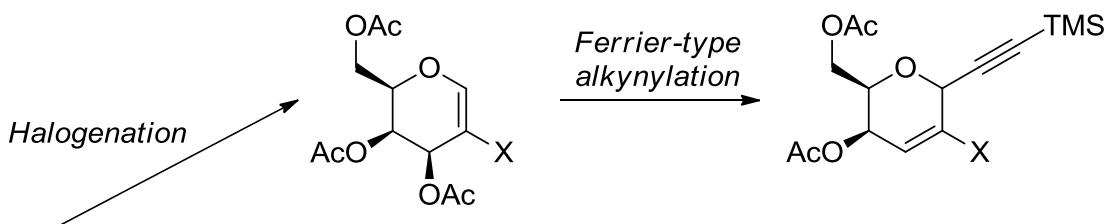<smiles>CC(=O)OC[C@H]1OC=C[C@H](OC(C)=O)[C@H]1OC(C)=O</smiles><smiles>CC(=O)OC[C@H]1OC=C(C=O)C(=O)[C@H]1OC(C)=O</smiles><smiles>C/C=C/[C@H]1O[C@H]2C(=C[C@H]1O)C(=O)O[C@H]2C</smiles>

2) Benzylation

3) Vilsmeier-Haack formylation<smiles>O=CC1=CO[C@H](COCc2ccccc2)[C@@H](O)[C@H]1OCc1ccccc1</smiles>

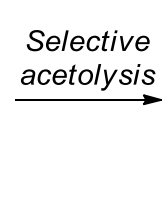<smiles>CC(=O)OC[C@H]1OC=C(C=O)[C@H](OC(C)=O)[C@H]1OC(=O)O</smiles>

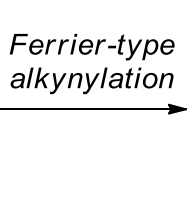<smiles>CC(C)(C)OC[C@H]1OC(C#C[13CH3])C(C=O)=C[C@H]1OCc1ccccc1</smiles> 


\section{ACKNOWLEDGEMENTS}

Thank you, Dr Joanne Harvey. Under your supervision I've learned a great deal. You've been a more than adequate mentor, and have also given me valuable insight in how my name can be made into chemistry puns. Your enthusiasm for, and maybe even some of your knowledge of organic chemistry have rubbed off on me. Unfortunately I haven't adopted your sense of punctuality or organisation skills.

The members of the organic synthesis research group have made my masters experience something great. In no particular order, Claire C, Jordan M, Tao X, Ethan W, Sophie G, Jamie FT, Matt F, Hedley S, Will D, Ash A, Thomas B, Chris O, Sarah B, Ben D, Jingjing W, José PR, Loïc L, Helena W, with a special mention to Amira B - thank you all for good times and good yarns.

Thank you to everyone in and around the SCPS who have made the department such an enjoyable place to be. Paul Teesdale-Spittle, your wisdom and sense of humour in group meeting and in life is unmatched. I have had some great times with people around the place at Friday drinks and beyond. I've made some friendships that I'm sure will be lasting.

I can't forget to thank Ian Vorster, Sarah A, Ethan W, and Sophie G, for assistance with NMR and MS experiments.

My flatmates past and present deserve a mention for being good distractions from study. Living with all of you has really been an awesome time.

Sarah A, this thesis wouldn't be what it is without you. You've helped me in so many ways from proofreading to paintball. Thank you so much.

My parents Arthur and Maria are probably the most supportive people in the world. A mention in this acknowledgements section does not nearly express how grateful I am to have you.

I think this is everything. Please enjoy the thesis. 


\section{TABLE OF CONTENTS}

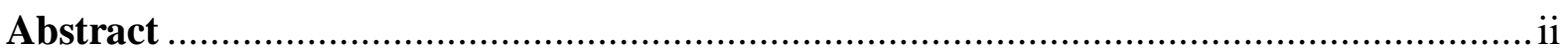

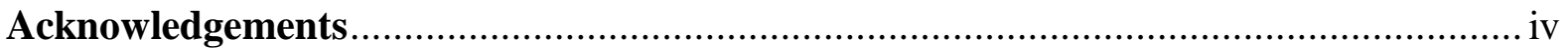

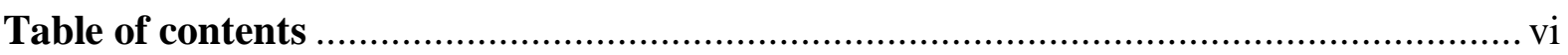

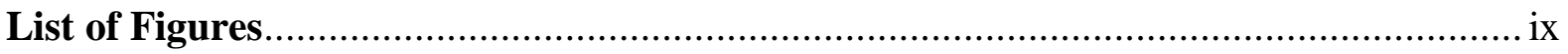

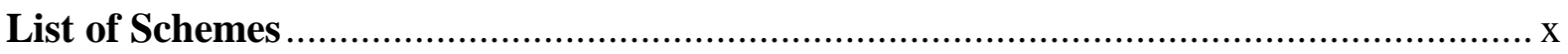

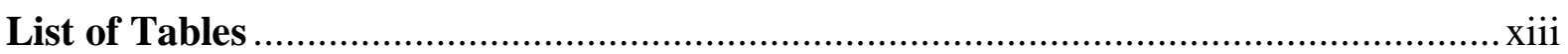

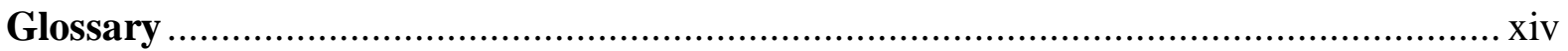

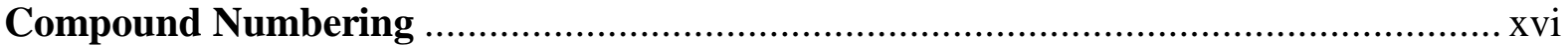

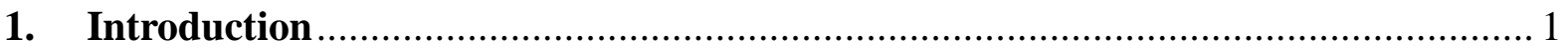

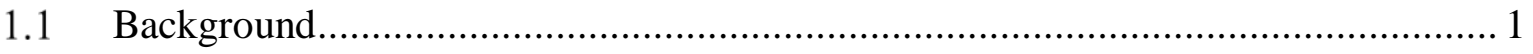

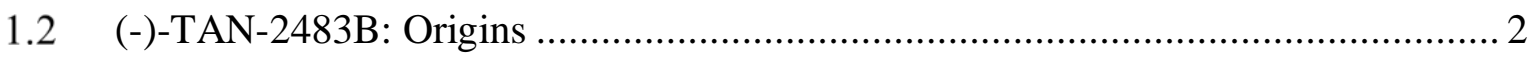

1.3 Therapeutic Potential: Biological Activity of Related Species ................................ 3

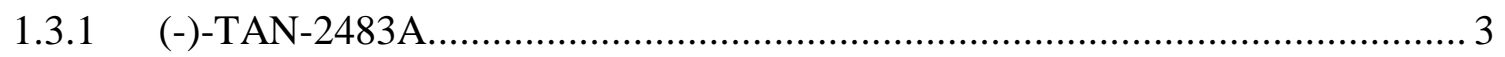

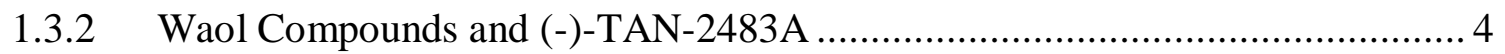

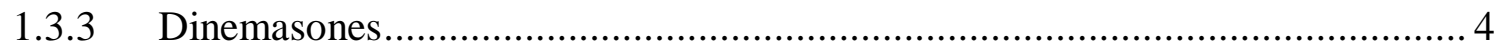

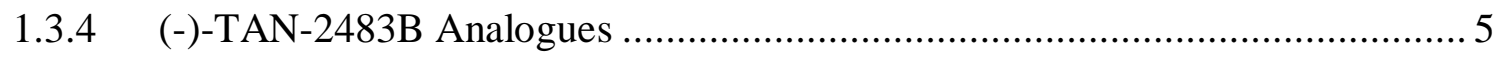

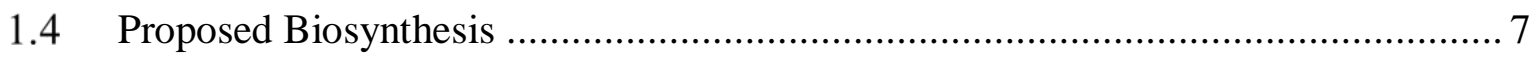

1.5 Synthesis of (-)-TAN-248A, Waol A, and Waol B ............................................... 8

1.6 Synthesis of (-)-TAN-2483B Analogues.......................................................... 10

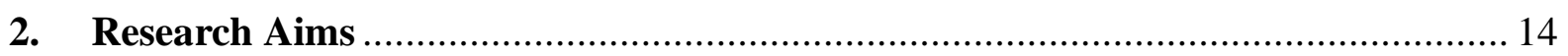

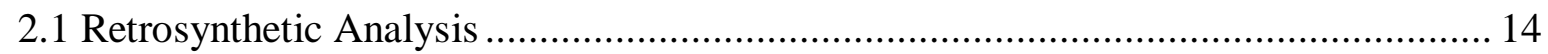

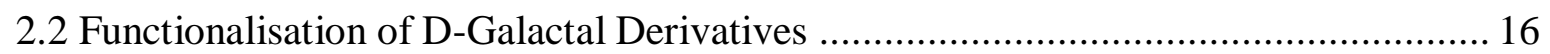

2.2.1 The Applicability of 2-Haloglycals to the Synthesis of (-)-TAN-2483B ......... 16

2.2.2 The Applicability of 2-Formylglycals to the Synthesis of (-)-TAN-2483B .......... 17

2.2.3 Ferrier-Type Alkynylation: Functionalisation at C-1 .................................. 21

2.3 Ring Closure via Formylation and Alkynylation............................................. 23

2.3.1 Pinnick Oxidation: $\alpha, \beta$-Unsaturated Aldehyde to the Acid ........................... 24

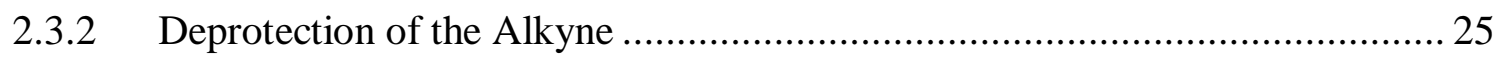

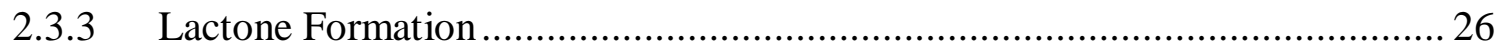

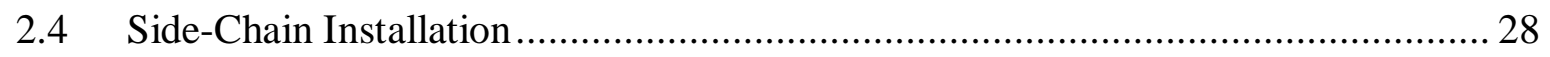

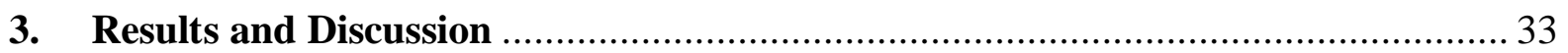

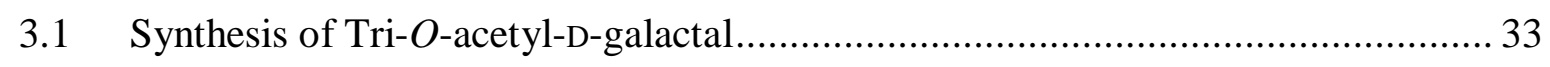

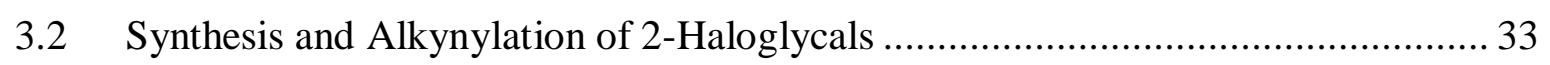

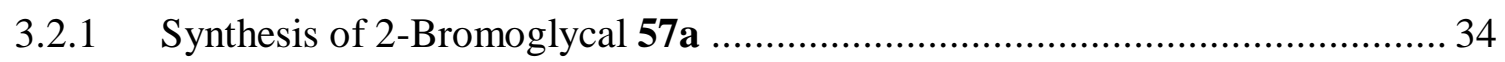




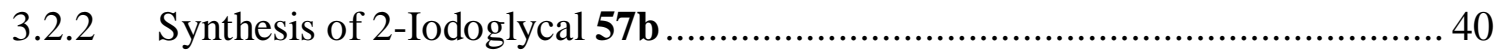

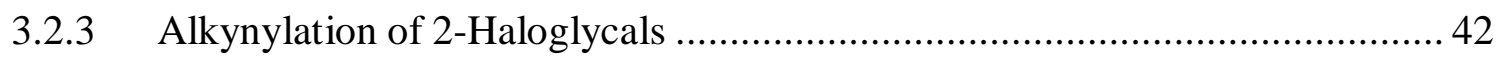

3.3 Vilsmeier-Haack Formylation of D-Galactal Derivatives .................................... 45

3.4 Synthesis of the Differentially Protected 2-Formylglycal 66 via Vilsmeier-Haack

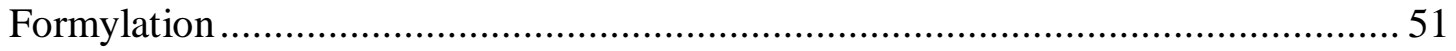

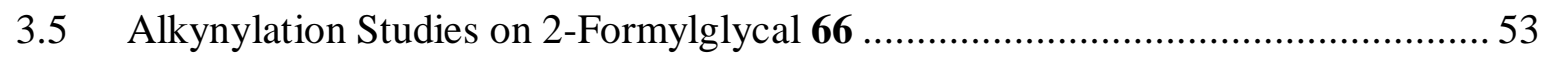

3.5.1 Initial Attempts at Ferrier-type Alkynylation of 66 ....................................5

3.5.2 Exploration of Boron Trifluoride Diethyl Etherate as a Lewis acid for Ferrier-

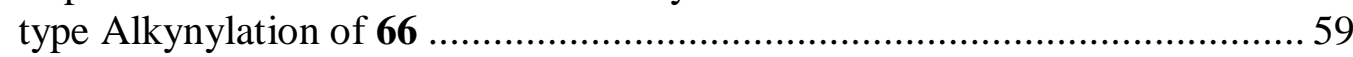

3.5.3 Exploration of Tin(IV) Chloride as a Lewis acid for Ferrier-type Alkynylation

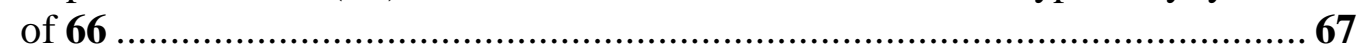

3.5.4 Exploration of Cossy's Methodology for Ferrier-type Alkynylation of 66 ...... 70

3.5.5 Exploration of Mukherjee's Methodology for Ferrier-type Alkynylation of $\mathbf{6 6 7 1}$

3.5.6 Attempts at Alkynylation of 2-Formylglycal 66 Using Acetylides ................. 72

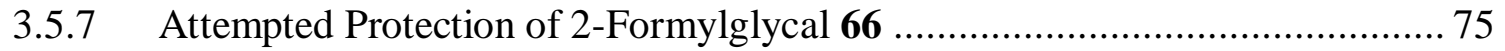

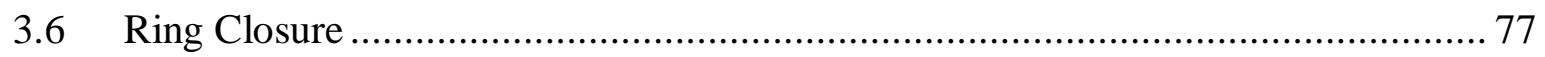

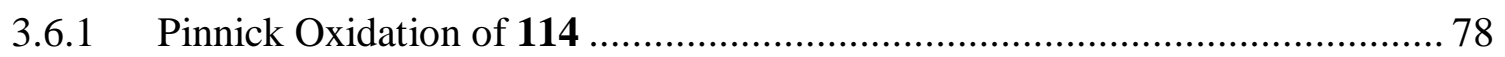

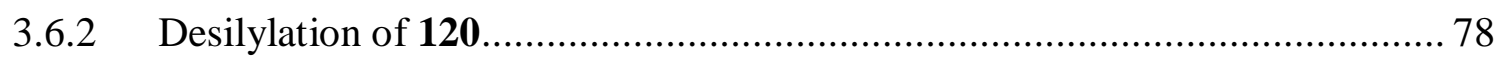

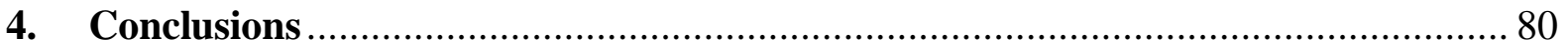

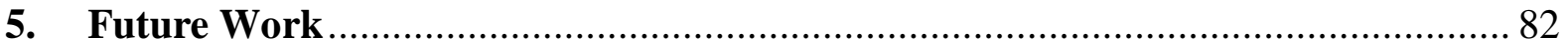

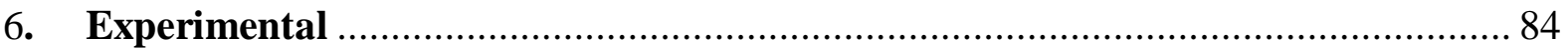

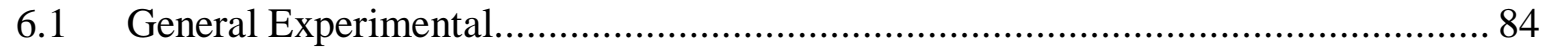

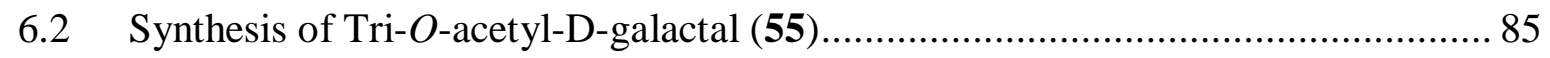

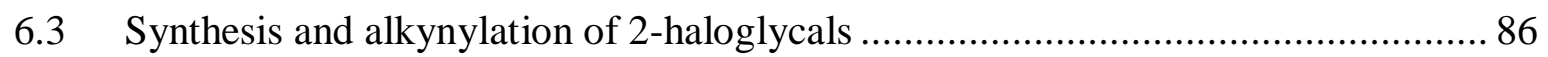

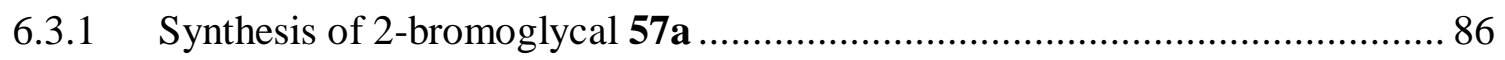

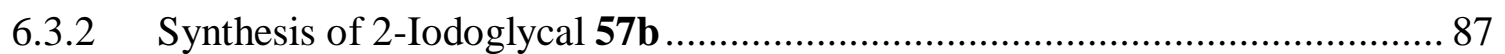

6.3.3 Formation of 112a and 113a from 2-Bromoglycal 57a ............................. 88

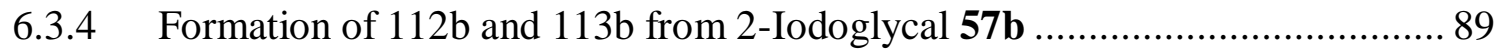

6.4 Synthesis of the Differentially Protected 2-Formylglycal 66 ............................... 90

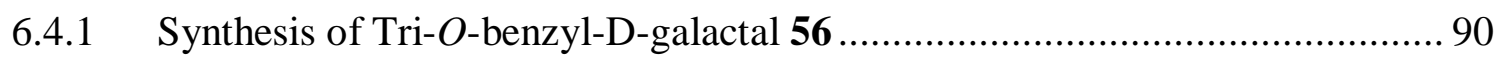

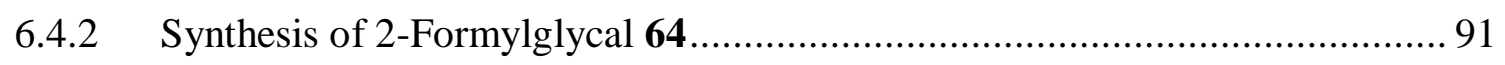

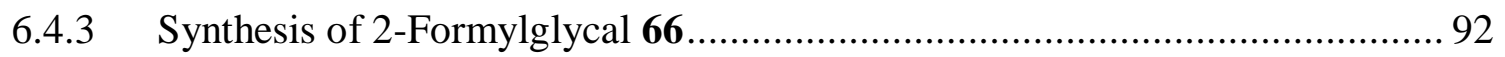

6.5 Products obtained from Ferrier-type Alkynylation Experiments ......................... 93

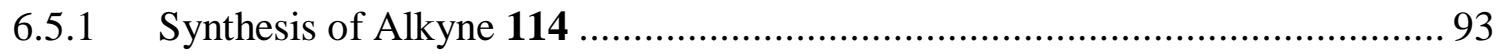

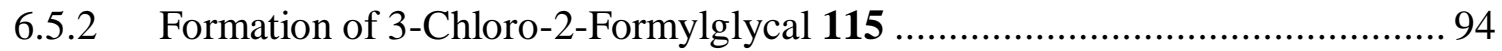

6.5.3 Formation of 3-Acetomido-2-formylglycal 116 ....................................... 95

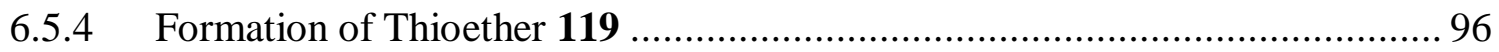

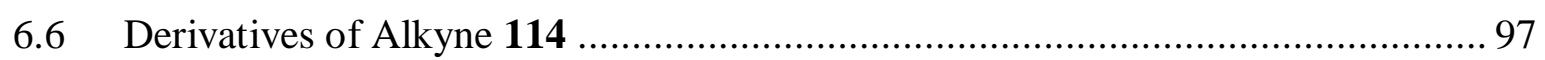




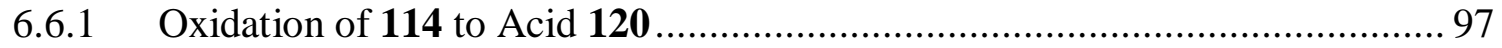

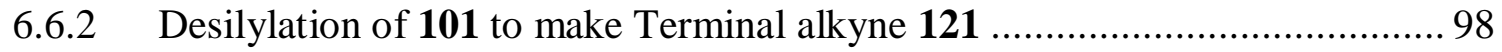

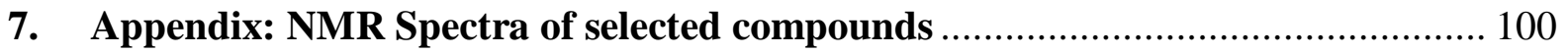

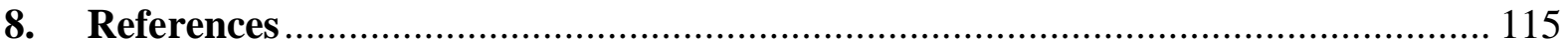




\section{LIST OF FIGURES}

Figure 1.1: Structure of the target compound (-)-TAN-2483B (1) ................................... 2

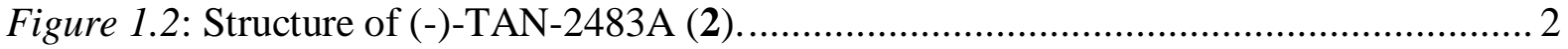

Figure 1.3: Incorrect structure of waol A proposed by Mizoue (3), and revised structure

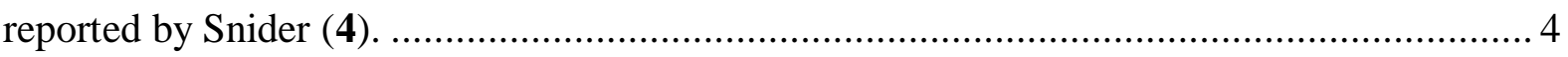

Figure 1.4: Compounds submitted for the NCI assay...................................................... 4

Figure 1.5: The dinemasone natural products isolated by Krohn.......................................5

Figure 1.6: Biologically active dinemasone species. ..................................................... 5

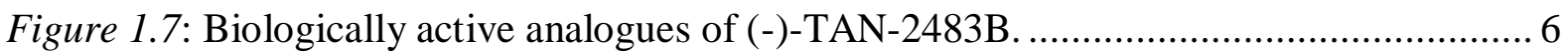

Figure 3.1: ${ }^{1} \mathrm{H}$ NMR spectra of 57a and by-products post-column (top); crude reaction mixture where both 57a and the by-products were observed (middle); reaction mixture where only trace 57a was observed (bottom).

Figure 3.2: Proposed structure of one of the persistent by-products (top left), isotope cluster of 111 (top right), ${ }^{1} \mathrm{H}$ NMR spectrum (middle), and except of ${ }^{13} \mathrm{C}$ NMR spectrum (bottom).37 Figure 3.3: 2-Iodoglycal 57b as a solid (left) and in chloroform after $\sim 2$ days (right)......... 41

Figure 3.4: ${ }^{1} \mathrm{H}$ NMR spectra of the crude reaction mixtures pictured in Scheme 3.9 .......... 47

Figure 3.5: ${ }^{1} \mathrm{H}$ NMR spectrum of the aqueous phase of entry 3 (Table 3.2) in $\mathrm{CDCl}_{3} \ldots \ldots \ldots . .50$

Figure 3.6: ${ }^{1} \mathrm{H}$ NMR spectrum of the crude reaction mixture of entry 4 (Table 3.4)............ 58

Figure 3.7: ${ }^{1} \mathrm{H}$ NMR spectrum of less polar species isolated from entry 7 (Table 3.4). ........ 58

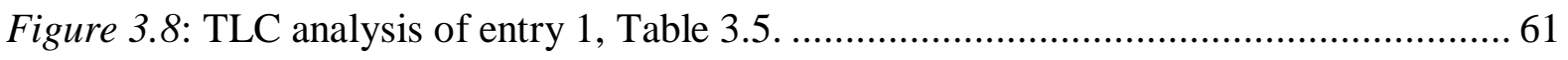

Figure 3.9: ${ }^{1} \mathrm{H}$ NMR spectrum of a non-sugar by-product isolated from alkynylation attempts

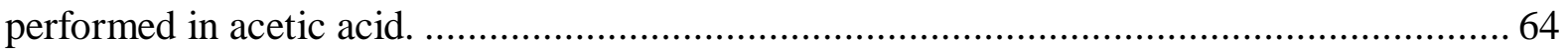

Figure 3.10: ${ }^{1} \mathrm{H}$ NMR spectra of 116 (above), and starting material 66 (below).................. 66

Figure 3.11: ${ }^{1} \mathrm{H}$ NMR spectrum of a less polar species isolated from an alkynylation attempt using a sodiated acetylide in dimethylformamide. 


\section{LIST OF SCHEMES}

Scheme 1.1: Proposed biosynthetic pathway to the TAN compounds. ................................. 7

Scheme 1.2: Synthesis of (-)-TAN-2483A, waol A, and waol B reported by Snider. .............. 8

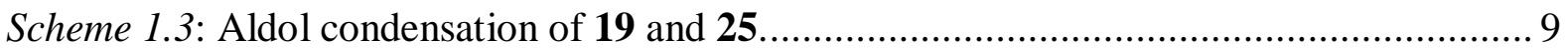

Scheme 1.4: Snider's attempted the synthesis of (-)-TAN-2483B via 29............................ 9

Scheme 1.5: Snider's attempt at the synthesis of (-)-TAN-2483B via epoxidation of 27...... 10

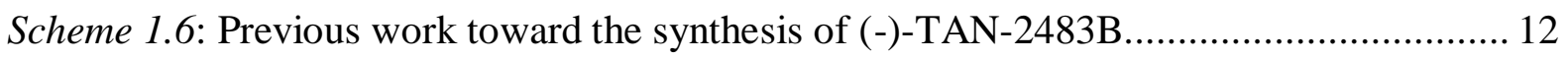

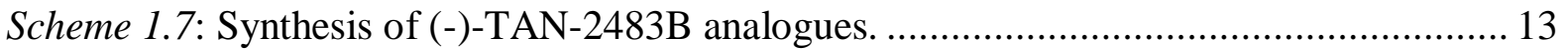

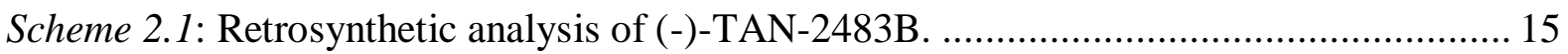

Scheme 2.2: Similarities between potential intermediate $\mathbf{5 8}$ and existing intermediate $\mathbf{4 0}$ of

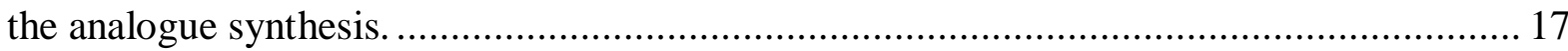

Scheme 2.3: Vilsmeier-Haack formylation of ether protected glycals............................... 18

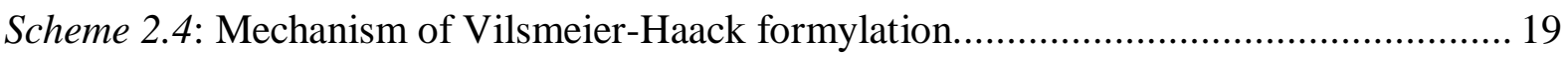

Scheme 2.5: Vilsmeier-Haack formylation of $\mathbf{5 6}$ reported by Balasubramanian. ................. 19

Scheme 2.6: Proposed transformation of $\mathbf{5 5}$ to $\mathbf{5 6}$ for use as a Vilsmeier-Haack substrate.... 20

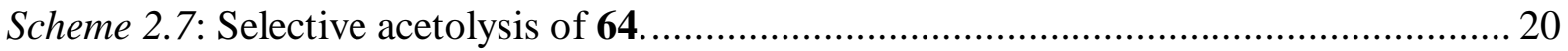

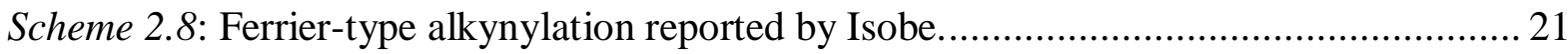

Scheme 2.9: Alkynylation of acetate protected 2-acetoxyglycals reported by Murkerjee. ..... 22

Scheme 2.10: Cossy's synthesis of 2-formyl-2,3-unsaturated $C$-glycosides......................... 22

Scheme 2.11: Proposed Ferrier-type alkynylation of 2-halo/2-formylglycals...................... 23

Scheme 2.12: Proposed Pinnick oxidation of $\alpha, \beta$-unsaturated aldehydes 72 and 73 ............ 24

Scheme 2.13: An illustration of alkyne stability under Pinnick-type conditions................... 25

Scheme 2.14: An illustration of non-reacting alkenes in Pinnick oxidation conditions. Circled

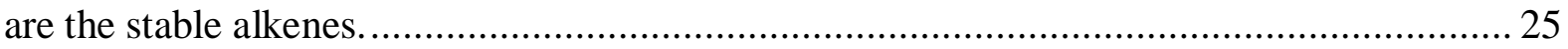

Scheme 2.15: Cleavage of the trimethylsilyl function to reveal the terminal alkyne. ........... 26

Scheme 2.16: Stability of the acetyl group in the presence of tetra- $n$-butylammonium fluoride.

Scheme 2.17: Intramolecular formation of enol lactones from terminal alkynes and carboxylic acids reported by $\mathrm{Li}$.

Scheme 2.18: Proposed cycloisomerisation of alkynoic acids $\mathbf{8 1}$ and $\mathbf{8 2}$ using the conditions prescribed by Li.

Scheme 2.19: Selective hydrogenation of an electron rich alkene in the presence of an electron deficient alkene as demonstrated by Marsh. 
Scheme 2.20: Proposed selective hydrogenation of the exo-alkene.

Scheme 2.21: Proposed Julia-Kocienski, and Takai-Utimoto olefination conditions............. 28

Scheme 2.22: Deprotection of the primary alcohol.......................................................... 29

Scheme 2.23: Aldehyde formation in the dinemasone synthesis. ..................................... 29

Scheme 2.24: Proposed olefination to install the propenyl side-chain.................................. 30

Scheme 2.25: Installation of the E-propenyl side chain of the related dinemasone species

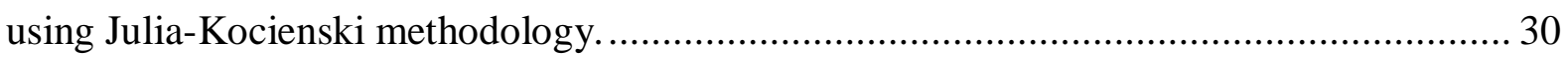

Scheme 2.26: Julia-Kocienski olefination in the toward the (-)-TAN-2483B synthesis......... 31

Scheme 2.27: Installation of the E-propenyl side chain in the dinemasone synthesis using

Takai-Utimoto methodology.

Scheme 2.28: Deprotection strategies in the final step of the proposed synthesis of (-)-TAN-

2483B.

Scheme 2.29: Lewis acid mediated benzyl cleavage as demonstrated by Somarathne. 32

Scheme 3.1: Synthesis of tri-O-acetyl-D-galactal. 33

Scheme 3.2: Vankar's synthesis of 2-haloglycals.

Scheme 3.3: Vankar's proposed mechanism of reaction between glycals and $\mathrm{N}$ -

halosuccinimides. 34

Scheme 3.4: Reactions of tri- $O$-acetyl-D-galactal (55) with $N$-bromosuccinimide................ 38

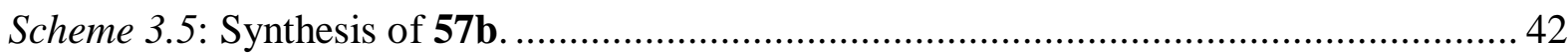

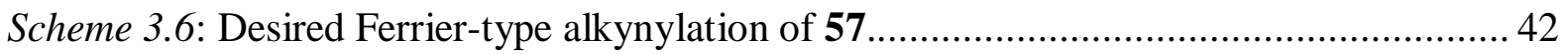

Scheme 3.7: Attempted synthesis of 93b using Mukherjee's methodology......................... 43

Scheme 3.8: Synthesis of 93 and 94 by Ferrier rearrangement........................................ 43

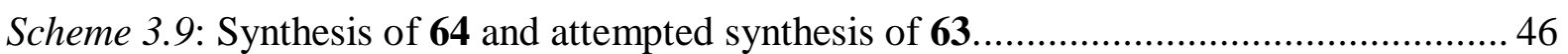

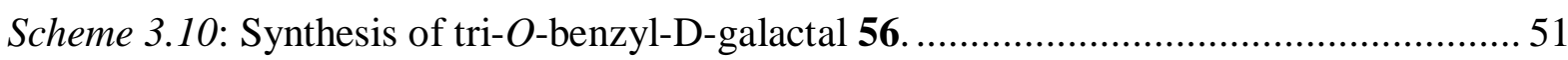

Scheme 3.11: Vilsmeier-Haack formylation of tri- $O$-benzyl-D-galactal 56. ........................ 52

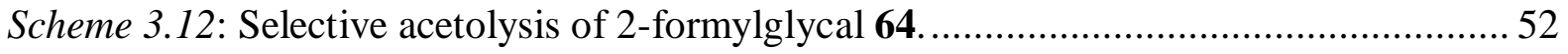

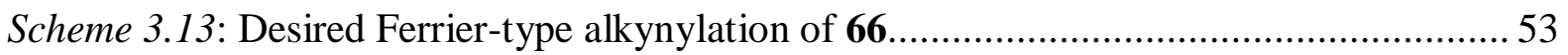

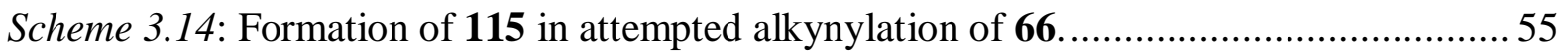

Scheme 3.15: Plausible mechanism for the formation of $\mathbf{1 1 6}$ from $\mathbf{6 6}$ in acetonitrile........... 67

Scheme 3.16: Attempted alkynylation of $\mathbf{6 6}$ using Cossy's methodology. ............................ 70

Scheme 3.17: Attempted alkynylation of 66 using Cossy's methodology in refluxing THF.. 71

Scheme 3.18: Attempt at alkynylation of 66 using Mukherjee's conditions. ........................ 72

Scheme 3.19: Attempted alkynylation of $\mathbf{6 6}$ using a sodiated acetylene. ............................ 73 
Scheme 3.20: Catalytic cycle for Sonogashira cross-coupling. Highlighted in red is the copper

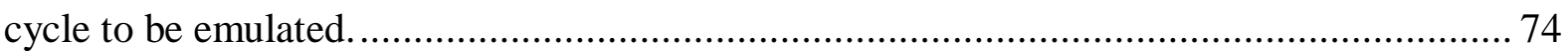

Scheme 3.21: Attempted alkynylation of $\mathbf{6 6}$ using a copper(I) acetylide............................ 74

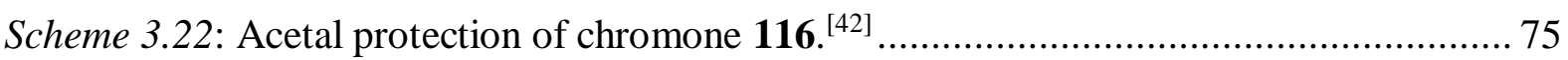

Scheme 3.23: Attempted protection of the aldehyde functionality on 2-formylglycal 66..... 76

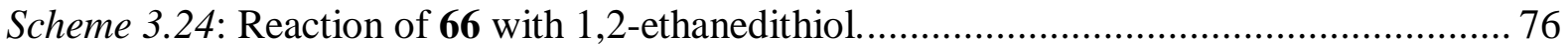

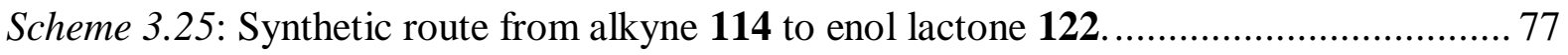

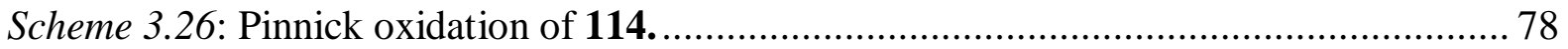

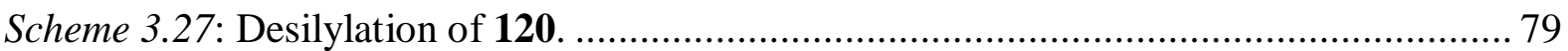




\section{LIST OF TABLES}

Table 1.1: Anti-cancer activity of (-)-TAN-2483B analogues. ....................................... 6

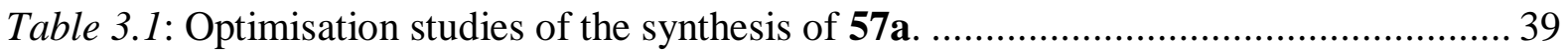

Table 3.2: Optimisation attempts of Vilsmeier-Haack formylation of 55. ........................... 49

Table 3.3: Lewis acids explored for the Ferrier-type alkynylation at room temperature........ 54

Table 3.4: Lewis acids explored for the Ferrier-type alkynylation of 66 at $40{ }^{\circ} \mathrm{C}$................ 57

Table 3.5: Optimisation of the formation of $\mathbf{9 5}$ from $\mathbf{6 6}$ using boron trifluoride diethyl

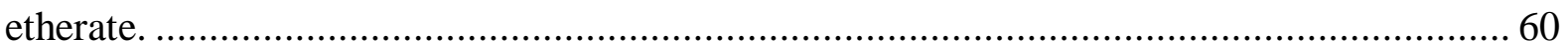

Table 3.6: Comparison of ${ }^{1} \mathrm{H}$ shifts of starting material 66 and species 116...................... 66

Table 3.7: Attempts at formation of $\mathbf{1 1 4}$ from $\mathbf{6 6}$ using tin(IV) chloride as the Lewis acid... 68 


\section{GLOSSARY}

\begin{tabular}{|c|c|}
\hline $\mathrm{ACN}$ & acetonitrile \\
\hline Ac & acetyl \\
\hline aq. & aqueous \\
\hline $\mathrm{Bn}$ & benzyl \\
\hline $\mathrm{d}$ & doublet \\
\hline DBU & 1,8-diazabicyclo[5.4.0]undec-7-ene \\
\hline DCE & 1,2-dichloroethane \\
\hline $\mathrm{DCM}$ & dichloromethane \\
\hline DMCHDA & $N, N$ 'dimethylcyclohexyldiamine \\
\hline DMF & $N, N$ '-dimethylformamide \\
\hline eq. & equivalents \\
\hline $\mathrm{Et}$ & ethyl \\
\hline gem & geminal \\
\hline $\mathrm{GI}_{50}$ & half maximal inhibition of cell proliferation \\
\hline HRMS & high resolution mass spectrometry \\
\hline$i$-Pr & iso-propyl \\
\hline $\mathrm{IC}_{50}$ & half maximal inhibitory concentration \\
\hline IR & infrared \\
\hline KHMDS & potassium hexamethyldisilazide \\
\hline LDA & lithium diisopropylamide \\
\hline LHMDS & lithium hexamethyldisilazide \\
\hline$m \mathrm{CPBA}$ & meta-chloroperoxybenzoic acid \\
\hline $\mathrm{Me}$ & methyl \\
\hline m.p. & melting point \\
\hline$n$-BuLi & normal-butyl lithium \\
\hline NBS & $N$-bromosuccinimide \\
\hline NIS & $\mathrm{N}$-iodosuccinimide \\
\hline NMR & nuclear magnetic resonance \\
\hline NOESY & nuclear Overhauser effect spectroscopy \\
\hline NXS & $N$-halosuccinimide \\
\hline PG & protecting group \\
\hline
\end{tabular}


$\mathrm{Ph}$

phenyl

PTH parathyroid hormone

PMB para-methoxybenzyl

q quartet

$\mathrm{R}_{f} \quad$ retention factor

r.t. room temperature

SM starting material

TBAF tetra- $n$-butylammonium fluoride

TBAI tetra- $n$-butylammonium iodide

Tf triflate

THF tetrahydrofuran

TLC thin layer chromatography

TMS trimethylsilyl 


\section{COMPOUND NUMBERING}

Unsaturated pyrans are numbered as carbohydrates.<smiles>C1=COCCC1</smiles><smiles>C1=CCOCC1</smiles><smiles>CC1=COCCC1</smiles><smiles>CC1=CCCOC1</smiles>

C-glycosides are numbered from the terminal end of the aglycon.<smiles>C#CC1C=CCCO1</smiles><smiles>C#CC1OCCC=C1C</smiles> 


\section{INTRODUCTION}

\subsection{Background}

In the search for chemical species with potential therapeutic biological activity, chemists look to nature for inspiration. As their structures were built by biological machinery, natural products are often predisposed for interaction with biological species.

Novel chemical transformations are often discovered in the synthesis of natural products. These new reactions could be intentional or serendipitous - in either case their discovery contributes to the collective understanding of organic chemistry. Specifically, novel chemical transformations contribute to the development of new methodology, expanding the toolkit available to organic chemists. Both efficiency and convenience are driving factors for the development of synthetic methods. Shorter routes using low toxicity reagents are ideal. The push for more efficient routes toward natural products contributes to the greater understanding of chemical transformations, as well as providing access to otherwise inaccessible compounds (be they fragments, analogues, or natural products themselves) with therapeutic potential.

One example of an elusive natural product is the title compound (-)-TAN-2483B (Figure 1.1). The fungal metabolite (-)-TAN-2483B (1) features a furo[3,4-b]pyran structure and has proven to be difficult to synthesise. Related compounds featuring the furopyran structure have been shown to be biologically active as anti-cancer and kinase inhibition agents. Syntheses have been reported which allow access to related furopyrans. However due to its unique configuration across the pyran oxygen, these methods have been inapplicable to (-)-TAN2483B. A synthesis of (-)-TAN-2483B analogues has been developed, though the natural product itself has yet to be attained. This work aims to develop methodology for the synthesis (-)-TAN-2483B and analogues. 


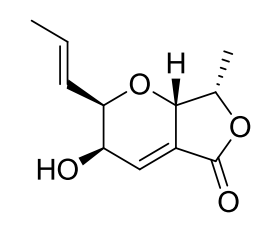

(-)-TAN-2483B (1)

Figure 1.1: Structure of the target compound (-)-TAN-2483B (1).

\section{2 (-)-TAN-2483B: Origins}

(-)-TAN-2483B (1) and the related compound (-)-TAN-2483A (2) were first isolated in 1998 by the Japanese company Takeda Chemical Industries (Figure 1.2). ${ }^{[1]}$ Hayashi and co-workers obtained the compounds from a culture of the filamentous fungus NF 2329. Despite the similar structure of the two compounds, (-)-TAN-2483B has been the less studied of the two. Extensive characterisation of (-)-TAN-2483A was reported in the original isolation patent, whereas only limited data was collected for (-)-TAN-2483B. Optical rotation, ${ }^{13} \mathrm{C}$ NMR, and FAB-MS spectra were reported for (-)-TAN-2483B itself, and 1D ${ }^{1} \mathrm{H}$ NMR spectra were obtained for the acetylated, and hydrogenated derivatives of (-)-TAN-2483B. (-)-TAN-2483A was obtained as “needle-like crystals" while (-)-TAN-2483B manifested as "an oily matter". Finally, a total synthesis has been developed for (-)-TAN-2483A, but the methodology was unable to be applied to (-)-TAN-2483B. ${ }^{[2]}$

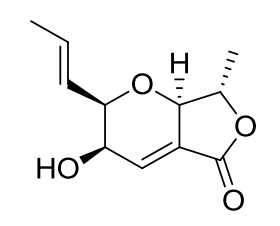

(-)-TAN-2483A (2)

Figure 1.2: Structure of (-)-TAN-2483A (2). 


\subsection{Therapeutic Potential: Biological Activity of Related Species}

\subsection{1 (-)-TAN-2483A}

Biological data detailed in the isolation patent reports (-)-TAN-2483A inhibiting both c-Src kinase and parathyroid hormone (PTH)-induced bone resorption. This biological activity could be harnessed for anti-cancer or preventative osteoporosis measures. ${ }^{[1]}$

c-Src is a proto-oncogene tyrosine-protein kinase. ${ }^{[3]}$ The gene products of c-Src are tyrosineprotein kinases - a family of enzymes that phosphorylate tyrosine residues in a protein. Phosphorylation of these proteins acts as an on/off switch, activating or deactivating said proteins. As a proto-oncogene, a mutation in $\mathrm{c}-\mathrm{Src}$ has the potential of turning it into an oncogene - a gene facilitating the growth and spread of cancer. When c-Src is activated, cell survival, proliferation, and angiogenesis are increased. ${ }^{[4]}$ Mutation in c-Src causing it to be in an 'always on' state leads to the cell constantly exhibiting these cancer hallmarks which ultimately results in a tumour. ${ }^{[5]}$ It has been reported that more than $50 \%$ of tumours in the colon, liver, lung, breast, and pancreas feature c-Src activation. ${ }^{[3]}$ Therefore compounds displaying tyrosine-kinase inhibition have therapeutic potential for these types of cancers. Hayashi's patent details that (-)-TAN-2483A inhibits human c-Src activity with an $\mathrm{IC}_{50}$ of 4 $\mu \mathrm{M}^{[1]}$

When $\mathrm{Ca}^{2+}$ levels in the blood drop below normal, the body compensates by sourcing $\mathrm{Ca}^{2+}$ from bone tissue. Bone tissue is disassembled by osteoclasts in a process termed bone resorption. The action of osteoclasts is triggered by PTH, released from the parathyroid gland when blood $\mathrm{Ca}^{2+}$ is low. ${ }^{[6]}$ Bone resorption increases the available $\mathrm{Ca}^{2+}$ in the blood, but decreases bone density. This is characteristic of bone diseases such as osteoporosis, where bone embrittlement increases the likelihood of fractures and breakages. As c-Src is pertinent in osteoclast function, it is plausible that inhibition of the gene has some effect on bone degradation. Hayashi's patent reports a 76\% inhibition of $\mathrm{PTH}$-induced bone resorption in mouse femurs. ${ }^{[1]}$ 


\subsubsection{Waol Compounds and (-)-TAN-2483A}

Waol A was first isolated by Mizoue and co-workers in 1994 from the fermentation broth of Myceliophthora lutea (TF-0409). Though reporting an incorrect chemical structure (3, Figure 1.3), the paper described waol A as having broad antitumour activity. ${ }^{[7]}$

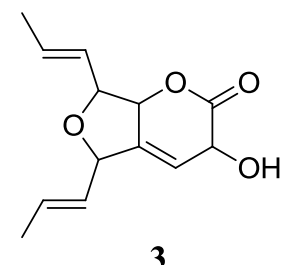

3

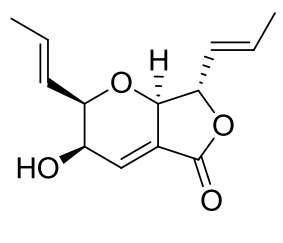

4

Figure 1.3: Incorrect structure of waol A proposed by Mizoue (3), and revised structure reported by Snider (4).

Subsequent research performed by Snider revised the structure (4, Figure 1.3), provided a synthesis, and further explored the biological activity of waol A. ${ }^{[2]}$ Biological assays were then performed on (-)-TAN-2483A (2), (+)-desmethyl-TAN-2483A (5), and a racemic sample of waol A (6) (Figure 1.4). The compounds were submitted to the NCI human disease-oriented 60 -cell line in vitro anti-tumour screening protocol. Results from the assay showed the three compounds having similar anti-tumour activity $\left(\mathrm{GI}_{50}: 10^{-5}-10^{-6} \mathrm{M}\right) .{ }^{[2]}$

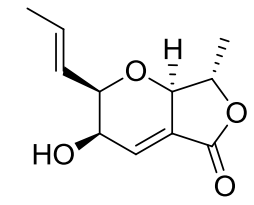

$(-)-T A N-2483 A(2)$

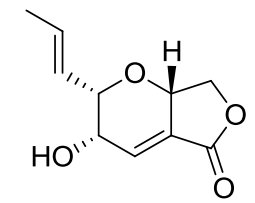

(+)-desmethyl-TAN-2483A (5)<smiles>C/C=C/C1O[C@@H]2C(=CC1O)C(=O)O[C@H]2/C=C/C</smiles>

racemic Waol A (6)

Figure 1.4: Compounds submitted for the NCI assay.

\subsubsection{Dinemasones}

Dinemasones B (7) and C (8) were first isolated by Krohn and co-workers from a culture of the endophytic fungus Dinemasporium strigosum (Figure 1.5). ${ }^{[8]}$ The fungus itself was extracted from the roots of Calystegia sepium, a herbaceous perennial plant. The isolation paper reported dinemasone $\mathrm{B}(7)$ as having promising antibacterial and antifungal activities. In a microtitre array assay at $\mathrm{mM}$ concentrations, 7 showed growth inhibition of bacteria, fungi, 
and algae in the species Bacillus megaterium (42\%), Microbotryum violaceum (58\%), and Chlorella fusca (15\%) respectively. Dinemasone C was unable to be isolated in pure form, and as such biological testing was not performed for $\mathbf{8}^{[8]}$

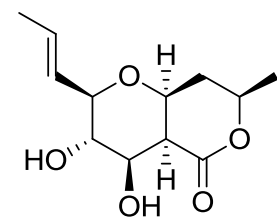

dinemasone B (7)

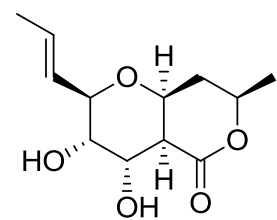

dinemasone $\mathrm{C}(\mathbf{8})$

Figure 1.5: The dinemasone natural products isolated by Krohn. ${ }^{[5]}$

The Snider group also have published a synthesis of dinemasone $\mathrm{C}(\mathbf{8})$ and its analogues. The dinemasones have similar structures to (-)-TAN-2483B, differing in ring size and saturation. The group submitted five compounds (Figure 1.6) obtained in their synthetic studies to agar diffusion assays. All five compounds showed antibacterial (Bacillus megaterium and Escherichia coli), antifungal (Microbotryum violaceum), and antialgal (Chlorella fusca) activity, with zones of inhibition ranging from $7-12 \mathrm{~mm} .^{[9]}$

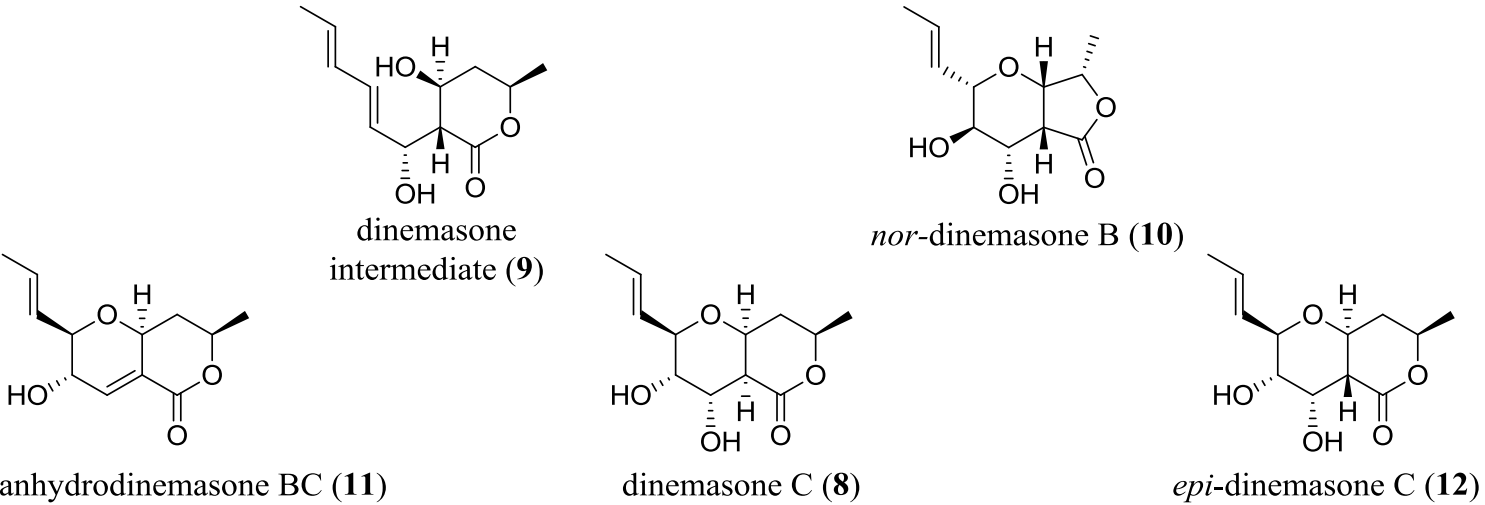

Figure 1.6: Biologically active dinemasone species.

\subsection{4 (-)-TAN-2483B Analogues}

A recent patent ${ }^{[10]}$ by the Harvey group details the synthesis and biological activity of (-)-TAN2483B analogues, building on the work done by Somarathne. Various analogues of (-)-TAN2483B (Figure 1.7) were submitted to assays measuring cancer cell growth and kinase inhibition. 


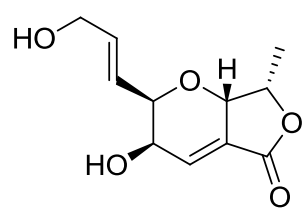

13

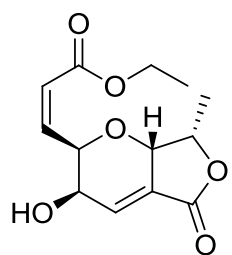

14

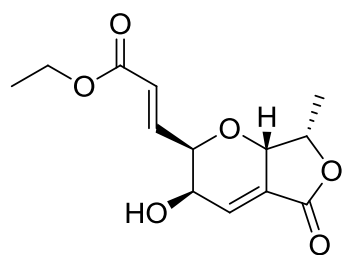

15

Figure 1.7: Biologically active analogues of (-)-TAN-2483B.

Hydroxy-(-)-TAN-2483B (13) showed modest activity against human leukaemia (HL-60) (Table 1.1). The Z-ethyl ester of (-)-TAN-2483B (14) also showed activity against human leukaemia, as well as activity against breast cancer (MCF7). The $E$-ethyl ester showed activity against human leukaemia and ovarian cancer (1A9).

Table 1.1: Anti-cancer activity of (-)-TAN-2483B analogues. ${ }^{[10]}$

\begin{tabular}{c|ccc} 
Cell line & \multicolumn{3}{|c}{$\mathrm{IC}_{50}(\mu \mathrm{M})$} \\
\hline HL-60 & $\mathbf{1 3}$ & $\mathbf{1 4}$ & $\mathbf{1 5}$ \\
MCF7 & Not active & 3.6 & 2.2 \\
1A9 & Not active & Not active & 3.0
\end{tabular}

The Z-ethyl ester of TAN-2483B (14) also showed inhibition of a range of kinases listed below. ${ }^{[10]}$ Inhibition of the following kinases are given in brackets as single-point, percent inhibitions at $10 \mu \mathrm{M}$, along with a brief description of the kinase.

- BTK: Bruton tyrosine kinase (83\%). BTK is a member of the TEC subfamily of tyrosine kinases and plays an important role in B-cell development.

- AMPK A2/B1/G1: AMP-activated protein kinase (81\%). AMPK acts as a sensor of cellular energy levels and is critical to regulating metabolic events in the liver, skeletal muscle, heart, adipose tissue, and pancreas.

- PLK1: Serine/threonine-protein kinase (81\%). PLK1 is a proto-oncogene involved in colon and lung cancers. Inhibition provides potential cancer therapy.

- BMX: Bone marrow tyrosine kinase (80\%). BMX plays an important role in cell survival. Inhibition provides potential cancer therapy.

- NUAK2 (76\%): NUAK2 is a melanoma oncogene. Inhibition provides potential cancer therapy. 
- MAPK14: Mitogen activated protein kinase (74\%). MAPK is a member of the stressactivated protein kinase class, and is involved in cell differentiation, proliferation, development, and transcription regulation. Inhibition provides potential cancer therapy.

- TXK1 (71\%): TXK1 is a member of the TEC subfamily of tyrosine kinases and is involved in T-helper cytokine production.

The biological activity of these structurally related species suggests that (-)-TAN-2483B is likely to have biological activity pertaining to kinase inhibition and potential anticancer therapy.

\subsection{Proposed Biosynthesis}

The similar structures of (-)-TAN-2483A and (-)-TAN-2483B suggest that the two compounds are produced by similar biosynthetic pathways from the same starting materials (Scheme 1.1). It has been postulated by Snider that the TAN compounds are produced via the reduction of a hydroxylated intermediate (18), which is itself made from the coupling of polyketide-derived aldehyde (16) and tetronic acid derivative 17. ${ }^{[2]}$

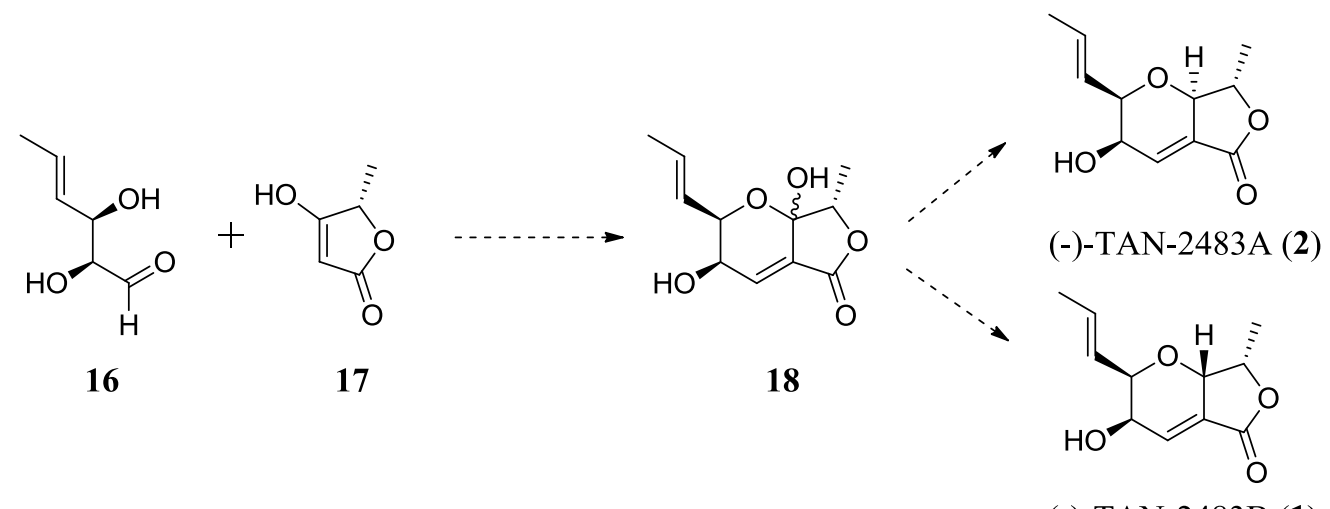

(-)-TAN-2483B (1)

Scheme 1.1: Proposed biosynthetic pathway to the TAN compounds. ${ }^{[2]}$

Synthetic attempts using the above strategy to access the TAN compounds and support the postulated biosynthetic mechanism had no success. ${ }^{[2]}$ 


\subsection{Synthesis of (-)-TAN-248A, Waol A, and Waol B}

First published as a letter in $2002^{[11]}$ and later as a full paper in $2004^{[2]}$ the successful synthesis of (-)-TAN-2483A (2), waol A (4), and waol B (24) was achieved by Snider and co-workers. The convergent strategy began with the coupling of a dienone $\mathbf{1 9}$ with a hydroxyfuranone $\mathbf{2 0}$ via an aldol condensation (Scheme 1.2). The resulting diene diol furanone 21 was subjected to iodoetherification conditions to form the pyran ring. The iodinated species $\mathbf{2 2}$ was then treated with trimethylamine, resulting in elimination via epoxide intermediate 23 giving either (-)TAN-2483A (2) or waol A (4) depending on the R substituent. Waol B (24) was then obtained by methanolysis of waol A.
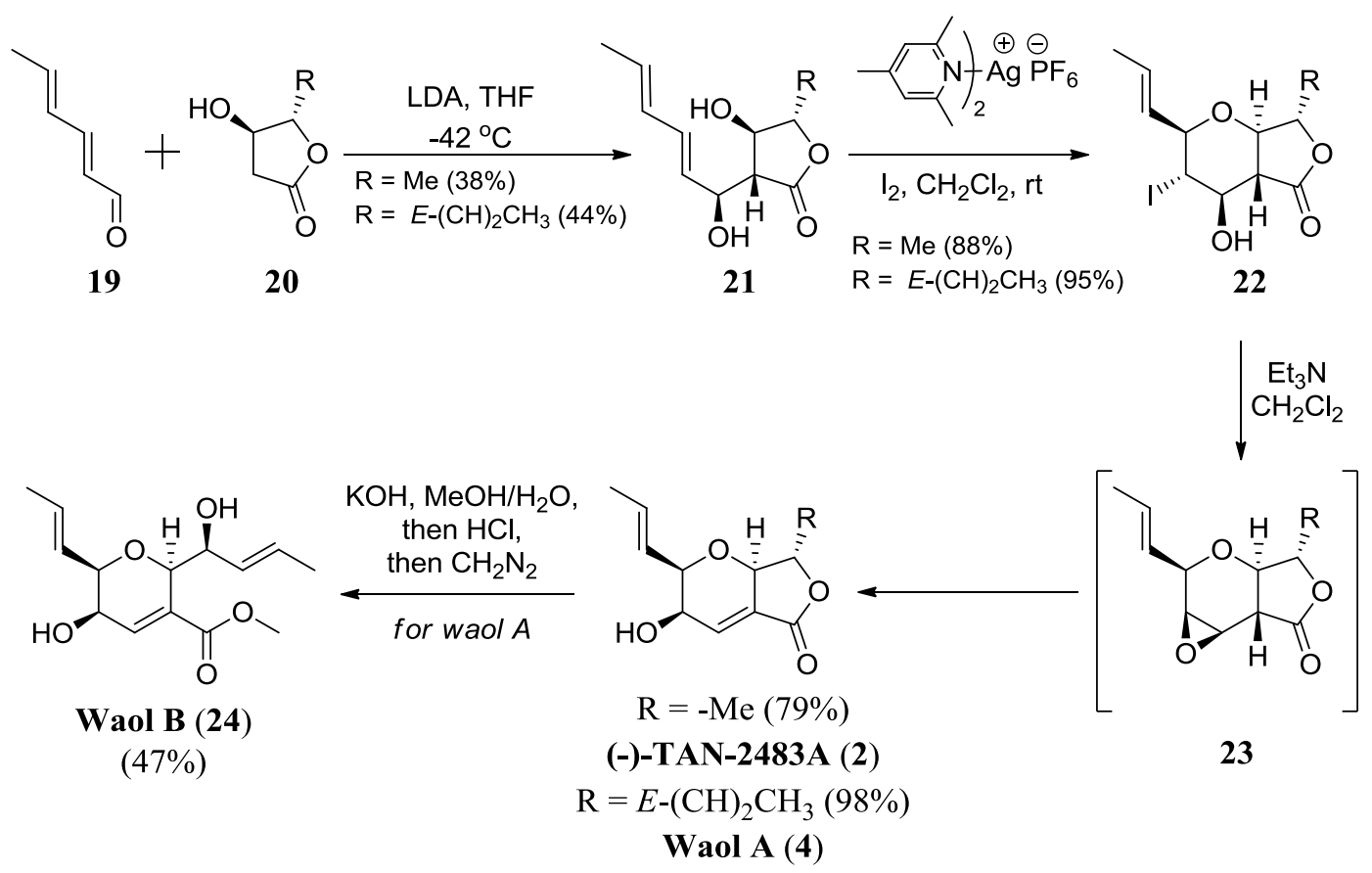

Scheme 1.2: Synthesis of (-)-TAN-2483A, waol A, and waol B reported by Snider. ${ }^{[2,11]}$

Despite these successful syntheses, this methodology could not be successfully applied to provide access to (-)-TAN-2483B due to the unique stereochemistry of its furopyran ring system. ${ }^{[2]}$ Hydroxy furanone $\mathbf{2 0}$ gave the correct configuration about the furopyran ring system of $\mathbf{2}$ (Scheme 1.2). Hydroxy furanone 25, being epimeric to $\mathbf{2 0}$ at the hydroxylated carbon, was used in attempt to obtain the correct configuration of $\mathbf{1}$. The aldol condensation of dienone $\mathbf{1 9}$ and hydroxyfuranone $\mathbf{2 5}$ gave epimers 26 and 27. 


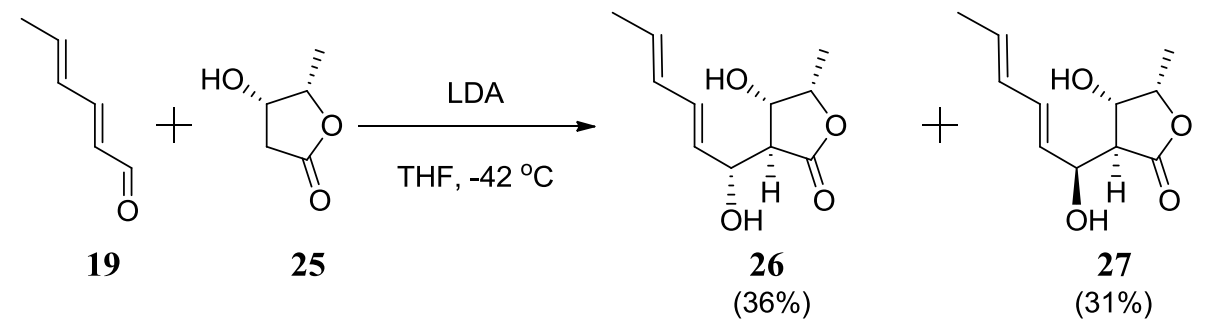

Scheme 1.3: Aldol condensation of 19 and 25. ${ }^{[2]}$

Diene 26, being analogous to $\mathbf{2 1}$, was subjected to iodoetherification conditions and gave $\mathbf{2 8}$ (Scheme 1.4). Following treatment of $\mathbf{2 8}$ with 1,8-diazabicyclo[5.4.0] undec-7-ene (DBU), 29 was found to have the opposite configuration to $\mathbf{1}$ at the hydroxyl carbon, and the propenyl oxymethine. Furopyran $\mathbf{2 9}$ was then oxidised to $\mathbf{3 0}$ in the hope that the propenyl group could be epimerised, and the enone selectively reduced to give $\mathbf{1}$. However $\mathbf{3 0}$ was unstable on silica gel, degrading into 32 (40 - 50\%), giving only $40-50 \%$ of $\mathbf{3 0}$. Formation of $\mathbf{3 2}$ occurs via intermediate 31. Considering epimerisation of the propenyl oxymethine would proceed via $\mathbf{3 1}$, one would expect 32 rather than the desired product.

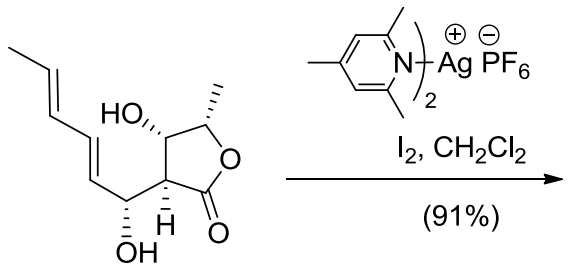

26<smiles>C/C=C/C(=O)/C(O)=C\C1=C[C@H](C)OC1=O</smiles>

32<smiles>C/C=C/[C@H]1O[C@H]2[C@@H](C)OC(=O)[C@@H]2[C@H](O)[C@@H]1I</smiles>

28

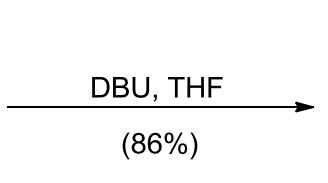

$(86 \%)$

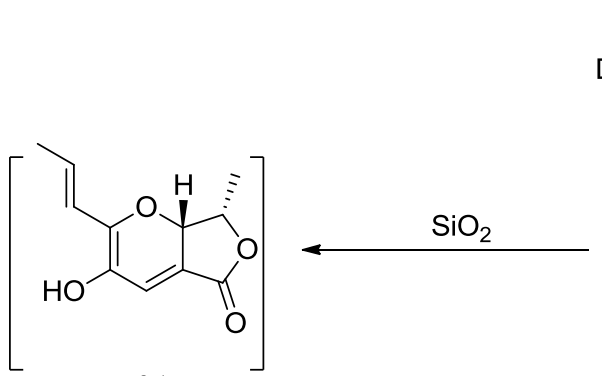

31<smiles>C/C=C/[C@H]1O[C@H]2C(=C[C@H]1O)C(=O)O[C@H]2C</smiles>

29

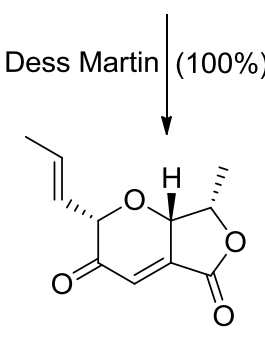

30

Scheme 1.4: Snider's attempted the synthesis of (-)-TAN-2483B via 29. ${ }^{[2]}$

It was hoped that the second epimeric product of the aldol condensation (27) would be able to form the pyran ring in the correct way if closed via epoxidation (Scheme 1.5). However, none of the desired product was obtained - epoxidation occurred preferentially at the more sterically accessible side-chain alkene (35). Epoxidation at the appropriate alkene for pyran formation occurred from the wrong face $(\mathbf{3 3})$, ultimately resulting in none of the desired $36 .{ }^{[2]}$ 


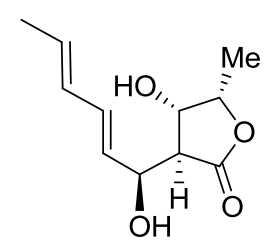

27

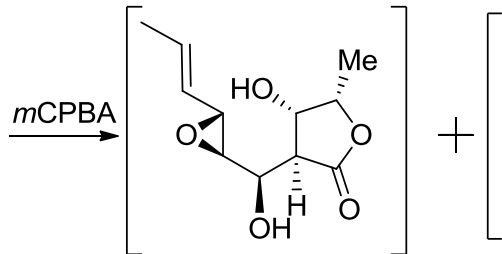

33

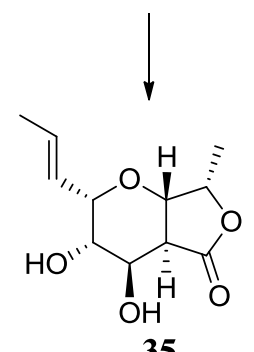

$(19 \%)$

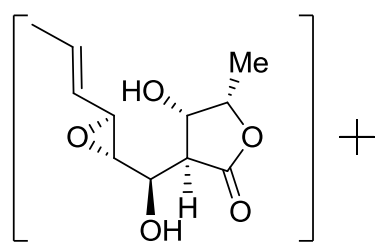

34

(not formed)

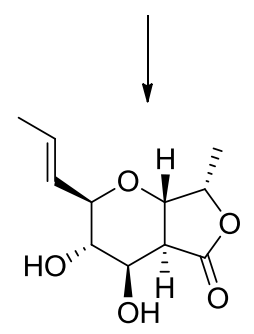

$(0 \%)$

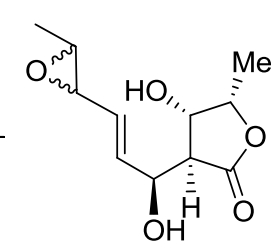

35

$(39 \%)$

Scheme 1.5: Snider's attempt at the synthesis of (-)-TAN-2483B via epoxidation of 27. ${ }^{[2]}$

\subsection{Synthesis of (-)-TAN-2483B Analogues}

The first step in the analogue synthesis was a cyclopropanation-ring expansion transformation, which provides access to the bicyclic core of (-)-TAN-2483B (Scheme 1.6). ${ }^{[12]}$ This strategy was utilised by Somarathne in her synthesis of (-)-TAN-2483B analogues. ${ }^{[13]}$ The starting glycal 37 was transformed into the pseudo-glycal 39 via the cyclopropanation-ring expansion mentioned above. The additional carbon is from the reaction of the in situ-generated dibromocarbene with 37 to form the gem-dibromocyclopropane 38. Ring expansion of the reactive ring-fused cyclopropane affords a delocalised oxonium ion that is trapped by the acetate nucleophile present in the reaction mixture. The tin-catalysed alkynylation of the anomeric mixture of acetates (39) yielded only the $\alpha$-alkyne 40, giving the desired stereochemistry present in the target (-)-TAN-2483B. Cleavage of the acetonide using trifluoroacetic acid revealed the diol of compound 41. It was reported that some cleavage of the trimethylsilyl group also occurred under these conditions. However, since alkyne deprotection (using potassium carbonate and methanol) was the next step in the synthesis, this detail is non-consequential. With the diol present in alkyne $\mathbf{4 2}$, periodate cleavage was used to form the aldehyde $\mathbf{4 3}$. The intermediate $\mathbf{4 3}$ has been used to access (-)-TAN-2483B ester analogues (Scheme 1.7). Toward the natural product, initial attempts at olefination of $\mathbf{4 3}$ using Julia-Kocienski methodology resulted in degradation of the starting material into unidentifiable fragments. As such, a stabilised ylide was reacted with $\mathbf{4 3}$ giving the appropriate $E$ - geometry 
about the newly formed $\alpha, \beta$-unsaturated aldehyde in $\mathbf{4 4}$. Oxygenation of alkyne $\mathbf{4 4}$ to ketone 45 was achieved with oxymercuration. Attempts to use reagents less toxic than those in the oxymercuration reaction proved unsuccessful, yielding only starting material. Ceriummediated reduction using sodium borohydride transformed both the $\alpha, \beta$-unsaturated aldehyde and the ketone in $\mathbf{4 5}$ to their respective alcohols in $\mathbf{4 6}$. The stereochemistry of the secondary alcohol was observed to be substrate controlled with the desired $S$ configuration being the only detectable major product. With the proximal alcohol and bromide functionalities in hand, the lactone ring was formed via palladium-catalysed carbonylation giving 47. Efforts to reductively cleave the terminal allylic alcohol to produce the $E$-propenyl side chain were unsuccessful - either the alcohol was unreactive or degradation of the pyran ring was observed. Current methods are looking into the use of an Appel reaction to substitute the allyl alcohol to an allyl halide (48), which then can be reductively cleaved with an appropriate hydride source in order to obtain the E-propenyl sidechain (49). The final step in the synthesis would be cleavage of the benzyl protecting group using titanium tetrachloride to give the target compound (-)-TAN-2483B (1). Titanium tetrachloride has been used to obtain hydroxy-(-)TAN-2483B (15, Scheme 1.7) and was preferred over more common hydrogenation conditions to cleave the benzyl in order to preserve the unsaturation of the compound. 

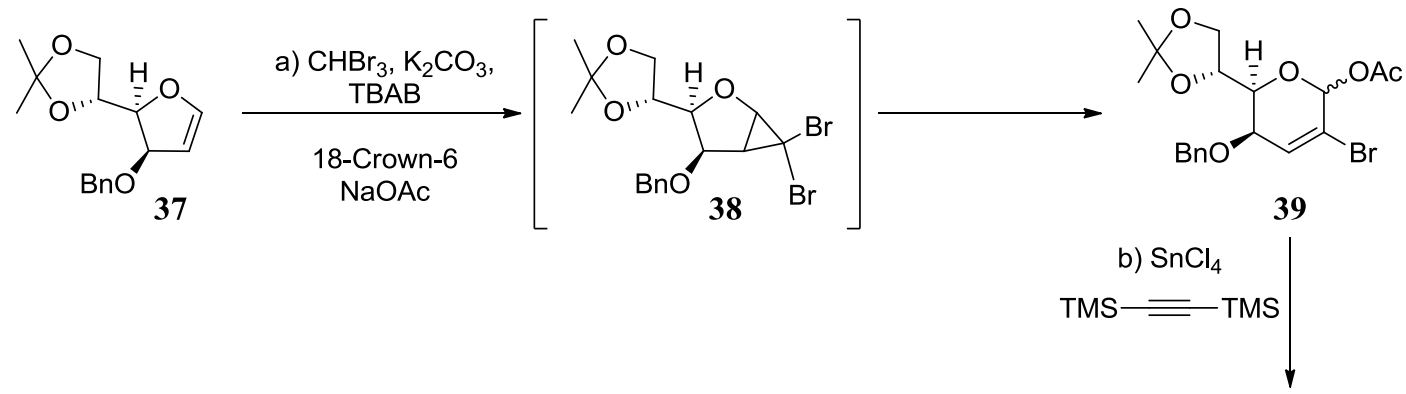<smiles>C#C[C@H]1O[C@H](C(O)CO)[C@@H](Br)C=C1Br</smiles>

42 e) $\mathrm{NaIO}_{4}$<smiles>C#CC1(C#C)OC(C=O)C(Br)C=C1Br</smiles>

43 d) $\mathrm{K}_{2} \mathrm{CO}_{3}$ $\mathrm{MeOH} / \mathrm{DCM}$
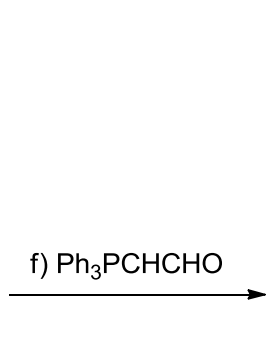

c) $\mathrm{CF}_{3} \mathrm{COOH}$,

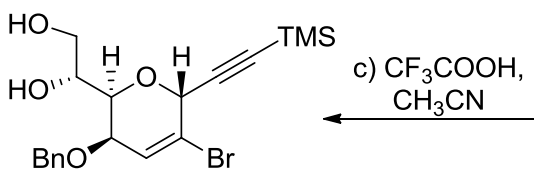

$41(35 \%)$<smiles>CC(C)(C)O[C@H]1C=C(Br)[C@H](C#C[As](C)(=O)=O)O[C@H]1C1COC(C)(C)O1</smiles>

$40(47 \%)$

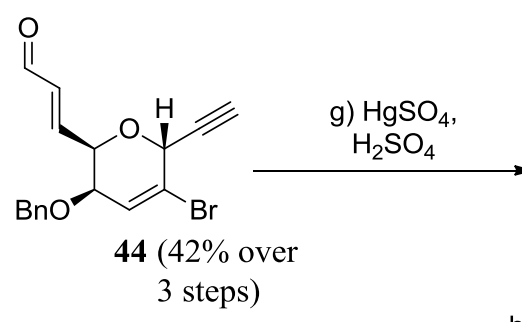

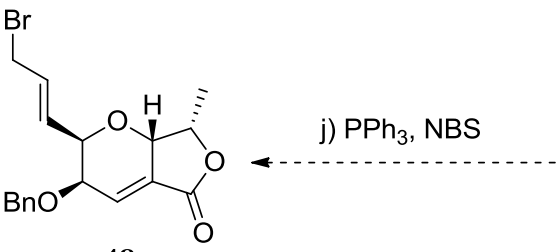

48

k) $\mathrm{ZnCl}_{2}$

$\mathrm{NaBH}_{3} \mathrm{CN}$<smiles>C/C=C/C1OC2C(=CC1OCc1ccccc1)C(=O)O[C@H]2C</smiles>

49<smiles>C[C@@H]1OC(=O)C2=C[C@H](O)[C@H](C(=O)OC(=O)c3ccccc3)O[C@H]21</smiles>

$47(52 \%)$

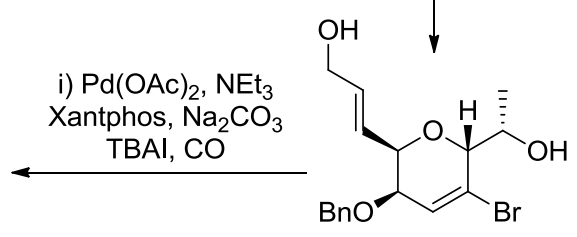

46(92\%)

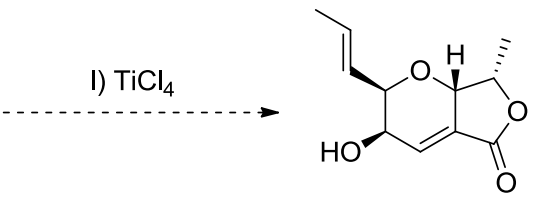

(-)-TAN-2483B (1)

Scheme 1.6: Previous work toward the synthesis of (-)-TAN-2483B.

Though (-)-TAN-2483B has yet to be obtained, the methodology has been used to access biologically active analogues of the natural product (Scheme 1.7). ${ }^{[10,13-14]}$ As mentioned, deprotection of the allyl alcohol 46 using titanium tetrachloride gave hydroxy-(-)-TAN-2483B (12). ${ }^{[13]}$ The intermediate 43 was used to access the (-)-TAN-2483B-ester species. Wittig reactions using the appropriate ester ylides were used to install the analogous ester sidechains in the (-)-TAN-2483B variants (50). The stabilised Wittig reagents used gave mixtures of both $E$ - and $Z$ - $\alpha, \beta$-unsaturated esters with unusually high $Z$ - ratios. Nonetheless, both $E$ - and Z- $\alpha, \beta$ unsaturated esters with ethyl ${ }^{[13]}$ and octadecyl ${ }^{[14]}$ chains were obtained. Methodology used to 
transform the proximal alkyne and bromide of $\mathbf{4 4}$ ultimately into the lactone ring (47) was employed for the transformation of $\mathbf{5 0}$ - 53. Lactone formation was successful for the $E$ - and $Z$ - ethyl, and $E$-octadecyl esters, but was unable to be achieved for the Z-octadecyl ester. Issues arose in the palladium-catalysed carbonylation of the Z-octadecyl ester $\mathbf{5 2}$ in that the reaction yielded unidentifiable products as well as starting material. This was attributed to impurities in the starting material as well as steric effects of the octadecyl chain impeding the carbonylation reaction. ${ }^{[14]}$ The $E$ - and $Z$ - ethyl, and $E$-octadecyl esters of lactone 53 were treated with titanium tetrachloride to cleave the benzyl group, giving 1, 15, and 54 as $Z$-ethyl, $E$-ethyl, and $E$ octadecyl esters of (-)-TAN-2483B respectively.

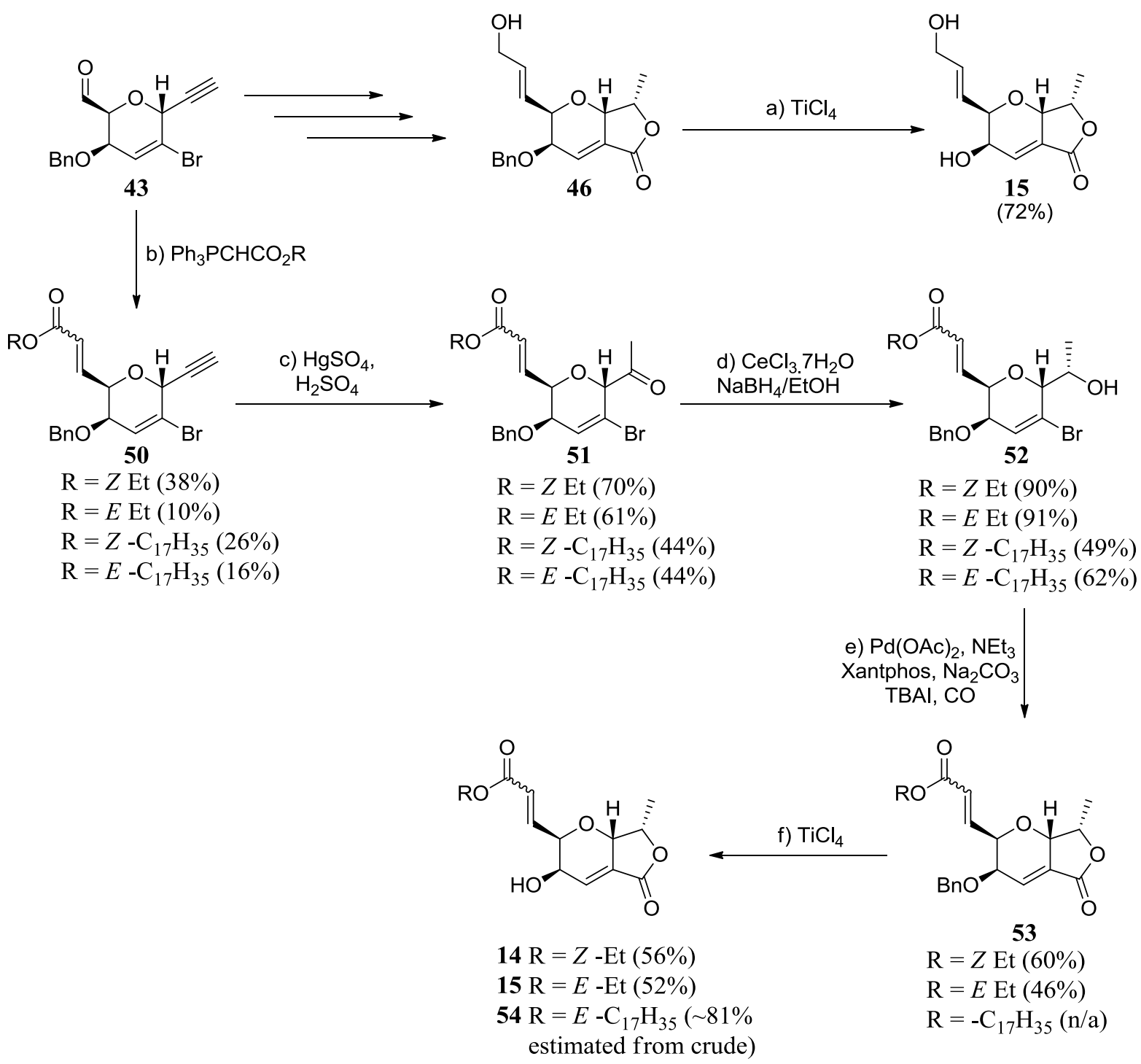

Scheme 1.7: Synthesis of (-)-TAN-2483B analogues. ${ }^{[13-14]}$ 


\section{RESEARCH AIMS}

\subsection{Retrosynthetic Analysis}

The proposed synthesis is based on work begun by Somarathne during her PhD studies. ${ }^{[13]}$ Preliminary investigations using a Vilsmeier-Haack approach toward a synthesis of (-)-TAN2483B were carried out but abandoned due to progress made in the current analogue synthesis. Advantages of the proposed method over the previous are the improved step efficiency, and obviation of difficult and hazardous steps. Though the key cyclopropanation-ring expansion step has recently been optimised, ${ }^{[15]}$ it is a difficult transformation with its success hinging on the familiarity of the researcher with the materials and conditions involved. The analogue synthesis uses oxymercuration, tin-catalysed alkynylation, and carbonylation to install important functionalities. Considering the inherent toxicity of mercury, tin, and carbon monoxide, one can understand why avoiding these procedures would be desirable.

A retrosynthetic analysis is proposed in Scheme 2.1. Installation of the E-propenyl side-chain and formation of the furanone ring are the structural modifications required to make the natural product. By no means are either of these transformations unchallenging. The final steps would be olefination to install the side-chain followed by deprotection of the benzyl group. Side-chain installation was envisioned to borrow from the existing synthesis using a Julia-Kocienski olefination on a late-stage intermediate. Since the failure of initial attempts, good progress has been made using this methodology by others in the research group,${ }^{[16]}$ but optimisation of yields is ongoing and exploring this chemistry is beyond the scope of this project. 


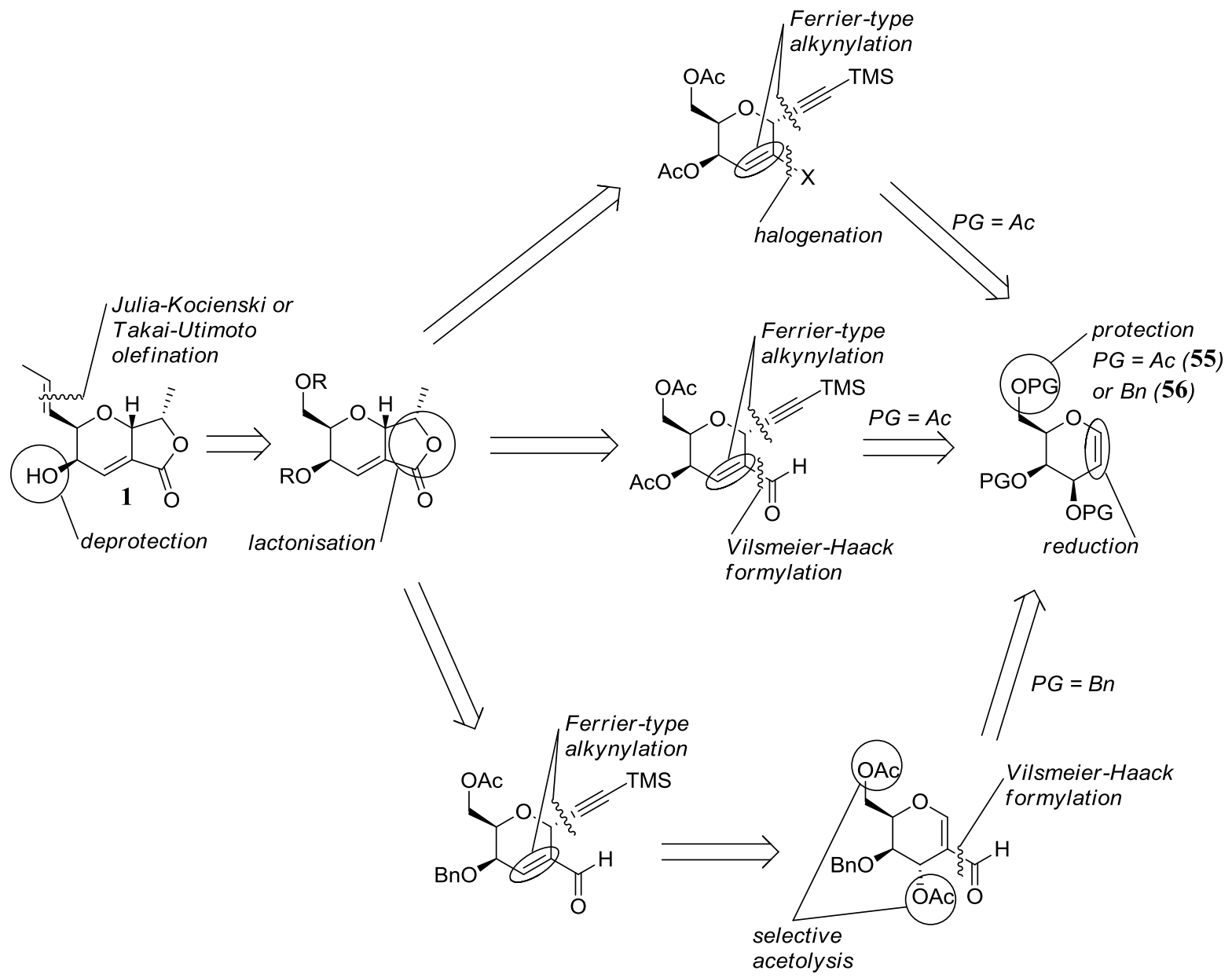

Scheme 2.1: Retrosynthetic analysis of (-)-TAN-2483B.

The proposed ring formation involves three distinct steps: functionalisation of the C-2 position, functionalisation of the C-1 position, and ring closure. Functionalisation of both the C-2 and especially C-1 positions of 1,2-unsaturated sugars is well established. ${ }^{[17]}$ Functionalisation of the glycal C-2 position is typically accomplished by exploiting the nucleophilicity of the enolether with an appropriate electrophile (e.g., $N$-halosuccinimides, or reactive iminium species). Transformations of this type preserve the unsaturation of the $\mathrm{C}-1$ and $\mathrm{C}-2$ positions, allowing C-1 to be modified in a similar manner to unsubstituted glycals.

A nucleophile can be installed at the glycal C-1 via a Ferrier rearrangement. ${ }^{[18]}$ Ferrier rearrangements shift the glycal double bond to the C-2 - C-3 position - the position of the double bond in the resulting pyran conveniently resembles that in (-)-TAN-2483B. Addition of the nucleophile typically results in a preference for the $\alpha$-anomer. ${ }^{[17 \mathrm{c}]}$ The relationship between the proton at the anomeric position and the adjacent proton across the ring in the $\alpha$-anomer resembles that across the pyran ring in (-)-TAN-2483B. 
Ring closure conditions depend heavily on the functionality able to be installed at the C-1 and $\mathrm{C}-2$ positions. If a halide is present at what was the $\mathrm{C}-2$ position of the glycal, ring-closure of subsequent intermediates can utilise the methodology of the existing analogue synthesis (viz. Section 2.2.1). If an aldehyde is present at the glycal C-2 position, copper based methodology will be used to form the ring (vide infra). ${ }^{[19]}$

Tri- $O$-acetyl-D-galactal 55 was envisioned as an easily accessible starting point in the synthesis of (-)-TAN-2483B. The pyran ring of the target compound is already in place, as are the stereocentres at the C-4 and C-5 positions of the pyran. The reactivity of the enol ether is useful in functionalising both the $\mathrm{C}-1$ and $\mathrm{C}-2$ positions vide supra. Substitution of the C-2 position of the glycal must be performed prior to the functionalisation of $\mathrm{C}-1$ in order to exploit the reactivity of the glycal enol ether.

\subsection{Functionalisation of D-Galactal Derivatives}

\subsubsection{The Applicability of 2-Haloglycals to the Synthesis of (-)-TAN-2483B}

A 2-haloglycal 57 is a useful intermediate in the synthesis of (-)-TAN-2483B. 2-Haloglycal 57 is reported to be easily made from tri- $O$-acetyl-D-galactal 55 (Scheme 2.1) in high yield. ${ }^{[20]}$ Ferrier-type alkynylation of the 2-haloglycal to install the two-carbon unit at C-1 gives an intermediate species $\mathbf{5 8}$ similar to alkyne $\mathbf{4 0}$ in the existing analogue synthesis (Scheme 2.2). As such, existing methodology for lactone formation could be applied to the alkynyl-halopyran (58) derived from these studies. The existing analogue synthesis generates the bromoalkene functionality in $\mathbf{4 0}$ from an in situ gem-dihalocyclopropanation-ring-expansion (37 to 39) - a reaction that has proven to be difficult to perform. Ferrier-rearrangement products of 57 using $O$-nucleophiles are known, ${ }^{[20]}$ but no reports exist of $C$-nucleophiles in Ferrierrearrangements of 2-haloglycals. 
This work:
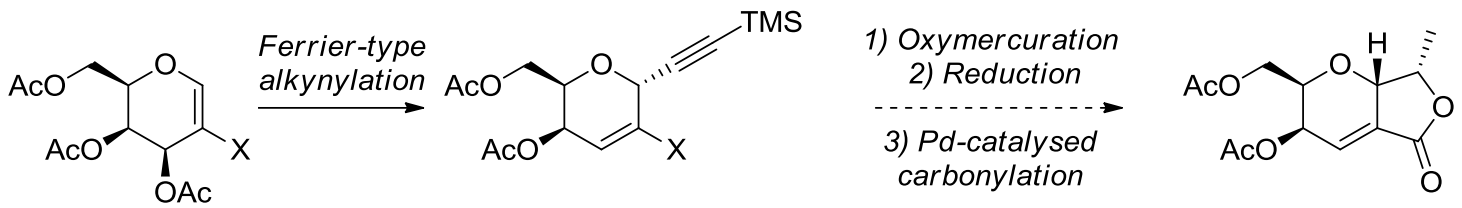
57a: $\mathrm{X}=\mathrm{Br}$
58a: $\mathrm{X}=\mathrm{Br}$
b: $\mathrm{X}=\mathrm{I}$
b: $\mathrm{X}=\mathrm{I}$

Existing analogue synthesis:

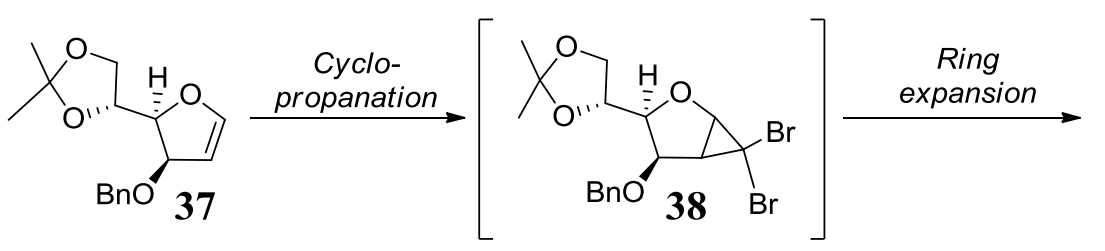

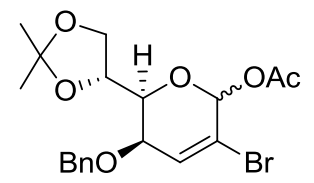

39

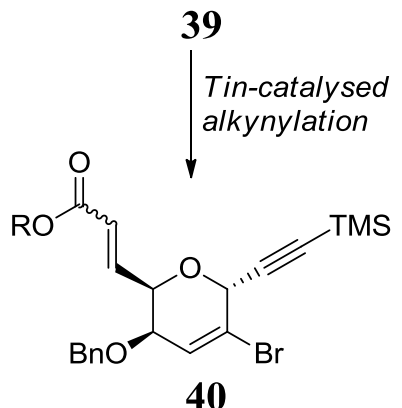

Scheme 2.2: Similarities between potential intermediate $\mathbf{5 8}$ and existing intermediate $\mathbf{4 0}$ of the analogue synthesis. ${ }^{[13]}$

Utilising the lactone ring-closure methodology of the existing analogue synthesis is advantageous as it already exists and works well. The disadvantage is the toxicity of the mercury species and carbon monoxide required to perform the ketone formation and lactonisation respectively. It should be noted that the ring-closure transformations in the existing analogue synthesis have not been explored with an iodo-variant of $\mathbf{4 0 .}$

\subsubsection{The Applicability of 2-Formylglycals to the Synthesis of (-)-TAN-2483B}

An aldehyde at the C-2 position is another functionality able to be used to form the lactone of (-)-TAN-2483B. The enol ether of tri- $O$-acetyl-D-galactal 55 could potentially be formylated using Vilsmeier-Haack conditions. Vilsmeier-Haack formylations are well known and are routine when installing aldehydes on aromatic systems. Since first reported by Balasubramanian and co-workers, ether-protected glycals have become known substrates for Vilsmeier-Haack formylation. ${ }^{[21]}$ Ether protected glycals are reported to formylate quite readily in good yields with reasonable reaction times (Scheme 2.3). In contrast, there are no literature 
examples or results pertaining to per-acetylated glycals. A hypothesis is that the acetates inductively withdraw electron density from the unsaturated C-2 carbon, decreasing its nucleophilicity and therefore its propensity to react with the Vilsmeier-Haack reagent $\mathbf{6 1 .}$ Despite this deactivation, resonance effects should dominate, and electron donation from the ring oxygen should allow the glycal to be adequately nucleophilic to react with the electrophilic Vilsmeier-Haack reagent. Formylation of tri- $O$-acetyl-D-galactal (55) would be advantageous in the synthesis of (-)-TAN-2483B as it would preserve the acetate protecting groups which are, in general, orthogonal to the functionality of intermediate species in the route proposed in this thesis.<smiles>[R]OC[C@H]1OC=C[C@@H]([R20])[C@H]1[OH2+]</smiles>

59

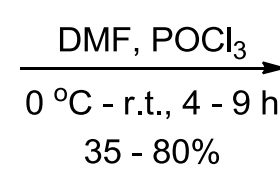
$35-80 \%$

$\mathrm{R}=\mathrm{Me}, \mathrm{Bn}$,

Allyl, PMB, Et<smiles>[R]OC[C@H]1OC=C(C=O)[C@@H]([R6])[C@H]1O[R]</smiles>

60

Scheme 2.3: Vilsmeier-Haack formylation of ether protected glycals. ${ }^{[21 b]}$

The Vilsmeier-Haack reaction uses phosphoryl chloride and dimethylformamide to form iminium species $\mathbf{6 1}$ which is the active formylating agent (Scheme 2.4). It should be noted that oxalyl chloride can also be used to form $\mathbf{6 1},{ }^{[22]}$ and trifluoromethanesulfonic anhydride can be used to form an analogous triflate species. ${ }^{[23]}$ Nucleophilic attack of the glycal enol ether on the electrophilic carbon of $\mathbf{6 1}$ forms the $\mathrm{C}-\mathrm{C}$ bond. The resulting iminium intermediate $\mathbf{6 2}$ is hydrolysed in a basic workup to give the aldehyde $\mathbf{6 3}$. 


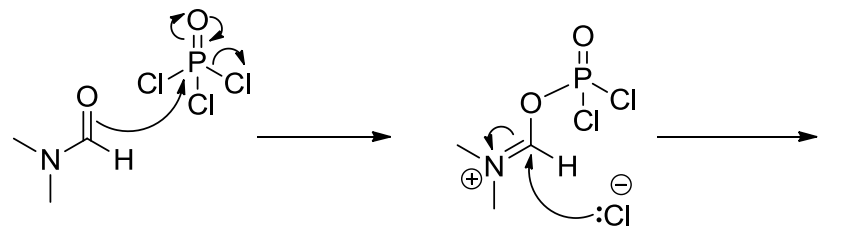<smiles>C[N+]1(C)CCOP(=O)(Cl)OC1C(Cl)Cl</smiles>

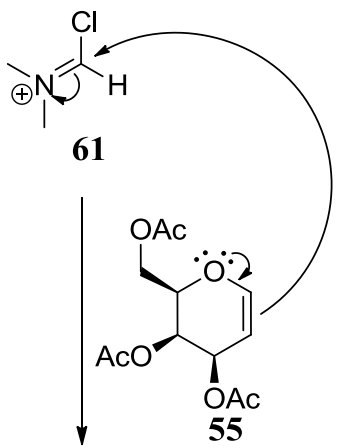

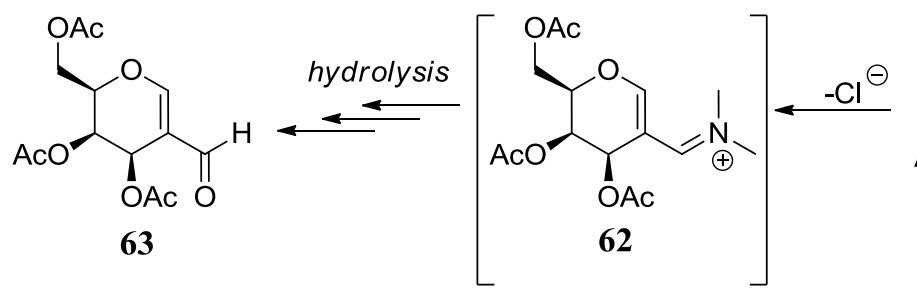

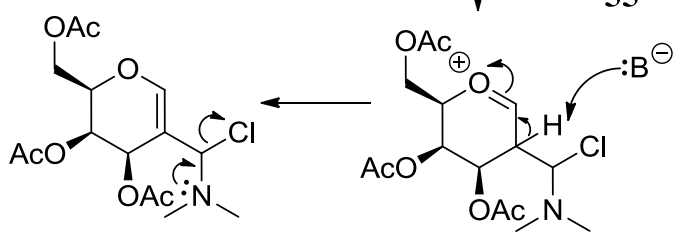

Scheme 2.4: Mechanism of Vilsmeier-Haack formylation.

Installation of the formyl group at the $\mathrm{C}-2$ position could alternatively be performed on a perbenzylated galactal (56). Balasubramanian reports the formation of 64 from 56 in excellent yield (Scheme 2.5). ${ }^{[21 \mathrm{a}]}$<smiles>O=CC1=CO[C@H](COCc2ccccc2)[C@@H](OBr)[C@@H]1OCc1ccccc1</smiles>

Scheme 2.5: Vilsmeier-Haack formylation of $\mathbf{5 6}$ reported by Balasubramanian. ${ }^{\text {[21a] }}$

Proceeding via a benzyl-protected species would require tri- $O$-acetyl-D-galactal $\mathbf{5 5}$ to be deprotected, and the resulting triol (65) and reprotected, and would also give a benzyl group at the C-3 position (Scheme 2.6). An acetate at the C-3 position is preferred as it makes the 2formylglycal a more likely candidate for C-1 alkynylation via Ferrier-rearrangement as acetates in this position are excellent leaving groups under Lewis acidic conditions. 


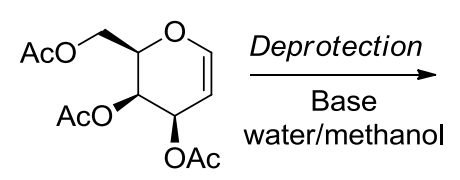

55<smiles>OCC1OC=CC(O)C1O</smiles>

65

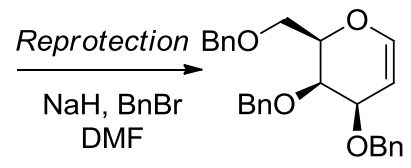

56

Scheme 2.6: Proposed transformation of $\mathbf{5 5}$ to $\mathbf{5 6}$ for use as a Vilsmeier-Haack substrate.

The acetolysis of the C-3 and C-6 benzyl ethers of 2-formylglycal 64 to make 2-formylglycal 66 can be performed using methodology developed by Vankar (Scheme 2.7). ${ }^{[24]}$ The prescribed conditions use zinc(II) chloride as a Lewis acid and a mixture of acetic acid and acetic anhydride as the acetate source. Interestingly, inversion of configuration at the C-3 position was reported. Vankar demonstrated that the C-3 benzyl ether was cleaved before the C- 6 benzyl ether and that selective C-3 acetolysis can be performed by using shorter reaction times. The higher reactivity of the C-3 benzyl ether is attributed to coordination of zinc(II) to the benzyl ether oxygen and the proximal aldehyde, thus activating the C-3 benzyl ether most effectively. Nucleophilic attack on the C-3 centre by acetic acid causes the activated benzyl ether to leave in an $\mathrm{S}_{\mathrm{N}} 2$ fashion, explaining the inversion of stereochemistry. The regioselectivity of the C-6 acetolysis over the C-4 position can be justified by the relative steric encumberment of the secondary $\mathrm{C}-4$ position compared to the primary C-6 position.

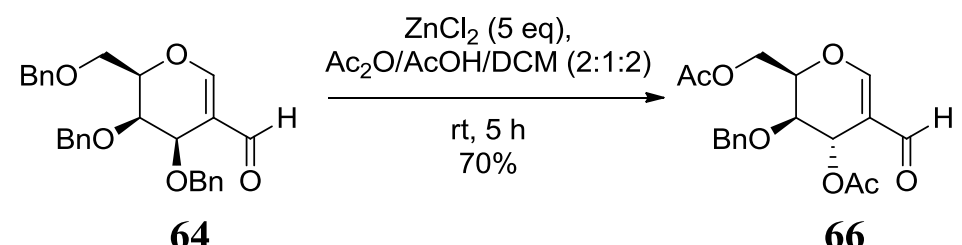

Scheme 2.7: Selective acetolysis of $\mathbf{6 4} .^{[24]}$

The differentially protected 2-formylglycal $\mathbf{6 6}$ is envisioned to be a key intermediate in the synthesis of (-)-TAN-2483B (1). The orthogonality between the benzyl-ether and acetate protecting groups at the C-4 and C-6 positions allows the hydroxy functionality at C-6 to be manipulated for side-chain installation without interference from the functionality at C-4. The benzyl protecting group at this position has been shown to be cleavable in late-stage intermediates in the existing analogue synthesis (Scheme 1.7). The acetate at the C-3 position suggests that 66 is a better substrate than 64 for Ferrier-rearrangement due to the lability of the group in Lewis acidic conditions as described above. 


\subsubsection{Ferrier-Type Alkynylation: Functionalisation at C-1}

The scaffold of the furanone ring requires a two-carbon unit be installed at the $\mathrm{C}-1$ position of the glycal. This reaction is key in providing the two-carbon unit at this position for the formation of the furanone ring. Ferrier-rearrangements often favour the formation of the $\alpha$ anomer of the resulting 2,3-unsaturated glycoside, ${ }^{[17 c]}$ the relationship of the substituents of the pyran ring resembling that of (-)-TAN-2483B (1). Ferrier-type alkynylation of glycals unsubstituted at the $\mathrm{C}-2$ position is well precedented. ${ }^{[17 \mathrm{~b}, 17 \mathrm{c}]}$ However Ferrier-type alkynylation of 2-substituted glycals is less common. Examples of the desired transformation coupling an alkyne nucleophile with a 2-halo, or 2-formylglycals $(57,63,66)$ have not been found in the literature. Nonetheless related reactions featuring 2-substitued glycals and carbon nucleophiles show that the proposed transformation is not unreasonable.

Acetylene nucleophiles have been installed via Ferrier-type alkynylation as demonstrated by Isobe. ${ }^{[25]}$ The acetylene nucleophiles installed on glucal 67 were trimethylsilyl protected at the reacting end in all cases. Tin(IV) chloride was used as the Lewis acid and the reaction performed using relatively complex acetylenes (Scheme 2.8).

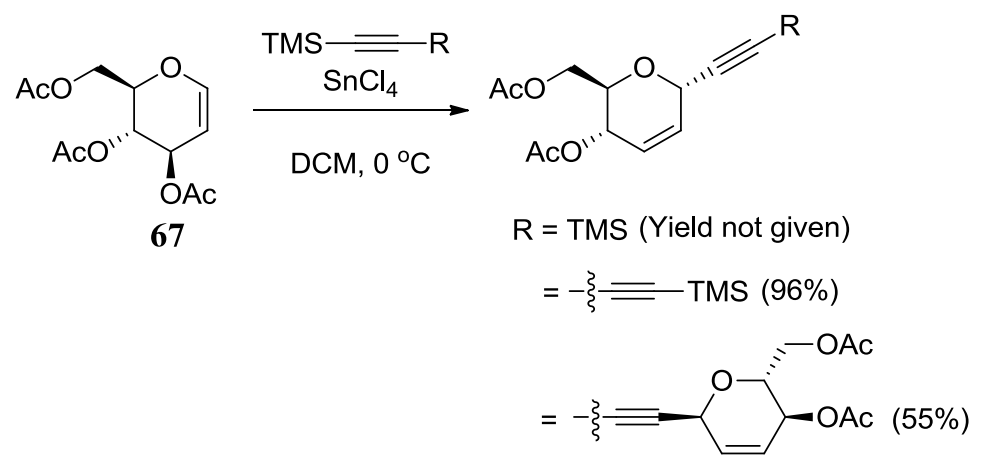

Scheme 2.8: Ferrier-type alkynylation reported by Isobe. ${ }^{[25]}$

Mukherjee reported the alkynylation of 2-acetoxyglycals, substrates somewhat similar electronically to 2-haloglycals. ${ }^{[26]}$ The acetyl-protected 2-acetoxyglucal 68 underwent Ferriertype rearrangement with an alkyne nucleophile to form 69 (Scheme 2.9). The reaction was mediated by an organozinc species formed in situ from zinc and ethyl bromoacetate in refluxing dichloromethane. The organozinc is postulated to act as an activator for the alkyne, and as a Lewis acid for the elimination of the acetate group at C-3. The observed $\alpha$-selectivity is 
explained by improved orbital overlap between the alkyne and the oxocarbenium intermediate during the transition state.

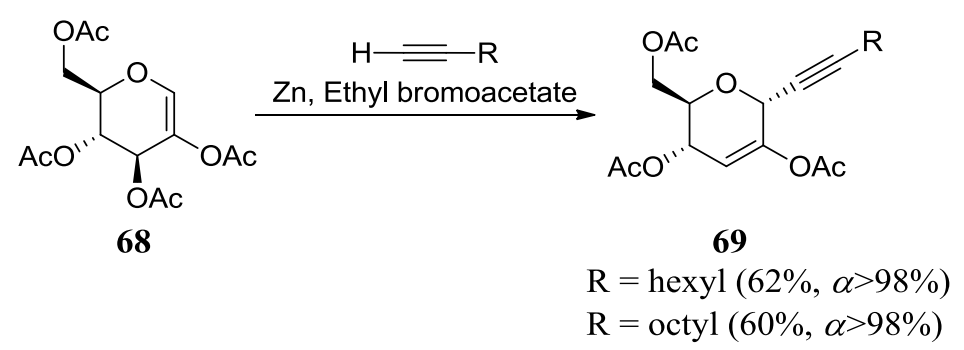

Scheme 2.9: Alkynylation of acetate protected 2-acetoxyglycals reported by Murkerjee. ${ }^{[26]}$

Ferrier-type $C$-glycosidation of 2-formylglycals (70, Scheme 2.10) with aliphatic nucleophiles has been reported by Cossy. ${ }^{[27]}$ Like the above reaction reported by Murkerjee, Cossy's method utilises an in situ generated organometallic species. It is posited that the aliphatic organolithium species transmetallates with copper(I), giving an organocopper species. ${ }^{[27]}$ The copperactivated alkane then attacks the glycal to form the $\mathrm{C}-\mathrm{C}$ bond. This reaction requires boron trifluoride diethyl etherate as a Lewis acid to facilitate the Ferrier-type elimination of the benzyl group at C-3 to afford 71. The preference for $\alpha$-product formation over $\beta$ - is attributed to energetic differences in the half-chair and half-boat transition states required to get to the respective products. The presence of the C- 6 benzyloxy group restricting access to the pro- $\beta$ face of the oxocarbenium intermediate is also posited as having implications in the selectivity for the $\alpha$-product. ${ }^{[27]}$

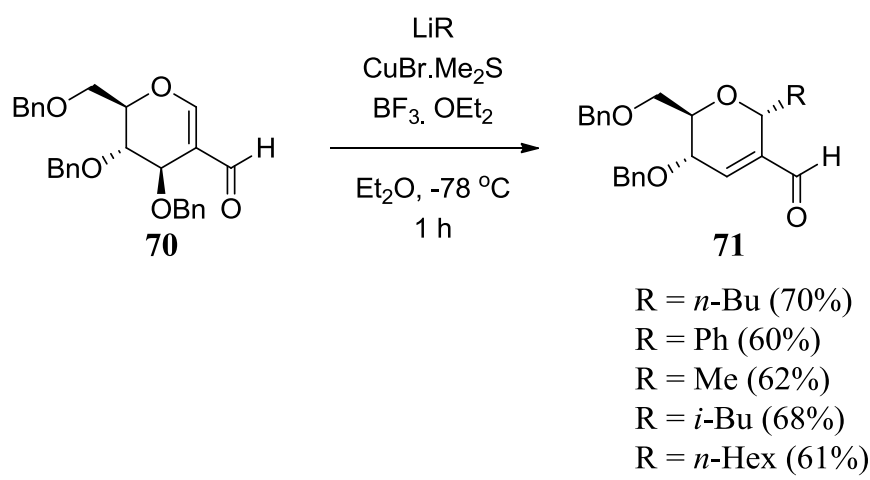

Scheme 2.10: Cossy's synthesis of 2-formyl-2,3-unsaturated $C$-glycosides. ${ }^{[27]}$

Cossy's reactions in Scheme 2.10 differ from the desired transformation in a number of ways. Firstly 2-formylglycal $\mathbf{7 0}$ is glucose derived whereas the 2-halo- or 2-formylglycal will be galactose derived, differing in stereochemistry at the C-4 position. Secondly the C-3 oxygen is 
benzyl protected where it is acetyl protected in 57, 63, and $\mathbf{6 6}$ (Scheme 2.11). Thirdly the desired transformation would use an acetylene nucleophile where Cossy used aliphatic and aromatic nucleophiles. The stereochemistry at the C-4 position should not have an effect on the chemistry of the Ferrier-rearrangement, since a benzyl ether is unlikely to provide anchimeric assistance to the C-3 position. Considering that the C-3 oxygen is protected with an acetyl group in 57, 63, and 66 rather than a benzyl group as in 70, the 2-halo- or 2formylglycals are more ideal candidates for Ferrier-type rearrangement due to acetates being better leaving groups than benzyloxides under Lewis acidic conditions. The reactions differ the most in that an acetylene nucleophile is desired rather than aliphatic or aromatic nucleophile.

With the above reactions in mind, the Ferrier-type alkynylation of 2-halo or 2-formylglycals was considered plausible (Scheme 2.11). The published conditions for Ferrier rearrangements provide a starting point for the reactions of the 2-halo or 2-formylglycals with an acetylene nucleophile.
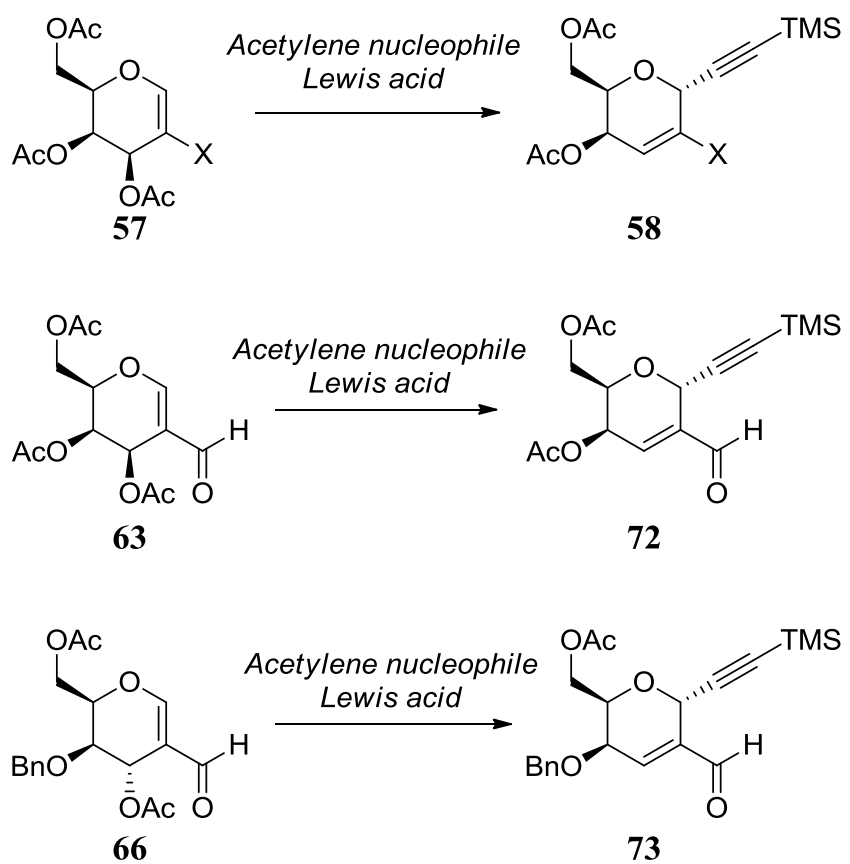

Scheme 2.11: Proposed Ferrier-type alkynylation of 2-halo/2-formylglycals.

\subsection{Ring Closure via Formylation and Alkynylation}

Upon formation of either $\mathbf{7 2}$ or $\mathbf{7 3}$, ring-closure can be performed following manipulation of the alkyne and aldehyde functionalities. Oxidation of the aldehyde to the carboxylic acid can 
be performed, followed by deprotection of the alkyne. From the terminal alkyne and the acid, an enol lactone can be performed using copper mediated conditions (vide infra). ${ }^{[19]}$

\subsubsection{Pinnick Oxidation: $\alpha, \beta$-Unsaturated Aldehyde to the Acid}

The Pinnick reaction is ideal for the oxidation of $\alpha, \beta$-unsaturated aldehydes. ${ }^{[28]}$ As such, conversion of the $\alpha, \beta$-unsaturated aldehydes (72 and 73) to the analogous acids (74 and 75) would use this methodology (Scheme 2.12).

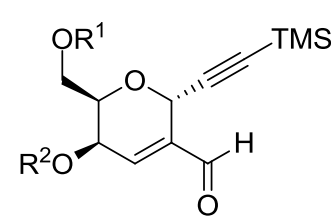

$72 \mathrm{R}_{1}=\mathrm{Ac}, \mathrm{R}_{2}=\mathrm{Ac}$ $73 \mathrm{R}_{1}=\mathrm{Ac}, \mathrm{R}_{2}=\mathrm{Bn}$

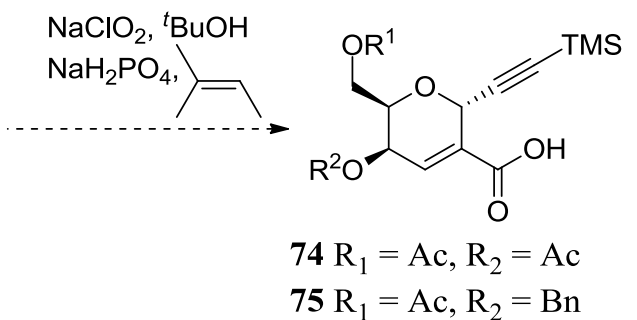

$75 \mathrm{R}_{1}=\mathrm{Ac}, \mathrm{R}_{2}=\mathrm{Bn}$

Scheme 2.12: Proposed Pinnick oxidation of $\alpha, \beta$-unsaturated aldehydes $\mathbf{7 2}$ and $\mathbf{7 3 .}$

An acid is desired to deliver the lactone in the ultimate ring structure. In contrast, ring formation using an aldehyde would result in a hemi-acetal and subsequent oxidation would be necessary. The active oxidant in the Pinnick reaction is chlorous acid, formed in situ from sodium chlorite and monosodium phosphate. Upon reaction between chlorous acid and the aldehyde, the byproduct hypochlorous acid is produced. 2-Methylbut-2-ene is included as a sacrificial alkene. The role of the sacrificial alkene is to react with the hypochlorous acid by-product, preventing further reaction with the starting material. A concern with the proposed transformation is the presence of the alkyne may react with hypochlorous acid before the sacrificial alkene - alkynes typically react more readily than alkenes. However, with the trimethylsilyl protecting group in place, the alkyne expected to be deactivated in terms of both sterics and electronics.

An example of a Pinnick-type oxidation with an alkyne starting material has been found in the literature using similar conditions (Scheme 2.13). ${ }^{[29]}$ Aldehyde $\mathbf{7 6}$ is coupled with alkyne 77 to form amide 78 using Pinnick reagents. It should be noted that alkyne in the starting material (77) is left intact under these conditions and is more sterically available than the alkynes in the 
proposed reaction (72, 73 Scheme 2.12). 2,3-Dimethylbut-2-ene is used over 2-methylbut-2ene as the sacrificial alkene due to its greater capacity for reaction with hypochlorous acid.

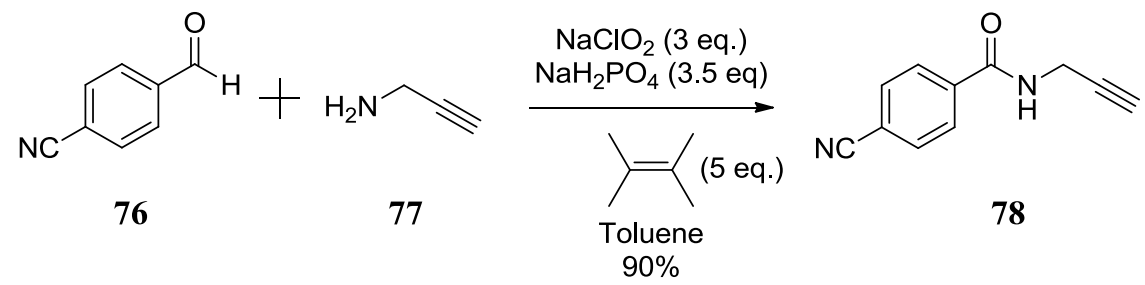

Scheme 2.13: An illustration of alkyne stability under Pinnick-type conditions. ${ }^{[29]}$

Highly substituted alkenes are relatively electron rich. These electron rich alkenes which could compete with the scavenger in reactivity with hypochlorous acid have been shown to be stable under Pinnick conditions (Scheme 2.14). ${ }^{[30]}$ Thus oxidation of diene aldehyde 79 using Pinnick conditions yielded the carboxylic acid $\mathbf{8 0}$ with the dienes intact.

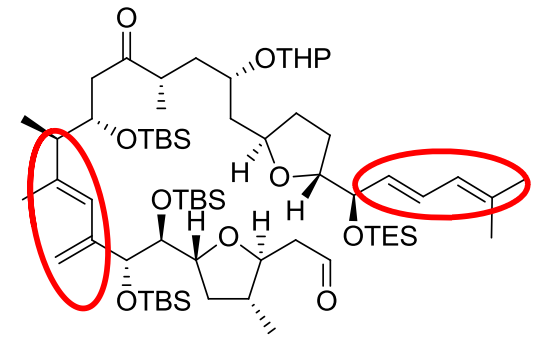

79

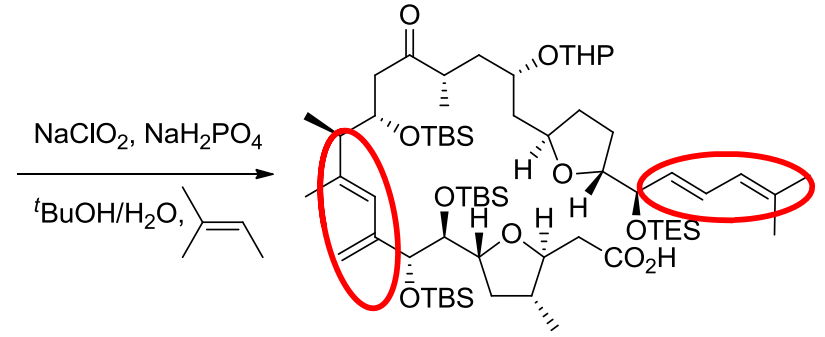

80

Scheme 2.14: An illustration of non-reacting alkenes in Pinnick oxidation conditions. ${ }^{[30]}$ Circled are the stable alkenes.

\subsubsection{Deprotection of the Alkyne}

The analogue synthesis involved removal of a similar trimethylsilyl protecting group using potassium carbonate and methanol. ${ }^{[13]}$ These conditions are unsuitable for the materials to be used in this reaction as potassium carbonate in methanol would cleave the acetyl protecting groups on compounds $\mathbf{7 4}$ and 75. Desilylation methodology using tetra- $n$-butylammonium fluoride would be employed to obtain the terminal alkynes 81 and 82 (Scheme 2.15). 


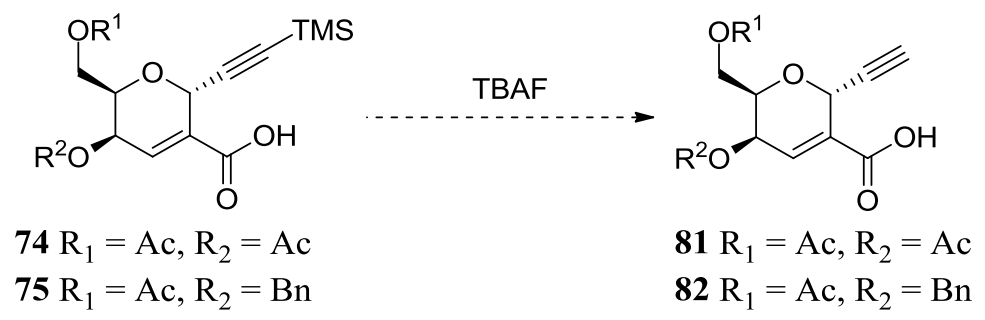

Scheme 2.15: Cleavage of the trimethylsilyl function to reveal the terminal alkyne.

As acetyl protecting groups are labile under basic conditions there was some concern in using tetra- $n$-butylammonium fluoride to perform the deprotection. However there is literature precedent for showing the removal of trimethylsilyl groups using the fluoride source while preserving acetyl esters. Trost reported the desilylation of $\mathbf{8 3}$ to give terminal alkyne 84 with the acetyl group in place (Scheme 2.16). ${ }^{[31]}$

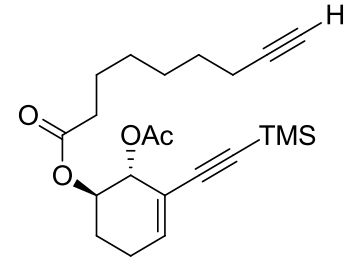

83

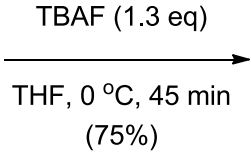

$(75 \%)$

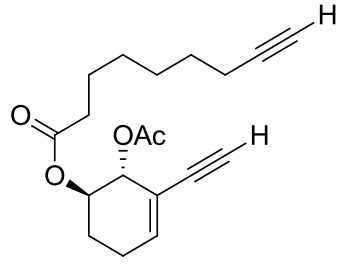

84

Scheme 2.16: Stability of the acetyl group in the presence of tetra- $n$-butylammonium fluoride. ${ }^{[31]}$

In the Trost transformation, however, the substrate has a secondary but no primary acetyl group, unlike compounds $\mathbf{7 4}$ and $\mathbf{7 5}$. It is hoped that by closely monitoring the reaction and stopping it as soon as starting material is consumed, the acetates could be preserved.

\subsubsection{Lactone Formation}

Intramolecular formation of enol lactones from terminal alkynes and carboxylic acids has been reported by Li and coworkers. ${ }^{[19]}$ The reaction is mediated by a copper(I)-amine species formed in situ from copper(I) iodide and $N, N$ '-dimethylcyclohexyl-1,2-diamine (DMCHDA) under basic conditions (Scheme 2.17). The cycloisomerism of $\mathbf{8 5}$ to $\mathbf{8 6}$ is the most pertinent example in the publication. 


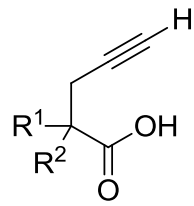

85

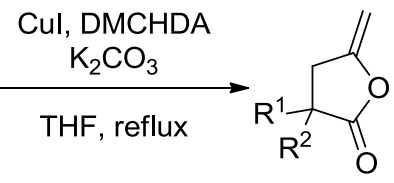

86

$\mathrm{R}_{1}=\mathrm{Ph}, \mathrm{R}_{2}=\mathrm{H}(88 \%)$

$\mathrm{R}_{1}=\mathrm{Me}, \mathrm{R}_{2}=\mathrm{Me}(96 \%)$

Scheme 2.17: Intramolecular formation of enol lactones from terminal alkynes and carboxylic acids reported by $\mathrm{Li}^{[19]}$

The methodology was hoped to be applicable to the lactone formation pictured in Scheme 2.18. As mentioned previously, there is concern about the lability of the acetyl groups of $\mathbf{8 1}$ and $\mathbf{8 2}$ under basic conditions. However acetate cleavage at this point in the synthesis is not a big issue, providing the free hydroxyls do not interfere in the lactone formation.<smiles>[R]OC[C@H]1O[C@H](C#C)C(C(=O)O)=C[C@H]1[R20]</smiles>

$81 \mathrm{R}_{1}=\mathrm{Ac}, \mathrm{R}_{2}=\mathrm{Ac}$

$82 \mathrm{R}_{1}=\mathrm{Ac}, \mathrm{R}_{2}=\mathrm{Bn}$

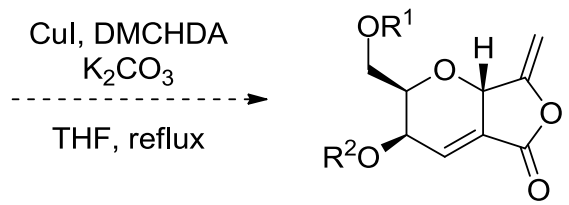

$87 \mathrm{R}_{1}=\mathrm{Ac}, \mathrm{R}_{2}=\mathrm{Ac}$

$88 \mathrm{R}_{1}=\mathrm{Ac}, \mathrm{R}_{2}=\mathrm{Bn}$

Scheme 2.18: Proposed cycloisomerisation of alkynoic acids $\mathbf{8 1}$ and $\mathbf{8 2}$ using the conditions prescribed by Li.

Following the formation of lactone $\mathbf{8 7}$ or $\mathbf{8 8}$, the resulting exo-alkene would be saturated whilst preserving the internal alkene of the pyran. As the exo-alkene is $O$-linked and therefore electron rich compared to the electron deficient internal alkene, it can be selectively hydrogenated. The selective hydrogenation of an electron rich alkene over an electron poor alkene was demonstrated by Marsh (89 to $\mathbf{9 0}$, Scheme 2.19). ${ }^{[32]}$

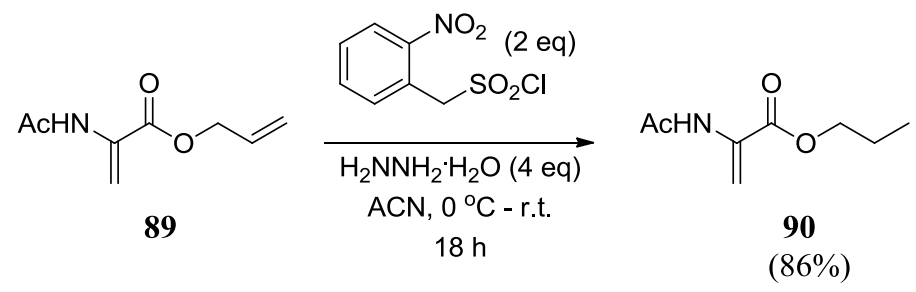

Scheme 2.19: Selective hydrogenation of an electron rich alkene in the presence of an electron deficient alkene as demonstrated by Marsh. ${ }^{[32]}$ 
Transfer hydrogenation is advantageous as it is easier to control the stoichiometry of the $\mathrm{H}_{2}$ donor reagent compared to using gaseous hydrogen. Marsh's conditions would be applied to either $\mathbf{8 7}$ or $\mathbf{8 8}$ (Scheme 2.20). Addition to the less hindered top face of $\mathbf{8 7 / 8 8}$ would give the appropriate stereochemistry of the resulting methyl.

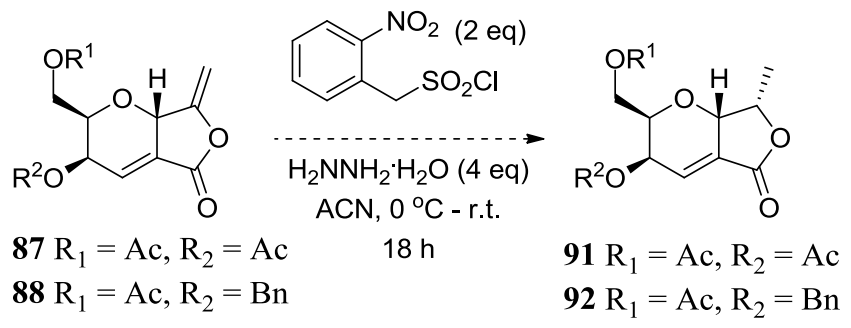

Scheme 2.20: Proposed selective hydrogenation of the exo-alkene.

\subsection{Side-Chain Installation}

The final steps in the proposed synthesis are deprotection of the primary alcohol, oxidation, olefination, and deprotection of the secondary alcohol.

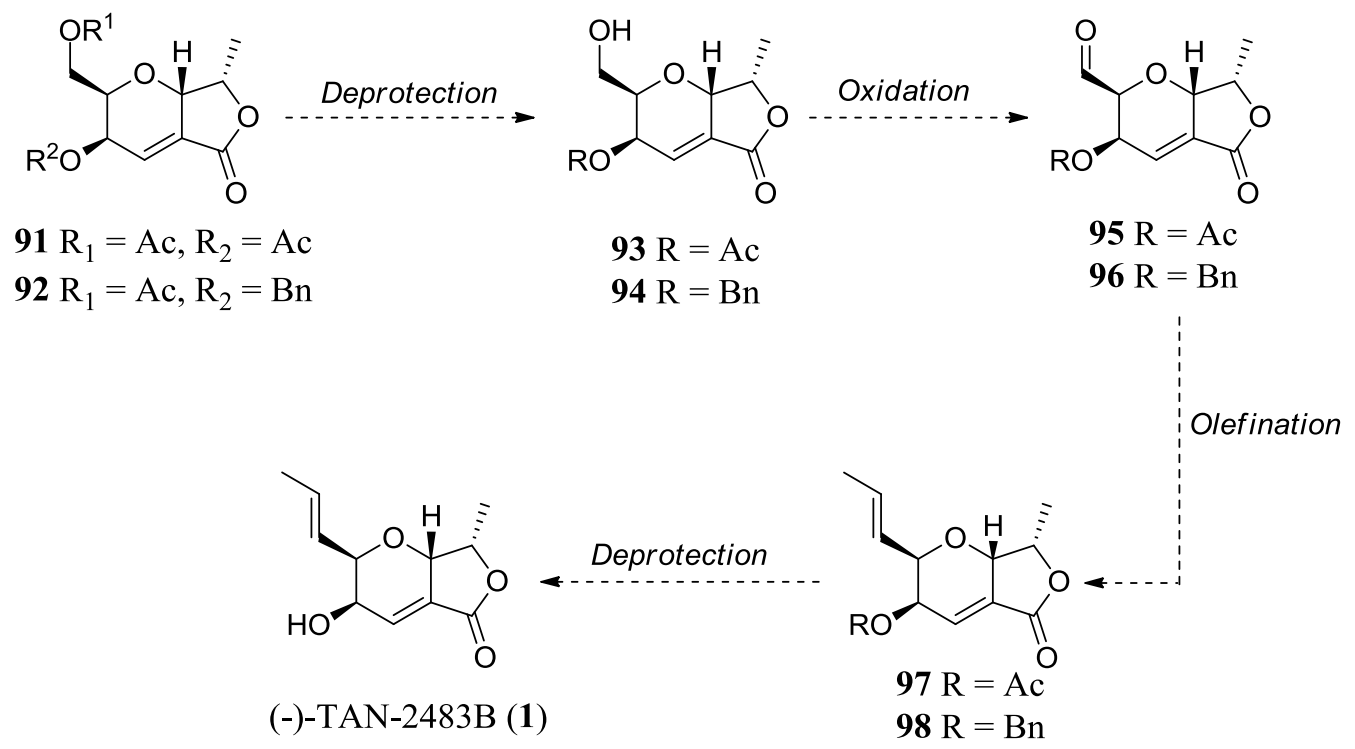

Scheme 2.21: Proposed Julia-Kocienski, and Takai-Utimoto olefination conditions.

There was some concern about the selective deprotection of the primary alcohol in the presence of the lactone ring (and the acetylated secondary alcohol as in 91) under classic Zemplen deacetylation conditions (sodium methoxide in methanol). ${ }^{[33]}$ The relative steric availability of the primary acetyl compared to the secondary acetyl and lactone, as well as the kinetic stability 
of the latter could be exploited in the deprotection. The alternative use of a mild acid, such as carbonic acid, and a stoichiometric amount of a bulky nucleophile such as tert-butanol could be used to enhance the selectivity of the process.

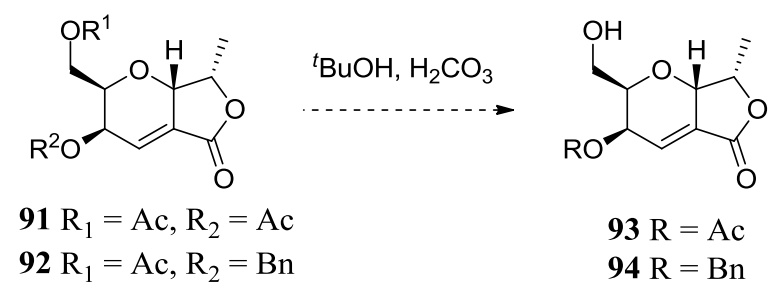

Scheme 2.22: Deprotection of the primary alcohol.

With the primary alcohol exposed, work towards side-chain installation could begin. The oxidation of the alcohols $\mathbf{9 3}$ or $\mathbf{9 4}$ to the corresponding aldehydes could be performed in a number of ways. While frequently used alcohol to aldehyde oxidations in synthesis include Swern, Dess-Martin, and Corey-Kim oxidations, the oxidation of similar substrates to 93/94 are reported in the literature to be achieved by other reagent sytems. For instance, Li and coworkers produce aldehyde $\mathbf{1 0 0}$ from the per-trimethylsilylated triol 99 precursor via a Collins oxidation $\left(\mathrm{CrO}_{3} \cdot 2 \mathrm{Py}\right.$, Scheme 2.23). Aldehyde $\mathbf{1 0 2}$ is produced from $\mathbf{1 0 1}$ using TEMPO/BAIB. ${ }^{[34]}$

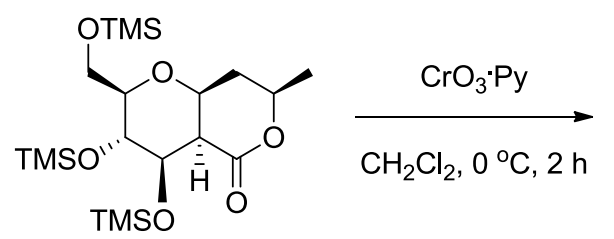

99<smiles>C[C@H]1C[C@H]2O[C@H](CO)[C@@H](Br)[C@H](O)[C@H]2C(=O)O1</smiles>

101<smiles>CO[C@H]1[C@@H](C=O)O[C@@H]2C[C@H](C)OC(=O)[C@@H]2[C@H]1OC</smiles>

100<smiles>C[C@H]1C[C@H]2O[C@H](C=O)[C@@H](Br)[C@H](O)[C@H]2C(=O)O1</smiles>

102

Scheme 2.23: Aldehyde formation in the dinemasone synthesis. ${ }^{[34]}$

Following oxidation, olefination of aldehydes 95 and 96 must produce the $E$-alkene in order to obtain the appropriate geometry of (-)-TAN-2483B's E-propenyl sidechain as in compounds 
97 and 98 (Scheme 2.24). Both Julia-Kocienski and Takai-Utimoto methodologies have been reported to achieve similar transformations. ${ }^{[34]}$

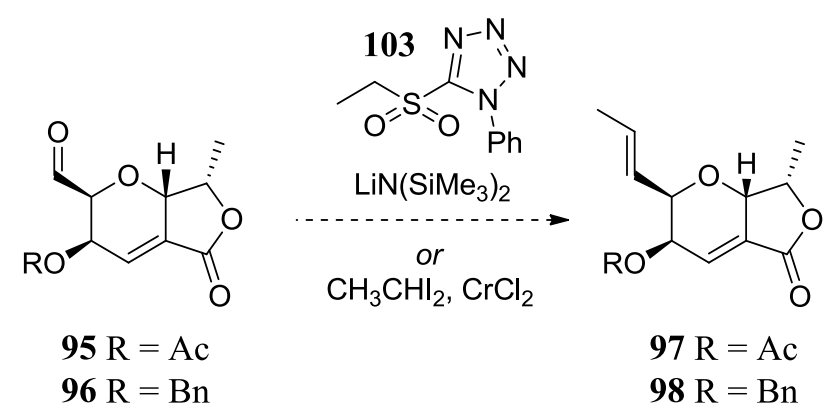

Scheme 2.24: Proposed olefination to install the propenyl side-chain.

The original Julia olefination involves the formation of a sulfone intermediate which must be cleaved using a sodium/mercury amalgam. ${ }^{[35]}$ This multi-step process was streamlined in 1991 into a one pot procedure by a different author of the same surname using a benzothiazolyl sulfonate reagent, ${ }^{[36]}$ the reaction being termed the modified Julia olefination. A further refinement offering more convenient and more selective methodology was reported in 1997 by Kocienski - the reaction being named the Julia-Kocienski olefination. ${ }^{[37]}$ The Julia-Kocienski reaction utilises a tetrazole sulfonate species (103) as the olefinating reagent and is mediated by a base such as lithium hexamethyldisilazide (LiHMDS). The advantage of the JuliaKocienski reaction is the enhanced selectivity attributable to the sterically demanding phenyl substituent on the tetrazole. This methodology has been used in a recent synthesis of the related dinemasone species (Section 1.3.3, Figure 1.5) published by Li and co-workers (Scheme $2.23)^{[34]}$, in which aldehyde $\mathbf{1 0 0}$ is reacted with the Julia-Kocienski reagent $\mathbf{1 0 3}$ to install the $E$-propenyl side chain of $\mathbf{1 0 4}$. Notably the lactone ring is stable under these conditions.

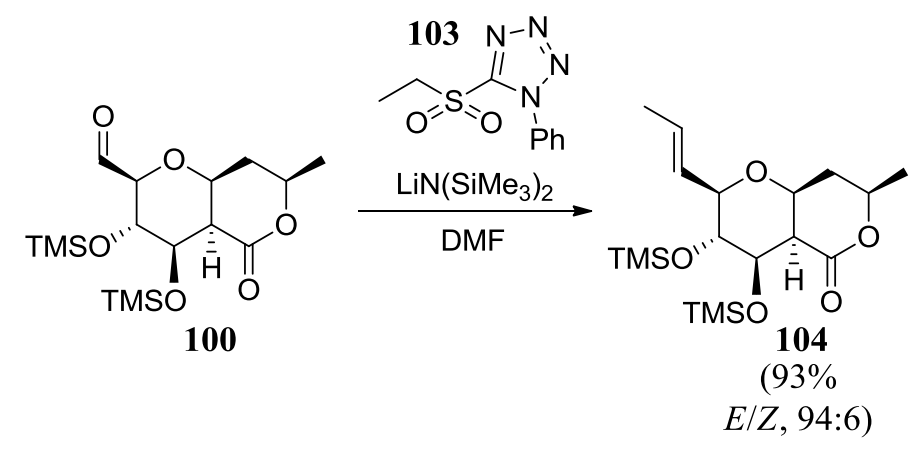

Scheme 2.25: Installation of the E-propenyl side chain of the related dinemasone species using JuliaKocienski methodology. ${ }^{[34]}$ 
Initial attempts at Julia-Kocienski olefination of $\mathbf{1 0 5}$ in tetrahydrofuran resulted in an unidentifiable mixture of degradation products. ${ }^{[13]}$ However, recent work done subsequent to Li's publication has seen some success in the production of $\mathbf{1 0 6}$ by using dimethylformamide (Scheme 2.24). ${ }^{[16]}$

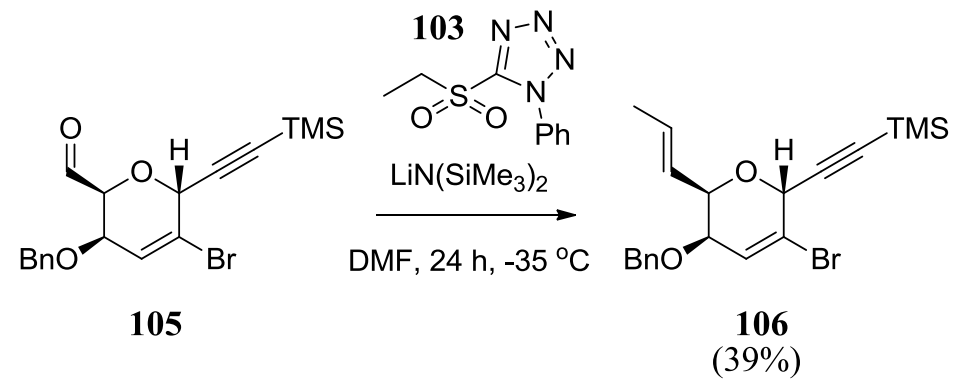

Scheme 2.26: Julia-Kocienski olefination in the toward the (-)-TAN-2483B synthesis. ${ }^{[16]}$

The dinemasone synthesis of $\mathrm{Li}$ and co-workers (mentioned above) also explored the use of a Takai-Utimoto olefination to install the side chain. ${ }^{[34]}$ Aldehyde 102 was treated with 1,1diiodoethane in the presence of chromium(II) chloride to afford the $E$-propenyl sidechain of 107 (Scheme 2.25). The Takai-Utimoto olefination proceeds via a gem-dichromium species which adopts an anti-conformation responsible for the selective production of $E$-products. ${ }^{[38]}$

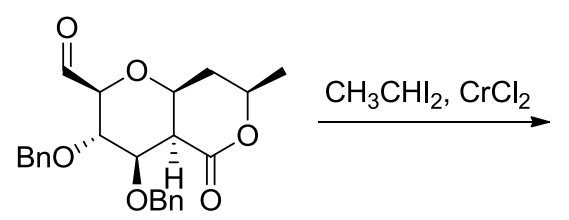

102

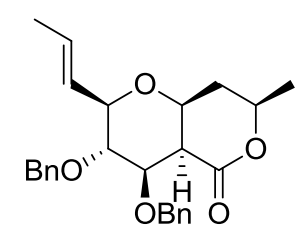

107

Scheme 2.27: Installation of the E-propenyl side chain in the dinemasone synthesis using Takai-

$$
\text { Utimoto methodology. }{ }^{[34]}
$$

The final step in the proposed synthesis is the deprotection of the secondary alcohol. The deprotection strategy will depend on the protecting group at this position. If the protecting group is an acetate, conditions described in Scheme 2.22 could be used, perhaps however with a less bulky nucleophile such as iso-propanol, longer reaction times, or higher temperatures (Scheme 2.26). If the protecting group is a benzyl ether, Lewis acid mediated deprotection could be used as demonstrated in the analogue synthesis. ${ }^{[13]}$ 


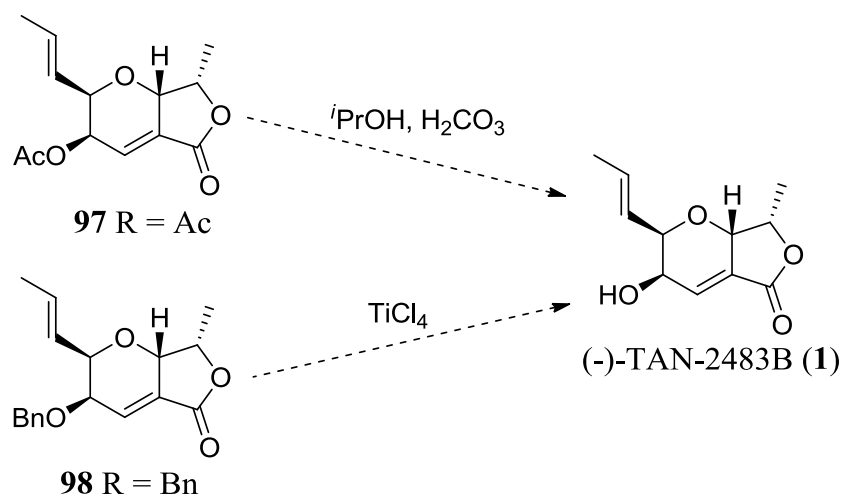

Scheme 2.28: Deprotection strategies in the final step of the proposed synthesis of (-)-TAN-2483B.

Lewis acid mediated cleavage of benzyl protecting groups has been demonstrated by Somarathne on similar species in the analogue synthesis (Scheme 2.27). ${ }^{[13]}$

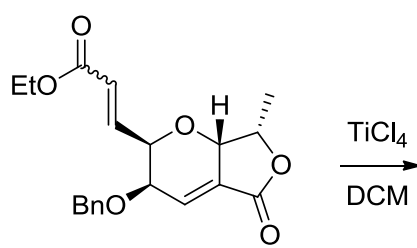

53<smiles>CCOC(=O)/C=C/[C@H]1O[C@H]2C(=C[C@H]1O)C(=O)O[C@H]2C</smiles>

$14 Z(56 \%)$

$15 E(52 \%)$

Scheme 2.29: Lewis acid mediated benzyl cleavage as demonstrated by Somarathne. ${ }^{[13]}$

The proposed synthesis of (-)-TAN-2483B offers a more step efficient and less hazardous approach to the natural product compared to the route currently used to produce analogues. The new route is 10 steps long and compares favourably to the existing 14-step method. Additionally, avoiding the difficult cyclopropanation-ring expansion transformation and the use of mercury, tin, and carbon monoxide make this route desirable over the reported strategy for the first generation synthesis. 


\section{RESULTS AND DISCUSSION}

\subsection{Synthesis of Tri- $O$-acetyl-D-galactal}

The synthesis of tri- $O$-acetyl-D-galactal 55 began with the acetylation of D-galactose 108 (Scheme 3.1). The per-acetylated sugar 109 was then treated with hydrogen bromide in acetic acid (33 wt\% solution) to install the anomeric bromide. Following basic work-up, the crude bromogalactoside 110 was reacted with zinc powder and copper sulfate to give tri- $O$-acetyl-Dgalactal 55 in $45 \%$ yield over 3 steps. While the yield for this synthesis was not on par with that reported in numerous literature accounts, ${ }^{[39]}$ the scales at which the reactions were performed provided ample material for subsequent reactions $(>10 \mathrm{~g})$. Literature precedence showed that this transformation could be performed with yields $>85 \%$ using alternate methodology. ${ }^{[39]}$

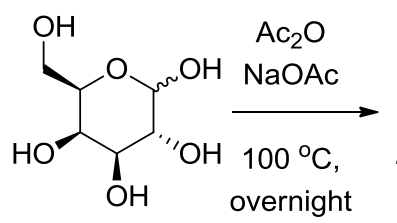

108

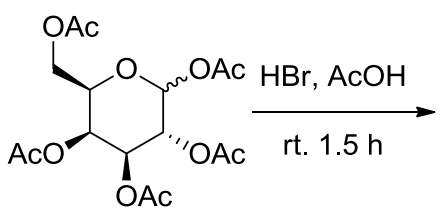

109

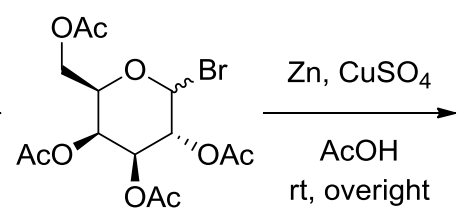

110

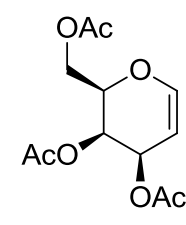

55

(45\% over 3 steps)

Scheme 3.1: Synthesis of tri-O-acetyl-D-galactal.

\subsection{Synthesis and Alkynylation of 2-Haloglycals}

The synthesis of 57a and 57b from tri- $O$-acetyl-D-galactal (55) was reported by Vankar (Scheme 3.2). ${ }^{[20]}$ The reported procedure describes the treatment of tri- $O$-acetyl-D-galactal (55) with the $N$-halosuccinimide (1.1 eq, bromo- or iodo-) and silver(I) nitrate ( 0.2 eq) in refluxing acetonitrile. After the starting material had been consumed as determined by TLC analysis (6 $\mathrm{h}$ bromo-, $3 \mathrm{~h}$ iodo-), the reaction mixture was filtered and the filtrate evaporated. The resulting crude product was then purified via silica gel chromatography to give the pure 2-haloglycals in good yield $(\mathbf{5 7 a} 71 \%, \mathbf{5 7 b} 82 \%)$. Vankar also reported successful analogous reactions using variously protected glycals (benzyl, methyl, silyl ethers), as well as 3,4-saturated furans. ${ }^{[20]}$ 


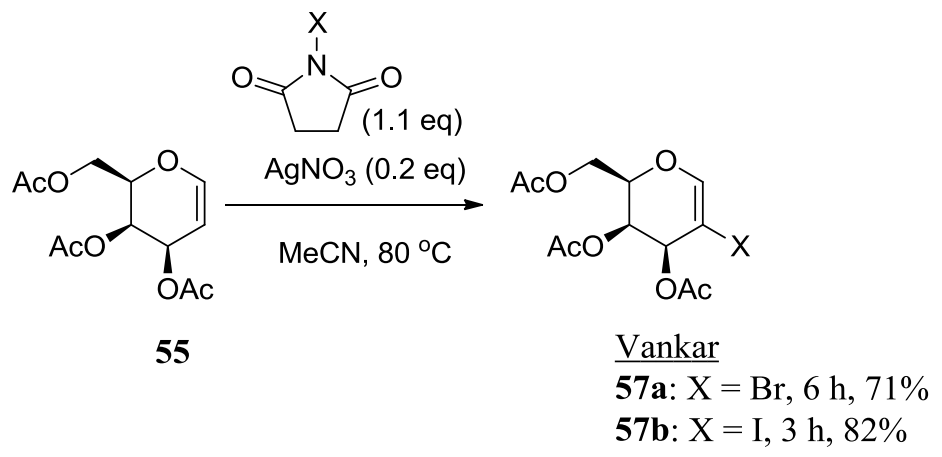

Scheme 3.2: Vankar's synthesis of 2-haloglycals. ${ }^{[20]}$

A proposed mechanism of the above reaction is given in the Vankar publication (Scheme 3.3). ${ }^{[20]} \mathrm{N}$-Halosuccinimides are widely used as a source of an electrophilic halogen. Electron demand from the imide functionality polarises the halogen-nitrogen bond making the halogen electrophilic. In the proposed mechanism silver(I) nitrate acts as a Lewis acid and activates the halosuccinimide. The nucleophilic enol-ether attacks the electrophilic halogen from the $\mathrm{C}-2$ position and succinimide is released. The nucleophilicity of C-2 is attributable to a shared electron density through resonance from the ring oxygen. Vankar then proposes that the nitrate anion binds to the oxocarbenium ion before subsequent deprotonation of $\mathrm{H}-2$ and elimination.

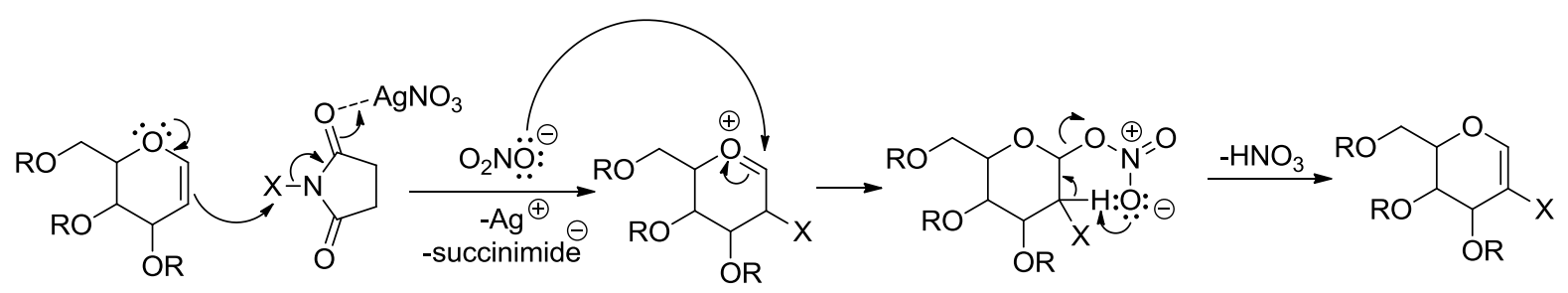

Scheme 3.3: Vankar's proposed mechanism of reaction between glycals and $N$-halosuccinimides. ${ }^{[20]}$

\subsubsection{Synthesis of 2-Bromoglycal 57a}

Unfortunately the successes of Vankar could not be replicated in this project, with formation of the bromoglycal somewhat more problematic than the iodoglycal. Attempted bromination using the conditions described above gave some of the desired product 57a, some starting material (55) as well as much degradation as observed in the ${ }^{1} \mathrm{H}$ NMR spectrum of the crude reaction mixture. Addition of an extra 0.2 equivalents of silver(I) nitrate and letting the reaction run longer (overnight) gave a similar result but starting material was consumed. After flash chromatography of the overnight reaction the desired 2-bromoglycal 57a was obtained but was contaminated with two by-products as observed in the ${ }^{1} \mathrm{H}$ NMR spectrum (Figure 3.1). TLC 
analysis of the NMR sample revealed only one spot despite the three species present. As the ratio of the product to the by-products in the ${ }^{1} \mathrm{H}$ NMR spectrum of the crude reaction mixture was near the same as that post-chromatography, it is likely that the by-products were being formed in the reaction mixture rather than upon exposure to deuterated chloroform or silica gel. If deuterated chloroform or silica gel were causing degradation of 57a into the aforementioned by-products, it would be expected that the ratio of the desired product to the two species would change with more by-product being observed after chromatography and spectroscopic analysis. The convergence of the two by-products and 57a into a single TLC spot meant that TLC analysis to monitor the success of the bromination in real-time was difficult. Repetition of Vankar's prescribed conditions often gave the by-products as the major species.

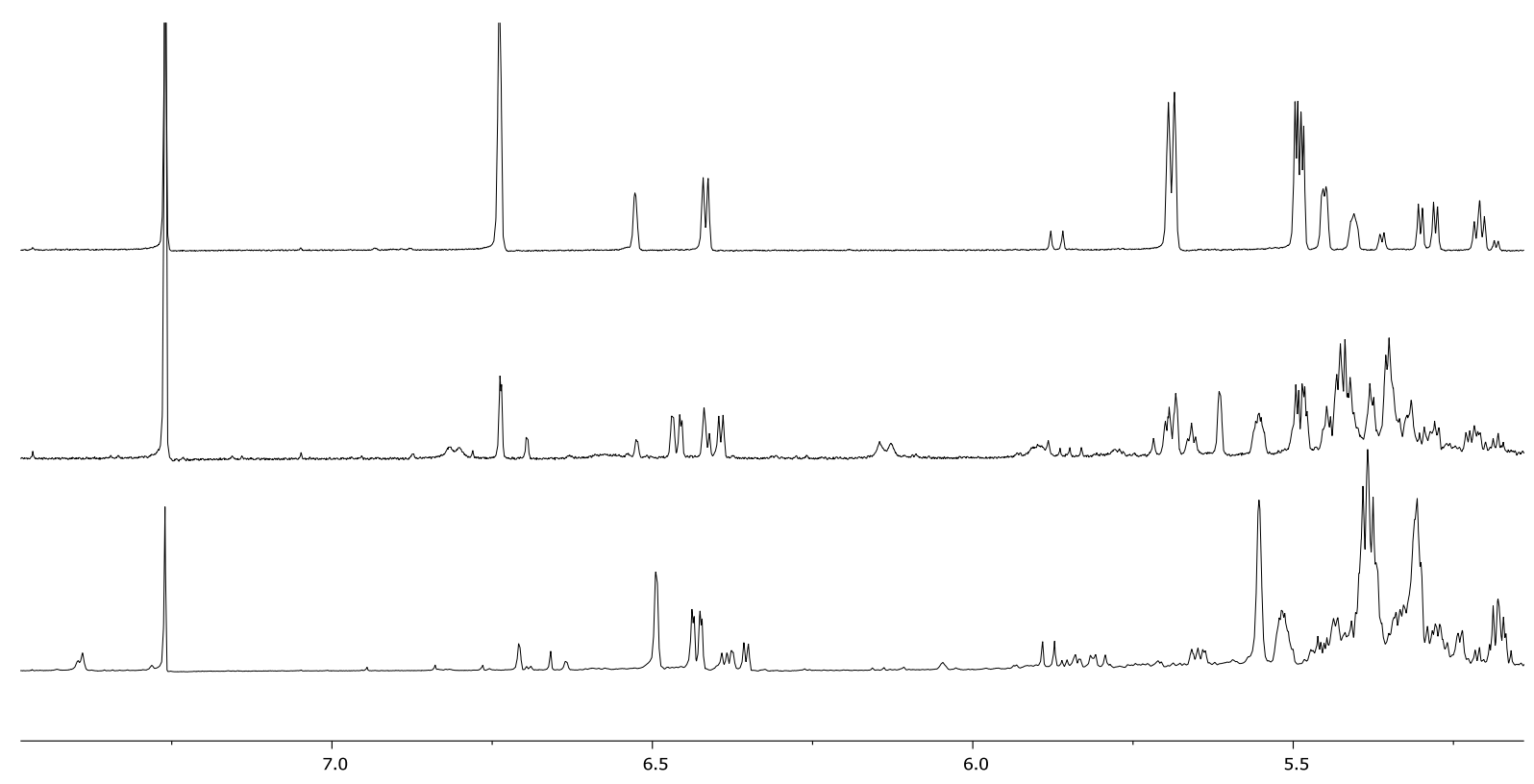

Figure 3.1: ${ }^{1} \mathrm{H}$ NMR spectra of $\mathbf{5 7 a}$ and by-products post-column (top); crude reaction mixture where both 57a and the by-products were observed (middle); reaction mixture where only trace 57a was observed (bottom).

One of the persistent by-products was isolated from a bromination attempt where only trace amounts of 57a were observed. The structure was studied using mass spectrometry, 1D and 2D NMR experiments. Three acetates were still present in the molecule as observed from the three singlets in the ${ }^{1} \mathrm{H}$ spectrum around $2 \mathrm{ppm}$ integrating for three protons each (Figure 3.2). The acetates were also observed in the ${ }^{13} \mathrm{C}$ spectrum, the carbonyl and methyl signals clustering around $170 \mathrm{ppm}$ and $20 \mathrm{ppm}$ respectively. Unsaturation was ruled out as there were no signals in the ${ }^{13} \mathrm{C}$ spectrum characteristic of alkenes. A signal at $100.3 \mathrm{ppm}$ was unlikely to be an alkene and was more characteristic of an acetal or hemiacetal. An HSQC correlation between 
the acetal carbon and a fine doublet at $6.52 \mathrm{ppm}$ in the ${ }^{1} \mathrm{H}$ spectrum was observed. A correlation was observed in the HH COSY spectrum between the proton at $6.52 \mathrm{ppm}$ and a broad doublet at $4.29 \mathrm{ppm}$, which in turn had an HSQC correlation to a carbon at $40.3 \mathrm{ppm}$. A signal near 40 $\mathrm{ppm}$ in ${ }^{13} \mathrm{C}$ spectra is characteristic of a brominated $\mathrm{sp}^{3}$ carbon. The acetal proton at $6.52 \mathrm{ppm}$ was assigned as $\mathrm{H}-1$, with the proton attached to the brominated position being assigned as $\mathrm{H}$ 2. The HH COSY correlations were able to be followed around the ring, the shifts of the oxymethines consistent with C-3, C-4, and C-6 still being acetylated. Mass spectrometry of the compound showed a mass of 431.0348 and an $\mathrm{M}$ isotope cluster characteristic of a mono-bromo species. The NMR data suggested that the structure of the by-product had a saturated pyranose with three acetylated oxygens, a bromine at the C-2 position, and an oxygen substituent at the $\mathrm{C}-1$ position $\left({ }^{1} \mathrm{H}\right.$ NMR $\delta \sim 6.5 ;{ }^{13} \mathrm{C}$ NMR $\left.\delta \sim 100\right)$. The molecular formula of an $O$-glycoside with the aforementioned functionality that best matched the mass found was the nitrate $\mathbf{1 1 1}$ (Figure 3.2) $\left(\mathrm{m} / \mathrm{z} \mathrm{C}_{12} \mathrm{H}_{20}{ }^{79} \mathrm{BrN}_{2} \mathrm{O}_{10}{ }^{+}\left[\mathrm{M}+\mathrm{NH}_{4}\right]^{+}\right.$calcd 431.0296, found $431.0348(\Delta=-12.01)$; an $\mathrm{M}+\mathrm{Na}$ signal for 111 was also found: $m / z \mathrm{C}_{12} \mathrm{H}_{16}{ }^{81} \mathrm{BrNO}_{10} \mathrm{Na}^{+}[\mathrm{M}+\mathrm{Na}]^{+}$calcd 437.9831, found $437.9878(\Delta=-10.6 \mathrm{ppm}))$. The chemical shifts of the anomeric centre in both the $1 \mathrm{H}$ and 13C NMR spectra were consistent with those seen previously in a glycosyl nitrate. ${ }^{[40]}$ The formation of the nitrate $\mathbf{1 1 1}$ was plausible given the presence of silver(I) nitrate in the reaction mixture, as well as Vankar's proposed mechanism of halogenation (Scheme 3.3). However no $\mathrm{M}+\mathrm{H}$ peak could be found in the mass spectrum, and the difference between the calculated mass of the ammonium and sodium adducts of $\mathbf{1 1 1}$ and those found were relatively large, making this assignment tentative. 

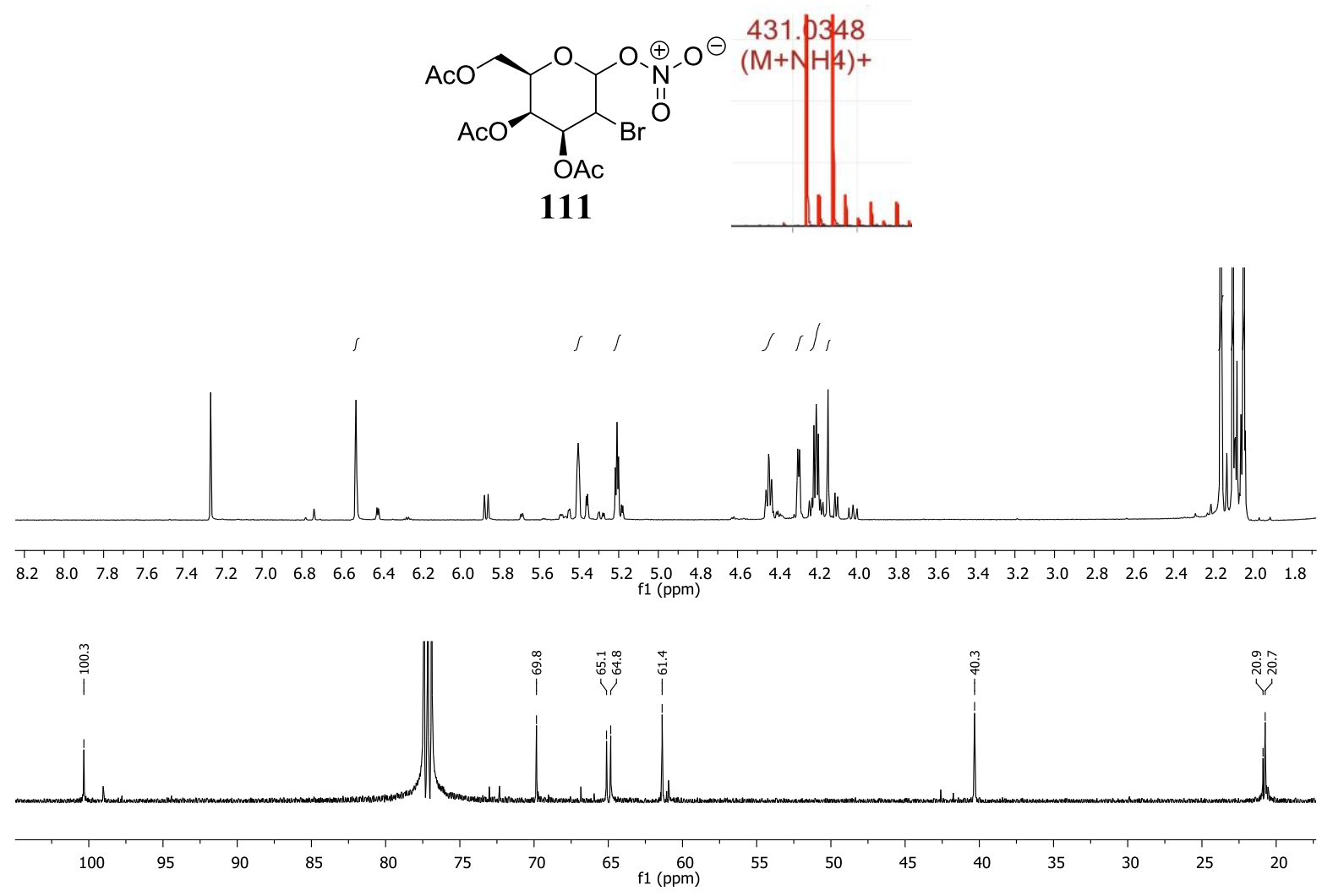

Figure 3.2: Proposed structure of one of the persistent by-products (top left), isotope cluster of $\mathbf{1 1 1}$

(top right), ${ }^{1} \mathrm{H}$ NMR spectrum (middle), and excerpt of ${ }^{13} \mathrm{C}$ NMR spectrum (bottom).

The probable detection of $\mathbf{1 1 1}$ indicated that the deprotonation event to restore the enol ether was not occurring. As such, the reaction was repeated with the addition of 0.2 equivalents of triethylamine. No reaction was observed via TLC analysis even after stirring overnight. Adding a second equivalent of $\mathrm{N}$-bromosuccinimide to the same reaction mixture appeared to trigger the consumption of starting material. After stirring overnight the mixture was filtered and concentrated under reduced pressure. A ${ }^{1} \mathrm{H}$ NMR spectrum was obtained of the crude reaction mixture which showed 2-bromoglycal 57a as the major sugar-like species. Subsequent chromatography of the mixture gave pure 57a with a yield of $32 \%$ (Scheme 3.4). 
<smiles></smiles>

55<smiles></smiles>

55
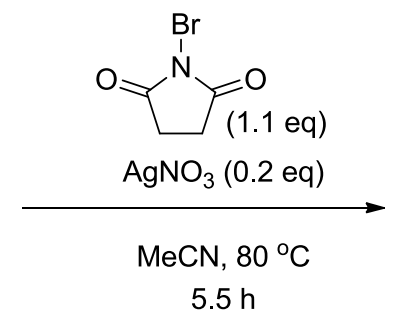

$5.5 \mathrm{~h}$

111<smiles>CC(=O)OCC1OC=C(Br)C(OC(C)=O)C1OC(C)=O</smiles>

57a

$<9 \%$ (inseparable from 111)

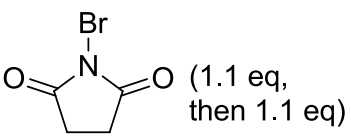

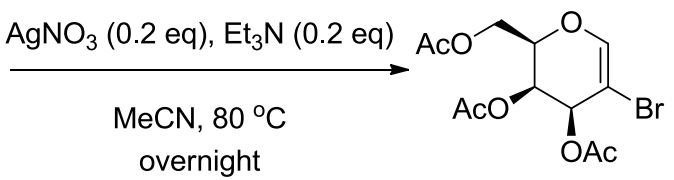

$57 \mathbf{a}$

$32 \%$

Scheme 3.4: Reactions of tri- $O$-acetyl-D-galactal (55) with $\mathrm{N}$-bromosuccinimide.

With formation of by-product 111 minimised by addition of triethylamine, optimisation of the reaction was attempted and the results are summarised in Table 3.1. 
Table 3.1: Optimisation studies of the synthesis of $\mathbf{5 7 a}$.

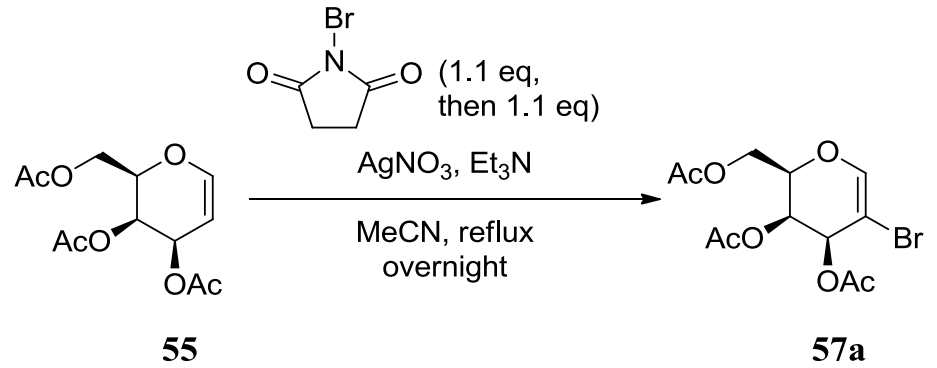

\begin{tabular}{ccccc}
\hline Entry & Time NBS $^{\mathrm{a}}$ & $\mathrm{Et}_{3} \mathrm{~N}(\mathrm{eq})$ & $\mathrm{AgNO}_{3}(\mathrm{eq})$ & Yield $^{\mathrm{b}}(\%)$ \\
\hline 1 & $\mathrm{o} / \mathrm{h}$ & 0.2 & 0.2 & 22 \\
2 & $2 \mathrm{~h}$ & 0.2 & 0.2 & 14 \\
3 & $4 \mathrm{~h}$ & 0.2 & 0.2 & 32 \\
4 & $1 \mathrm{~h}$ & 0.2 & 1.1 & $0^{\mathrm{c}}$ \\
5 & $1 \mathrm{~h}$ & 1.1 & 0 & $0^{\mathrm{c}}$ \\
6 & $2.5 \mathrm{~h}$ & 1.1 & 0 & $0^{\mathrm{c}}$ \\
7 & $\mathrm{n} / \mathrm{a}^{\mathrm{d}}$ & 0.2 & 0.2 & 6
\end{tabular}

${ }^{\mathrm{a}}$ Time NBS refers to the amount of time between combination of $\mathrm{AgNO}_{3}, \mathrm{Et}_{3} \mathrm{~N}$ and the first equivalent of NBS,

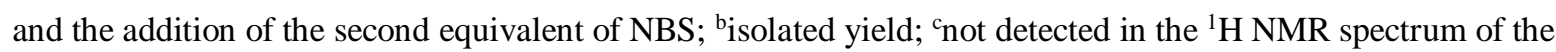
crude reaction mixture (and not isolated); ${ }^{\mathrm{d}}$ no second equivalent of NBS was added.

Optimisation was carried out by altering the amounts of silver(I) nitrate and triethylamine. Despite $N$-bromosuccinimide being a good electrophile, it appears that the presence of silver(I) nitrate as a Lewis acid is necessary for the enol ether to react with the halogen source (entries 5 and 6, Table 3.1). Too much triethylamine caused degradation, and the second equivalent of $\mathrm{N}$-bromosuccinimide was necessary (entries 4 , and 7 respectively). Vankar reported a 2-halo1-succinimidyl glycoside by-product when alternative Lewis acids were explored $\left(\mathrm{BF}_{3} . \mathrm{OEt}_{2}\right.$, AgOTf, $\mathrm{InCl}_{3}, \mathrm{Yb}(\mathrm{OTf})_{3}$, and $\left.\operatorname{In}(\mathrm{OTf})_{3}\right) .{ }^{[20]}$ The formation of Vankar's by-product suggests that succinimide is quenching the oxocarbenium ion (Scheme 3.3) and subsequent deprotonation of H-2 was not occurring. It is possible that the addition of a base such as triethylamine in reactions with Lewis acids other than silver(I) nitrate would favour the formation of 57a. The optimisations described in Table 3.1 were carried out with no thought toward the time between addition of the reagents and the second equivalent of $\mathrm{N}$ bromosuccimide (column "Time NBS"). However the above results hint that the amount of 
time before the second equivalent of $N$-bromosuccinimide was added is a factor (entries 1,2 , and 3).

The requirement of a second equivalent of $N$-bromosuccinimide after initial mixing of the reagents was somewhat puzzling with no definite conclusion being reached. The two key observations were that triethylamine prevented the reaction between 55 and $\mathrm{N}$ bromosuccinimide when 0.2 equivalents were present, yet addition of a second equivalent of $\mathrm{N}$-bromosuccinimide caused the starting material to be consumed and production of the desired product. Considering that triethylamine is a Lewis base, interaction with the silver(I) Lewis acid was plausible and explained why only 0.2 equivalents stopped the reaction. Silver(I) amine complexes are known, the most notable being Tollen's reagent $\left(\left[\mathrm{Ag}\left(\mathrm{NH}_{3}\right)_{2}\right] \mathrm{NO}_{3}\right) .{ }^{[41]}$ Addition of the second equivalent of $N$-bromosuccinimide perhaps somehow disrupted the Lewis acidbase complex, freeing silver(I) to activate $N$-bromosuccinimide for reaction, and triethylamine for deprotonation. However if the complexation of silver(I) and triethylamine is occurring and subsequently being disrupted by $N$-bromosuccinimide, there is no discernible reason why the initial equivalent of $\mathrm{N}$-bromosuccinimide would not play this role. Additional experiments which could be performed to help solve this mystery would be replication of entry 7 instead using 2 equivalents of $\mathrm{N}$-bromosuccinimide. Results of this would show if an incubation period before a second equivalent of $N$-bromosuccinimide was required. Attempting the reaction without silver(I) nitrate or triethylamine (i.e., only $\mathbf{5 5}$ and $\mathrm{N}$-bromosuccinimide) would give insight to the roles these reagents play in the reaction.

With only limited success in Table 3.1 (entries $1-3$ ), as well as progress made in the formation of the differentially protected 2-formylglycal for alkynylation studies (Section 3.4), further investigation of the formation of $\mathbf{5 7} \mathbf{a}$ was abandoned.

\subsubsection{Synthesis of 2-Iodoglycal 57b}

Initial attempts to form 2-iodoglycal 57b using Vankar's prescribed methodology were somewhat more successful than the analogous bromination. Reaction of tri- $O$-acetyl-D-galactal (55) with $\mathrm{N}$-iodosuccinimide proceeded quite readily in concordance with the trends reported by Vankar. This result is also expected as iodated species are typically more reactive than their brominated counterparts. Starting material was consumed within $2 \mathrm{~h}$, with $\mathbf{5 7 b}$ being the major 
species observed in the ${ }^{1} \mathrm{H}$ NMR spectrum of the crude reaction mixture, with what was likely a by-product analogous to $\mathbf{1 1 1}$ present. This by-product was also present post-chromatography. However iodoglycal 57b was always observed as the major product using Vankar's conditions. During purification via silica-gel chromatography a fast moving pink band was observed on the column, indicative of molecular iodine. 2-Iodoglycal 57b manifested as a white solid, but upon dissolution in deuterated chloroform became pink. The pink colour grew in intensity the longer 57b was in the solvent (Figure 3.3). Treatment of the silica-gel with triethylamine, and the deuterated chloroform with potassium carbonate before exposure to samples containing 57b prevented the pink colour from initially forming, however some colour was observed in the chloroform solution after a day or so. The arising pink colour indicates the formation of molecular iodine, which in turn suggests degradation of 57b. The development of the pink colour being mitigated by basifying the silica and chloroform hints at an acid sensitivity. However light sensitivity was not ruled out.

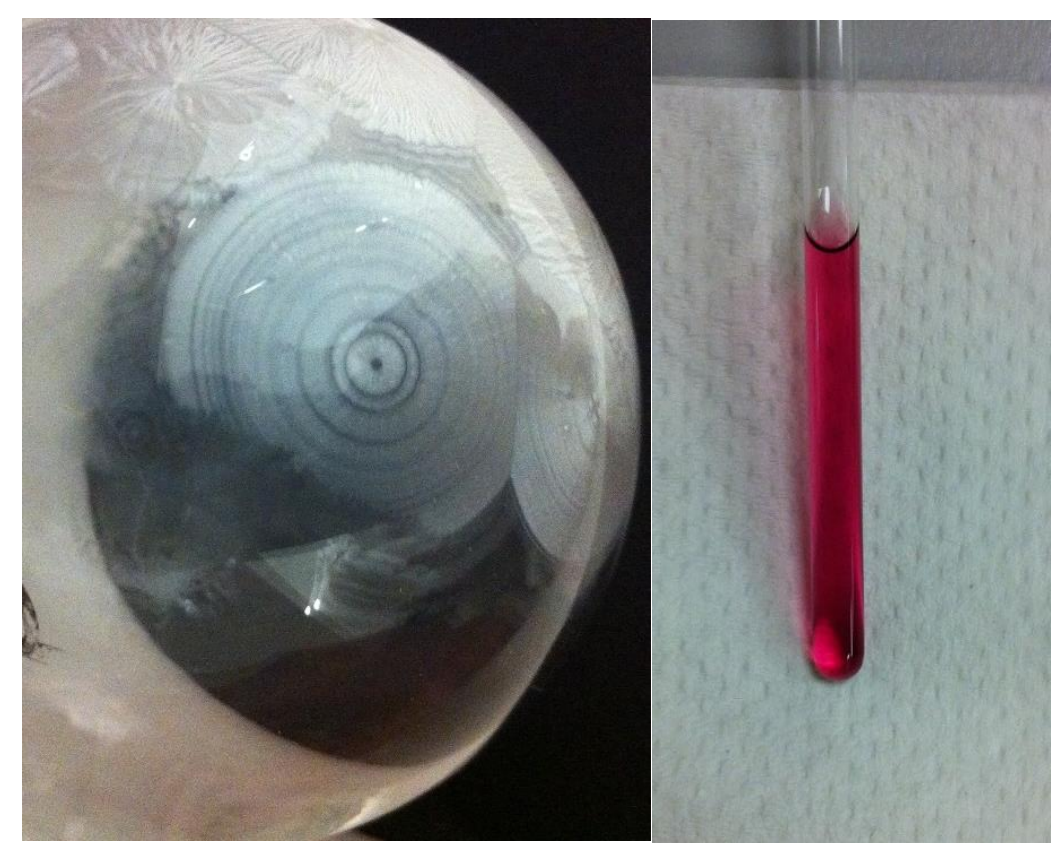

Figure 3.3: 2-Iodoglycal $\mathbf{5 7 b}$ as a solid (left) and in chloroform after $\sim 2$ days (right).

The best yield obtained for the 2-iodoglycal (57b) was $37 \%$ albeit contaminated with some byproduct (Scheme 3.5). Addition of triethylamine to the reaction resulted in degradation in contrast to the results with $N$-bromosuccinimide. 


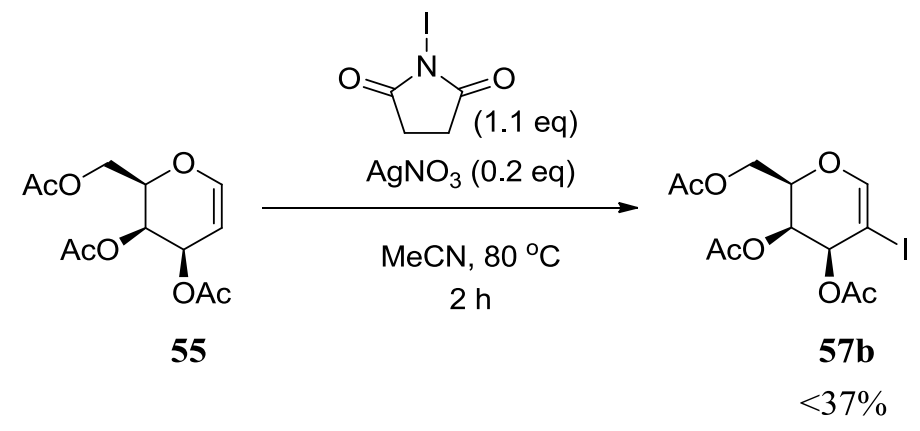

Scheme 3.5: Synthesis of $\mathbf{5 7 b}$.

The 2-iodoglycal $\mathbf{5 7 b}$ proved to be unstable and was only able to be made in modest yields. As such, accrued material for further alkynylation studies was low. Consideration of these factors, as well as developments made in the synthesis of 2-formylglycal 66 as a Ferrier substrate (Section 3.4), further optimisation toward 2-iodoglycal formation was abandoned.

\subsubsection{Alkynylation of 2-Haloglycals}

Despite the difficulties in synthesising 2-haloglycals 57 in high yields, enough material was collected to perform some alkynylation studies. The desired transformation is pictured in Scheme 3.6. As the stereochemistry of alkyne products made was unable to be determined (vide infra), discussion of experimental results will refer to alkyne 112, rather than $\mathbf{5 8}$. However only one anomer of 112 was observed; due to Ferrier rearrangements favouring the $\alpha$-anomer of the resulting 2,3-unsaturated glycoside, ${ }^{[17 c]} \mathbf{1 1 2}$ can tentatively be assumed to be $\mathbf{5 8}$.
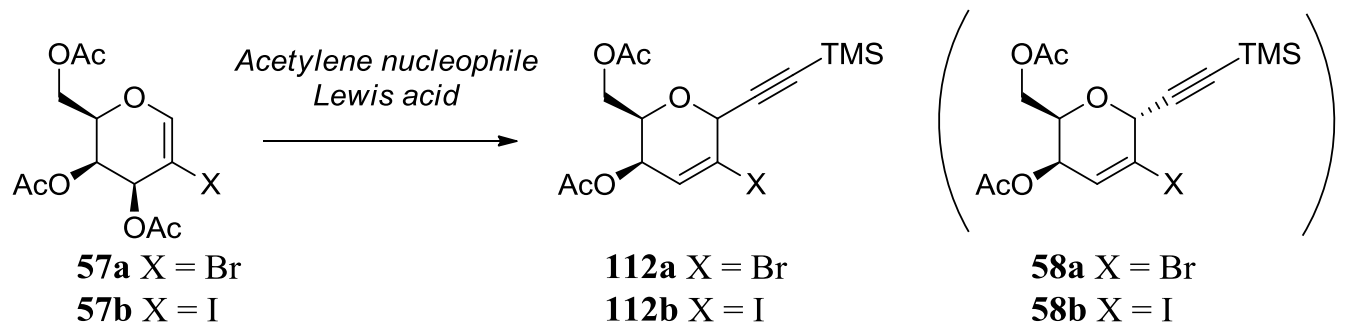

Scheme 3.6: Desired Ferrier-type alkynylation of 57.

Mukherjee's methodology (Section 2.2.3) was applied in the attempted alkynylation of 57b. ${ }^{[26]}$ Methylbromoacetate was used instead of ethylbromoacetate because it was already in the laboratory's inventory and the identity of the alkyl group was deemed to be immaterial to the result. Zinc powder, methylbromoacetate, and trimethylsilylacetylene were stirred in refluxing 
dichloromethane for $2 \mathrm{~h}$ (Scheme 3.7). 2-Iodoglycal 57b was then added and the reaction was stirred overnight. No reaction was observed by TLC analysis or ${ }^{1} \mathrm{H}$ NMR spectroscopy.

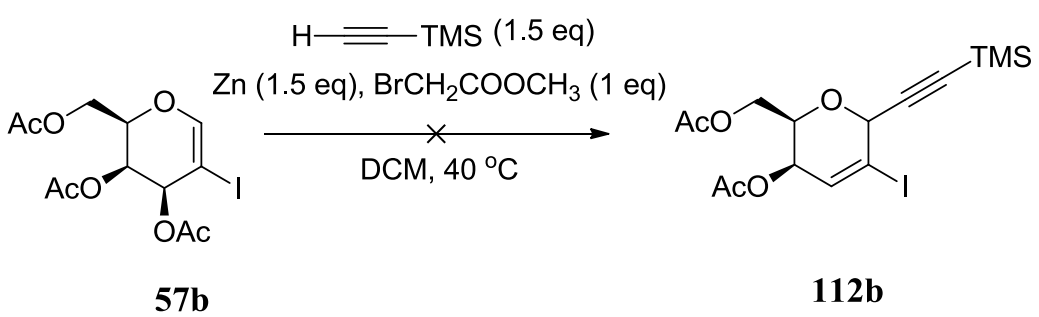

Scheme 3.7: Attempted synthesis of $\mathbf{9 3 b}$ using Mukherjee's methodology.

In the publication detailing the syntheses of $\mathbf{5 7} \mathbf{a}$ and $\mathbf{5 7 b}$, Ferrier-rearrangement was performed on the 2-haloglycals using 2 equivalents of boron trifluororide diethyl etherate and 1.1 equivalents of the $O$-nucleophile in dichloromethane at room temperature. Vankar reported yields up to $92 \%$ with selectivity of the $\alpha$-anomer of the resulting 2,3-unsaturated $O$ glycoside. ${ }^{[20]}$ This methodology was applied to 2-haloglycals $57 \mathbf{a}$ and $\mathbf{5 7 \mathbf { b }}$ using an acetylene nucleophile. Bis(trimethylsilyl)acetylene was chosen as the nucleophile due to literature precedence in Isobe's work (Section 2.2.3). ${ }^{[25]}$

2-Haloglycals 57a and 57b were treated with 1.1 equivalents of bis(trimethylsilyl)acetylene and 2 equivalents of boron trifluoride diethyl etherate in dichloromethane at room temperature (Scheme 3.8). TLC analysis of the reaction mixtures after $2.5 \mathrm{~h}$ for $\mathbf{5 7 a}$ and $7 \mathrm{~h}$ for $\mathbf{5 7 b}$ revealed almost complete consumption of starting material accompanied by the appearance of both a less polar species and a more polar species. Isolation of the less polar species from both reactions using silica-gel chromatography revealed them to be the alkyne adducts of both the bromo and the iodo species (112a and 112b). Alkynes 112a and 112b were obtained in $17 \%$ and $13 \%$ yield respectively. This reaction was not optimised due to the difficulty in preparing the starting materials.

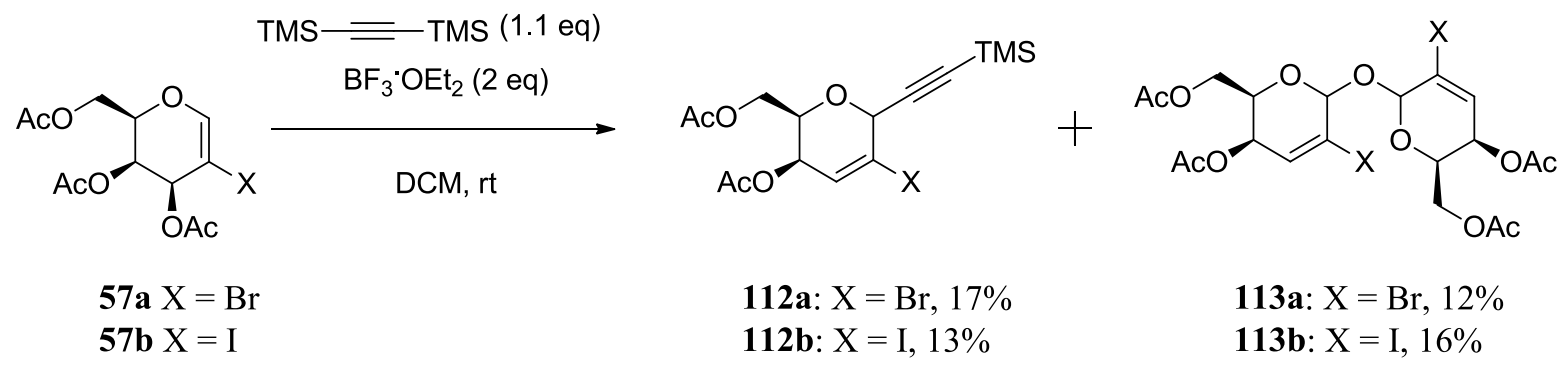

Scheme 3.8: Synthesis of $\mathbf{9 3}$ and $\mathbf{9 4}$ by Ferrier rearrangement. 
The structure of 112b was determined using 1D and 2D NMR experiments, and mass spectrometry. The structure of 112a was determined by comparison of 1D NMR spectra to 112b. 2D NMR data was unable to be obtained for 112a as only a small amount remained after spillage of the purified sample.

Two singlets at 2.08 and $2.09 \mathrm{ppm}$ integrating to three protons each in the ${ }^{1} \mathrm{H}$ NMR spectrum of $112 \mathrm{~b}$ each indicated the presence of two acetates. The trimethylsilyl group was visible as a singlet integrating to nine protons at $0.20 \mathrm{ppm}$. The signal at $6.79 \mathrm{ppm}$ representing $\mathrm{H}-1$ in the starting material 57b had shifted upfield to become part of a complex multiplet with $\mathrm{H}-4$ from $5.04-5.00 \mathrm{ppm}$. A doublet at $6.59 \mathrm{ppm}$ was characteristic of the alkene proton $\mathrm{H}-3$ in $\mathbf{1 1 2} \mathbf{b}$. The ${ }^{13} \mathrm{C}$ NMR spectrum also showed the presence of two acetates in signals at 170.8 and 170.3 ppm representing the carbonyls, and two signals at 20.9 ppm being the methyl groups. Signals at 98.5 and $93.7 \mathrm{ppm}$ were characteristic of a trimethylsilyl protected alkyne and both showed HMBC correlations to the multiplet representing $\mathrm{H}-1$, confirming the correct connectivity. Mass spectrometry confirmed the formula of 112b: $\mathrm{m} / \mathrm{z} \quad \mathrm{C}_{15} \mathrm{H}_{21} \mathrm{IO}_{5} \mathrm{SiNa}^{+}[\mathrm{M}+\mathrm{Na}]^{+}$calcd 460.0120 , found $460.0117(\Delta=0.73 \mathrm{ppm})$. The configuration at the alkynylated carbon is still unknown as NOESY experiments did not reveal any correlations of the H-1 proton, and attempts at crystallising the small mass of white solid for x-ray diffraction were unsuccessful. Nonetheless the lack of a positive NOE correlation could suggest an $\alpha$-configuration.

Also observed in the Ferrier-type alkynylations of both 57a and 57b was a more polar species. The following structural elucidation pertains to $\mathbf{1 1 3 b}$. The signals of $\mathbf{1 1 3 a}$ and $\mathbf{1 1 3 b}$ are very similar and can be interchanged in the discussion. Analysis of the ${ }^{1} \mathrm{H}$ NMR spectrum showed signals at 2.09 and $2.10 \mathrm{ppm}$ indicative of two acetates. A doublet at $6.78 \mathrm{ppm}$ in $\mathbf{1 1 3 b}$ resembled the H-3 alkene in 113b which suggested a Ferrier-rearranged product. No signals suggesting the presence of the trimethylsilyl group a terminal alkyne protons were observed. The ${ }^{13} \mathrm{C}$ spectrum also lacked trimethylsilyl and alkyne signals. The peaks representative of the protons around the pyran ring in the more polar product resembled that of $\mathbf{1 1 3 b}$, the most notable difference being the signal representing H-1 (5.04 - 5.00 ppm in 112b, 5.47 in 113b). This downfield shift in H-1 was more characteristic of an acetal proton rather than an oxymethine. Mass spectrometry detected a mass approximately double that of the starting material hinting at dimer formation (113b: $m / z \mathrm{C}_{20} \mathrm{H}_{24} \mathrm{I}_{2} \mathrm{O}_{11} \mathrm{Na}^{+}[\mathrm{M}+\mathrm{Na}]^{+}$calcd 717.9334, found $717.9329\left(\Delta=0.77\right.$ ppm), 113a: $m / z \mathrm{C}_{20} \mathrm{H}_{24} \mathrm{Br}_{2} \mathrm{O}_{11} \mathrm{Na}^{+}[\mathrm{M}+\mathrm{Na}]^{+}$calcd 622.9559, found 
$622.9560(\Delta=-0.19 \mathrm{ppm}))$. The nature of the ${ }^{1} \mathrm{H}$ NMR spectrum suggests that if the species is dimeric, it is symmetrical. A correlation between H-1 and C-1' was observed in the HMBC, with the signal at $5.47 \mathrm{ppm}$ correlating to $95.0 \mathrm{ppm}$. The structure of $\mathbf{1 1 3 b}$ is consistent with the discussed results, being dimeric, the product of a Ferrier rearrangement, and having an acetal at the $\mathrm{C}-1$ position.

The formation of the dimeric species $113 \mathrm{a}$ and $\mathbf{1 1 3 b}$ can be explained by the presence of water in the reaction mixture. Ferrier-rearrangement of $\mathbf{5 7}$ with water as a nucleophile would give the hydroxy analogue of 112. The resulting 2,3-unsaturated hemiacetal then itself would act as a nucleophile in another Ferrier rearrangement of $\mathbf{5 7}$ to give 113. The stereochemistry of the C-1 and C-1' positions in $\mathbf{1 1 3}$ is not known; NOESY experiments and crystallisation in order to obtain x-ray data were not attempted (due to time constraints and the fact $\mathbf{1 1 3}$ was not the desired product). The ${ }^{1} J_{\mathrm{CH}}$ coupling of $\mathrm{H}-1 / \mathrm{H}-1$ ' and C-1/C-1' in $\mathbf{1 1 3}$ could be compared to the 2,3-unsaturated-2-halo- $O$-glycosides produced by Vankar had they been published, to probe the configuration at this position. The configuration about $\mathrm{C}-1 / \mathrm{C}-1$ ' in $\mathbf{1 1 3}$ could give insight to the analogous centre in $\mathbf{1 1 2}$. However it cannot be assumed that the stereochemistry about $\mathrm{C}-1$ and $\mathrm{C}-1$ ' in $\mathbf{1 1 3}$ would be the same as the anomeric centre in $\mathbf{1 1 2}$ due to the differences in reactivity between alkynyl and hydroxy nucleophiles. As the reactions were performed under argon in heat-gun-dried glassware, water was probably introduced in one of the reagents. Due to the small scale of the reactions, a small amount of water present would have a noticeable effect.

\subsection{Vilsmeier-Haack Formylation of D-Galactal Derivatives}

Formylation of tri- $O$-acetyl-D-galactal 55 was performed alongside that of tri- $O$-benzyl-Dgalactal 56 using the same conditions (apart from scale). Phosphoryl chloride ( 3 eq) was added dropwise to $\mathrm{N}, \mathrm{N}$-dimethylformamide under a nitrogen atmosphere in an ice-water bath. The solution was left to stir for $0.5 \mathrm{~h}$ at $0{ }^{\circ} \mathrm{C}$, then warmed to room temperature. The glycal (1 eq) was then added dropwise over $10 \mathrm{~min}$ in an ice-water bath, warmed to room temperature and stirred overnight. TLC analysis showed almost complete conversion of 56 to 64, while the spot representing $\mathbf{5 5}$ was still visible and accompanied by several more polar species. 
<smiles>CC(=O)OC[C@H]1OC=C[C@@H](OC(C)=O)[C@H]1OC(C)=O</smiles>

55

$53 \mathrm{mg}$<smiles>O[C@H]1C=CO[C@H](COc2ccccc2)[C@@H]1OCc1ccccc1</smiles>

56

$850 \mathrm{mg}$

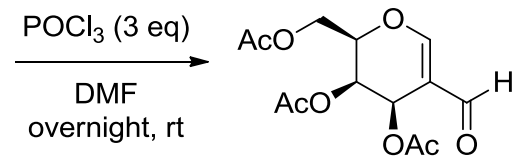

63

trace

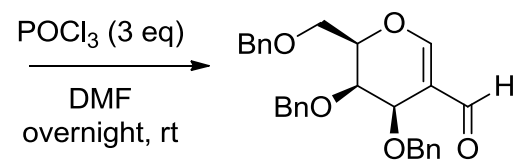

64

$681 \mathrm{mg}(75 \%)$

Scheme 3.9: Synthesis of $\mathbf{6 4}$ and attempted synthesis of $\mathbf{6 3}$.

After basic workup and removal of volatiles under reduced pressure, ${ }^{1} \mathrm{H}$ NMR spectra of the crude reaction mixtures showed almost complete conversion of the per-benzylated species $\mathbf{5 6}$ but approximately a 1:0.3 ratio of the starting glycal $\mathbf{5 5}$ to the aldehyde product $\mathbf{6 3}$, along with unidentified by-products (Figure 3.4). The aldehyde product $\mathbf{6 3}$ was recognised from diagnostic shifts at $9.33(\mathrm{~s}, \mathrm{CHO}), 7.39(\mathrm{~s}, \mathrm{H}-1)$, and $6.02(\mathrm{~d}, \mathrm{H}-3)$. The mass recovered from the reaction of the per-acetylated glycal was only $29 \mathrm{mg}$ (including residual dimethylformamide) from 53 $\mathrm{mg}$ of starting material. Aldehyde $\mathbf{6 3}$ could not be isolated using flash chromatography, whereas 64 was obtained in $75 \%$ yield. 


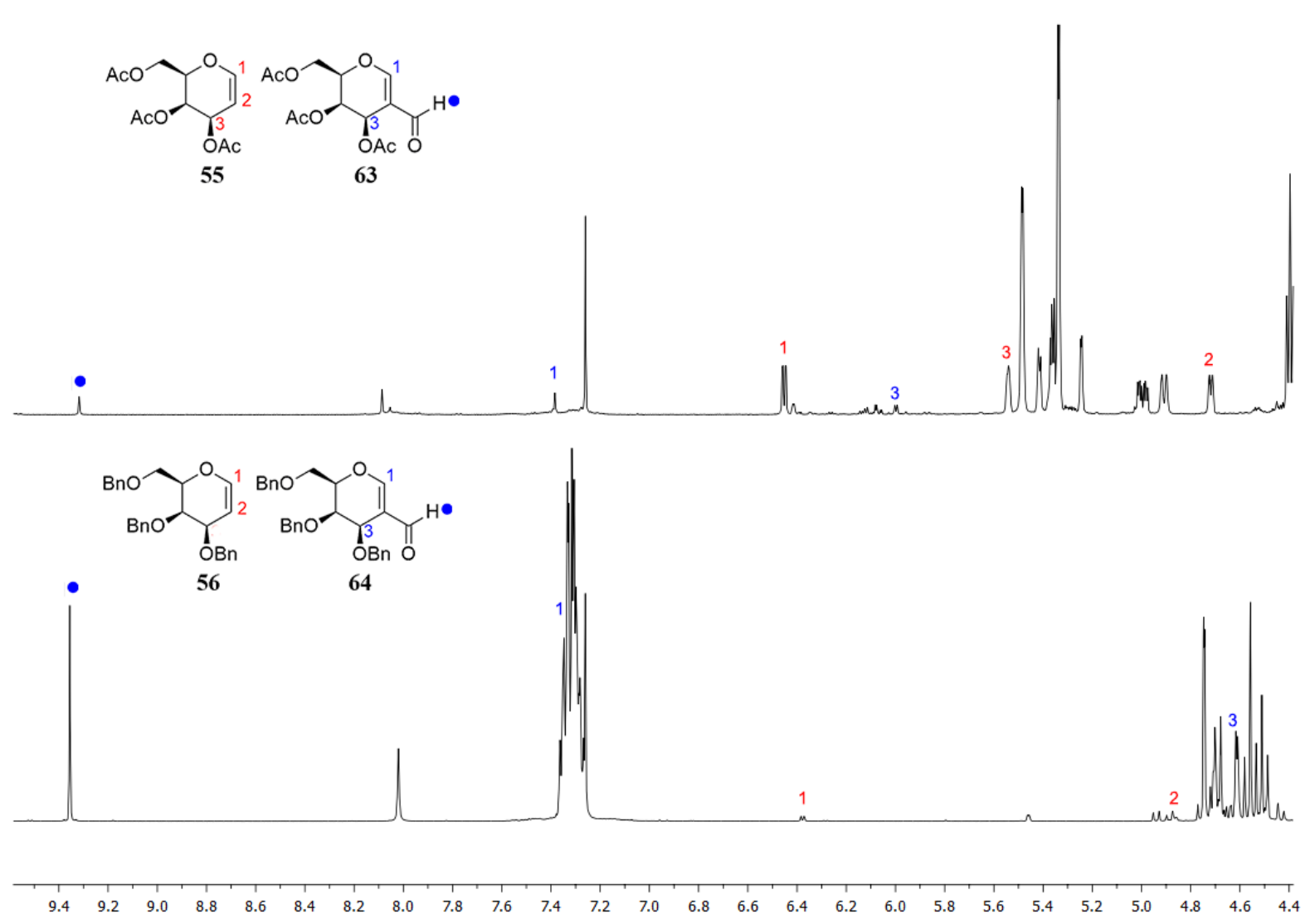

Figure 3.4: ${ }^{1} \mathrm{H}$ NMR spectra of the crude reaction mixtures pictured in Scheme 3.9.

Top: Vilsmeier-Haack formylation of $\mathbf{5 5}$; bottom: Vilsmeier-Haack formylation of $\mathbf{5 6}$ (H-3 at 4.21 ppm).

The low conversion of starting material 55 to product $\mathbf{6 3}$ indicates that reaction between $\mathbf{5 5}$ and the formylating agent 61 (Scheme 2.4, viz. Section 2.2.2) is slow compared to the analogous per-benzylated species. The low mass recovery of the reaction indicates that degradation of $\mathbf{5 5}$, $\mathbf{6 3}$ or both is occurring in such a manner that the degradation products are not being extracted into the organic phase of the work-up. That is to say the solubility of the degradation species in ethyl acetate is low, which hints at a more water soluble, or completely insoluble species. Loss of the acetate groups to give a triol, or polymerisation fit these descriptions. Both of these degradation mechanisms are plausible given that phosphoryl chloride readily hydrolyses to phosphoric acid and hydrochloric acid - strong acids which could catalyse acetate deprotection and polymerisation.

Attempts to optimise the formylation of $\mathbf{5 5}$ are summarised in Table 3.2. Efforts here were focused on getting the formylation event to take place to a reasonable extent. Increased reaction times and equivalents of phosphoryl chloride were explored. Longer reaction times would 
allow more opportunity for the formylation to take place and more equivalents of phosphoryl chloride would in turn increase the amounts of $\mathbf{6 1}$ present. It should be noted that the target aldehyde 63 was difficult to isolate using chromatographic methods, being contaminated with an indiscernible mixture of what are presumably glycal degradation products. As such, yields were unable to be obtained. Success of the reaction was assessed based on starting material to product ratio and mass recovery. The starting material to product ratio was used as a measure of conversion of 55 to 63 , and mass recovery was a reverse measure of degradation via acetyl cleavage and polymerisation pathways. Mass recovery does not account for the organic soluble degradation products observed in the ${ }^{1} \mathrm{H}$ NMR spectra of the crude reaction mixtures. The crude mass also included residual dimethylformamide as observed in the ${ }^{1} \mathrm{H}$ NMR spectra so the amount of product would be somewhat lower than the mass measured on the balance. 
Table 3.2: Optimisation attempts of Vilsmeier-Haack formylation of $\mathbf{5 5}$.

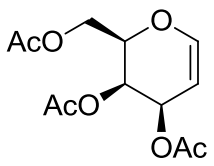

55

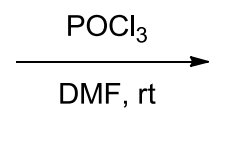

\section{Starting \\ $\mathrm{POCl}_{3}$ Reaction \\ Mass recovered}

(eq) duration (d)

material $(\mathrm{mg})$

\begin{tabular}{|c|c|c|c|c|c|}
\hline Entry & (eq) & duration $(\mathrm{d})$ & material $(\mathrm{mg})$ & (mg) & $\mathrm{SM}(\mathbf{5 5}): \mathrm{P}(\mathbf{6 3})^{\mathrm{a}}$ \\
\hline 1 & 3 & 1 & 51.3 & 29.1 & $1: 0.05$ \\
\hline 2 & 3 & 2 & 54.7 & 37.3 & $1: 1.4$ \\
\hline 3 & 3 & 3 & 66.4 & $\mathrm{n} / \mathrm{a}^{\mathrm{b}}$ & 1:0.15 \\
\hline 4 & 3 & 4 & 237.9 & 292.8 & 1:0.6 \\
\hline 5 & 3 & 5 & 43.6 & 17.8 & $1: 1.3$ \\
\hline 6 & 4 & 2 & 61.8 & 29.5 & 1:0 \\
\hline 7 & 5 & 5 & 74.0 & $\mathrm{n} / \mathrm{a}^{\mathrm{b}}$ & 1:0 \\
\hline 8 & 10 & 5 & 46.1 & 38.4 & $1: 0.3$ \\
\hline 9 & 40 & 3 & 61.7 & $\mathrm{n} / \mathrm{a}^{\mathrm{b}}$ & $1: 3.5$ \\
\hline 10 & 40 & 2 & 48.0 & $\mathrm{n} / \mathrm{a}^{\mathrm{b}}$ & Charred $^{\mathrm{c}}$ \\
\hline 11 & 40 & 2 & 179.0 & 72.5 & Charred $^{\mathrm{c}}$ \\
\hline 12 & 40 & 5 & 47.4 & 34.7 & Charred $^{\mathrm{c}}$ \\
\hline 13 & 50 & 1 & 132.0 & $\mathrm{n} / \mathrm{a}^{\mathrm{b}}$ & $\begin{array}{l}55 \text { undetectable } \\
\text { (trace } 63 \text { ) }\end{array}$ \\
\hline
\end{tabular}

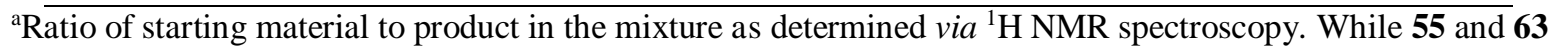
were never the only species present, their diagnostic signals at 6.4 and $7.4 \mathrm{ppm}$ respectively allowed relative amounts to be determined; ${ }^{b}$ masses were not recorded in these cases as there was far too much solvent (DMF) visibly present; ${ }^{\mathrm{c}}$ contents of the reaction flask were exposed to an exotherm upon quenching, despite efforts to avoid this.

Entries $1-5$ in Table 3.2 show the effect of prolonged reaction times on the transformation of 55 to 63. There is no trend in the starting material to product ratio, however starting material was clearly visible at the time of quench in all cases via TLC analysis. Comparing these entries to the results obtained in the formylation of $\mathbf{5 6}$, it can be concluded that the formylation of $\mathbf{5 5}$ is much slower than its benzylated counter-part. 
To see if acetate cleavage was occurring, the aqueous phase of the workup of entry 3 was evaporated under reduced pressure and the residue analysed using ${ }^{1} \mathrm{H}$ NMR spectroscopy (Figure 3.5). Signals which could be deprotected 55 were visible, however no characteristic aldehyde signals were detected between 9 and $10 \mathrm{ppm}$. It is possible that the aldehyde signals were not observed due to insolubility of the deprotected species in deuterated chloroform. However the absence of acetate, and presence of oxymethine signals indicated the presence of species similar in polarity to the triol of 63 . This suggests that deprotected $\mathbf{6 3}$ should at least be sparingly soluble in chloroform, such that its presence would be detected in the ${ }^{1} \mathrm{H}$ NMR spectrum. As signals that could be deacetylated $\mathbf{5 5}$ were detected with the absence of anything that could be deprotected $\mathbf{6 3}$, this could suggest that the triol of $\mathbf{5 5}$ is unreactive toward formylation.

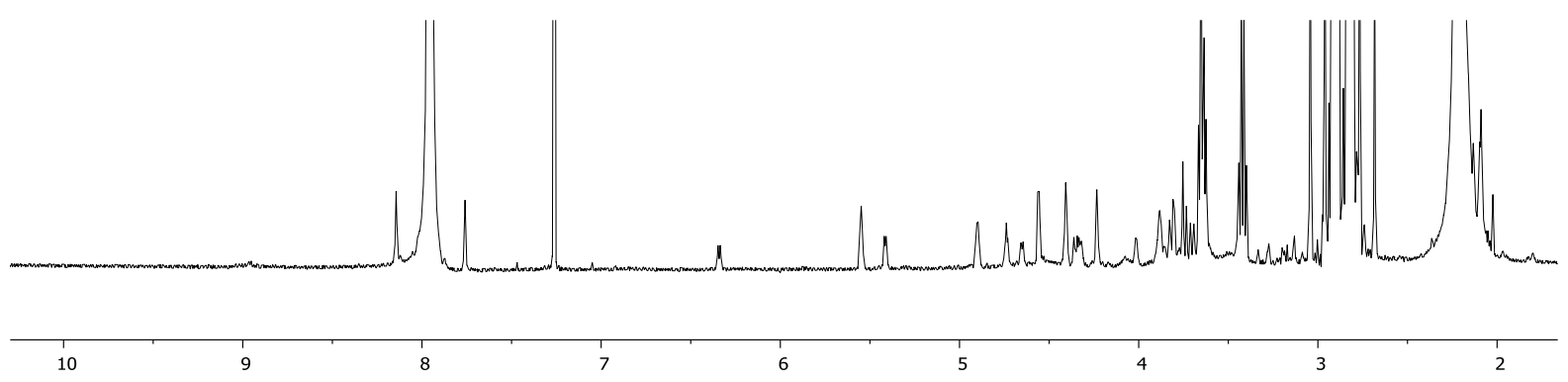

Figure 3.5: ${ }^{1} \mathrm{H}$ NMR spectrum of the aqueous phase of entry 3 (Table 3.2) in $\mathrm{CDCl}_{3}$.

With 40 equivalents of phosphoryl chloride, the ratio of 55 to 63 was 1:3.5 - the best conversion obtained (entry 9, Table 3.2). Attempts to repeat this reaction were difficult, an exotherm caused by quenching under basic conditions being an issue. The heat evolved in the quench visibly charred the contents of the reaction mixture turning the orange-brown solution to black. The exotherm arises from the vigorous reaction of water or hydroxide with the VilsmeierHaack reagent, phosphoryl chloride or its acidic hydrolysis products. The difficulty of the quench was that charring occurred in entries $10-12$ despite the use of an ice-water bath and the extremely slow addition of the basic solution. The char-free quench of entry 9 was not able to be attributed to any variables investigated.

Attempts to use oxalyl chloride in the place of phosphoryl chloride gave similar results to those in Table 3.2. Starting material and degradation products were the main species observed in the ${ }^{1} \mathrm{H}$ NMR spectra of the crude reaction mixtures with only traces if any aldehyde $\mathbf{6 3}$ observed. 
The results presented in Table 3.2 were not entirely replicable with no strict trend being observed. However overarching themes could be derived, especially when compared to the formylation of 56. Starting material was visible via TLC analysis of the reaction mixture after prolonged time. Considering that per-benzylated species 63 was barely detectable after overnight reaction, it can be said that the reaction between 55 and $\mathbf{6 1}$ is very slow. A large excess of phosphoryl chloride was able to give appreciable conversion of $\mathbf{5 5}$ to $\mathbf{6 3}$ over five days, however starting material was still detectable. This result suggests even harsher conditions are required to obtain similar results to the formylation of 56. The use of 40 equivalents of phosphoryl chloride is not economical, and could also be dangerous on scale up. Throughout all the results in Table 3.2, insoluble black solid was often observed, and the ${ }^{1} \mathrm{H}$ NMR spectra of the crude reaction mixtures showed degradation species present in higher amounts than either $\mathbf{5 5}$ or $\mathbf{6 3}$. The acetyl groups do not seem compatible with Vilsmeier-Haack conditions.

\subsection{Synthesis of the Differentially Protected 2-Formylglycal 66 via Vilsmeier-Haack Formylation}

2-Formylglycal 66 can be readily accessed from tri- $O$-acetyl-D-galactal (55) in four steps. ${ }^{[13]}$ Tri- $O$-acetyl-D-galactal (55) was deprotected by treatment with triethylamine in aqueous methanol followed by concentration under reduced pressure (Scheme 3.10). The resulting brown solid was dissolved in water and treated with sodium carbonate to neutralise the triethylammonium salts present. The solution was concentrated again, and the brown solid washed with methanol until the washings were colourless. After removing the solvent under reduced pressure D-galactal $\mathbf{6 5}$ was obtained as a brown tar. Without further purification, Dgalactal 65 was reprotected with benzyl bromide to give tri- $O$-benzyl-D-galactal 56 in yields up to $73 \%$ over two steps.

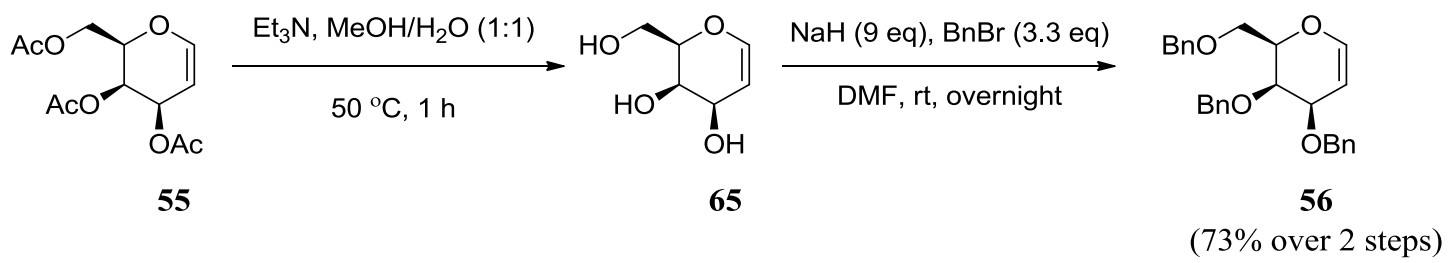

Scheme 3.10: Synthesis of tri- $O$-benzyl-D-galactal 56. 
2-Formylglycal 64 was synthesised from tri- $O$-benzyl-D-galactal 56 using Vilsmeier-Haack methodology. Phosphoryl chloride ( $3 \mathrm{eq}$ ) and dimethylformamide prior to addition of tri- $O$ benzyl-D-galactal 56 (Scheme 3.11). After stirring overnight at room temperature and purification the 2-formylglycal 64 was obtained in $78 \%$ yield. The formylation and previous transformations starting from glycal 55 can be performed on scales up to $18 \mathrm{~g}$ without purification of intermediates. Conveniently, the yield over the three steps in the transformation of glycal 55 to 2-formylglycal 64 when intermediates were not purified was $84 \%$.<smiles>O[C@@H]1C=CO[C@H](COBr)[C@H]1O[Bi]Br</smiles>

56

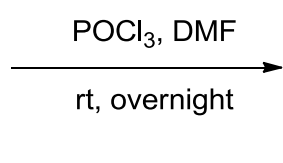<smiles>O=CC1=CO[C@H](COc2ccccc2)[C@@H](O)[C@H]1OCc1ccccc1</smiles>

64

$(78 \%)$

Scheme 3.11: Vilsmeier-Haack formylation of tri-O-benzyl-D-galactal 56.

Acetolysis of the C-3 and C-6 benzyl ethers of 2-formylglycal 64 to make 2-formylglycal 66 was performed using methodology developed by Vankar. ${ }^{[24]} \mathrm{Zinc}(\mathrm{II})$ chloride was dissolved in a mixture of acetic acid, acetic anhydride, and dichloromethane (Scheme 3.12). 2-Formylglycal 64 was added and the solution was stirred overnight. Following workup and chromatography, 2-formylglycal 66 was obtained in 91\% yield as a colourless oil. 2-Formylglycal 66 is prone to degradation if left exposed to air at ambient temperature, though keeps well if stored in a freezer.

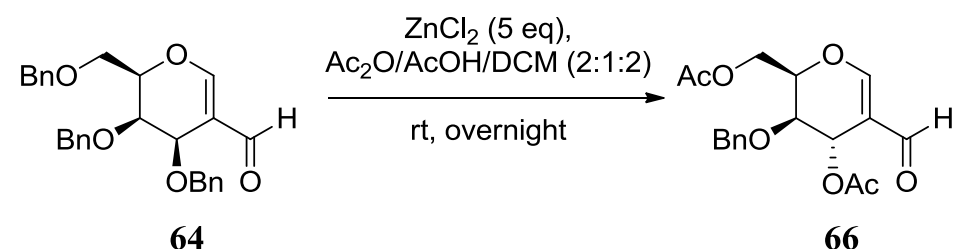

$(91 \%)$

Scheme 3.12: Selective acetolysis of 2-formylglycal 64.

Synthesis of compound $\mathbf{6 6}$ as the Ferrier rearrangement substrate requires more steps than simply formylating tri- $O$-acetyl-D-galactal $\mathbf{5 5}$, but the steps are high yielding, scalable, and easy to perform in contrast to the formylation of $\mathbf{5 5}$ (Section 3.3). 


\subsection{Alkynylation Studies on 2-Formylglycal 66}

\subsubsection{Initial Attempts at Ferrier-type Alkynylation of 66}

The desired alkynylation is depicted in Scheme 3.13. As the configuration at the alkynylation pyran carbon was unable to be confirmed upon the synthesis of the alkyne (vide supra), discussion pertaining to the product of the Ferrier-type alkynylation will refer to $\mathbf{1 1 4}$ rather than 73.

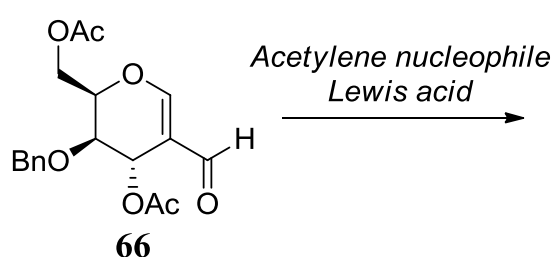

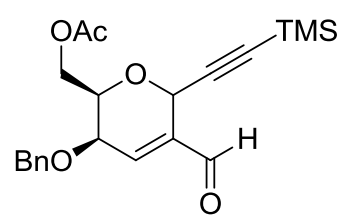

114

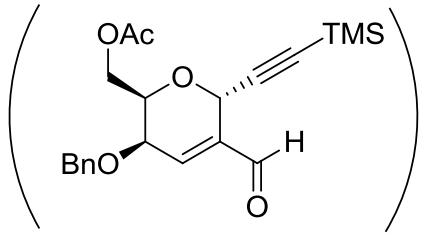

73

Scheme 3.13: Desired Ferrier-type alkynylation of 66.

Encouraged by the results obtained in the synthesis of alkynes 112a and 112b (Section 3.2.3), and having ample and readily available material to optimise with, the methodology was applied to 2-formylglycal 66 in attempt to synthesise alkyne $\mathbf{1 1 4}$.

A solution of 2-formylglycal 66 (1 eq) and bis(trimethylsilyl)acetylene $(1.1 \mathrm{eq})$ in dichloromethane was treated with boron trifluoride diethyl etherate ( 2 eq) at room temperature (entry 1, Table 3.3). The formation of a less polar species was a key feature in mind when performing TLC analyses, as the product was expected to be less polar than the starting material. The reaction was monitored via TLC analysis but no obvious reaction was occurring; therefore after $2.5 \mathrm{~h}$ the mixture was quenched with a saturated aqueous solution of sodium bicarbonate. Analysis of the ${ }^{1} \mathrm{H}$ NMR spectrum of the crude reaction mixture supported the observations via TLC with only starting material being observed. The reaction was repeated for a longer period (overnight) giving the same result.

Compared to the result obtained in the Ferrier-type alkynylation of the 2-haloglycals 57a and 57b (Section 3.2.3), it appeared that the formyl group at the C-2 position was stifling the reaction. Interestingly it appeared that the formyl group reduced the reactivity of $\mathbf{6 6}$ in the presence of boron trifluoride diethyl etherate, whereas it enhanced the reactivity of the C-3 benzyloxy group of $\mathbf{6 4}$ in the synthesis of $\mathbf{6 6}$ (Scheme 3.11). As zinc(II) chloride was the Lewis 
acid used to perform the transformation of $\mathbf{6 4}$ to $\mathbf{6 6}$, it was employed in the attempted synthesis of $\mathbf{1 1 4}$ (entry 2, Table 3.3).

The conditions used were those described above, substituting zinc(II) chloride for boron trifluoride diethyl etherate, and stirred overnight. Unfortunately zinc(II) chloride gave the same result as that obtained using boron trifuororide diethyl etherate, returning only starting material.

As Ferrier rearrangements have been shown to be catalysed by a vast range of Lewis acids ${ }^{[17 c]}$ a range of Lewis acids were screened using the above conditions at room temperature. The conditions used in most cases were 2 equivalents of Lewis acid and 1.1 equivalents of bis(trimethylsilyl)acetylene, and overnight stirring in dichloromethane at room temperature. Typical catalyst loading of Montmorillonite $\mathrm{K}-10$ is $5 \mathrm{wt} \%$ and this was what was used in entry 6 (Table 3.3). ${ }^{[42]}$ Silver(I) triflate and titanium(IV) tetraisopropoxide were used in substoichiometric amounts (0.2 equivalents) for reasons explained later on (vide infra).

Table 3.3: Lewis acids explored for the Ferrier-type alkynylation at room temperature.

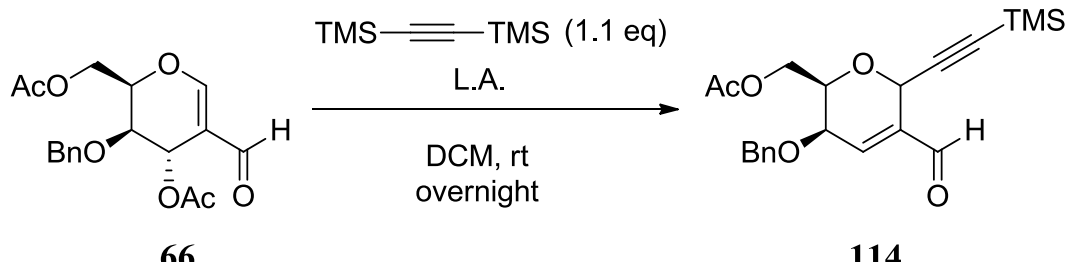

66

114

\begin{tabular}{cccc}
\hline Entry & Lewis acid & Equivalents & Result \\
\hline 1 & $\mathrm{BF}_{3} \cdot \mathrm{OEt}_{2}$ & 2 & Starting material only \\
2 & $\mathrm{ZnCl}_{2}$ & 2 & Starting material only \\
3 & $\mathrm{InCl}_{3}$ & 2 & Starting material only \\
4 & $\mathrm{SnCl}_{4}$ & 2 & $\mathbf{1 1 5}(6 \%)$ \\
5 & $\mathrm{TiCl}_{4}$ & 2 & Starting material only \\
6 & Montmorillonite K-10 & $5 \mathrm{wt} \%$ & Starting material only \\
$7^{\mathrm{a}}$ & $\mathrm{Ti}\left(\mathrm{O}{ }^{i} \mathrm{Pr}\right)_{4}$ & 0.2 & Starting material only \\
$8^{\mathrm{a}}$ & $\mathrm{AgOTf}$ & 0.2 & Starting material only \\
\hline
\end{tabular}

a2 Equivalents of bis(trimethylsilyl)acetylene were used, and the reactions performed in 1,2-dichloroethane to allow for subsequent heating; ${ }^{b}$ as determined via TLC analysis after $2 \mathrm{~h}$. These reactions were then heated to 40

${ }^{\circ} \mathrm{C}$ vide infra, Table 3.4. All other results were confirmed by ${ }^{1} \mathrm{H}$ NMR of the crude reaction mixture. 
No reactivity was observed for any of the Lewis acids explored in Table 3.3 with the exception of tin(IV) chloride. The ${ }^{1} \mathrm{H}$ NMR spectra of the crude reaction mixtures obtained using all other Lewis acids showed clean starting material - no degradation products were observed.

Formation of a less polar species was observed via TLC analysis of the tin(IV) chloride mediated reaction. The new compound was isolated ( $3 \mathrm{mg}$ from $53 \mathrm{mg}$ of starting material 66) and its structure elucidated using 1D and 2D NMR experiments, and mass spectrometry.

Analysis of the ${ }^{1} \mathrm{H}$ NMR spectrum of the less polar product showed one acetate signal at 2.05 ppm with both the aromatic protons of the benzyl group and the aldehyde proton at $9.37 \mathrm{ppm}$ still in place. However there was no significant change in the signal representative of $\mathrm{H}-1$ in the less polar product $(7.45 \mathrm{ppm})$ compared to that of starting material $66(7.54 \mathrm{ppm})$. The similarities of the shifts representing H-1 suggested the enol ether was present in the new species. The signal representative of H-3 in $\mathbf{6 6}$ shifted upfield from $5.75 \mathrm{ppm}$ to $4.91 \mathrm{ppm}$ in the product. This is indicative that reaction had occurred at the C-3 position. Analysis of the HSQC spectrum showed a correlation between the H-3 proton at 4.91 ppm to a carbon at 42.9 ppm. A carbon appearing in this region of the spectrum is characteristic of being halogenated. As the only halogen source $\mathbf{6 6}$ had been exposed to was tin(IV) chloride (and dichloromethane), it was suspected that there was a chlorine substituent in place of an acetate at the C-3 position. The postulated structure of the apparently chlorinated new species was that of $\mathbf{1 1 5}$ (Scheme 3.14). Mass spectrometry of the compound confirmed the presence of chlorine on $\mathbf{1 1 5}$ showing the characteristic $\mathrm{Cl}$ isotope cluster, and the molecular formula $\left(m / z \mathrm{C}_{16} \mathrm{H}_{17} \mathrm{ClO}_{5}[\mathrm{M}+\mathrm{H}]^{+}\right.$calcd 327.0814, found 327.0800, $\Delta=4.19 \mathrm{ppm})$. The stereochemistry pictured in $\mathbf{1 1 5}$ at the C-3 position was tentatively assigned by comparison of the ${ }^{3} J_{\mathrm{H}-3, \mathrm{H}-4}$ values of $\mathbf{1 1 5}\left({ }^{3} J_{\mathrm{H}-3, \mathrm{H}-4}=2.3\right.$ $\mathrm{Hz}), 66\left({ }^{3} J_{\mathrm{H}-3, \mathrm{H}-4}=2.3 \mathrm{~Hz}\right)$, and $64\left({ }^{3} J_{\mathrm{H}-3, \mathrm{H}-4}=3.5 \mathrm{~Hz}\right)$. The similarity of the coupling constant in $\mathbf{1 1 5}$ with that of $\mathbf{6 6}$ led to the assignment of the stereochemistry pictured.

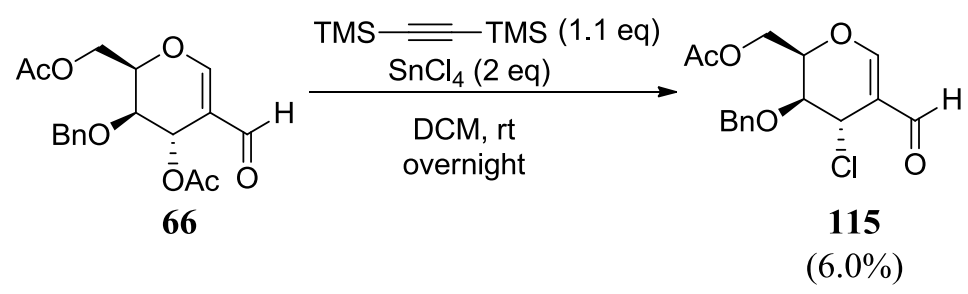

Scheme 3.14: Formation of $\mathbf{1 1 5}$ in attempted alkynylation of $\mathbf{6 6 .}$ 
The formation of $\mathbf{1 1 5}$ demonstrated that the cleavage of the C-3 acetate could be mediated by a Lewis acid - the loss of the C-3 acetate being required for Ferrier rearrangement. Tin(IV) chloride is a relatively strong Lewis acid and was able to elicit reactivity at the C-3 position of 66. However reaction with a chloride source was observed rather than the acetylene. From this it was concluded that harsher reaction conditions were required either in the form of a stronger Lewis acid, higher reaction temperatures, or both. Importantly the Lewis acid would need either a less nucleophilic or less labile anion than chloride.

Entries 7 and 8 using titanium(IV) tetraisopropoxide and silver(I) triflate respectively were performed after obtaining the results of entry 4 in Table 3.3. As such, titanium(IV) tetraisopropoxide was used in substoichiometric amounts in attempt to mitigate a potential isopropoxide adduct as the alkoxide is a better nucleophile than the acetylene. Silver(I) triflate was only used in 0.2 equivalents as the intention was to use a combination of a silver salt and tin(IV) chloride in further optimisation studies. Silver(I) would be added to activate the chloride in $\mathbf{1 1 5}$ to perhaps facilitate the Ferrier rearrangement. Following the observed lack of reactivity of these two Lewis acids at room temperature, the reaction mixtures were heated to $40{ }^{\circ} \mathrm{C}$, the results of which are discussed later.

Considering that it is not uncommon for Ferrier rearrangements to be performed in refluxing dichloromethane, ${ }^{[17 \mathrm{~b}, 17 \mathrm{c}, 39 \mathrm{c}]}$ the alkynylation was attempted at $40{ }^{\circ} \mathrm{C}$ with a range of Lewis acids (Table 3.4). The solvent used was 1,2-dichloroethane as it has similar properties to dichloromethane but a boiling point of $83.5^{\circ} \mathrm{C}$. Switching to 1,2-dichloroethane meant that a reflux condenser was not needed to set up the experiments. 
Table 3.4: Lewis acids explored for the Ferrier-type alkynylation of 66 at $40{ }^{\circ} \mathrm{C}$.

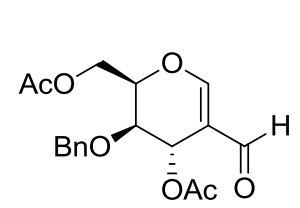

66

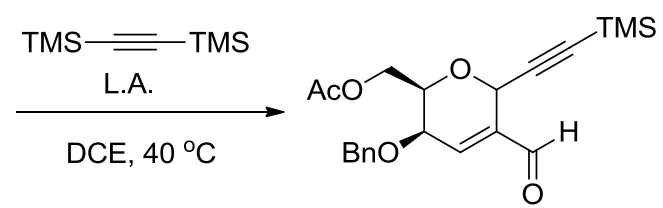

114

\begin{tabular}{|c|c|c|c|c|c|}
\hline Entry & Lewis acid & L. A. eq & Alkyne eq & Duration & Result \\
\hline 1 & $\mathrm{ZnCl}_{2}$ & 2 & 1.1 & $5.5 \mathrm{~h}$ & 66 only \\
\hline 2 & AgOTf & 0.2 & 2 & $3.5 \mathrm{~h}$ & 66 only \\
\hline 3 & Montmorillonite K-10 & $10 \mathrm{wt} \%$ & 1.1 & $\mathrm{o} / \mathrm{n}$ & Mostly 66 \\
\hline 4 & $\mathrm{Ti}\left(\mathrm{O}^{i} \mathrm{Pr}\right)_{4}$ & 0.2 & 2 & $3.5 \mathrm{~h}$ & Some reactivity ${ }^{a}$ \\
\hline 5 & $\mathrm{SnCl}_{4}$ & 2 & 1.1 & $6 \mathrm{~h}$ & $1: 3, \mathbf{6 6}: 115$ \\
\hline 6 & $\mathrm{TiCl}_{4}$ & 0.2 & 2 & $7 \mathrm{~h}$ & $1: 0.2, \mathbf{6 6}: 115$ \\
\hline 7 & $\mathrm{BF}_{3} . \mathrm{OEt}_{2}$ & 2 & 1.1 & $\mathrm{o} / \mathrm{n}$ & Some reactivity ${ }^{a}$ \\
\hline
\end{tabular}

${ }^{\mathrm{a} S e e}$ text.

Zinc(II) chloride and silver(I) triflate showed only starting material in the ${ }^{1} \mathrm{H}$ NMR spectrum of the crude reaction mixture despite the elevated temperature (entries 1 and 2, Table 3.4). In hindsight, silver(I) may have reacted with the solvent 1,2-dichloroethane due to its high affinity for halides. This could be a reason for the lack of reactivity of silver(I) triflate. If the silver salt did react with the solvent to form silver(I) chloride, the results obtained suggest that silver(I) chloride is a poor Lewis acid for facilitating the desired transformation.

A small amount of by-product was observed in the ${ }^{1} \mathrm{H}$ NMR spectrum of the crude reaction mixture of the reaction catalysed by montmorillonite K-10 (entry 3). Considering the byproduct was only present in a very small quantity, as well as not having signals that could be 114, this by-product was not pursued.

The ${ }^{1} \mathrm{H}$ NMR spectrum of the titanium(IV) tetraisopropoxide reaction showed a minor byproduct, less polar than the starting material as determined via TLC analysis (entry 4). Though not isolated from this reaction, the same by-product was observed when the alkynylation of 66 was attempted using two equivalents of the Lewis acid in refluxing 1,2-dichloroethane. The by-product was isolated, however only enough material was obtained to get a ${ }^{1} \mathrm{H}$ NMR 
spectrum $-{ }^{13} \mathrm{C}$ and 2D NMR experiments showed no signals. Analysis of the ${ }^{1} \mathrm{H}$ NMR spectrum showed the presence of the aldehyde and the benzyl group, but no acetates (Figure 3.6). The signal representing $\mathrm{H}-1$ in the starting material 66 was gone, however signals which could be an alkene and an acetal were observed. As there were no acetates or trimethylsilyl protons observed, it was deemed unlikely this species was alkyne $\mathbf{1 1 4}$.

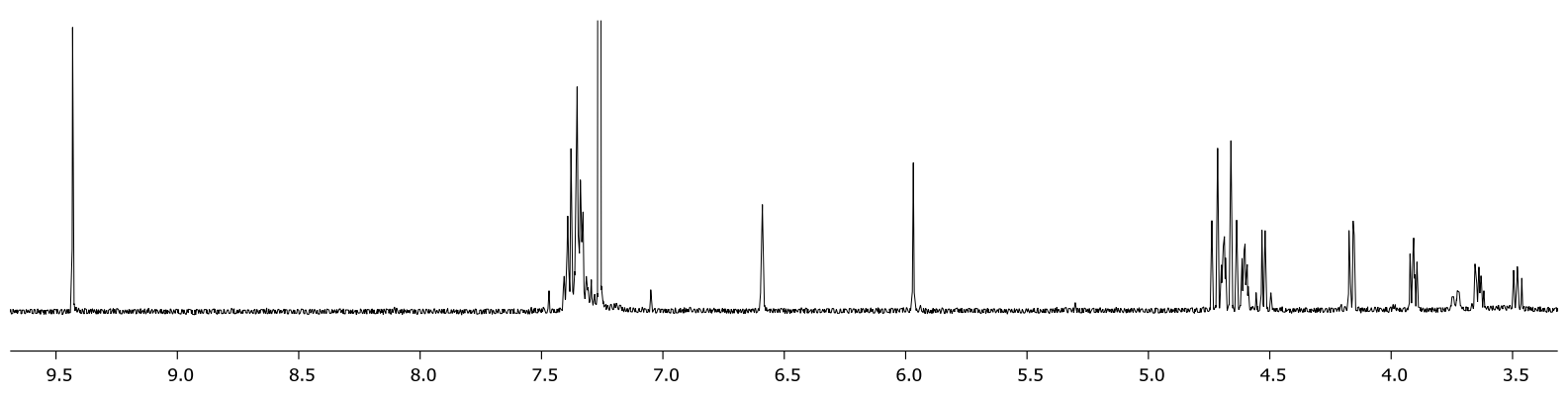

Figure 3.6: ${ }^{1} \mathrm{H}$ NMR spectrum of the crude reaction mixture of entry 4 (Table 3.4).

Reactions involving tin(IV) chloride and titanium(IV) chloride formed $\mathbf{1 1 5}$ as the most significant product (entries 5 and 6, Table 3.4). As 115 was formed when using two equivalents of tin(IV) chloride, the attempt at alkynylation using the analogous titanium Lewis acid was performed using only 0.2 equivalents in effort to mitigate the formation of $\mathbf{1 1 5}$. Nonetheless 115 was still observed in the reaction which used titanium(IV) chloride. Further explorations of the tin(IV) chloride reaction are detailed in a Section 3.5.3.

Boron trifluoride diethyl etherate caused consumption of starting material at $40{ }^{\circ} \mathrm{C}$ with a less polar species being observed via TLC analysis (entry 7, Table 3.4). The ${ }^{1} \mathrm{H}$ NMR spectrum of the crude reaction mixture showed multiple species present (Figure 3.7). Purification of these species was difficult being unable to be isolated separately. Nonetheless the spectroscopic features observed in the ${ }^{1} \mathrm{H}$ NMR spectra (9.5 (s), 6.8 (dd) ppm) of these mixtures suggested that there might be material resembling $\mathbf{1 1 4}$ present in the mixture.

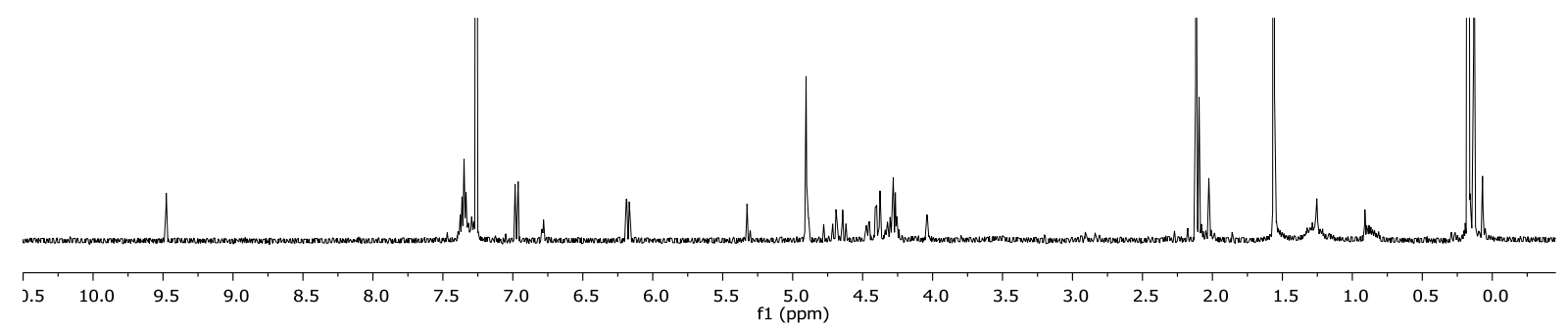

Figure 3.7: ${ }^{1} \mathrm{H}$ NMR spectrum of less polar species isolated from entry 7 (Table 3.4). 


\subsubsection{Exploration of Boron Trifluoride Diethyl Etherate as a Lewis acid for Ferrier-type Alkynylation of 66}

Encouraged by the structural motifs observed in species present in the boron trifluoride diethyl etherate reaction mixture (entry 7, Table 3.4), further attempts to make 114 from 66 using the Lewis acid were performed. The results of the optimisation attempts are summarised in Table 3.5. The reactions involving boron trifluoride diethyl etherate already discussed above are included in Table 3.5 for ease of results comparison. 
Table 3.5: Optimisation of the formation of $\mathbf{9 5}$ from $\mathbf{6 6}$ using boron trifluoride diethyl etherate.

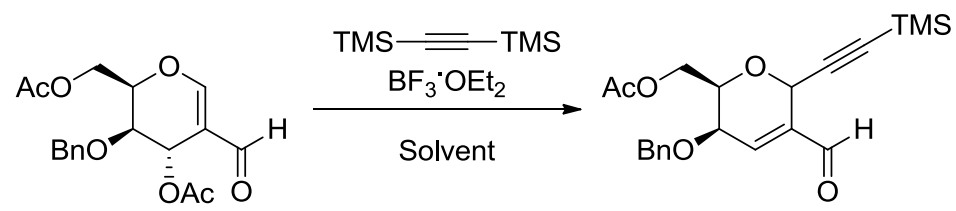

66

114

\begin{tabular}{|c|c|c|c|c|c|}
\hline Entry & $\mathrm{BF}_{3} \cdot \mathrm{OEt}_{2} \mathrm{eq}$ & Solvent & Temp. & Duration & Result \\
\hline 1 & 2 & DCM & $\mathrm{Rt}$ & $2.5 \mathrm{~h}$ or $\mathrm{o} / \mathrm{n}$ & No reaction \\
\hline 2 & 2 & DCE & $40^{\circ} \mathrm{C}$ & $\mathrm{o} / \mathrm{n}$ & Some reactivity ${ }^{a}$ \\
\hline 3 & 2 & $\mathrm{DCE}$ & reflux & $45 \mathrm{~min}$ & $114(7 \%)+$ degr. \\
\hline 4 & 0.2 & DCE & reflux & $7 \mathrm{~h}$ & $66+$ degr. \\
\hline 5 & 1 & DCE & reflux & $5 \mathrm{~h}$ & 1:1.2. 66:114 + degr. \\
\hline $6^{\mathrm{a}}$ & 2 & $\mathrm{DCE}$ & reflux & $2.5 \mathrm{~h}$ & Trace $\mathbf{1 1 4}+$ degr. \\
\hline 7 & 2 & DCE & $30^{\circ} \mathrm{C}$ & $\mathrm{o} / \mathrm{n}$ & $66+$ degr. \\
\hline 8 & 2 & DCE & $60^{\circ} \mathrm{C}$ & $5 \mathrm{~h}$ & $66+$ trace 114 \\
\hline 9 & 1 & DCE & $60^{\circ} \mathrm{C}$ & $5 \mathrm{~h}$ & $66+$ degr. \\
\hline $10^{\mathrm{c}}$ & 2 & DCE & reflux & $4 \mathrm{~h}$ & $114(4 \%)+$ degr. \\
\hline 11 & 0.2 & $\mathrm{AcOH}$ & $\mathrm{Rt}-100^{\circ} \mathrm{C}$ & See text & 66 only \\
\hline 12 & 2 & $\mathrm{AcOH}$ & $\mathrm{Rt}-100^{\circ} \mathrm{C}$ & See text & $66+$ degr. \\
\hline 13 & 2 & $\mathrm{AcOH}$ & reflux & $4 \mathrm{~h}$ & Complete degr. \\
\hline 14 & 2 & $\mathrm{DMF}$ & $\mathrm{Rt}-130^{\circ} \mathrm{C}$ & See text & See text \\
\hline 15 & 2 & Toluene & $\mathrm{Rt}-80^{\circ} \mathrm{C}$ & See text & See text \\
\hline 16 & 2 & Toluene & Reflux & $20 \mathrm{~min}$ & $66+$ degr. \\
\hline 17 & 2 & $\mathrm{ACN}$ & $\mathrm{Rt}-60^{\circ} \mathrm{C}$ & See text & See text \\
\hline
\end{tabular}

${ }^{\mathrm{a}}$ See text; ${ }^{b}$ reaction was performed with $3 \times$ more solvent than the other entries $(3 \mathrm{~mL}$, rather than $1 \mathrm{~mL})$; ${ }^{\mathrm{c}} \mathrm{scale}$ up.

Attempted alkynylation of $\mathbf{6 6}$ with boron trifluoride diethyl etherate in refluxing 1,2dichloroethane gave alkyne $\mathbf{1 1 4}$ in 7\% yield as a yellow oil (entry 3, Table 3.5). Unlike alkynylation attempts at lower temperatures, TLC monitoring of the reaction showed decisive formation of a less polar product, later determined to be $\mathbf{1 1 4}$ (Figure 3.8). The reaction was halted after $45 \mathrm{~min}$ due to the visible formation of solid and the apparent consumption of starting material. The ${ }^{1} \mathrm{H}$ spectrum of the crude reaction mixture showed a 1:1.25 ratio of 
66:114, among unidentifiable degradation products. Notably only one anomer of the 2,3unsaturated glycoside was observed.

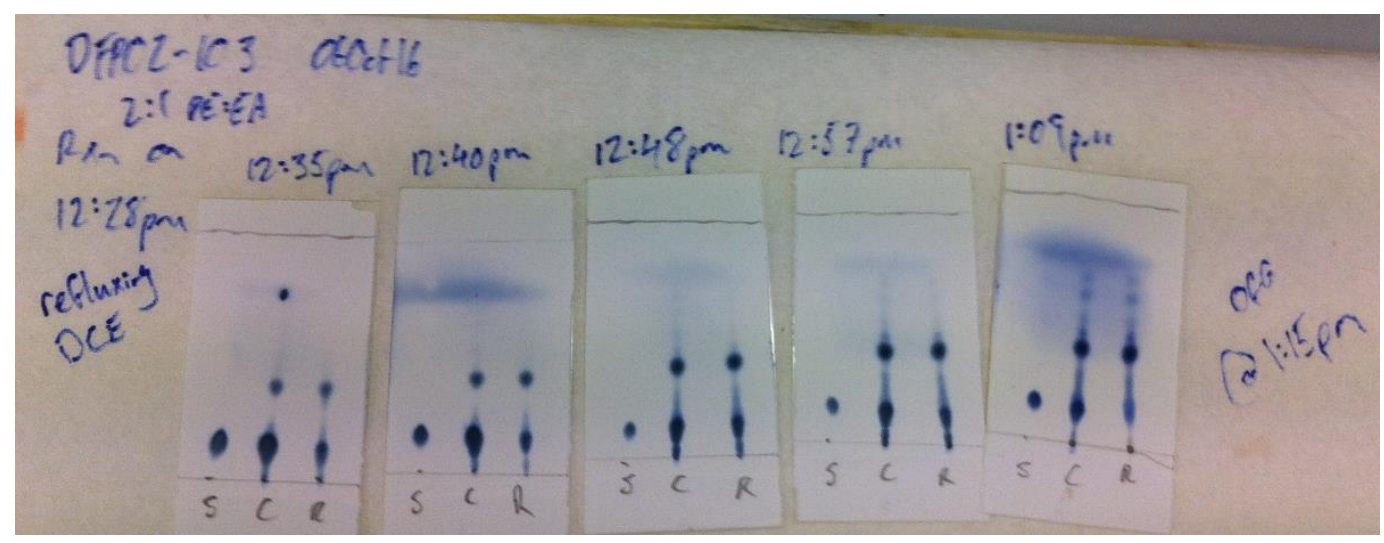

Figure 3.8: TLC analysis of entry 1, Table 3.5.

The structure of 114 was elucidated using 1D and 2D NMR experiments, and mass spectrometry. The ${ }^{1} \mathrm{H}$ NMR spectrum showed the presence of all the appropriate functionalities of 114. The aldehyde proton was observed at $9.47 \mathrm{ppm}$, the presence of the benzyl was confirmed by a complex multiplet between $7.32-7.29 \mathrm{ppm}$ representing the aromatic protons and two highly tenting doublets at 4.70 and $4.63 \mathrm{ppm}$ representing the oxymethylene of the benzyl group. A singlet at $2.09 \mathrm{ppm}$ integrating to three protons suggested that only one acetate was present in the product, and a singlet integrating to nine protons observed at $-0.13 \mathrm{ppm}$ was indicative of a trimethylsilyl group. The absence of a singlet with a similar shift to H-1 in 66 (7.54 ppm) suggested that the unsaturation between the $\mathrm{C}-1$ and $\mathrm{C}-2$ positions was no more. A doublet of doublets at $6.78 \mathrm{ppm}$ however was indicative of the presence of an alkene likely representing H-3 of 114. Protons H-4 - H-6 were assigned by following correlations through the COSY spectrum. The alkene signal at $6.78 \mathrm{ppm}$ was confirmed to be $\mathrm{H}-3$ as it showed a correlation in the COSY spectrum to the doublet of doublets at $4.04 \mathrm{ppm}$ determined to be $\mathrm{H}$ 4. An HMBC correlation was observed between $\mathrm{H}-3$ and a $\mathrm{CH}$ at $62.7 \mathrm{ppm}$ - an oxymethine which was not assigned to C-4 or C-5. The proton attached to the carbon at $62.7 \mathrm{ppm}$ appeared as fine doublet at $5.32 \mathrm{ppm}$ - this was assigned as the $\mathrm{CH}$ of $\mathrm{C}-1$. The ${ }^{13} \mathrm{C}$ spectrum showed signals corresponding to the aforementioned functionalities, as well as alkyne carbons at 92.2 and $99.7 \mathrm{ppm}$. Correlations between $\mathrm{H}-1$ at $5.32 \mathrm{ppm}$ and the aforementioned alkyne carbons suggested that the alkyne was attached to $\mathrm{C}-1$ as in the structure of 114. Mass spectrometry of the compound fitted that calculated for $8\left(\mathrm{~m} / z \mathrm{C}_{21} \mathrm{H}_{26} \mathrm{O}_{5} \mathrm{SiNa}^{+}[\mathrm{M}+\mathrm{Na}]^{+}\right.$calcd 411.1460 , found $411.1459(\Delta=0.09))$. The configuration about the $\mathrm{C}-1$ position was difficult to determine as 
no NOESY correlations were observed for H-1. Unfortunately compound $\mathbf{1 1 4}$ manifested as a yellow oil, rather than a crystalline solid so an x-ray crystal structure to reveal stereochemistry could not be obtained. Analysis of the ${ }^{1} J_{\mathrm{CH}}$ of the C-1 position is somewhat finicky as there are not many if any compounds that can be compared $\mathbf{1 1 4}$ to in the literature due to the somewhat unique substitution pattern of the $\mathrm{C}-1$ and $\mathrm{C}-2$ positions of the pyran. As of yet there is no confirmation of the configuration, the determination of which is being left for later steps. Nonetheless, literature precedent from related reactions would indicate that the $\alpha$-product is likely. ${ }^{[26-27]}$

Alkyne 114 was only obtained in 7\% yield using the conditions in entry 3 despite the starting material and product being the only significant species detectable via TLC of the reaction mixture (Figure 3.8). Degradation on slightly acidic silica upon chromatographic purification was considered as a reason for the low yield. As such the reaction was repeated and the silica was neutralised with triethylamine prior to chromatography of the reaction mixture but a similarly low yield was obtained (4\%, entry 11 Table 3.5). Entry 11 was performed in order to make material for explorations in the lactone formation of $\mathbf{1}$.

Entries 4, 5 and 6 in Table 3.5 were attempts at minimising the observed degradation by altering the presence of the Lewis acid. Using only 0.2 equivalents of boron trifluoride diethyl etherate slowed the reaction rate significantly with starting material $\mathbf{6 6}$ being the major identifiable species in the ${ }^{1} \mathrm{H}$ NMR spectrum of the crude reaction mixture, among unidentifiable degradation products (entry 4). Traces of $\mathbf{1 1 4}$ may have been present, however these signals were not much bigger than the baseline noise.

Using one equivalent of boron trifluoride diethyl etherate also slowed the reaction rate significantly (entry 5), in comparison to entry 3. Many spots not attributable to either $\mathbf{6 6}$ or 114 were observed by the time a compromise between visible degradation and starting material consumption had been reached. The ${ }^{1} \mathrm{H}$ NMR of the crude reaction mixture showed a ratio of 1:1.2, 66:114 among unidentifiable species. Considering that using only one equivalent of boron trifluoride diethyl etherate gave a messier TLC, a slightly lower starting material to product ratio compared to using two equivalents, and that the reaction took more than five times as long, it was concluded to be worse than entry 3 . 
Entry 6 uses two equivalents of boron trifluoride diethyl etherate but three times as much solvent as entry 3 (Table 3.5). It was hoped that the effect of a more dilute reaction mixture would decrease degradation by lowering the likelihood of 2-formylglycal 66 reacting with itself if indeed degradation was occurring by mechanism of polymerisation. However the result of the more dilute reaction mixture decreased the rate of product formation, requiring a longer reaction time. Analysis of the ${ }^{1} \mathrm{H}$ NMR spectrum of the crude reaction mixture revealed much more degradation than that of entry 3 .

Considering that a prolonged reaction time in refluxing 1,2-dichloroethane caused much degradation, the reaction was performed at $30{ }^{\circ} \mathrm{C}$, (entry 7 , Table 3.5 ) and $60{ }^{\circ} \mathrm{C}$ (entries 8 and 9). The intent with these reactions was to find an appropriate temperature which would minimise degradation and maximise formation of alkyne 114, so that longer reaction times could be attained while minimising degradation. No formation of $\mathbf{1 1 4}$ was observed after stirring overnight at $30{ }^{\circ} \mathrm{C}$, with only starting material 66 and degradation products appearing in the ${ }^{1} \mathrm{H}$ spectrum of the crude reaction mixture. Similar results were obtained by running the reaction at $60{ }^{\circ} \mathrm{C}$, with trace amounts of $\mathbf{1 1 4}$ being detected when two equivalents of Lewis acid were used, whereas none was detected when only one equivalent was used.

Considering the above findings, the conclusion was drawn that prolonged reaction times above room temperature resulted in more degradation of $\mathbf{6 6}$.

Entries 11 - 13 detail the exploration of acetic acid as a potential solvent for Ferrier-type alkynylation. The properties of acetic acid that were desired were its high boiling point, ease of removal in an aqueous workup, and that it is a nucleophile in itself. Reaching higher temperatures was hoped to increase the rate of alkynylation in the face of degradation. However as the presence of a Lewis acid would increase the Brønsted acidity of acetic acid, acid catalysed degradation of materials was anticipated. For this reason 0.2 equivalents of boron trifluoride diethyl etherate was explored alongside the higher loading of 2 equivalents of Lewis acid. Unlike other high boiling solvents that would be difficult to remove under reduced pressure, acetic acid can be washed out of the organic phase with a basic work-up. The nucleophilicity of acetic acid gives opportunity for it to participate in Ferrier rearrangements. Under these conditions, the anticipated product would be analogous to the acetyl-glycoside of 114. Under these Lewis acidic conditions, the aforementioned $O$-glycoside may undergo 
alkynolysis, installing the acetylene at C-1. Despite this hopeful speculation there was no success here.

Entries 11 and 12 were set up at room temperature and after $8 \mathrm{~h}$ only starting material was observed via TLC analysis. The reactions were then heated to $80{ }^{\circ} \mathrm{C}$ in an oil bath and no change in the TLC profile was observed after $30 \mathrm{~min}$. A second equivalent of bis(trimethylsilyl)acetylene was added and over the next hour there was only starting material observed. After $11 \mathrm{~h}$ the faint presence of a less polar species was detected in both reaction mixtures. There was little change after $2.5 \mathrm{~h}$, so the reaction mixtures were heated to $100{ }^{\circ} \mathrm{C}$. In the following half hour, the less polar spot became slightly more vivid and the reactions were both finally quenched and worked-up. The ${ }^{1} \mathrm{H}$ NMR spectra of the crude reaction mixtures revealed mostly starting material (as observed via TLC analysis) but no trace of alkyne $\mathbf{1 1 4 .}$ As there appeared to be some reactivity when using acetic acid at higher temperatures, the reaction using two equivalents of boron trifluoride diethyl etherate was repeated, being heated to reflux from the beginning (entry 13, Table 3.5). After $4 \mathrm{~h}$ the less polar species appeared relatively vivid via TLC analysis, so the reaction was worked-up. Analysis of the ${ }^{1} \mathrm{H}$ NMR spectrum of the crude reaction mixture showed no presence of alkyne 114. The less polar species was isolated (Figure 3.9) and determined to be not related in structure to either $\mathbf{6 6}$ or 114, and was perhaps a by-product arising from reaction of acetic acid with the C-4 benzyl group.

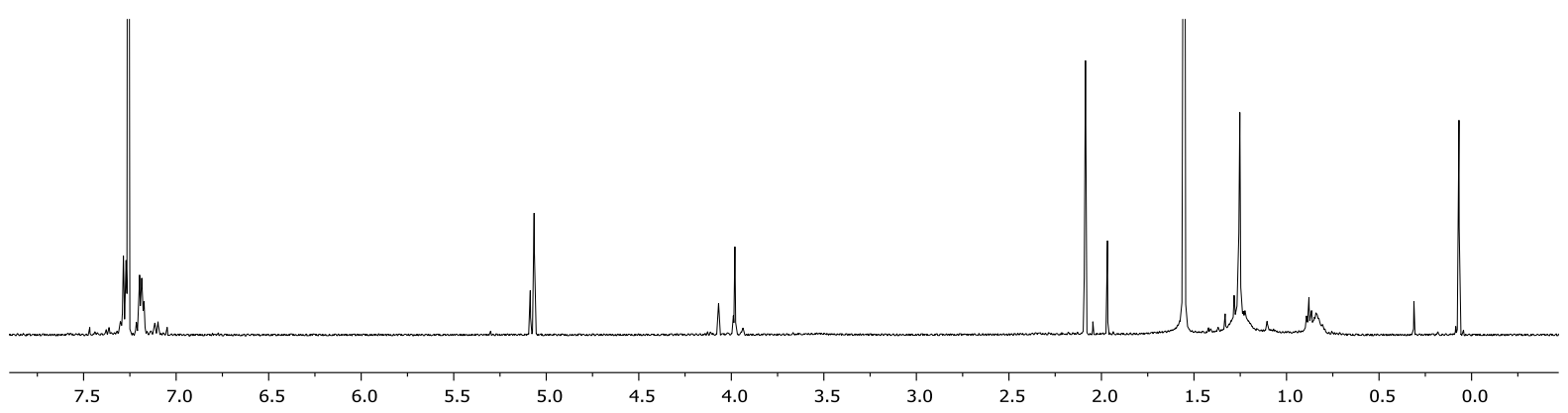

Figure 3.9: ${ }^{1} \mathrm{H}$ NMR spectrum of a non-sugar by-product isolated from alkynylation attempts performed in acetic acid.

Dimethylformamide, toluene, and acetonitrile were also explored as solvents for this reaction (entries 14, 15 and 16, and 17 in Table 3.5 respectively). The objective was to probe the rate of starting material consumption as a proxy for the activation of $\mathbf{6 6}$ at varying temperatures. After $1.5 \mathrm{~h}$ at room temperature, only starting material was observed for reactions in 
acetonitrile and dimethylformamide, and the reaction in toluene showed hints of both more and less polar species via TLC analysis. The reactions were then heated to $40{ }^{\circ} \mathrm{C}$ and after $1.5 \mathrm{~h}$ multiple species were visible in the toluene reaction, more polar species were present in acetonitrile, and mostly starting material was present in the reaction containing dimethylformamide. The reactions were then heated to $60{ }^{\circ} \mathrm{C}$, and after $40 \mathrm{~min}$ there was little change in the TLC from the previous. At this point the reaction in acetonitrile was quenched due to the requirement for a reflux condenser for increased heating. The toluene and dimethylformamide reactions were heated to $80{ }^{\circ} \mathrm{C}$, and after $1.5 \mathrm{~h}$, there was no detectable starting material in the toluene reaction. There was little change in the TLC of the dimethylformamide reaction after stirring at $80^{\circ} \mathrm{C}, 100{ }^{\circ} \mathrm{C}$, and $130{ }^{\circ} \mathrm{C}$.

The reaction performed in dimethylformamide (entry 14, Table 3.5) gave no reaction apart from some slight degradation observed in the ${ }^{1} \mathrm{H}$ NMR spectrum of the crude reaction mixture.

The ${ }^{1} \mathrm{H}$ NMR spectrum of the crude reaction mixture obtained from the reaction performed in toluene (entry 15, Table 3.5) showed no presence of starting material 66 or desired alkyne 114. However as reactivity was observed in starting material being consumed, the reaction was repeated at $111{ }^{\circ} \mathrm{C}$ (refluxing toluene) from the start of the reaction (entry 16). Within three minutes of stirring in refluxing toluene multiple species both more and less polar than the starting material was observed via TLC analysis. Within 20 minutes the starting material was nearly all consumed and the reaction was quenched using a saturated aqueous solution of sodium bicarbonate. The ${ }^{1} \mathrm{H}$ NMR spectrum of the crude reaction mixture showed the presence of some starting material, but no detectable 114. These results indicate that performing the reaction in toluene encourages the formation of by-products and hinders alkynylation when boron trifluoride diethyl etherate is used as the Lewis acid.

Analysis of the ${ }^{1} \mathrm{H}$ NMR spectrum of the crude reaction mixture performed in acetonitrile (entry 17) showed a very clean spectrum of a compound initially mistaken for starting material 66. The most significant differences being changes in the shifts of $\mathrm{H}-3, \mathrm{H}-4$, one of the acetate signals, and a new doublet at $5.86 \mathrm{ppm}$ (Table 3.6, Figure 3.10). Judging from this it was clear that a change had occurred at the C-3 acetate. 
Table 3.6: Comparison of ${ }^{1} \mathrm{H}$ shifts of starting material 66 and species 116.
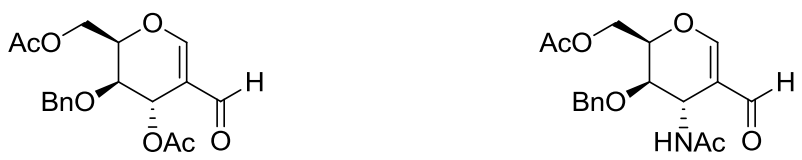

\begin{tabular}{ccc}
\hline Proton & $\mathbf{6 6}$ & $\mathbf{1 1 6}$ \\
\hline $\mathrm{CHO}$ & $9.39(\mathrm{~s}, 1 \mathrm{H})$ & $9.33(\mathrm{~s}, 1 \mathrm{H})$ \\
$\mathrm{H}-1$ & $7.54(\mathrm{~s}, 1 \mathrm{H})$ & $7.52(\mathrm{~s}, 1 \mathrm{H})$ \\
$\mathrm{Ph}-\mathrm{H}$ & $7.36-7.28($ complex m, $5 \mathrm{H})$ & $7.36-7.28($ complex m, $5 \mathrm{H})$ \\
$\mathrm{H}-3$ & $5.78(\mathrm{~d}, J=2.3 \mathrm{~Hz}, 1 \mathrm{H})$ & $4.83(\mathrm{dd}, J=5.2,1.9 \mathrm{~Hz}, 1 \mathrm{H})$ \\
$\mathrm{NH}$ & - & $5.86(\mathrm{~d}, J=5.2 \mathrm{~Hz}, 1 \mathrm{H})$ \\
$\mathrm{CH}_{2} \mathrm{Ph}_{\mathrm{A}}$ & $4.76(\mathrm{~d}, J=12.0 \mathrm{~Hz}, 1 \mathrm{H})$ & $4.78(\mathrm{~d}, J=12.0 \mathrm{~Hz}, 1 \mathrm{H})$ \\
$\mathrm{CH}_{2} \mathrm{Ph}_{\mathrm{B}}$ & $4.56(\mathrm{~d}, J=12.0 \mathrm{~Hz}, 1 \mathrm{H})$ & $4.62(\mathrm{~d}, J=12.0 \mathrm{~Hz}, 1 \mathrm{H})$ \\
$\mathrm{H}-6 \mathrm{~A}$ & $4.34(\mathrm{dd}, J=11.7,7.5 \mathrm{~Hz}, 1 \mathrm{H})$ & $4.33(\mathrm{dd}, J=11.7,7.6 \mathrm{~Hz}, 1 \mathrm{H})$ \\
$\mathrm{H}-5$ & $4.20(\mathrm{t}, J=6.1 \mathrm{~Hz}, 1 \mathrm{H})$ & $4.17(\mathrm{t}, J=4.7 \mathrm{~Hz}, 1 \mathrm{H})$ \\
$\mathrm{H}-6_{\mathrm{B}}$ & $4.13(\mathrm{dd}, J=11.7,4.7 \mathrm{~Hz}, 1 \mathrm{H})$ & $4.07(\mathrm{dd}, J=11.7,4.7 \mathrm{~Hz}, 1 \mathrm{H})$ \\
$\mathrm{H}-4$ & $3.66(\mathrm{t}, J=1.9 \mathrm{~Hz}, 1 \mathrm{H})$ & $3.86(\mathrm{~s}, 1 \mathrm{H})$ \\
$\mathrm{COCH}_{3}$ & $2.06(\mathrm{~s}, 3 \mathrm{H})$ & $1.97(\mathrm{~s}, 3 \mathrm{H})$ \\
$\mathrm{COCH}_{3}$ & $1.99(\mathrm{~s}, 3 \mathrm{H})$ & $1.98(\mathrm{~s}, 3 \mathrm{H})$ \\
\hline
\end{tabular}

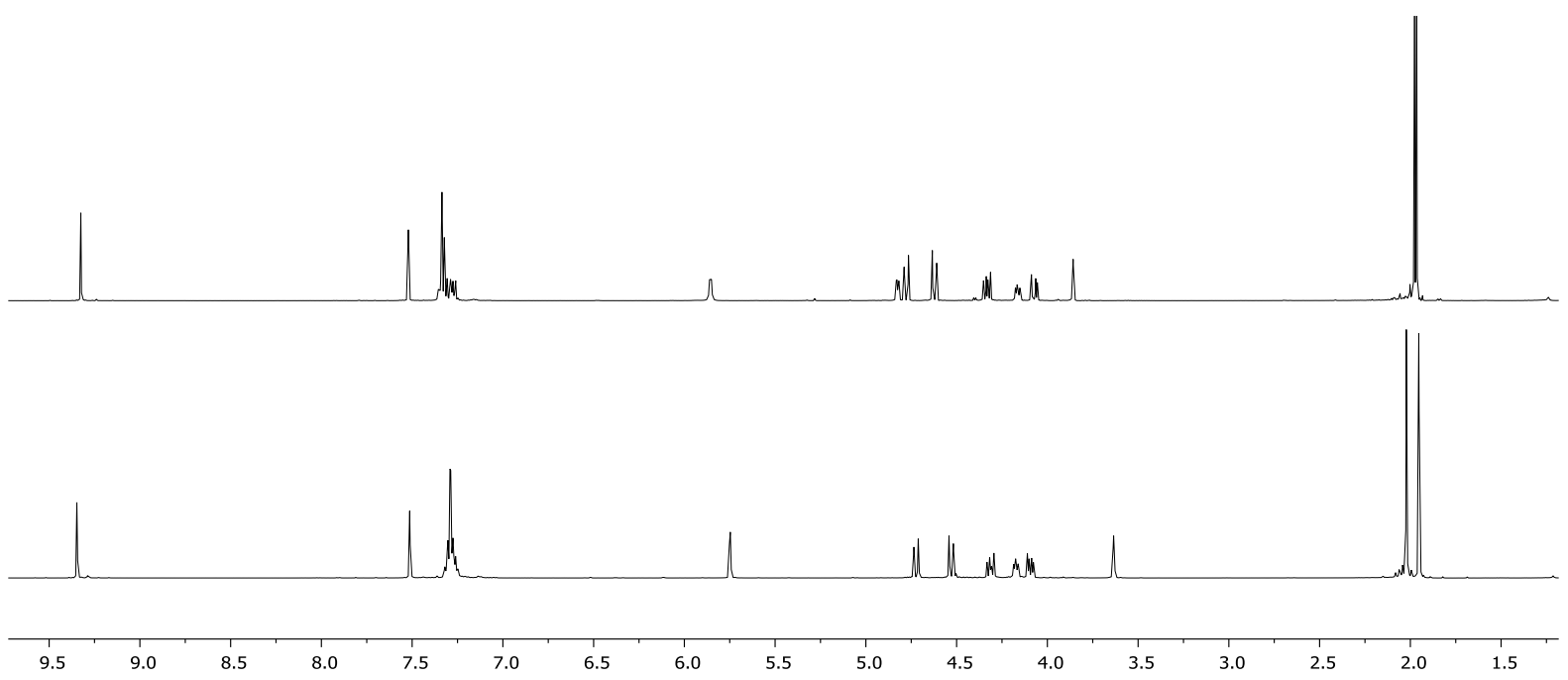

Figure 3.10: ${ }^{1} \mathrm{H}$ NMR spectra of $\mathbf{1 1 6}$ (above), and starting material $\mathbf{6 6}$ (below). 
Possible happenings at the C-3 position were an inversion of configuration with the acetate still attached, or substitution of the acetate by another nucleophile. An inversion of configuration would be plausible if the signal at $5.86 \mathrm{ppm}$ were omitted. However the signal was real and showed a correlation in the COSY to the signal at 4.83 ppm representing H-3. Had an acetylene nucleophile substituted for the acetate it would be expected that there were either a new signal at around $0 \mathrm{ppm}$ if the trimethylsilyl group were in place, or around $2 \mathrm{ppm}$ if the alkyne were terminal. On consideration of the reaction conditions, it was deemed plausible that acetonitrile acted as a nucleophile to form species 117 (Scheme 3.15). Nitrile 117 would then hydrolyse in the basic work-up, and after tautomerisation give amide 116. Mass spectrometry found a mass which matched that of $\mathbf{1 1 6}\left(\mathrm{m} / z, \mathrm{C}_{18} \mathrm{H}_{21} \mathrm{NO}_{6} \mathrm{Na}^{+}[\mathrm{M}+\mathrm{Na}]^{+}\right.$calcd. 372.1318, found $372.1320(\Delta$ $=-0.63 \mathrm{ppm})$ ).

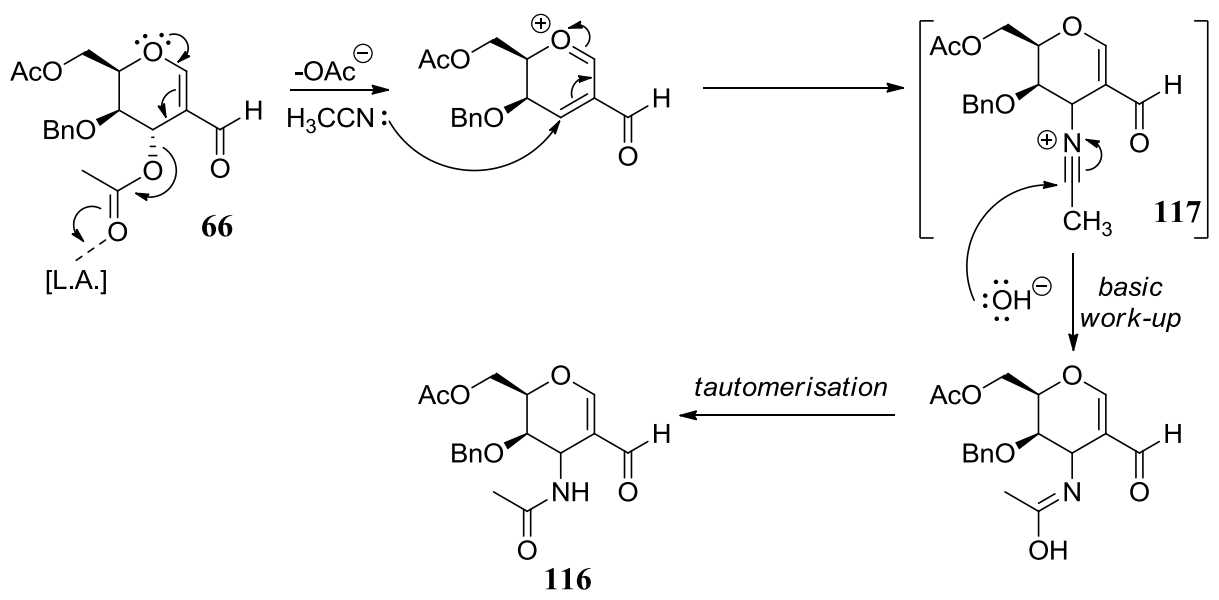

Scheme 3.15: Plausible mechanism for the formation of $\mathbf{1 1 6}$ from $\mathbf{6 6}$ in acetonitrile.

Amide 116 was obtained in $60 \%$ yield without purification. Considering that the conditions used were somewhat harsh in an effort to activate the starting material, there is room for the optimisation. Amide 116 could be a precursor amino acid derivatives following the oxidation of the aldehyde and deacetylation of the amide as demonstrated in using similar compounds by Vankar. ${ }^{[24]}$

\subsubsection{Exploration of Tin(IV) Chloride as a Lewis acid for Ferrier-type Alkynylation of 66}

As mentioned above, tin(IV) chloride was eliciting some reactivity from 2-formylglycal 66. The use of a tin catalyst is not ideal for this transformation due to its inherent toxicity. However 
interesting results were obtained and perhaps the use of tin would give further insight into the reactivity of 66. Attempts forming alkyne 114 from 2-formylglycal 66 using tin(IV) chloride as the Lewis acid are summarised in Table 3.7. Entries 1 and 2 were discussed earlier, but are included in the below table for ease of results comparison.

Table 3.7: Attempts at formation of $\mathbf{1 1 4}$ from $\mathbf{6 6}$ using tin(IV) chloride as the Lewis acid.

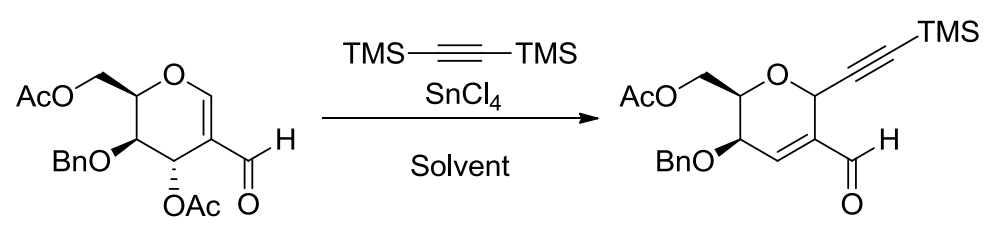

66
114<smiles>CC(F)(F)OC[C@H]1OC=C(C=O)[C@H](Cl)[C@@H]1Br</smiles>

115

\begin{tabular}{ccccccc}
\hline Entry & L.A. eq & Alkyne eq & Solvent & Temp. & Duration & Result \\
\hline 1 & 2 & 1.1 & DCM & Rt & o/n & $\mathbf{1 1 5}(6 \%)$ \\
2 & 2 & 1.1 & DCE & $40^{\circ} \mathrm{C}$ & $6 \mathrm{~h}$ & $1: 3, \mathbf{6 6 : 1 1 5}$ \\
3 & 0.2 & 2 & DCE & $40^{\circ} \mathrm{C}$ & $7 \mathrm{~h}$ & $1: 2, \mathbf{6 6 : 1 1 5}+$ degr. \\
$4^{\mathrm{a}}$ & 0.2 & 2 & DCE & $40^{\circ} \mathrm{C}$ & $5 \mathrm{~h}$ & $1: 1.4, \mathbf{6 6 : 1 1 5}$ \\
5 & 2 & 1.1 & DCE & reflux & $2 \mathrm{~h}$ & $\mathbf{1 1 4}(6 \%), \mathbf{1 1 5}(11 \%)$ \\
6 & 2 & 1.1 & DCE & reflux & o/n & $\mathbf{1 1 4}(1 \%), \mathbf{1 1 5}(2 \%)$ \\
\hline $7^{\mathrm{b}}$ & 2 & 1.1 & DCE & reflux & $1.5 \mathrm{~h}$ & $\mathbf{1 1 5}+\operatorname{degr}$. \\
\hline 8 & 2 & 1.1 & Toluene & $85^{\circ} \mathrm{C}$ & $2 \mathrm{~h}$ & $\mathbf{1 1 5}+\operatorname{degr}$. \\
$9^{\mathrm{c}}$ & 2 & 1.1 & Toluene & $85^{\circ} \mathrm{C}$ & $2 \mathrm{~h}$ & Trace 114, no 115 \\
\hline
\end{tabular}

${ }^{\mathrm{a}}$ Also +0.2 eq AgOTf; ${ }^{\mathrm{b}}$ used 115 instead of $\mathbf{6 6}$ as the starting material ${ }^{\mathrm{c}}$ also +2 eq $\mathrm{AgNO}_{3}$

The presence of $\mathbf{1 1 5}$ in the reactions corresponding to entries 1 and 2 in Table 3.7 indicates that there is activation of the $\mathrm{C}-3$ acetate by tin(IV) chloride. However, the chloride anion outcompetes the acetylene as a nucleophile. As such, the reaction was attempted using 0.2 equivalents of tin(IV) chloride in effort to minimise the amount of chloride present while still having appreciable amounts of Lewis acid (entry 3, Table 3.7). Understanding that for each equivalent of tin(IV) chloride there are four equivalents of chloride, 2 equivalents of acetylene were used in an attempt to out-compete chloride in terms of availability. However none of alkyne 114 was observed in the ${ }^{1} \mathrm{H}$ NMR spectrum of the crude reaction mixture, and a significant amount of chloride 115 observed $(1: 3, \mathbf{6 6}: 115)$. The reaction was repeated with the addition of silver(I) triflate to the reaction mixture (entry 4). The idea being that silver(I) would activate the chloride of $\mathbf{1 1 5}$ as a leaving group for subsequent Ferrier-type rearrangement with 
the acetylene nucleophile. Unfortunately this was not the case with 115 still being abundant in the ${ }^{1} \mathrm{H}$ NMR spectrum of the crude reaction mixture. It is possible that the silver(I) salt reacted with the chlorinated solvent before it could react with $\mathbf{1 1 5}$.

Additional equivalents of bis(trimethylsilyl)acetylene may be needed to out compete the chloride nucleophile, or higher temperatures to get the 2-formylglycal and the acetylene to react. Mechanistically there could be a coordination effect and a direct transfer of the chloride from the tin complex to the glycal. If this is the case, an increased amount of acetylene would have little effect on the reaction - as soon as the C-3 acetate was activated by tin(IV) chloride, a chloride would be right there to intercept the positive charge left by the acetate leaving.

As alkyne 114 was able to be obtained using boron trifluoride diethyl etherate in refluxing 1,2dichloroethane (Section 3.5.2), the formation of 114 was attempted using tin(IV) chloride in the same conditions (entry 5, Table 3.7). After $2 \mathrm{~h}$ of stirring, less polar materials were observed by TLC analysis of the crude reaction mixture corresponding to both 114 and potentially 115 . However the reaction mixture was very brown/black in colour with some visible particulate visible in the organic phase of the work-up. The less polar species were isolated using silica gel chromatography, the least polar species being the desired alkyne $114(6 \%)$ and the slightly more polar species being 115 (11\%). The yield of 114 in this case was comparable to that obtained under the same conditions using boron trifluoride diethyl etherate, with much of the chlorinated species observed. As there was suspicion that $\mathbf{1 1 5}$ may be an intermediate en route to 114 , the reaction time was extended in hopes 115 would become 114. Letting the reaction run overnight decreased the yield of both desired alkyne 114 and chlorinated species $\mathbf{1 1 5}$, giving only $1 \%$ and $2 \%$ yields respectively. Following this reaction, enough material of 115 was obtained to probe whether it indeed would form 114 under these conditions. As such, 115 was treated with bis(trimethylsilyl)acetylene (1.1 eq) and tin(IV) chloride in refluxing 1,2dichloroethane as described in entry 7. No formation of $\mathbf{1 1 4}$ was observed via TLC analysis as only 115 and more polar by-products were visible.

Tin(IV) chloride was explored as a Lewis acid in toluene at $85^{\circ} \mathrm{C}$ (entry 8, Table 3.7). Within eight minutes of the reaction beginning, a spot on the TLC plate was observed with similar polarity to 115. Within $2 \mathrm{~h}$ the starting material was consumed and the reaction worked-up. Analysis of the ${ }^{1} \mathrm{H}$ NMR spectrum of the crude reaction mixture showed $\mathbf{1 1 5}$ as the major product with no $\mathbf{1 1 4}$ observable. The reaction was repeated with the addition of silver(I) nitrate 
(entry 9, Table 3.7) and the ${ }^{1} \mathrm{H}$ NMR spectrum of the crude reaction mixture showed no trace of 115, but some 114 present among unidentifiable degradation products. This result either suggests that a combination tin and silver complex is causing preferential interaction between 2-formylglycal 66 and bis(trimethylsilyl)acetylene, or more likely silver(I) is activating the chloride at the C-3 position of $\mathbf{1 1 5}$ formed in the reaction mixture, allowing for the acetylene nucleophile to react with the 2-formylglycal. Either way the result supports the earlier speculation that the silver salt was reacting with 1,2-dichloroethane in previous reactions.

\subsubsection{Exploration of Cossy's Methodology for Ferrier-type Alkynylation of 66}

Alkynylation of 2-formylglycal $\mathbf{6 6}$ was attempted using the conditions described by Cossy (Scheme 3.16). ${ }^{[27]}$ The copper-acetylene species required was prepared by mixing trimethylsilylacetylene with $n$-butyllithium in a dry-ice/acetone bath $\left(-78{ }^{\circ} \mathrm{C}\right)$ for $10 \mathrm{~min}$. Copper bromide dimethylsulfide was then added and the reaction mixture transferred to a dryice/acetonitrile bath $\left(-41^{\circ} \mathrm{C}\right)$ and let stir for $30 \mathrm{~min}$. The reaction was again transferred to a dry-ice/acetone bath $\left(-78^{\circ} \mathrm{C}\right)$ and boron trifluoride diethyl etherate followed by 2-formylglycal 66 added. No reaction was observed at $-78{ }^{\circ} \mathrm{C}$ over $1.5 \mathrm{~h}$ as determined via TLC analysis. As such, the reaction was warmed to room temperature and a less polar species (having a different $\mathrm{R}_{f}$ to 114 ) was observed after $18 \mathrm{~h}$, with starting material still visible. The reaction was workedup using an aqueous ammonium chloride solution and the higher running spot isolated. Before the isolated species could be analysed via ${ }^{1} \mathrm{H}$ NMR spectroscopy it had severely degraded. Signals in the region of the functionalities of $\mathbf{6 6}$ could be detected (aldehyde, benzyl, and acetyl protons), but nothing resembling a trimethylsilyl group.

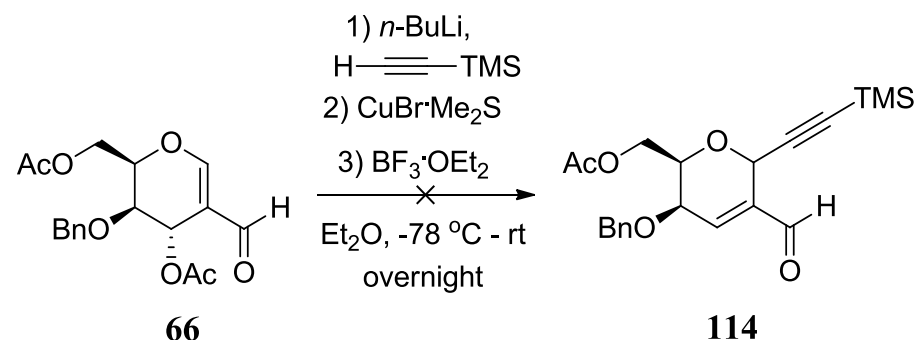

Scheme 3.16: Attempted alkynylation of $\mathbf{6 6}$ using Cossy's methodology.

As the reaction using the above conditions seemed sluggish even at room temperature, the reaction was repeated using tetrahydrofuran as the solvent in order to reach higher temperatures 
(Scheme 3.17). The copper-acetylene species was made as described above, and the Lewis acid and 2-formylglycal 66 were added at $-78^{\circ} \mathrm{C}$. After $30 \mathrm{~min}$ at $-78^{\circ} \mathrm{C}$, no reaction was observed. The reaction was then warmed to room temperature and after $1.5 \mathrm{~h}$ a less polar species was faintly detected. The reaction mixture was heated to reflux $\left(66^{\circ} \mathrm{C}\right)$ and after $3 \mathrm{~h}$ still showed starting material. After overnight stirring, TLC analysis revealed complete degradation with neither starting material nor the less polar species observed.

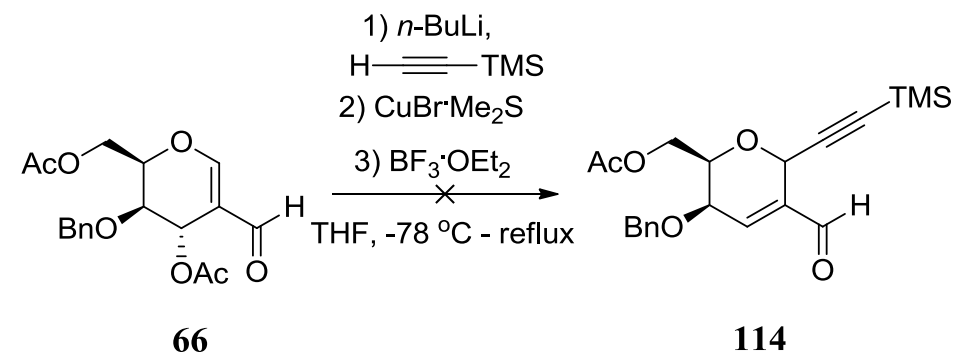

Scheme 3.17: Attempted alkynylation of $\mathbf{6 6}$ using Cossy's methodology in refluxing THF.

The starting material was being converted into a less polar species in both attempts at alkynylation using Cossy's conditions. However the less polar species was not $\mathbf{1 1 4}$ as it had a different $\mathrm{R}_{f}$, degraded fairly rapidly (compared to $\mathbf{1 1 4}$ ), and 114 was not observed in the ${ }^{1} \mathrm{H}$ NMR spectra of the crude reaction mixtures. The unknown product could perhaps be identified if spectral data were collected immediately after purification.

\subsubsection{Exploration of Mukherjee's Methodology for Ferrier-type Alkynylation of 66}

Despite having no success using this methodology in the alkynylation of 2-haloglycals 57, the alkynylation of 2-formylglycal 66 was attempted using Mukherjee's conditions. ${ }^{[26]}$

Bromomethyl acetate (1 eq) and trimethylsilylacetrylene (1.5 eq) was added to a solution of zinc powder (1.5 eq) in 1,2-dichloroethane (Scheme 3.18). After stirring at $40{ }^{\circ} \mathrm{C}$ for $1 \mathrm{~h}, 2$ formylglycal 66 (1 eq) was added. As no observable reaction was observed after $3 \mathrm{~h}$, the mixture was warmed to $70{ }^{\circ} \mathrm{C}$. After a further $1 \mathrm{~h}$ TLC analysis still showed only starting material. Solid was observed at the bottom of the flask suggested that perhaps the organozinc species was not forming, so tetra- $n$-butylammonium iodide ( 1 eq) was added. After stirring for a further $15 \mathrm{~h}$, only starting material and more polar products were visible via TLC analysis. 
Analysis of the ${ }^{1} \mathrm{H}$ NMR spectrum showed only starting material $\mathbf{6 6}$ and unidentifiable degradation products.

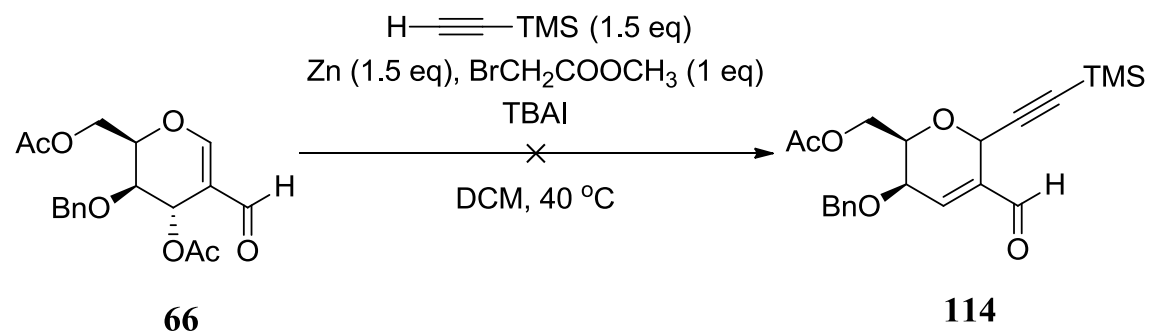

Scheme 3.18: Attempt at alkynylation of $\mathbf{6 6}$ using Mukherjee's conditions.

Speculation regarding the lack of reaction of $\mathbf{6 6}$ was initially that the organozinc species was not forming. However addition of tetra- $n$-butylammonium iodide to encourage the formation of the organozinc produced no better reactivity. The lack of formation of the organozinc species could still be the reason for the failure of this reaction - methylbromoacetate could have evaporated by the time tetra- $n$-butylammonium iodide was introduced. This reaction could be explored further by repeating the reaction with tetra- $n$-butylammonium iodide present from the beginning. Alternatively the zinc powder used could be activated. Perhaps the use of ethylbromoacetate was necessary, rather than using the methyl variant.

\subsubsection{Attempts at Alkynylation of 2-Formylglycal 66 Using Acetylides}

2-Formylglycal 66 has shown reactivity at the C-3 position with non-acetylene nucleophiles (viz. chloride [Section 3.5.3], acetonitrile [Section 3.5.2], and $S$-nucleophiles [Section 3.5.7]). This could mean that bis(trimethylsilyl)acetylene was not an appropriate nucleophile for this system. As such, attempts at alkynylation were made using sodium and copper acetylides.

Sodium hydride (1.2 eq) and trimethylsilylacetylene (11 eq) were mixed in dichloromethane for $45 \mathrm{~min}$ in an ice-water bath. 2-Formylglycal $\mathbf{6 6}$ was added, the mixture warmed to room temperature and stirred overnight (Scheme 3.19). Nothing could be discerned from the ${ }^{1} \mathrm{H}$ NMR spectrum of the crude reaction mixture due to the amount of species present, but TLC analysis revealed a less polar product. The less polar species was isolated, but upon analysis of the ${ }^{1} \mathrm{H}$ NMR spectrum no sugar-like signals were detected. 


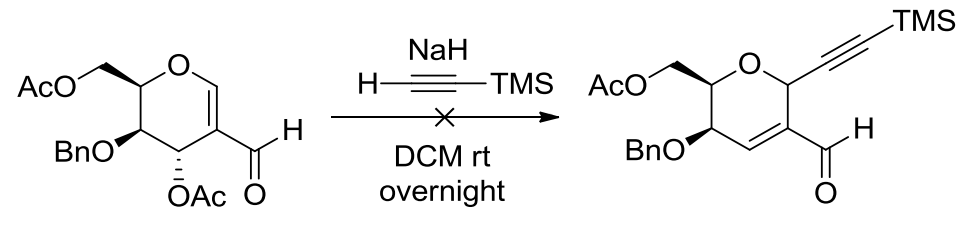

66

114

Scheme 3.19: Attempted alkynylation of $\mathbf{6 6}$ using a sodiated acetylene.

The above reaction was repeated in dimethylformamide. However following addition of 2formylglycal 66, the reaction was warmed to $40{ }^{\circ} \mathrm{C}$ and 2 equivalents of boron trifluoride diethyl etherate added. The reaction was monitored via TLC analysis and the formation of a less polar product was observed. After $4 \mathrm{~h}$ the reaction was halted despite starting material still being present. The less polar species was isolated, the ${ }^{1} \mathrm{H}$ NMR spectrum pictured in Figure 3.11. This by-product was unable to be identified despite full $2 \mathrm{D}$ data being obtained. From the ${ }^{1} \mathrm{H}$ NMR spectrum, it appeared the by-product still had an aldehyde, a benzyl group (with the oxymethylenes coalescing into one singlet at $4.88 \mathrm{ppm})$, and an acetate.

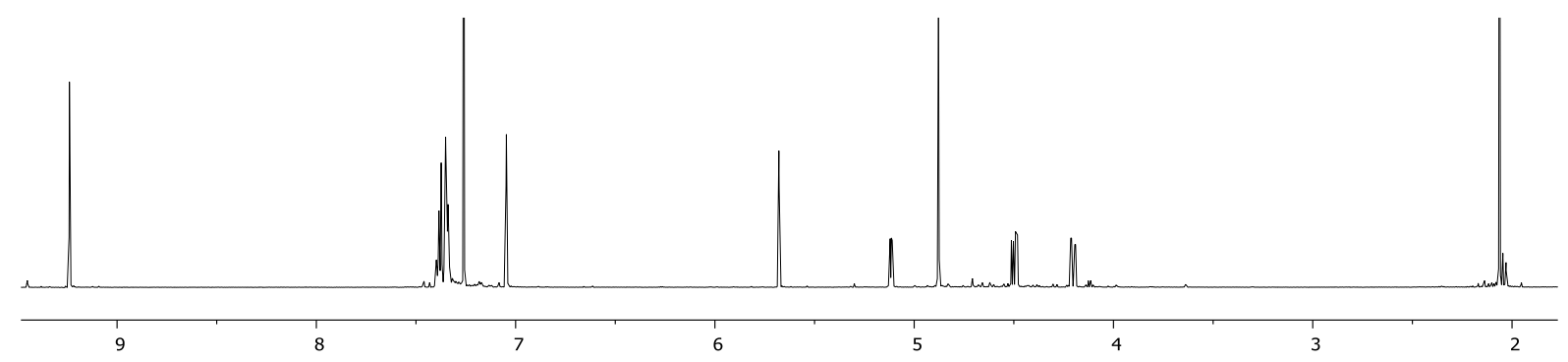

Figure 3.11: ${ }^{1} \mathrm{H}$ NMR spectrum of a less polar species isolated from an alkynylation attempt using a sodiated acetylide in dimethylformamide.

Sonogashira cross-coupling reactions form carbon-carbon bonds from aryl- and vinyl- halides and terminal alkynes using palladium(II) and copper(I) as catalysts. The terminal alkyne is deprotonated with a base and a copper acetylide is formed before transmetallation with palladium (Scheme 3.20). Formation of the copper acetylide was attempted in the hope that the organometallic species would be a more appropriate nucleophile for the alkynylation of 66. 


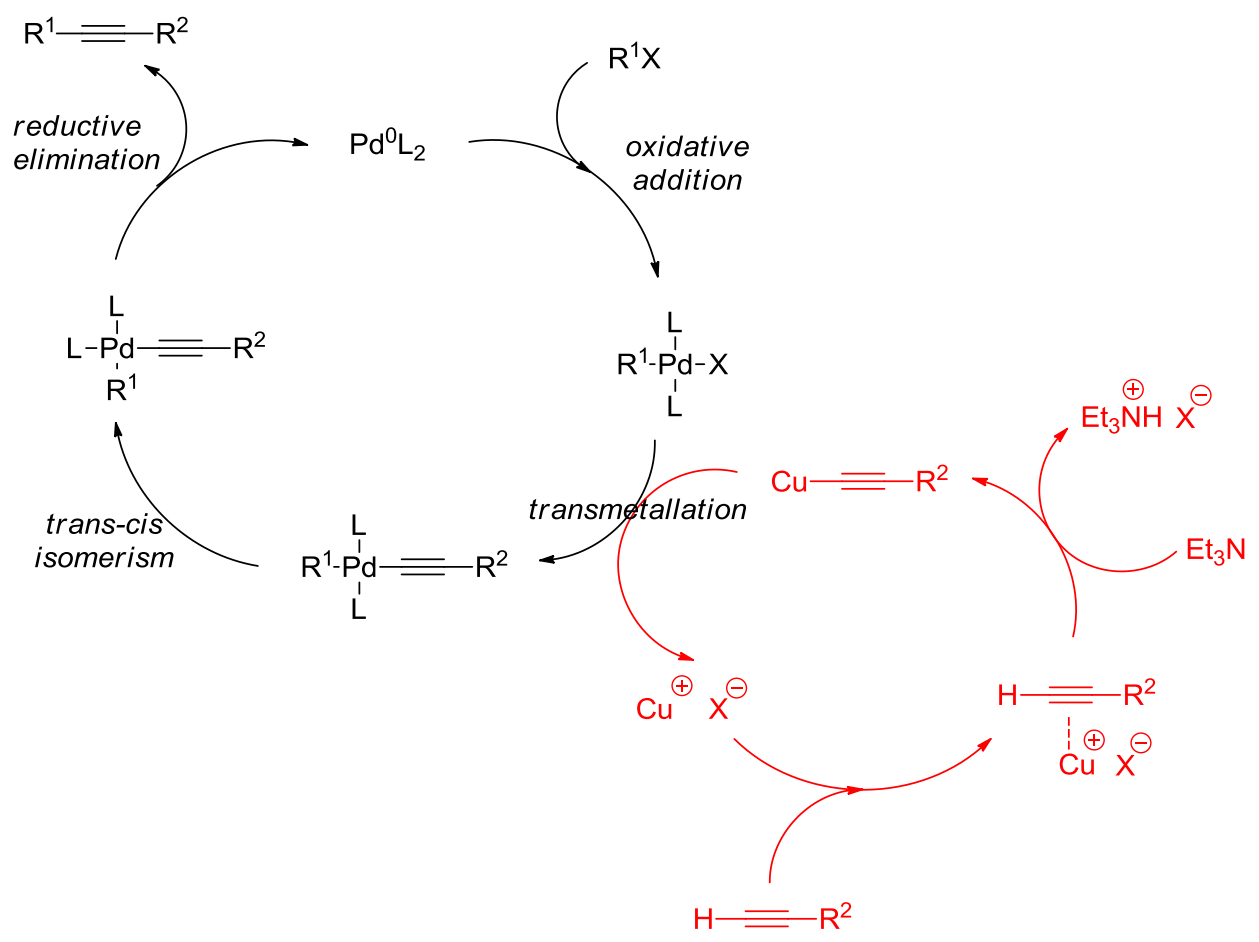

Scheme 3.20: Catalytic cycle for Sonogashira cross-coupling. Highlighted in red is the copper cycle to be emulated.

To a solution of triethylamine (1.1 eq) and trimethylsilylacetylene (11 eq) in acetonitrile was added copper(I) iodide ( $0.15 \mathrm{eq})$. The reaction was stirred in an ice-water bath for $30 \mathrm{~min}$ before the addition of 2-formylglycal 66. The reaction was warmed to room temperature and over $3 \mathrm{~h}$ the mixture turned from colourless to a pale yellow, to bright red. Despite the colour, no reaction was observed via TLC analysis. After overnight stirring the reaction mixture was a dark brown, with only starting material and less polar products visible via TLC. Analysis of the ${ }^{1} \mathrm{H}$ NMR spectrum of the crude reaction mixture revealed only starting material (Scheme $3.21)$.

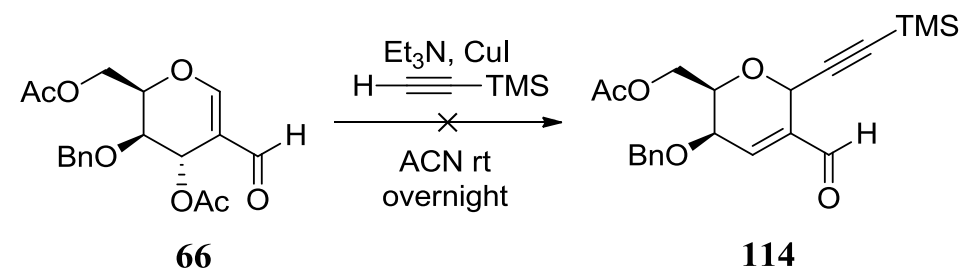

Scheme 3.21: Attempted alkynylation of $\mathbf{6 6}$ using a copper(I) acetylide.

The reaction conditions used were similar to the methodology developed by Cossy (Scheme 3.16). ${ }^{[27]}$ However the reaction, as shown in Scheme 3.20, gave only starting material, whereas some reactivity was observed in both the attempts at using Cossy's methodology. The 
difference between the above reaction and those in Schemes 3.16 and 3.17 is the base used to deprotonate the acetylene - triethylamine is a much weaker base compared to $n$-butyllithium. From this, the lack of reactivity observed here can be attributed to triethylamine not irreversibly deprotonating the acetylene. Alternatively, a triethylamine-copper(I) complexation was occurring and interfering with reactivity.

\subsubsection{Attempted Protection of 2-Formylglycal 66}

Compared to C-2 substituted glycals reported in the literature, 2-formylglycal $\mathbf{6 6}$ seemed less prone to Ferrier rearrangement. The functionality that seemed to be causing issues was the aldehyde conjugated with the enol ether. The hypothesis was that protection of the aldehyde as an acetal or thioacetal would dampen the interference it had with the reactivity of the glycal. Methodology was found which protected aldehyde of chromone 116 (Scheme 3.22). ${ }^{[43]}$ The methodology uses $p$-toluenesulfonic acid as a catalyst and performed the reaction using a solvent mixture of 1:2 ethylene glycol:toluene.

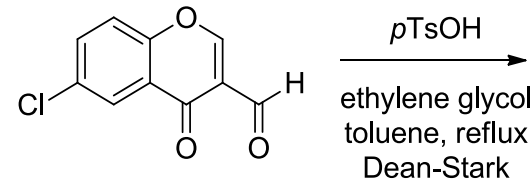

116

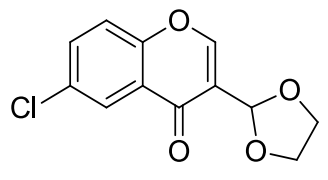

117

Scheme 3.22: Acetal protection of chromone 116. ${ }^{[43]}$

Acetal protection of 2-formylglycal 66 was attempted using the conditions in Scheme 3.21 (described in Scheme 3.23). The procedure differed to that in Scheme 3.18 in the use of $4 \AA$ molecular sieves rather than a Dean-Stark apparatus. This was due to the small scale the reaction was performed on. After $2 \mathrm{~h}$ the starting material was consumed and a more polar product visible via TLC analysis. Analysis of the crude reaction mixture showed a major product featuring both an aldehyde shift at $9.37 \mathrm{ppm}$ and an $\mathrm{H}-1$ similar to that of the starting material at $7.48 \mathrm{ppm}$. From this it was concluded that the protection of the aldehyde did not work and due to time constraints, the less product was not pursued. 


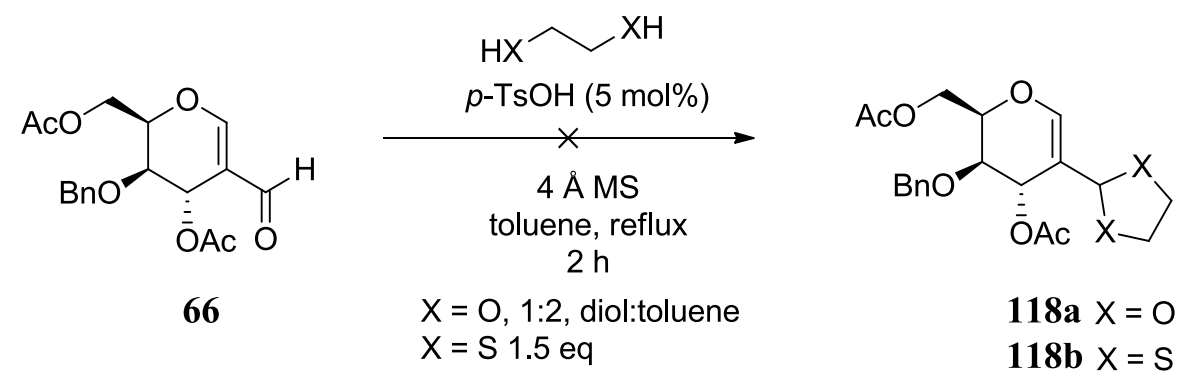

Scheme 3.23: Attempted protection of the aldehyde functionality on 2-formylglycal 66.

Alongside the attempt at acetal formation an attempt at thioacetal formation was performed. The procedure used was the same as the acetal formation, however only 1.5 equivalents of 1,2ethanedithiol were used, rather than a 1:2 solvent mixture with toluene (Scheme 3.24). This was because the dithiol was unpleasant to work with. After $2 \mathrm{~h}$ stirring in refluxing toluene, a less polar species was observed via TLC analysis.

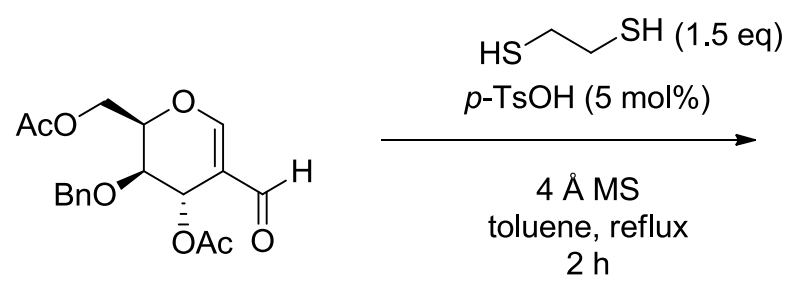

66

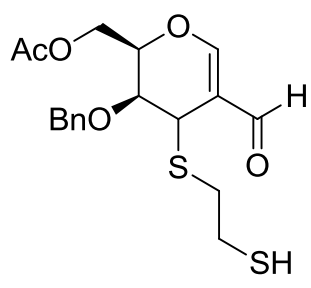

119

Scheme 3.24: Reaction of $\mathbf{6 6}$ with 1,2-ethanedithiol.

The less polar species was isolated and its structure deduced using 1D and 2D NMR experiments and mass spectrometry. The aldehyde was still present as evidenced by the singlet at $9.32 \mathrm{ppm}$ in the ${ }^{1} \mathrm{H}$ NMR spectrum, and $189.1 \mathrm{ppm}$ in the ${ }^{13} \mathrm{C}$ spectrum. Initially it was thought that a Ferrier-rearrangement had occurred, as only one acetate was observed in the 1D spectra $\left(\delta_{\mathrm{H}}=2.07 \mathrm{ppm}, \mathrm{s}, 3 \mathrm{H} ; \delta_{\mathrm{C}} 170.6 \mathrm{ppm} \mathrm{CO}\right.$ and $\left.20.9 \mathrm{ppm} \mathrm{CH}_{3}\right)$, and the proton signal representing H-1 in $\mathbf{6 6}$ seeming to have disappeared. However the shifts of the C-1 and C-2 carbons were relatively unchanged $\left(66\right.$ : $\delta_{\mathrm{C}} 165.6 \mathrm{C}-1,115.7 \mathrm{C}-2 ; 119: \delta_{\mathrm{C}} 163.7 \mathrm{C}-1,117.5 \mathrm{C}-$ 2), and an HSQC correlation was observed between the aromatic proton pocket and the carbon at $163.7 \mathrm{ppm}$. As the position of the benzyl group was not expected to change under these conditions, as well as an HMBC correlation from the benzyl oxymethylene carbon (71.8 ppm) and H-4 (3.73 ppm), it was deduced that the signal representing $\mathrm{H}-1$ had shifted downfield 
from that of the starting material and appeared in the multiplet representing the aromatic protons. HMBC correlations were observed between a signal at $3.77 \mathrm{ppm}$ and carbons at 117.5 (C-2) and $37.0 \mathrm{ppm}$ (characteristic of a sulfur substituted carbon); which suggested that $\mathrm{H}-3$ was the aforementioned proton signal and part of a thioether. A HSQC correlation between $\mathrm{H}-$ 3 and a carbon at 34.4 ppm supported the thioether structure. Mass spectrometry confirmed the molecular formula of 119: $\mathrm{m} / z \mathrm{C}_{18} \mathrm{H}_{22} \mathrm{O}_{5} \mathrm{~S}_{2}[\mathrm{M}+\mathrm{H}]^{+}$calcd 383.0981 , found $383.0983(\Delta=-0.38$ ppm).

Protection of the aldehyde of $\mathbf{6 6}$ failed due to competing reactivity of the C-3 position. The C3 acetate group has been shown to be relatively unreactive at lower temperatures (at least toward Ferrier-type alkynylation) as demonstrated in Section 3.5.1. Attempting the thioacetal formation at lower temperatures could favour reaction with the aldehyde over the C-3 position. This was not attempted due to time constraints.

\subsection{Ring Closure}

Following the alkynylation studies in Section 3.5, enough material was accrued to attempt to form a lactone ring. With alkyne $\mathbf{1 1 4}$ in hand, ring-closure between the alkyne and the acid functionalities in $\mathbf{1 2 0}$ was envisioned to afford the enol-lactone $\mathbf{1 2 1}$ (Scheme 3.25). Oxidation of the $\alpha, \beta$-unsaturated aldehyde to the analogous acid would be performed using Pinnick conditions, followed by tetra- $n$-butylammonium fluoride deprotection to remove the trimethylsilyl group from the alkyne. The Pinnick oxidation was performed before tetra- $n$ butylammonium fluoride deprotection as there was concern that a terminal alkyne may participate in side reactions with hypochlorous acid produced in the reaction.

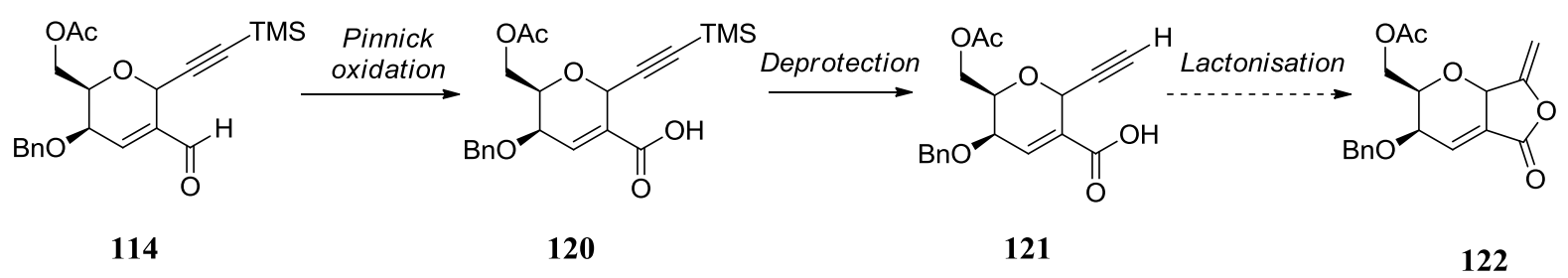

Scheme 3.25: Synthetic route from alkyne $\mathbf{1 1 4}$ to enol lactone $\mathbf{1 2 2}$. 


\subsubsection{Pinnick Oxidation of 114}

Pinnick methodology was successfully used to oxidise aldehyde 114 to acid $\mathbf{1 2 0}$. To a mixture of aldehyde 114 and resorcinol in 2:1 tert-butanol:water was added sodium chlorite and monosodium phosphate (Scheme 3.26). After stirring overnight starting material had been consumed so the reaction mixture was acidified with acetic acid and worked up. Analysis of the ${ }^{1} \mathrm{H}$ NMR spectrum of the crude reaction mixture showed only acid $\mathbf{1 2 0}$ and the resorcinol oxidation product 2-hydroxy-1,4-benzoquinone. Purification of the mixture was difficult as the $\mathrm{R}_{f}$ of acid 120 and the resorcinol oxidation product were very similar. However the mixture of the aforementioned species post-chromatography was successfully used in the following deprotection step.

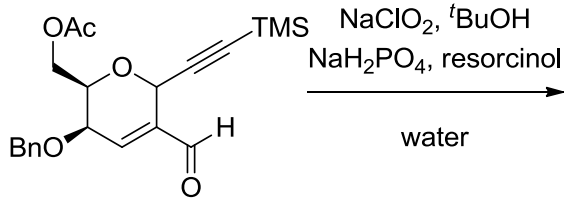

114

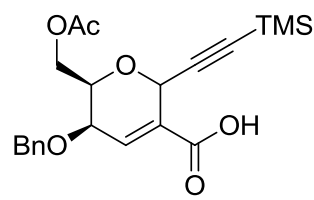

120

Scheme 3.26: Pinnick oxidation of 114.

\subsubsection{Desilylation of 120}

Desilylation of $\mathbf{1 2 0}$ was attempted using tetra- $n$-butylammonium fluoride. Alternative methodologies using potassium carbonate in methanol were not suitable as the acetyl group at the C-6 position is labile under these conditions. Crude acid $\mathbf{1 2 0}$ was treated with tetra- $n$ butylammonium fluoride at $0{ }^{\circ} \mathrm{C}$ (Scheme 3.27). After $35 \mathrm{~min}$, the starting material had been consumed, so the reaction mixture was filtered through a plug of silica-gel, eluting with a mixture of methanol in ethyl acetate. An aqueous work-up was avoided as all spots on the TLC plate were significantly lower than that of $\mathbf{1 2 0}$ and there was concern of losing $\mathbf{1 2 1}$ in an aqueous wash. Considering that tetra- $n$-butylammonium fluoride is slightly basic, it was hoped that 121 would become protonated on the silica plug or when methanol was added to the eluent. After an attempt at purification using silica gel chromatography it was apparent that this was not the case. The species suspected of being 121 eluted only when methanol was added to an ethyl acetate flush and tetra- $n$-butylammonium as observed in the ${ }^{1} \mathrm{H}$ NMR spectrum. In subsequent purification, acetic acid was added to the solvent and alkynoic acid $\mathbf{1 2 1}$ eluted 
cleanly in $67 \%$ yield (over two steps). The primary acetyl group was still in place, not being cleaved under these basic conditions.

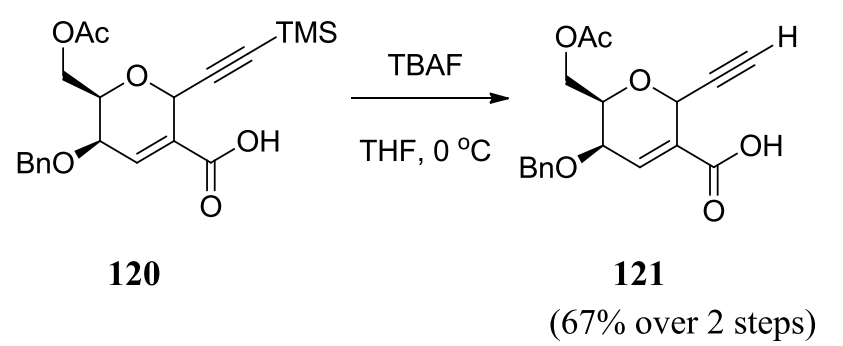

Scheme 3.27: Desilylation of $\mathbf{1 2 0 .}$

Due to time constraints, the ring closure was not able to be investigated. 


\section{CONCLUSIONS}

2-Haloglycals 57a and 57b were synthesised with yields of $32 \%$ and $<37 \%$ respectively following optimisation studies. 2-Bromoglycal 57a could potentially be an intermediate in the synthesis of (-)-TAN2583B if its synthesis can be optimised further. Considering the instability of $\mathbf{5 7 b}$ toward acid or light, the 2-iodoglycal is less likely to be an intermediate for the synthesis of 1 .

Ferrier-type alkynylation of 57a and 57b was explored and the alkynes $\mathbf{1 1 2 a}$ and $\mathbf{1 1 2 b}$ obtained in $17 \%$ and $13 \%$ respectively. Optimisation of this reaction was unable to be performed due to the difficulty in synthesising the 2-haloglycals (57). Results of these reactions demonstrate that 2-substituted glycals are able to undergo Ferrier-type alkynylation at room temperature. Only one anomer of $\mathbf{1 1 2}$ was observed, but the configuration about the $\mathrm{C}-1$ position unable to be determined.

Optimisation studies were performed for the formylation of tri- $O$-acetyl-D-galactal (55). It was found that the per-acetylated galactal was an unsuitable material for Vilsmeier-Haack conditions. Nonetheless, Vilsmeier-Haack conditions were successfully applied to tri- $O$ benzyl-D-galactal, with yields up to $78 \%$ of 2-formylglycal 64 obtained.

The product (66) of the selective acetolysis of $\mathbf{6 4}$ was explored as a substrate for Ferrier-type alkynylation. It was found that the C-3 position of $\mathbf{6 6}$ was more reactive than $\mathrm{C}-1$ or the aldehyde toward nucleophilic attack under Lewis acidic conditions. Formation of alkyne 114 was achieved in $7 \%$ yield using Ferrier conditions, though the configuration about the alkynylated carbon was unable to be confirmed. Only one anomer of alkyne 114 was observed throughout the optimisation studies.

The alkyne and aldehyde functionalities on $\mathbf{1 1 4}$ were oxidised and deprotected to give alkynoic acid $\mathbf{1 2 1}$ in $67 \%$ from 114. Alkynoic acid $\mathbf{1 2 1}$ has the appropriate functionality for the copper(I) mediated enol lactone formation reported by $\mathrm{Li}^{\left[{ }^{[19]}\right.}$ The formation of the enol lactone $\mathbf{1 2 2}$ was unable to be explored due to time constraints. 
The use of tri- $O$-acetyl-D-galactal (55) as a starting point in the synthesis of (-)-TAN-2483B was explored, with the groundwork laid for further studies. Functionalisation of the C-1 and $\mathrm{C}-2$ positions was achieved in the form of an alkyne, and halogens/formyl groups respectively. 


\section{FUTURE WORK}

There is room for further exploration in almost all the sections of this thesis. Optimisation of the 2-haloglycal synthesis could be performed, specifically investigations into the formation of 57a (Section 2.2.1). Performing the reaction using 2 equivalents of $N$-bromosuccinimide from the beginning, as well as performing the reaction without addition of silver(I) nitrate and triethylamine (i.e., only $\mathbf{5 5}$ and $\mathrm{N}$-bromosuccinimide) would both be experiments that give mechanistic insight.

The configuration about the C-1 position of the 2,3-unsaturated alkynylglycosides has yet to be determined. Attempts at crystallisation of 112a, 112b, 114, or any of the derivatives of these compounds could be performed in order to get x-ray data. Derivatisation of these alkynes via hydrogenation would saturated the pyran ring giving substrates more suitable for NOESY experiments.

In terms of the alkynylation of $\mathbf{6 6}$ there is still much to be explored. Stronger Lewis acids with less nucleophilic anions such as aluminium triflate would be ideal candidates as Lewis acids for Ferrier-type alkynylation. The formation of $\mathbf{1 1 4}$ in toluene with tin(IV) chloride and silver(I) nitrate is a potential lead for the transformation. Perhaps $\mathbf{6 6}$ could be treated with more benign chlorinated Lewis acid in excess, followed by a silver(I) salt in a one-pot, two-step procedure in order to form 114.

Investigation of the C-4 group on 2-formylglycals could give useful mechanistic insight into the reaction. 2-Formylglycal $\mathbf{6 6}$ has a benzyl at the C-4 position, a group incapable of anchimeric assistance. Perhaps if there were an acetyl group at this position interaction with the positive charge left from the C-3 acetate leaving, stabilising this intermediate for further reaction with an acetylene nucleophile.

Oxidation of aldehyde $\mathbf{6 6}$ to the analogous acid or ester would give an interesting substrate for Ferrier-type alkynylation. There has been no reports found in the literature showing Ferrierrearrangements on 2-acid or 2-ester glycals. 
Alkynoic acid $\mathbf{1 2 1}$ is a substrate primed for ring closure. Attempts to form the enol lactone $\mathbf{1 2 2}$ using the copper-mediated methodology described in Section 2.3.3 could be performed. 


\section{EXPERIMENTAL}

\subsection{General Experimental}

Unless otherwise stated, the following conditions apply. All reactions were performed under a positive pressure of argon or nitrogen, delivered via manifold or balloon. Glassware was dried by heating with a heat-gun set to $630{ }^{\circ} \mathrm{C}$ under a vacuum. Dichloromethane, tetrahydrofuran, toluene, and diethyl ether were obtained from a PureSolve MD 5 purification system (Innovative Technology). Dry dimethylformamide was purchased from Acros and used without further purification. Boron trifluoride diethyl etherate was freshly distilled before use. Acetonitrile was distilled in the presence of calcium hydride. Triethylamine was distilled in the presence of potassium carbonate. 1,2-Dichloroethane was dried by passing over a column of anhydrous silica-gel. $\mathrm{N}$-bromosuccinimide was recrystallized from water. Analytical grade reagents were used for aqueous work-up and flash chromatography (petroleum ether, ethylacetate). Flash chromatography was performed on silica-gel $60 \AA$ (Pure Science, 40 - 63 micron) with the eluent mixtures stated in the corresponding procedures. Thin-layer chromatography was performed on silica-coated plastic plates (Macherey-Nagel, POLYGRAM® Sil G/UV254). UV-active compounds were detected under UV irradiation $(\lambda=254 \mathrm{~nm})$, while non$\mathrm{UV}$-active compounds were visualised with iodine on silica-gel, sulfuric acid (10\% in methanol), or ceric ammonium molybdate (Hanessian's stain). All other chemicals were purchased from Pure Science, Sigma-Aldrich, AK Scientific, Acros, Merck, British Drug House, Burkes Research, Thermo Fisher Scientific, Avocado, Panreac Riedel-de Haën and Apollo. Infra-red (IR) spectra were collected from liquid films on a Perkin Elmer Spectrum One FT-IR spectrometer or neat sample on an ALPHA FT-IR spectrometer (Bruker) fitted with attenuated total reflectance (ATR). Mass spectra were collected on an Agilent 6530 Accurate-Mass Q-TOF LC/MS high-resolution mass spectrometer (HRMS). The specific rotations were collected on an AUTOPOL II automatic polarimeter (Rudolph Research Analytical), and the reported values are an average of 10 measurements and concentrations are reported in $\mathrm{g} / 100 \mathrm{~mL}$.

Nuclear magnetic resonance (NMR) spectra were obtained in deuterated chloroform using Varian Inova instruments operating at 300,500 , or $600 \mathrm{MHz}$ for proton and 125 , or $150 \mathrm{MHz}$ for carbon. Proton and carbon chemical shifts are reported in parts per million (ppm) relative to residual $\mathrm{CHCl}_{3}$ $\left(\mathrm{CDCl}_{3}:{ }^{1} \mathrm{H}-7.26 \mathrm{ppm},{ }^{13} \mathrm{C}-77.16 \mathrm{ppm}\right.$. Signals are defined as: $\mathrm{s}=$ singlet, $\mathrm{d}=$ doublet, $\mathrm{t}=$ triplet, $\mathrm{q}=$ quartet, quin $=$ quintet, $\mathrm{m}=$ multiplet, app. $=$ apparent, $\mathrm{br}=$ broad. Coupling constants $(\mathrm{J})$ are 
reported in Hertz $(\mathrm{Hz})$. Assignments were determined by two-dimensional NMR experiments $(\mathrm{HH}$ COSY, HSQC and HMBC).

\subsection{Synthesis of Tri- $O$-acetyl-D-galactal (55)}

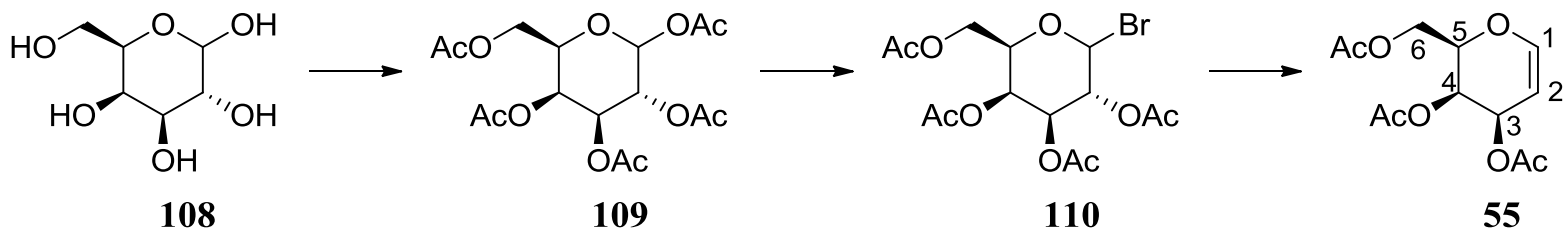

To powdered anhydrous sodium acetate $(10.5 \mathrm{~g}, 0.128 \mathrm{~mol})$ and D-galactose $(\mathbf{1 0 8})(20.2 \mathrm{~g}$, $0.112 \mathrm{~mol})$ was added acetic anhydride $(100 \mathrm{~mL})$. After stirring at $100{ }^{\circ} \mathrm{C}$ overnight, the reaction mixture was poured onto $\sim 400 \mathrm{~g}$ of ice and the precipitating oil crystallised over 30 min. The resulting solid was filtered, washed with cold water and dried under a reduced pressure to give the crude per-acetylated galactose 109. The solid was then dissolved in dichloromethane $(400 \mathrm{~mL})$, cooled in an ice-water bath, and hydrogen bromide $(33 \% \mathrm{w} / \mathrm{w}$ in acetic acid, $96 \mathrm{~mL}, 0.530 \mathrm{~mol}$ ) was added dropwise over $45 \mathrm{~min}$. After $30 \mathrm{~min}$, the reaction mixture was warmed to room temperature and stirred until satisfactory conversion of starting material as determined by TLC analysis $(1.5 \mathrm{~h})$. The organic phase was then washed sequentially with water $(2 \times 75 \mathrm{~mL})$, saturated aqueous sodium bicarbonate solution $(2 \times 75$ $\mathrm{mL})$, and brine $(1 \times 75 \mathrm{~mL})$, dried over anhydrous magnesium sulfate, and filtered through cotton wool. The volatiles were removed under reduced pressure to give the crude bromoglycoside $\mathbf{1 1 0}$ as an orange oil. The orange oil was then dissolved in acetic acid (500 $\mathrm{mL}$ ) and cooled to $0{ }^{\circ} \mathrm{C}$ using an ice-water bath. A saturated aqueous solution of copper sulfate ( $9 \mathrm{~mL}, 0.018 \mathrm{~mol})$ was added over $5 \mathrm{~min}$, followed by zinc powder $(50.1 \mathrm{~g}, 0.767 \mathrm{~mol})$ over 5 min, warmed to room temperature, and stirred overnight. The reaction mixture was filtered through sand and the solid washed with dichloromethane. The organic phase was washed with water $(2 \times 100 \mathrm{~mL})$, a saturated aqueous sodium bicarbonate solution $(2 \times 100 \mathrm{~mL})$, and brine $(1 \times 100 \mathrm{~mL})$, filtered through cotton wool and the volatiles removed under reduced pressure. The resulting pale yellow oil was purified via flash chromatography (silica gel, 2:1 petroleum ether:ethyl acetate) to give the pure per-acetylated galactal 55 as white crystals (13.8 g, 45\%). 


\section{3,4,6-Tri- $O$-acetyl-D-galactal (55)}

$\mathrm{R}_{f}=0.39$ (2:1 petroleum ether:ethyl acetate); m.p. 34.0-34.8 ${ }^{\circ} \mathrm{C}$ (lit. $\left.30{ }^{\circ} \mathrm{C}\right){ }^{[44]}$; ${ }^{1} \mathrm{H}$ NMR $(600$ $\left.\mathrm{MHz}, \mathrm{CDCl}_{3}\right): \delta_{\mathrm{H}} 6.47(\mathrm{dd}, J=6.3,1.7 \mathrm{~Hz}, 1 \mathrm{H}, \mathrm{H}-1), 5.59-5.53(\mathrm{~m}, 1 \mathrm{H}, \mathrm{H}-3), 5.43$ (dt, $J=$ 4.5, 1.6 Hz, 1H, H-4), 4.73 (ddd, $J=6.3,2.6,1.5 \mathrm{~Hz}, 1 \mathrm{H}, \mathrm{H}-2$ ), 4.32 (app. t, $J=6.3 \mathrm{~Hz}, 1 \mathrm{H}$, H-5), 4.27 (dd, $\left.J=11.6,7.4 \mathrm{~Hz}, 1 \mathrm{H}, \mathrm{H}-6_{\mathrm{A}}\right), 4.22$ (dd, $\left.J=11.6,5.2 \mathrm{~Hz}, 1 \mathrm{H}, \mathrm{H}-6_{\mathrm{B}}\right), 2.13$ (s, 3H, $\left.\mathrm{COCH}_{3}\right), 2.09\left(\mathrm{~s}, 3 \mathrm{H}, \mathrm{COCH}_{3}\right), 2.03\left(\mathrm{~s}, 3 \mathrm{H}, \mathrm{COCH}_{3}\right) ;{ }^{13} \mathrm{C} \mathrm{NMR}\left(150 \mathrm{MHz}, \mathrm{CDCl}_{3}\right): \delta_{\mathrm{C}} 170.7$ $\left(\mathrm{C}, \mathbf{C O C H}_{3}\right), 170.5\left(\mathrm{C}, \mathbf{C O C H}_{3}\right), 170.3\left(\mathrm{C}, \mathbf{C O C H}_{3}\right), 145.6(\mathrm{CH}, \mathrm{C}-1), 99.0(\mathrm{CH}, \mathrm{C}-2), 72.9$ (CH, C-5), 64.0 (CH, C-3), 63.9 (CH, C-4), $62.1\left(\mathrm{CH}_{2}, \mathrm{C}-6\right), 21.0\left(\mathrm{CH}_{3}, \mathrm{COCH}_{3}\right), 20.9\left(\mathrm{CH}_{3}\right.$, $\left.\mathrm{COCH}_{3}\right), 20.8\left(\mathrm{CH}_{3}, \mathrm{COCH}_{3}\right)$; HRMS: $m / z \mathrm{C}_{12} \mathrm{H}_{16} \mathrm{O}_{7} \mathrm{Na}^{+}[\mathrm{M}+\mathrm{Na}]^{+}$calcd 296.0822, found 296.0807 ( $\Delta=5.12 \mathrm{ppm})$. The spectral data matched those reported previously. ${ }^{[13]}$

\subsection{Synthesis and alkynylation of 2-haloglycals}

\subsubsection{Synthesis of 2-bromoglycal 57a}

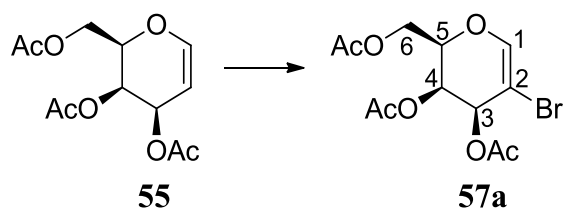

To a solution of per-acetylated galactal $55(52 \mathrm{mg}, 0.218 \mathrm{mmol})$ in refluxing acetonitrile (1 $\mathrm{mL}$ ) was added triethylamine $(0.005 \mathrm{~mL}), N$-bromosuccinimide $(37 \mathrm{mg}, 0.207 \mathrm{mmol})$, and silver(I) nitrate ( $8 \mathrm{mg}, 0.0471 \mathrm{mmol})$ in quick succession. After stirring at reflux for $4 \mathrm{~h}$, more $\mathrm{N}$-bromosuccinimide (36 mg, $0.202 \mathrm{mmol}$ ) was added. After stirring for a further $24 \mathrm{~h}$, the reaction mixture was filtered through a pad of Celite and the volatiles removed under reduced pressure. The crude mixture was purified via flash chromatography (deactivated silica gel, 2:1 petroleum ether:ethyl acetate) to give the pure 2-bromoglycal 57a as a white solid (21 mg, $32 \%)$.

(2R,3S,4S)-2-(Acetoxymethyl)-5-bromo-3,4-dihydro-2H-pyran-3,4-diyl diacetate (57a)

$\mathrm{R}_{f}=0.31$ (2:1 petroleum ether:ethyl acetate); $[a]_{\mathrm{D}}^{18}+43.5\left(\mathrm{c} 0.78, \mathrm{CHCl}_{3}\right) ;$ m.p., $74.2-76.0$ ${ }^{\circ} \mathrm{C} ;{ }^{1} \mathrm{H}$ NMR $\left(600 \mathrm{MHz}, \mathrm{CDCl}_{3}\right): \delta_{\mathrm{H}} 6.74(\mathrm{~d}, J=1.0 \mathrm{~Hz}, 1 \mathrm{H}, \mathrm{H}-1), 5.69$ (d, $J=4.8 \mathrm{~Hz}, 1 \mathrm{H}, \mathrm{H}-$ 3), 5.49 (dd, $J=4.7,2.3 \mathrm{~Hz}, 1 \mathrm{H}, \mathrm{H}-4), 4.40-4.36$ (m, 1H, H-5), 4.29 (dd, $J=11.8,7.7 \mathrm{~Hz}$, $\left.1 \mathrm{H}, \mathrm{H}-6_{\mathrm{A}}\right), 4.20$ (dd, $\left.J=11.8,5.0 \mathrm{~Hz}, 1 \mathrm{H}, \mathrm{H}-6_{\mathrm{B}}\right), 2.13\left(\mathrm{~s}, 3 \mathrm{H}, \mathrm{COCH}_{3}\right), 2.09$ (s, 3H, $\left.\mathrm{COCH}_{3}\right)$, $2.08\left(\mathrm{~s}, 3 \mathrm{H}, \mathrm{COCH}_{3}\right) ;{ }^{13} \mathrm{C} \mathrm{NMR}\left(150 \mathrm{MHz}, \mathrm{CDCl}_{3}\right): \delta_{\mathrm{C}} 170.6\left(\mathrm{C}, \mathrm{COCH}_{3}\right), 170.1\left(\mathrm{C}, \mathbf{C O C H}_{3}\right)$, 
$170.0\left(\mathrm{C}, \mathbf{C O C H}_{3}\right), 145.2(\mathrm{CH}, \mathrm{C}-1), 96.4(\mathrm{C}, \mathrm{C}-2), 73.4(\mathrm{CH}, \mathrm{C}-5), 65.9(\mathrm{CH}, \mathrm{C}-3), 64.8(\mathrm{CH}$, C-4), $61.5\left(\mathrm{CH}_{2}, \mathrm{C}-6\right), 20.9\left(\mathrm{CH}_{3}, \mathrm{COCH}_{3}\right), 20.7\left(\mathrm{CH}_{3}, \mathrm{COCH}_{3}\right), 20.7\left(\mathrm{CH}_{3}, \mathrm{COCH}_{3}\right)$; IR (Film from $\mathrm{CH}_{2} \mathrm{Cl}_{2}$ ): $v_{\max } 3100$ - 2900, 1748, 1644, 1600, 1580, 1369, 1229, 1185, 1123, 1048, 912, $825 \mathrm{~cm}^{-1}$; HRMS: $m / z \mathrm{C}_{12} \mathrm{H}_{16}{ }^{79} \mathrm{BrO}_{7}^{+}[\mathrm{M}+\mathrm{H}]^{+}$calcd 351.0074, found $351.0083(\Delta=-2.53$ ppm). The spectral data matched those reported previously. ${ }^{[20]}$

\subsubsection{Synthesis of 2-Iodoglycal $57 b^{[20]}$}

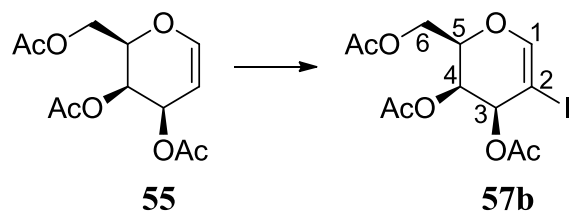

To a solution of per-acetylated galactal $55(55 \mathrm{mg}, 0.201 \mathrm{mmol})$ in refluxing acetonitrile (1 $\mathrm{mL}$ ) was added $N$-iodosuccinimide $(47 \mathrm{mg}, 0.249 \mathrm{mmol})$ and silver(I) nitrate $(7 \mathrm{mg}, 0.0435$ mmol) in quick succession. After satisfactory conversion as determined by TLC analysis ( $2 \mathrm{~h})$, the reaction mixture was filtered through a pad of Celite and the volatiles removed under reduced pressure. The crude mixture was purified via flash chromatography (deactivated silica gel, 2:1 petroleum ether:ethyl acetate) to give the 2-iodoglycal $\mathbf{5 7 b}$ as a white solid (29 $\mathrm{mg}$, $37 \%)$.

\section{(2R,3S,4S)-2-(Acetoxymethyl)-5-iodo-3,4-dihydro-2H-pyran-3,4-diyl diacetate (57b)}

$\mathrm{R}_{f}=0.28$ (2:1, petroleum ether: ethyl acetate); $[\alpha]_{\mathrm{D}}^{18}+47.6$ (c 2.1, $\left.\mathrm{CH}_{2} \mathrm{Cl}_{2}\right)$; m.p. $108.9-110.8$ ${ }^{\circ} \mathrm{C} ;{ }^{1} \mathrm{H}$ NMR $\left(600 \mathrm{MHz}, \mathrm{CDCl}_{3}\right): \delta_{\mathrm{H}} 6.79$ (s, $\left.1 \mathrm{H}, \mathrm{H}-1\right), 5.59$ (d, J=4.6 Hz, 1H, H-3), 5.50 (dd, $J=4.6,1.9 \mathrm{~Hz}, 1 \mathrm{H}, \mathrm{H}-4), 4.43$ (app. t, $J=6.3 \mathrm{~Hz}, 1 \mathrm{H}, \mathrm{H}-5$ ), 4.27 (dd, $J=11.8,7.4 \mathrm{~Hz}, 1 \mathrm{H}, \mathrm{H}-$ $\left.6_{\mathrm{A}}\right), 4.20\left(\mathrm{dd}, J=11.9,5.3 \mathrm{~Hz}, 1 \mathrm{H}, \mathrm{H}-6_{\mathrm{B}}\right), 2.13$ (s, 3H, $\left.\mathrm{COCH}_{3}\right), 2.10$ (s, 3H, $\left.\mathrm{COCH}_{3}\right), 2.09$ (s, $\left.3 \mathrm{H}, \mathrm{COCH}_{3}\right) ;{ }^{13} \mathrm{C} \mathrm{NMR}\left(150 \mathrm{MHz}, \mathrm{CDCl}_{3}\right): \delta_{\mathrm{C}} 170.6\left(\mathrm{C}, \mathbf{C O C H}_{3}\right), 170.1\left(\mathrm{C}, \mathbf{C O C H}_{3} \times 2\right)$, 149.4 (CH, C-1), 73.3 (CH, C-5), 67.1 (CH, C-3), 67.0 (C, C-2), $64.6(\mathrm{CH}, \mathrm{C}-4), 61.6\left(\mathrm{CH}_{2}\right.$, C-6), $20.9\left(\mathrm{CH}_{3}, \mathrm{COCH}_{3}\right), 20.8\left(\mathrm{CH}_{3}, \mathrm{COCH}_{3}\right), 20.8\left(\mathrm{CH}_{3}, \mathrm{COCH}_{3}\right)$; IR (Film from $\left.\mathrm{CH}_{2} \mathrm{Cl}_{2}\right)$ : $v_{\max } 3000-2900,1745,1626,1432,1368,1227,1176,1043,910 \mathrm{~cm}^{-1}$; HRMS: $\mathrm{m} / \mathrm{z}$ $\mathrm{C}_{12} \mathrm{H}_{15} \mathrm{IO}_{7} \mathrm{Na}^{+}[\mathrm{M}+\mathrm{Na}]^{+}$calcd 421.9789 , found $421.9794(\Delta=-1.17 \mathrm{ppm})$. The spectral data matched those reported previously. ${ }^{[20]}$ 


\subsubsection{Formation of 112a and 113a from 2-Bromoglycal 57a}

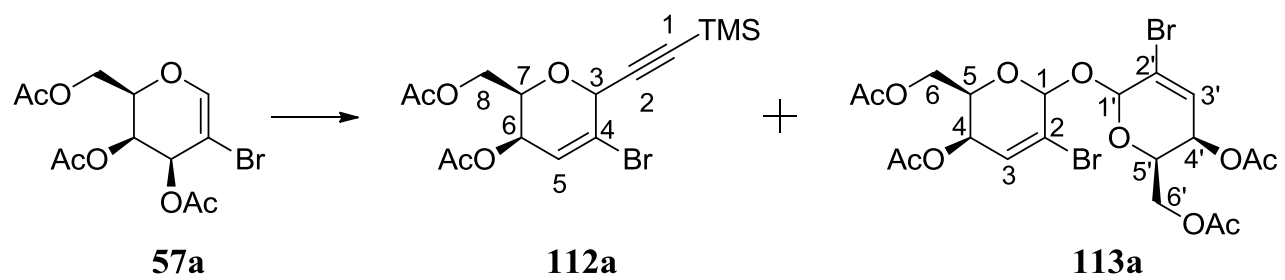

To a solution of bromoglycal $57 \mathbf{a}(13.7 \mathrm{mg}, 0.0390 \mathrm{mmol})$ and bis(trimethylsilyl)acetylene (8.3 $\mathrm{mg}, 0.0487 \mathrm{mmol})$ in dichloromethane was added boron trifluoride diethyletherate $(0.011 \mathrm{~mL}$, $0.0891 \mathrm{mmol})$. After satisfactory conversion as determined by TLC analysis $(2.5 \mathrm{~h})$, the reaction mixture was cooled to $0{ }^{\circ} \mathrm{C}$ and treated with a saturated aqueous solution of sodium bicarbonate $(5 \mathrm{~mL})$. The mixture was extracted with dichloromethane $(3 \times 2 \mathrm{~mL})$. The organic phase was washed with a saturated aqueous solution of sodium bicarbonate $(1 \times 2 \mathrm{~mL})$ and brine $(1 \times 2 \mathrm{~mL})$, dried over anhydrous magnesium sulfate, and filter through cotton wool. The volatiles were removed under reduced pressure and the crude black tar was purified via flash chromatography (silica gel, 3:1 petroleum ether:ethyl acetate) to give the pure alkyne 112a as a white residue $(2.6 \mathrm{mg}, 17 \%)$, and dimer 113a as a white residue $(3.1 \mathrm{mg}, 12 \%)$

\section{((2R,3R)-3-Acetoxy-5-bromo-6-((trimethylsilyl)ethynyl)-3,6-dihydro-2H-pyran-2- yl)methyl acetate (112a)}

$\mathrm{R}_{f}=0.30$ (5:1, petroleum ether: ethyl acetate); $[\alpha]_{\mathrm{D}}^{21}-2600.0 *\left(\mathrm{c} 0.03, \mathrm{CH}_{2} \mathrm{Cl}_{2}\right) ;{ }^{1} \mathrm{H}$ NMR (500 $\left.\mathrm{MHz}, \mathrm{CDCl}_{3}\right): \delta_{\mathrm{H}} 6.33(\mathrm{dd}, J=5.8,1.4 \mathrm{~Hz}, 1 \mathrm{H}, \mathrm{H}-5), 5.10(\mathrm{dd}, J=5.8,2.4 \mathrm{~Hz}, 1 \mathrm{H}, \mathrm{H}-6), 5.00$ $(\mathrm{d}, J=1.3 \mathrm{~Hz}, 1 \mathrm{H}, \mathrm{H}-3), 4.39$ (ddd, $J=7.3,4.8,2.5 \mathrm{~Hz}, 1 \mathrm{H}, \mathrm{H}-7), 4.28$ (dd, $J=11.6,4.8 \mathrm{~Hz}$, $\left.1 \mathrm{H}, \mathrm{H}-8_{\mathrm{A}}\right), 4.16$ (dd, $\left.J=11.6,7.5 \mathrm{~Hz}, 1 \mathrm{H}, \mathrm{H}-8 \mathrm{~B}\right), 2.09$ (s, 3H, $\left.\mathrm{COCH}_{3}\right), 2.09$ (s, 3H, $\left.\mathrm{COCH}_{3}\right)$, 0.20 (s, 9H, $\left.\mathrm{Si}\left(\mathrm{CH}_{3}\right)_{3}\right)$; IR (Film from $\mathrm{CH}_{2} \mathrm{Cl}_{2}$ ): $v_{\max } 2958,2925,2854,1744,1681,1634,1371$, 1228, 1110, 1078, 1052, $846 \mathrm{~cm}^{-1}$.

*This is an unusually large value. The measurement is likely to be inaccurate due to the low concentration of sample.

(2R,2'R,3R,3'R)-6,6'-Oxybis(2-(acetoxymethyl)-5-bromo-3,6-dihydro-2H-pyran-6,3diyl) diacetate (113a)

$\mathrm{R}_{f}=0.20$ (2:1, petroleum ether: ethyl acetate); ${ }^{1} \mathrm{H}$ NMR (500 MHz, $\left.\mathrm{CDCl}_{3}\right): \delta_{\mathrm{H}} 6.51(\mathrm{~d}, J=5.9$ Hz, 2H, H-3, H-3'), 5.44 (s, 2H, H-1, H-1'), 5.09 (dd, J = 5.9, 2.6 Hz, 2H, H-4, H-4'), 4.59 4.51 (m, 2H, H-5, H-5'), 4.27 - 4.22 (complex m., 4H, H-6 ${ }_{\mathrm{A}}, \mathrm{H}-6_{\mathrm{A}}$ ', H-6,, H-6 ' ') 2.10 (s, 6H, $\left.2 \times \mathrm{COCH}_{3}\right), 2.07\left(\mathrm{~s}, 6 \mathrm{H}, 2 \times \mathrm{COCH}_{3}\right) ;{ }^{13} \mathrm{C} \mathrm{NMR}\left(126 \mathrm{MHz}, \mathrm{CDCl}_{3}\right) \delta_{\mathrm{C}} 170.7\left(\mathrm{C}, 2 \times \mathrm{COCH}_{3}\right)$, 
$170.2\left(\mathrm{C}, 2 \times \mathrm{COCH}_{3}\right), 127.5(\mathrm{CH}, \mathrm{C}-3, \mathrm{C}-3$ ') 125.9 (C, C-2, C-2'), 93.1 (CH, C-1, C-1'), 67.2 (CH, C-5, C-5'), 65.0 (CH, C-4, C-4'), $62.3\left(\mathrm{CH}_{2}, \mathrm{C}-6, \mathrm{C}-6\right.$ ') $, 21.0\left(\mathrm{CH}_{3}, 2 \times \mathrm{COCH}_{3}\right), 20.9$ $\left(\mathrm{CH}_{3}, 2 \times \mathrm{COCH}_{3}\right.$ ); IR (Film from $\mathrm{CH}_{2} \mathrm{Cl}_{2}$ ): $v_{\max } 2950,2945,1742,1652,1369,1235,1109$, 1056, 994, $920 \mathrm{~cm}^{-1}$; HRMS: $m / z \mathrm{C}_{20} \mathrm{H}_{24} \mathrm{Br}_{2} \mathrm{O}_{11} \mathrm{Na}^{+}[\mathrm{M}+\mathrm{Na}]^{+}$calcd 622.9559 , found 622.9560 $(\Delta=-0.19 \mathrm{ppm})$.

\subsubsection{Formation of 112b and 113b from 2-Iodoglycal 57b}

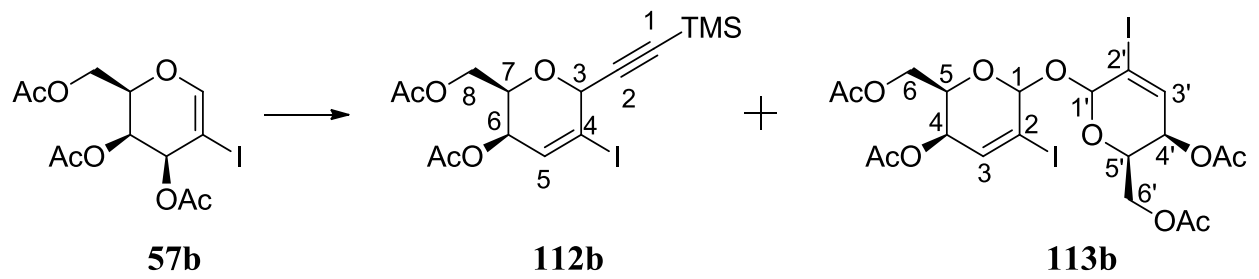

To a solution of 2-iodoglycal 57b $(20.4 \mathrm{mg}, 0.0512 \mathrm{mmol})$ and bis(trimethylsilyl)acetylene $(9.9 \mathrm{mg}, 0.0581 \mathrm{mmol})$ in dichloromethane was added boron trifluoride diethyl etherate $(0.013$ $\mathrm{mL}, 0.105 \mathrm{mmol})$. After satisfactory conversion as determined by TLC analysis $(7 \mathrm{~h})$, the reaction mixture was cooled to $0{ }^{\circ} \mathrm{C}$ and treated with a saturated aqueous solution of sodium bicarbonate $(5 \mathrm{~mL})$. The mixture was extracted with dichloromethane $(3 \times 2 \mathrm{~mL})$. The organic phase was washed with a saturated aqueous solution of sodium bicarbonate $(1 \times 2 \mathrm{~mL})$ and brine $(1 \times 2 \mathrm{~mL})$, dried over anhydrous magnesium sulfate, and filtered through cotton wool. The volatiles were removed under reduced pressure and the crude black tar was purified via flash chromatography (silica gel, 3:1 petroleum ether:ethyl acetate) to give the pure alkyne 112b as a white residue $(2.8 \mathrm{mg}, 13 \%)$ and dimer $\mathbf{1 1 3 b}$ as a white residue $(6.5 \mathrm{mg}, 16 \%)$.

\section{((2R,3R)-3-Acetoxy-5-iodo-6-((trimethylsilyl)ethynyl)-3,6-dihydro-2H-pyran-2-}

\section{yl)methyl acetate (112b)}

$\mathrm{R}_{f}=0.56\left(2: 1\right.$, petroleum ether:ethyl acetate); ${ }^{1} \mathrm{H}$ NMR: $\left(500 \mathrm{MHz}, \mathrm{CDCl}_{3}\right): \delta_{\mathrm{H}} 6.59(\mathrm{~d}, J=5.7$ Hz, 1H, H-5), $5.04-5.00$ (complex m, 2H, H-6, H-3), 4.43 - 4.37 (m, 1H, H-7), 4.26 (dd, $J=$ 11.8, $\left.5.0 \mathrm{~Hz}, 1 \mathrm{H}, \mathrm{H}-8_{\mathrm{A}}\right), 4.14$ (dd, $J=11.6,7.5 \mathrm{~Hz}, 1 \mathrm{H}, \mathrm{H}-8_{\mathrm{B}}$ ), 2.09 (s, 3H, $\mathrm{COCH}_{3}$ ), 2.08 (s, $\left.3 \mathrm{H}, \mathrm{COCH}_{3}\right), 0.20\left(\mathrm{~s}, 9 \mathrm{H}, \mathrm{Si}\left(\mathrm{CH}_{3}\right)_{3}\right) ;{ }^{13} \mathrm{C} \mathrm{NMR}\left(126 \mathrm{MHz}, \mathrm{CDCl}_{3}\right): \delta_{\mathrm{C}} 170.8\left(\mathrm{C}, \mathrm{COCH}_{3}\right)$, $170.3\left(\mathrm{C}, \mathbf{C O C H}_{3}\right), 132.5$ (CH, C-5), 103.3 (C, C-4), 98.5 (C, C-2), 93.7 (C, C-1), 72.9 (CH, C-3), $69.0(\mathrm{CH}, \mathrm{C}-7), 66.0(\mathrm{CH}, \mathrm{C}-6), 62.7\left(\mathrm{CH}_{2}, \mathrm{C}-8\right), 20.9\left(\mathrm{C}, \mathrm{COCH}_{3}\right), 20.9\left(\mathrm{C}, \mathrm{COCH}_{3}\right),-$ $0.2\left(\mathrm{CH}_{3}, \mathrm{Si}\left(\mathrm{CH}_{3}\right)_{3}\right)$; IR (Film from $\left.\mathrm{CH}_{2} \mathrm{Cl}_{2}\right): v_{\max } 2958,2924,2854,1745,1371,1227,1057$, 
1053, 1026, 845, $761 \mathrm{~cm}^{-1}$; HRMS: $m / z \mathrm{C}_{15} \mathrm{H}_{21} \mathrm{IO}_{5} \mathrm{SiNa}^{+}[\mathrm{M}+\mathrm{Na}]^{+}$calcd 460.0120, found $460.0117(\Delta=0.73 \mathrm{ppm})$.

(2R,2'R,3R,3' R)-6,6'-Oxybis(2-(acetoxymethyl)-5-iodo-3,6-dihydro-2H-pyran-6,3-diyl) diacetate (113b)

$\mathrm{R}_{f}=0.17$ (2:1, petroleum ether:ethyl acetate); ${ }^{1} \mathrm{H}$ NMR $\left(500 \mathrm{MHz}, \mathrm{CDCl}_{3}\right): \delta_{\mathrm{H}} 6.78(\mathrm{~d}, J=5.7$ Hz, 2H, H-3, H-3'), 5.47 (s, 2H, H-1, H-1'), 5.01 (dd, J = 5.8, 2.6 Hz, 2H, H-4, H-4'), 4.61 (td, $J=6.5,2.5 \mathrm{~Hz}, 2 \mathrm{H}, \mathrm{H}-5, \mathrm{H}-5$ ') 4.27 (dd, $\left.J=11.6,7.0 \mathrm{~Hz}, 2 \mathrm{H}, \mathrm{H}-6_{\mathrm{A}}, \mathrm{H}-6_{\mathrm{A}}{ }^{\prime}\right), 4.24$ (dd, $J=$ 11.6, $\left.5.8 \mathrm{~Hz}, 2 \mathrm{H}, \mathrm{H}-6_{\mathrm{B}}, \mathrm{H}-6_{\mathrm{B}}{ }^{\prime}\right), 2.10\left(\mathrm{~s}, 6 \mathrm{H}, 2 \times \mathrm{COCH}_{3}\right), 2.09\left(\mathrm{~s}, 6 \mathrm{H}, 2 \times \mathrm{COCH}_{3}\right) ;{ }^{13} \mathrm{C} \mathrm{NMR}$ (126 MHz, $\left.\mathrm{CDCl}_{3}\right): \delta_{\mathrm{C}} 170.7\left(\mathrm{C}, \mathbf{C O C H}_{3}\right), 170.2\left(\mathrm{C}, \mathbf{C O C H}_{3}\right), 135.3(\mathrm{C}, \mathrm{C}-2, \mathrm{C}-2$ '), 101.2 (CH, C-3, C-3'), 95.0 (CH, C-1, C-1'), 66.7 (CH, C-5, C-5'), 65.3 (CH, C-4, C-4'), 62.3 ( $\mathrm{CH}_{2}$, C-6, C-6'), $21.1\left(\mathrm{CH}_{3}, 2 \times \mathrm{COCH}_{3}\right), 20.9\left(\mathrm{CH}_{3}, 2 \times \mathrm{COCH}_{3}\right)$; IR (Film from $\left.\mathrm{CH}_{2} \mathrm{Cl}_{2}\right)$ : v $\max$ 2961, 2926, 2854, 1738, 1635, 1371, 1233, 1106, 1050, 1022, 988, 918, $888 \mathrm{~cm}^{-1}$; HRMS: $\mathrm{m} / z$ $\mathrm{C}_{20} \mathrm{H}_{24} \mathrm{I}_{2} \mathrm{O}_{11} \mathrm{Na}^{+}[\mathrm{M}+\mathrm{Na}]^{+}$calcd 717.9334 , found $717.9329(\Delta=0.77 \mathrm{ppm})$.

\subsection{Synthesis of the Differentially Protected 2-Formylglycal 66}

\subsubsection{Synthesis of Tri- $O$-benzyl-D-galactal 56}<smiles></smiles>

55<smiles>OC[C@H]1OC=C[C@@H](O)[C@@H]1O</smiles>

65

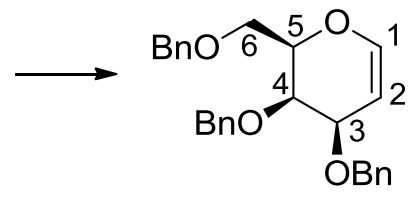

56

To a solution of per-acetylated galactal $55(350.7 \mathrm{mg}, 1.29 \mathrm{mmol})$ in an aqueous methanol solution (1:1, water:methanol, $3.5 \mathrm{~mL})$ was added triethylamine $(0.175 \mathrm{~mL}, 1.26 \mathrm{mmol})$. The reaction mixture was warmed to $50{ }^{\circ} \mathrm{C}$ and left to stir until satisfactory conversion was determined via TLC analysis $(1 \mathrm{~h})$. The volatiles were then removed under reduced pressure, and the crude residue dissolved in water $(2 \mathrm{~mL})$ and treated with anhydrous sodium carbonate (69.7 mg, $0.66 \mathrm{mmol})$. The solvent was removed under reduced pressure and the brown powder washed with methanol. The methanol washings were collected and the volatiles removed to give the crude unprotected galactal $\mathbf{6 5}$ as a brown tar (202.9 mg). The crude triol was used directly in the next step. 
To a solution of sodium hydride $(60 \% \mathrm{w} / \mathrm{w}$ on mineral oil, $511.3 \mathrm{mg}, 12 \mathrm{mmol})$ in dimethylformamide (2 $\mathrm{mL})$ was added crude D-galactal $65(202.9 \mathrm{mg})$ in dimethylformamide $(5 \mathrm{~mL})$ dropwise over $10 \mathrm{~min}$. Following triol addition, the reaction mixture was warmed to room temperature. After $20 \mathrm{~min}$, the reaction mixture was again cooled to $0{ }^{\circ} \mathrm{C}$ using an icewater bath, and benzyl bromide $(0.55 \mathrm{~mL}, 4.63 \mathrm{mmol})$ was added dropwise over $20 \mathrm{~min}$. The reaction mixture was stirred at room temperature overnight, after which it was cooled to $0{ }^{\circ} \mathrm{C}$ and ice-water $(30 \mathrm{~mL})$ was added dropwise over $30 \mathrm{~min}$. The aqueous phase was extracted with ethyl acetate $(5 \times 10 \mathrm{~mL})$ and the organic washings washed with water $(5 \times 10 \mathrm{~mL})$ and brine $(1 \times 10 \mathrm{~mL})$, dried over anhydrous magnesium sulfate, filtered through cotton wool and the solvent removed under reduced pressure. The crude orange oil was purified via flash chromatography (silica gel, 9:1 petroleum ether:ethyl acetate) to give the per-benzylated species 56 (390.3 mg, 73\% over 2 steps) as white crystals.

\section{Tri- $O$-benzyl-D-galactal (56)}

$\mathrm{R}_{f}=0.13$ (9:1, petroleum ether: ethyl acetate); ${ }^{1} \mathrm{H} \mathrm{NMR}\left(500 \mathrm{MHz}, \mathrm{CDCl}_{3}\right) \delta_{\mathrm{H}} 7.38-7.26$ (complex m, 15H), 6.39 (d, $J=6.3 \mathrm{~Hz}, 1 \mathrm{H}, \mathrm{H}-1), 4.90\left(\mathrm{~d}, J=12.0 \mathrm{~Hz}, 1 \mathrm{H}, \mathrm{CH}_{2} \mathrm{Ph}\right), 4.88-$ $4.86(\mathrm{~m}, 1 \mathrm{H}, \mathrm{H}-2), 4.68$ (d, $\left.J=12.1 \mathrm{~Hz}, 1 \mathrm{H}, \mathrm{CH}_{2} \mathrm{Ph}\right), 4.66$ (d, J = 12.3 Hz, 1H, $\left.\mathrm{CH}_{2} \mathrm{Ph}\right), 4.63$ $\left(\mathrm{d}, J=12.1 \mathrm{~Hz}, 1 \mathrm{H}, \mathrm{CH}_{2} \mathrm{Ph}\right), 4.52$ (d, $\left.J=11.9 \mathrm{~Hz}, 1 \mathrm{H}, \mathrm{CH}_{2} \mathrm{Ph}\right), 4.44(\mathrm{~d}, J=11.9 \mathrm{~Hz}, 1 \mathrm{H}$, $\mathrm{CH}_{2} \mathrm{Ph}$ ), 4.21 (complex m, 2H, H-3, H-4), 3.97 (m, 1H, H-5), 3.80 (dd, $J=10.0,7.4 \mathrm{~Hz}, 1 \mathrm{H}$, H-6 $\left.6_{\mathrm{A}}\right), 3.67$ (dd, $\left.J=10.1,5.1 \mathrm{~Hz}, 1 \mathrm{H}, \mathrm{H}-6_{\mathrm{B}}\right) ;{ }^{13} \mathrm{C} \mathrm{NMR}\left(151 \mathrm{MHz}, \mathrm{CDCl}_{3}\right): \delta_{\mathrm{C}} 144.3(\mathrm{CH}, \mathrm{C}-$ 1), 138.6 (C, Bn), 138.46 (C, Bn), 138.45 (C, Bn), 128.52 (CH, Bn), 128.46 (CH, Bn), 128.3 (CH, Bn), 128.1 (CH, Bn), 127.8 (CH, Bn), 127.7 (CH, Bn), 127.6 (CH, Bn), 100.1 (CH, C-2), $75.8(\mathrm{CH}, \mathrm{C}-5), 73.6\left(\mathrm{CH}_{2}, \mathrm{PhCH}_{2}\right), 73.5\left(\mathrm{CH}_{2}, \mathrm{PhCH}_{2}\right), 71.3(\mathrm{CH}, \mathrm{C}-4), 71.0\left(\mathrm{CH}_{2}, \mathrm{CH}_{2} \mathrm{Ph}\right.$ and $\mathrm{CH}, \mathrm{C}-3), 68.6\left(\mathrm{CH}_{2}, \mathrm{C}-6\right)$. The spectral data matched those reported previously. ${ }^{[13]}$

\subsubsection{Synthesis of 2-Formylglycal $64^{[13]}$}

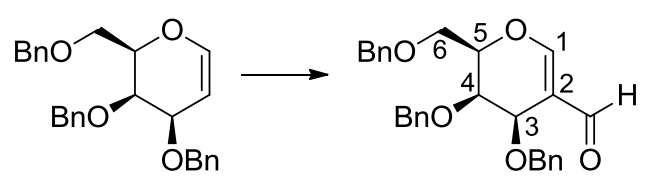

56

64

Phosphoryl chloride $(0.27 \mathrm{~mL}, 2.89 \mathrm{mmol})$ was added to dimethylformamide $(1 \mathrm{~mL})$ at $0{ }^{\circ} \mathrm{C}$ over $5 \mathrm{~min}$. The solution was warmed to room temperature over $40 \mathrm{~min}$. The solution was again cooled to $0{ }^{\circ} \mathrm{C}$ using an ice-water bath and the per-benzylated galactal $\mathbf{5 6}$ in 
dimethylformamide (390.3 $\mathrm{mg}, 0.94 \mathrm{mmol}$ in $1 \mathrm{~mL}$ ) was added over $15 \mathrm{~min}$. The reaction was then warmed to room temperature and left to stir overnight. A pre-cooled saturated aqueous solution of sodium bicarbonate $(10 \mathrm{~mL})$ was added over $15 \mathrm{~min}$ at $0{ }^{\circ} \mathrm{C}$ and the mixture left to stirred for a further $15 \mathrm{~min}$. Water $(10 \mathrm{~mL})$ was added, and the aqueous phase was washed with ethyl acetate $(5 \times 8 \mathrm{~mL})$, and the organic phase washed with a saturated aqueous solution of sodium bicarbonate $(1 \times 10 \mathrm{~mL})$, water $(5 \times 10 \mathrm{~mL})$ and brine $(1 \times 10 \mathrm{~mL})$, dried over anhydrous magnesium sulfate, filtered through cotton wool, and the solvent removed under reduced pressure. The crude oil was purified via flash chromatography (silica gel, 2:1 petroleum ether:ethyl acetate) to give the formylated glycal $64(324.1 \mathrm{mg}, 78 \%)$ as a colourless oil.

(2R,3R,4R)-3,4-Bis(benzyloxy)-2-((benzyloxy)methyl)-3,4-dihydro-2H-pyran-5carbaldehyde (64)

$\mathrm{R}_{f}=0.27$ (2:1, petroleum ether: ethyl acetate); ${ }^{1} \mathrm{H}$ NMR $\left(500 \mathrm{MHz}, \mathrm{CDCl}_{3}\right): \delta_{\mathrm{H}} 9.36(\mathrm{~s}, 1 \mathrm{H}$, CHO), 7.37 - 7.26 (complex m, 16H, Ph-H, H-1), 4.77 - 4.67 (complex m, 4H, $3 \times \mathrm{CH}_{2} \mathrm{Ph}, \mathrm{H}-$ 5), 4.61 (dd, $J=3.5,1.3 \mathrm{~Hz}, 1 \mathrm{H}, \mathrm{H}-3), 4.56$ (d, $\left.J=11.5 \mathrm{~Hz}, 1 \mathrm{H}, \mathrm{CH}_{2} \mathrm{Ph}\right), 4.54$ (d, $J=11.4 \mathrm{~Hz}$, $1 \mathrm{H}, \mathrm{CH}_{2} \mathrm{Ph}$ ). 4.50 (d, $J=11.9 \mathrm{~Hz}, 1 \mathrm{H}, \mathrm{CH}_{2} \mathrm{Ph}$ ), 3.99 (d, $J=5.4 \mathrm{~Hz}, 2 \mathrm{H}, \mathrm{H}-6$ ), 3.83 (dd, $J=5.4$, 3.6 Hz, 1H, H-4); ${ }^{13} \mathrm{C}$ NMR (126 MHz, $\left.\mathrm{CDCl}_{3}\right)$ : $\delta_{\mathrm{C}} 189.5(\mathrm{CH}, \mathrm{CHO}), 164.5(\mathrm{C}, \mathrm{C}-2), 138.8$ (C, Bn), 138.0 (C, Bn), 137.5 (C, Bn), 128.7 (CH, Bn), 128.6 (CH, Bn), 128.3 (CH, Bn), 128.2 (CH, Bn), 128.03 (CH, Bn), 127.9 (CH, Bn), $127.81(\mathrm{CH}, \mathrm{Bn}), 127.75(\mathrm{CH}, \mathrm{Bn}), 127.6(\mathrm{CH}$, $\mathrm{Bn}), 119.4(\mathrm{CH}, \mathrm{C}-1), 78.9(\mathrm{CH}, \mathrm{C}-5), 73.8\left(\mathrm{CH}_{2}, \mathrm{CH}_{2} \mathrm{Ph}\right), 73.6\left(\mathrm{CH}_{2}, \mathrm{CH}_{2} \mathrm{Ph}\right), 73.2(\mathrm{CH}, \mathrm{C}-$ 4), $71.6\left(\mathrm{CH}_{2}, \mathrm{CH}_{2} \mathrm{Ph}\right), 68.6\left(\mathrm{CH}_{2}, \mathrm{C}-6\right), 64.8(\mathrm{CH}, \mathrm{C}-3)$; HRMS: $m / z \mathrm{C}_{28} \mathrm{H}_{28} \mathrm{O}_{5} \mathrm{Na}^{+}[\mathrm{M}+\mathrm{Na}]^{+}$ calcd 468.1863, found $468.1876(\Delta=-2.90 \mathrm{ppm})$. The spectral data matched those reported previously. ${ }^{[13]}$

\subsubsection{Synthesis of 2-Formylglycal $66^{[24]}$}

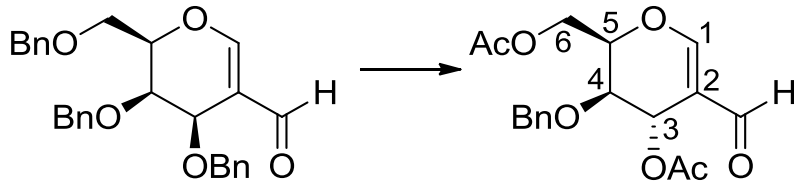

64

66

To a solution of acetic acid, and acetic anhydride $(1: 2,3.75 \mathrm{~mL})$ was added zinc(II) chloride $(1.00 \mathrm{~g}, 7.34 \mathrm{mmol})$ and cooled to $0{ }^{\circ} \mathrm{C}$. A solution of the per-benzylated 2-formylglycal 64 
(628 $\mathrm{mg}, 1.41 \mathrm{mmol})$ in dichoromethane $(2.5 \mathrm{~mL})$ was quickly added, and the mixture warmed to room temperature. After stirring overnight, the reaction mixture was then cooled to $0{ }^{\circ} \mathrm{C}$ and quenched with a saturated aqueous solution of sodium bicarbonate ( $30 \mathrm{~mL}$ over $30 \mathrm{~min})$. The aqueous phase was extracted with dichloromethane $(3 \times 20 \mathrm{~mL})$, and the organic phase washed with a saturated aqueous solution of sodium bicarbonate $(1 \times 20 \mathrm{~mL})$, water $(1 \times 20 \mathrm{~mL})$ and brine $(1 \times 20 \mathrm{~mL})$, dried over anhydrous sodium sulfate, and filtered through cotton wool. The volatiles were removed under reduced pressure to give a crude yellow oil. The crude mixture was then purified via flash chromatography (silica gel, 1:1 petroleum ether:ethyl acetate) to give the differentially protected 2-formylglycal 66 as a colourless oil (521.2 mg, quant.).

\section{((2R,3R,4S)-4-Acetoxy-3-(benzyloxy)-5-formyl-3,4-dihydro-2H-pyran-2-yl)methyl} acetate (66)

$\mathrm{R}_{f}=0.15$ (2:1, petroleum ether: ethyl acetate); ${ }^{1} \mathrm{H} \mathrm{NMR}\left(600 \mathrm{MHz}, \mathrm{CDCl}_{3}\right): \delta_{\mathrm{H}} 9.39(\mathrm{~s}, 1 \mathrm{H}$, CHO), 7.54 (s, 1H, H-1), 7.36 - 7.28 (complex m, 5H, Ph-H), 5.78 (d, $J=2.3 \mathrm{~Hz}, 1 \mathrm{H}, \mathrm{H}-3$ ), $4.76\left(\mathrm{~d}, J=12.0 \mathrm{~Hz}, 1 \mathrm{H}, \mathrm{CH}_{2} \mathrm{Ph}\right), 4.56\left(\mathrm{~d}, J=12.0 \mathrm{~Hz}, 1 \mathrm{H}, \mathrm{CH}_{2} \mathrm{Ph}\right), 4.34(\mathrm{dd}, J=11.7,7.5$ Hz, 1H, H-6 ${ }_{\mathrm{A}}$ ), 4.20 (mult., 1H, H-5), 4.13 (dd, $J=11.7,4.7$ Hz, 1H, H-6B), 3.66 (t, $J=1.9 \mathrm{~Hz}$, $1 \mathrm{H}, \mathrm{H}-4), 2.06$ (s, 3H, $\left.\mathrm{COCH}_{3}\right), 1.99$ (s, 3H, $\left.\left.\mathrm{COCH}_{3}\right) ;{ }^{13} \mathrm{C} \mathrm{NMR} \mathrm{(150} \mathrm{MHz,} \mathrm{CDCl}_{3}\right): \delta_{\mathrm{C}} 189.1$ (C, $\mathrm{CHO}), 170.5\left(\mathrm{C}, \mathbf{C O C H}_{3}\right), 170.0\left(\mathrm{C}, \mathbf{C H O C H}_{3}\right), 165.6(\mathrm{CH}, \mathrm{C}-1), 136.7(\mathrm{C}, \mathrm{Bn}), 128.8$ (CH, Bn), 128.7 (CH, Bn), 128.5 (CH, Bn), 115.7 (C, C-2), $74.9(\mathrm{CH}, \mathrm{C}-5), 71.8\left(\mathrm{CH}_{2}, \mathrm{CH}_{2} \mathrm{Ph}\right)$, 69.4 (CH, C-4), $62.7\left(\mathrm{CH}_{2}, \mathrm{C}-6\right), 58.6(\mathrm{CH}, \mathrm{C}-3), 21.2\left(\mathrm{CH}_{3}, \mathrm{CHOCH}_{3}\right), 20.8\left(\mathrm{CH}_{3}, \mathrm{CHOCH}_{3}\right)$; HRMS: $m / z \mathrm{C}_{18} \mathrm{H}_{20} \mathrm{O}_{7} \mathrm{Na}^{+}[\mathrm{M}+\mathrm{Na}]^{+}$calcd 371.1101 , found 371.1100 ( $\left.\Delta=0.41 \mathrm{ppm}\right)$. The spectral data matched those reported previously. ${ }^{[24]}$

\subsection{Products obtained from Ferrier-type Alkynylation Experiments}

\subsubsection{Synthesis of Alkyne 114}

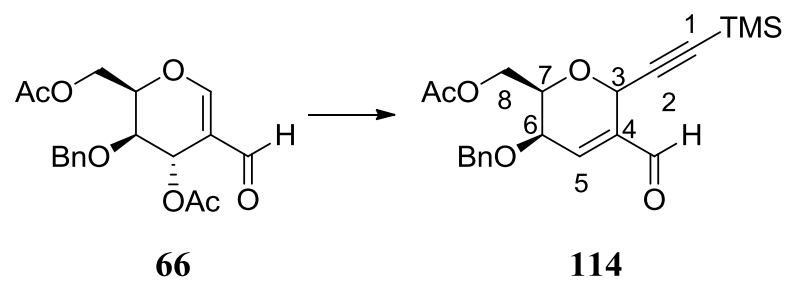

To a solution of 2-formylglycal $66(50 \mathrm{mg}, 0.144 \mathrm{mmol})$ and bis(trimethylsilyl)acetylene (0.04 $\mathrm{mL}, 0.297 \mathrm{mmol}$ ) in refluxing 1,2-dichloroethane was added boron trifluoride diethyl etherate 
(0.04 mL, $0.245 \mathrm{mmol})$. After satisfactory conversion as determined by TLC analysis (45 min), the reaction mixture was cooled to $0{ }^{\circ} \mathrm{C}$ and treated with a saturated aqueous solution of sodium bicarbonate $(5 \mathrm{~mL})$. The mixture was diluted with water $(10 \mathrm{~mL})$ and extracted with dichloromethane $(3 \times 8 \mathrm{~mL})$. The organic phase was washed with a saturated aqueous solution of sodium bicarbonate $(1 \times 8 \mathrm{~mL})$, water $(1 \times 8 \mathrm{~mL})$, and brine $(1 \times 8 \mathrm{~mL})$, and dried over anhydrous magnesium sulfate. The volatiles were removed under reduced pressure and the crude black tar was purified via flash chromatography (silica gel, 3:1 petroleum ether:ethyl acetate to give alkyne $\mathbf{1 1 4}$ as a yellow oil (4 mg, 7\%).

((2R,3R)-3-(Benzyloxy)-5-formyl-6-((trimethylsilyl)ethynyl)-3,6-dihydro-2H-pyran-2yl)methyl acetate (114)

$\mathrm{R}_{f}=0.58\left(2: 1\right.$, petroleum ether: ethyl acetate); $[\alpha]_{\mathrm{D}}^{22}-182.1$ (c $\left.0.56, \mathrm{CHCl}_{3}\right) ;{ }^{1} \mathrm{H}$ NMR: $(600$ $\mathrm{MHz}, \mathrm{CDCl}_{3}$ ): $\delta_{\mathrm{H}} 9.47$ (s, 1H, CHO), $7.40-7.31$ (complex m, 5H, Ph-H), 6.78 (dd, J=4.8, $1.2 \mathrm{~Hz}, 1 \mathrm{H}, \mathrm{H}-5), 5.32$ (s, 1H, H-3), 4.70 (d, $\left.J=11.8 \mathrm{~Hz}, 1 \mathrm{H}, \mathrm{CH}_{2} \mathrm{Ph}\right), 4.63$ (d, $J=11.8 \mathrm{~Hz}$, $1 \mathrm{H}, \mathrm{CH}_{2} \mathrm{Ph}$ ), 4.46 (dd, $J=11.1,5.3 \mathrm{~Hz}, 1 \mathrm{H}, \mathrm{H}-8_{\mathrm{A}}$ ), 4.33 (mult., $1 \mathrm{H}, \mathrm{H}-7$ ), 4.28 (dd, $J=11.4$, $7.7 \mathrm{~Hz}, 1 \mathrm{H}, \mathrm{H}-8_{\mathrm{B}}$ ), 4.04 (dd, $J=4.8,2.8 \mathrm{~Hz}, 1 \mathrm{H}, \mathrm{H}-6$ ), 2.09 (s, 3H, $\mathrm{COCH}_{3}$ ), 0.13 (s, 9H, $\left.\mathrm{Si}\left(\mathrm{CH}_{3}\right)_{3}\right) ;{ }^{13} \mathrm{C} \mathrm{NMR}\left(150 \mathrm{MHz}, \mathrm{CDCl}_{3}\right): \delta_{\mathrm{C}} 190.4(\mathrm{CH}, \mathrm{CHO}), 171.0\left(\mathrm{C}, \mathbf{C O C H}_{3}\right), 142.1(\mathrm{C}$, C-4), 141.3 (CH, C-5), 137.4 (C, Bn), 128.8 (CH, Bn), 128.5 (CH, Bn), 128.3 (CH, Bn), 99.7 (C, C-2), 92.2 (C, C-1), $72.3\left(\mathrm{CH}_{2}, \mathrm{CH}_{2} \mathrm{Ph}\right), 71.6(\mathrm{CH}, \mathrm{C}-7), 67.7(\mathrm{CH}, \mathrm{C}-6), 63.5\left(\mathrm{CH}_{2}, \mathrm{C}-8\right)$, $62.7(\mathrm{CH}, \mathrm{C}-3), 21.0\left(\mathrm{CH}_{3}, \mathrm{COCH}_{3}\right),-0.2\left(\mathrm{CH}_{3}, \mathrm{Si}\left(\mathrm{CH}_{3}\right)_{3}\right)$; HRMS: m/z $\mathrm{C}_{21} \mathrm{H}_{26} \mathrm{O}_{5} \mathrm{SiNa}^{+}$ $[\mathrm{M}+\mathrm{Na}]^{+}$calcd 411.1460, found $411.1459(\Delta=0.09 \mathrm{ppm})$.

\subsubsection{Formation of 3-Chloro-2-Formylglycal 115}

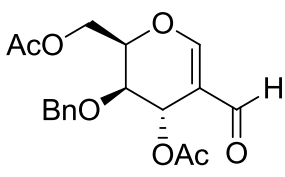

66

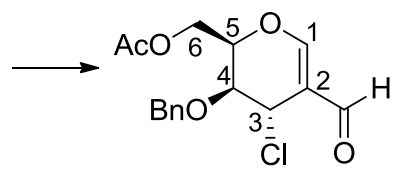

115

To a solution of 2-formylglycal $66(53 \mathrm{mg}, 0.153 \mathrm{mmol})$ and bis(trimethylsilyl)acetylene (0.04 $\mathrm{mL}, 0.297 \mathrm{mmol})$ in dichloromethane $(1 \mathrm{~mL})$ at room temperature was added the tin(IV) chloride $(0.22 \mathrm{~mL}, 1 \mathrm{M}$ in dichloromethane, $0.220 \mathrm{mmol})$. After overnight stirring, the reaction mixture was cooled to $0{ }^{\circ} \mathrm{C}$ and treated with a saturated aqueous solution of sodium bicarbonate $(5 \mathrm{~mL})$. The mixture was diluted with water $(10 \mathrm{~mL})$ and extracted with dichloromethane $(3 \times$ $8 \mathrm{~mL}$ ). The organic phase was washed with a saturated aqueous solution of sodium bicarbonate 
$(1 \times 8 \mathrm{~mL})$, water $(1 \times 8 \mathrm{~mL})$, and brine $(1 \times 8 \mathrm{~mL})$, and dried over anhydrous magnesium sulfate. The volatiles were removed under reduced pressure and the crude black tar was purified via flash chromatography (silica gel, 3:1 petroleum ether:ethyl acetate to give $\mathbf{1 1 5}$ as a white residue ( $3 \mathrm{mg}, 6 \%)$.

((2R,3S,4S)-3-(Benzyloxy)-4-chloro-5-formyl-3,4-dihydro-2H-pyran-2-yl)methyl acetate (115)

$\mathrm{R}_{f}=0.32\left(2: 1\right.$, petroleum ether:ethyl acetate); $[\alpha]_{\mathrm{D}}^{20}+10.1\left(\mathrm{c} 0.50, \mathrm{CH}_{2} \mathrm{Cl}_{2}\right) ;{ }^{1} \mathrm{H}$ NMR (500 $\mathrm{MHz}, \mathrm{CDCl}_{3}$ ): $\delta_{\mathrm{H}} 9.37$ (s, 1H, CHO), 7.45 (s, 1H, H-1), $7.40-7.27$ (m, 5H, Ph-H), 4.91 (d, J $=2.3 \mathrm{~Hz}, 1 \mathrm{H}, \mathrm{H}-3), 4.69\left(\mathrm{~d}, J=11.8 \mathrm{~Hz}, 1 \mathrm{H}, \mathrm{CH}_{2} \mathrm{Ph}\right), 4.65$ (t, $\left.J=6.2 \mathrm{~Hz}, 1 \mathrm{H}, \mathrm{H}-5\right), 4.48(\mathrm{~d}, J$ $\left.=11.8 \mathrm{~Hz}, 1 \mathrm{H}, \mathrm{CH}_{2} \mathrm{Ph}\right), 4.42\left(\mathrm{dd}, J=11.7,7.3 \mathrm{~Hz}, 1 \mathrm{H}, \mathrm{H}-6_{\mathrm{A}}\right), 4.25(\mathrm{dd}, J=11.7,5.2 \mathrm{~Hz}, 1 \mathrm{H}$, H-6B), 3.89 (s, 1H, H-4), 2.05 (s, 3H, $\left.\left.\mathrm{COCH}_{3}\right) ;{ }^{13} \mathrm{C} \mathrm{NMR} \mathrm{(125} \mathrm{MHz,} \mathrm{CDCl}_{3}\right): \delta_{\mathrm{C}} 188.4(\mathrm{CH}$, $\mathrm{CHO}), 170.5\left(\mathrm{C}, \mathrm{COCH}_{3}\right), 164.5$ (CH, C-1), 136.3 (C, Bn), 128.9 (CH, Bn), 128.7 (CH, Bn), 128.4 (CH, Bn), 118.0 (C, C-2), 74.0 (CH, C-5), 72.9 (CH, C-4), $72.5\left(\mathrm{CH}_{2}, \mathrm{CH}_{2} \mathrm{Ph}\right), 62.6$ $\left(\mathrm{CH}_{2}, \mathrm{C}-6\right), 43.0(\mathrm{CH}, \mathrm{C}-3), 20.9\left(\mathrm{CH}_{3}, \mathrm{COCH}_{3}\right)$; IR (Film from $\left.\mathrm{CH}_{2} \mathrm{Cl}_{2}\right): v_{\max } 3050-2800$, 1743, 1677, 1625, 1211, 1048, $764 \mathrm{~cm}^{-1}$; HRMS: $m / z \mathrm{C}_{16} \mathrm{H}_{17} \mathrm{ClO}_{5}[\mathrm{M}+\mathrm{H}]^{+}$calcd 327.0814, found $327.0800,(\Delta=4.19 \mathrm{ppm})$.

\subsubsection{Formation of 3-Acetomido-2-formylglycal 116}

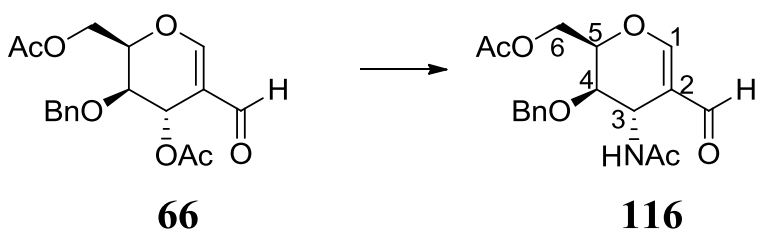

To a solution of $66(59 \mathrm{mg}, 0.169 \mathrm{mmol})$ in acetonitrile $(1 \mathrm{~mL})$ at room temperature was added bis(trimethylsilyl)acetylene $(0.04 \mathrm{~mL}, 0.297 \mathrm{mmol})$, and boron trifluoride diethyl etherate $(0.04 \mathrm{~mL}, 0.245 \mathrm{mmol})$. After stirring at room temperature for $1.5 \mathrm{~h}$, the reaction was warmed to $40{ }^{\circ} \mathrm{C}$. After a further $1.5 \mathrm{~h}$, the reaction mixture was heated to $60{ }^{\circ} \mathrm{C}$ where it was stirred for a further $40 \mathrm{~min}$. The reaction was then cooled to $0{ }^{\circ} \mathrm{C}$ and treated with a saturated aqueous solution of sodium bicarbonate $(5 \mathrm{~mL})$, and diluted with water $(10 \mathrm{~mL})$. The aqueous phase was extracted with dichoromethane $(3 \times 5 \mathrm{~mL})$, and the combined organic phase washed with a saturated solution of sodium bicarbonate $(1 \times 5 \mathrm{~mL})$ and brine $(1 \times 5 \mathrm{~mL})$; dried over anhydrous magnesium sulfate and filtered through cotton wool. The volatiles were removed under reduced pressure to give $\mathbf{1 1 6}$ as a colourless oil (22.6 mg 60\%). 
((2R,3R,4S)-4-Acetamido-3-(benzyloxy)-5-formyl-3,4-dihydro-2H-pyran-2-yl)methyl acetate (116)

${ }^{1} \mathrm{H}$ NMR (500 MHz, $\mathrm{CDCl}_{3}$ ): $\delta_{\mathrm{H}} 9.33$ (s, 1H, CHO), 7.36 - 7.28 (complex m., 5H, Bn), 5.86 $(\mathrm{d}, J=5.2 \mathrm{~Hz}, 1 \mathrm{H}, \mathrm{NH}), 4.83(\mathrm{dd}, J=5.2,1.9 \mathrm{~Hz}, 1 \mathrm{H}, \mathrm{H}-3), 4.78$ (d, $\left.J=12.0 \mathrm{~Hz}, 1 \mathrm{H}, \mathrm{CH}_{2} \mathrm{Ph}\right)$, $4.62\left(\mathrm{~d}, J=12.0 \mathrm{~Hz}, 1 \mathrm{H}, \mathrm{CH}_{2} \mathrm{Ph}\right), 4.33\left(\mathrm{dd}, J=11.7,7.6 \mathrm{~Hz}, 1 \mathrm{H}, \mathrm{H}-6_{\mathrm{A}}\right), 4.17$ (t, $J=4.7 \mathrm{~Hz}$, 1H, H-5), 4.07 (dd, $J=11.7,4.7$ Hz, 1H, H-6в), 3.86 (s, 1H, H-4), 1.98 (s, 3H, NCOCH $), 1.97$ (s, 3H, $\left.\mathrm{OCOCH}_{3}\right) ;{ }^{13} \mathrm{C} \mathrm{NMR}\left(150 \mathrm{MHz}, \mathrm{CDCl}_{3}\right): \delta_{\mathrm{C}} 189.8(\mathrm{CH}, \mathrm{CHO}), 170.6\left(\mathrm{OCOCH}_{3}\right)$, $170.3\left(\mathrm{NCOCH}_{3}\right), 166.0(\mathrm{CH}, \mathrm{C}-1), 137.1$ (C, Bn), $128.7(\mathrm{CH}, \mathrm{Bn}), 128.6(\mathrm{CH}, \mathrm{Bn}), 128.2$ $(\mathrm{CH}, \mathrm{Bn}), 116.2$ (C, C-2), $74.9(\mathrm{CH}, \mathrm{C}-5), 71.7\left(\mathrm{CH}_{2}, \mathrm{Bn}\right), 70.2(\mathrm{CH}, \mathrm{C}-4), 63.1\left(\mathrm{CH}_{2}, \mathrm{C}-6\right)$, $40.3(\mathrm{CH}, \mathrm{C}-3), 23.2\left(\mathrm{NCOCH}_{3}\right), 20.8\left(\mathrm{OCOCH}_{3}\right)$; HRMS: $m / z \mathrm{C}_{18} \mathrm{H}_{21} \mathrm{NO}_{6} \mathrm{Na}^{+}[\mathrm{M}+\mathrm{Na}]^{+}$calcd 372.1318 , found $372.1320(\Delta=-0.63 \mathrm{ppm})$.

\subsubsection{Formation of Thioether 119}

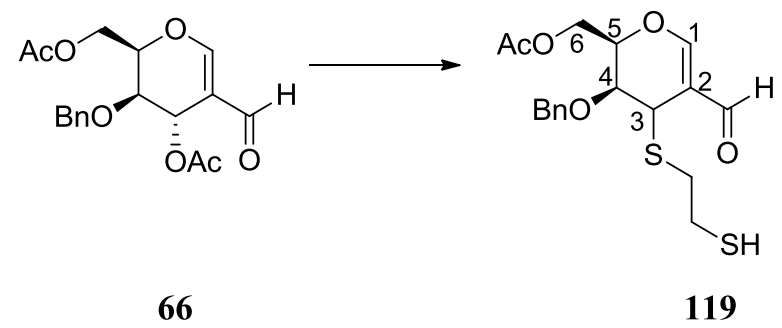

To a solution of 66 (50 mg, $0.144 \mathrm{mmol})$ and $4 \AA$ molecular sieves (approx. $100 \mathrm{mg}$ ) in refluxing toluene $(1.4 \mathrm{~mL})$ was added 1,2-ethanedithiol $(0.018 \mathrm{~mL}, 0.215 \mathrm{mmol})$ and $p$ toluenesulfonic acid $(1.2 \mathrm{mg}, 0.007 \mathrm{mmol})$. After stirring overnight, the reaction mixture was cooled to $0{ }^{\circ} \mathrm{C}$ and treated with a saturated aqueous solution of sodium bicarbonate $(5 \mathrm{~mL})$. The mixture was diluted with water $(10 \mathrm{~mL})$ and extracted with dichloromethane $(3 \times 8 \mathrm{~mL})$. The combined organic phase was washed with water $(2 \times 7 \mathrm{~mL})$, and brine $(1 \times 7 \mathrm{~mL})$; dried over anhydrous magnesium sulfate, and filtered through cotton wool. After the volatiles were removed under reduced pressure, the crude residue was purified via flash chromatography (silica gel, 3:1 petroleum ether:ethyl acetate) to give 119 as a pale yellow oil (25 $\mathrm{mg}, 46 \%)$.

((2R,3S)-3-(Benzyloxy)-5-formyl-4-((2-mercaptoethyl)thio)-3,4-dihydro-2H-pyran-2yl)methyl acetate (119) 
$\mathrm{R}_{f}=0.30$ (2:1, petroleum ether:ethyl acetate); ${ }^{1} \mathrm{H} \mathrm{NMR}\left(500 \mathrm{MHz}, \mathrm{CDCl}_{3}\right): \delta_{\mathrm{H}} 9.32(\mathrm{~s}, 1 \mathrm{H})$, 7.41 - 7.27 (complex m., 6H, Bn, H-1), 4.62 (d, $J=12.1 \mathrm{~Hz}, 1 \mathrm{H}, \mathrm{CH}_{2} \mathrm{Ph}$ ), $4.58-4.53$ (m, 1H, $\mathrm{H}-5), 4.49\left(\mathrm{~d}, J=12.1 \mathrm{~Hz}, 1 \mathrm{H}, \mathrm{CH}_{2} \mathrm{Ph}\right), 4.43\left(\mathrm{dd}, J=11.7,7.4 \mathrm{~Hz}, 1 \mathrm{H}, \mathrm{H}-6_{\mathrm{A}}\right), 4.31$ (dd, $J=$ 11.7, 4.8 Hz, 1H, H-6в), 3.77 (d, $J=1.9 \mathrm{~Hz}, 1 \mathrm{H}, \mathrm{H}-3$ ), 3.73 (br. s, 1H, H-4), $2.78-2.68$ (complex m., 4H, $2 \times \mathrm{SCH}_{2}$ ), 2.07 (s, 3H, $\left.\mathrm{COCH}_{3}\right) ;{ }^{13} \mathrm{C} \mathrm{NMR} \mathrm{(126} \mathrm{MHz,} \mathrm{CDCl}_{3}$ ): $\delta_{\mathrm{C}} 189.2$ (CH, $\mathrm{CHO}), 170.7\left(\mathrm{COCH}_{3}\right), 163.8(\mathrm{CH}, \mathrm{C}-1), 136.8(\mathrm{C}, \mathrm{Bn}), 129.0(\mathrm{CH}, \mathrm{Bn}), 128.8(\mathrm{CH}, \mathrm{Bn})$, $128.6(\mathrm{CH}, \mathrm{Bn}), 117.6(\mathrm{C}, \mathrm{C}-2), 74.8(\mathrm{CH}, \mathrm{C}-5), 72.4(\mathrm{CH}, \mathrm{C}-4), 71.9\left(\mathrm{CH}_{2}, \mathrm{Bn}\right), 63.4\left(\mathrm{CH}_{2}\right.$, C-6), $37.1\left(\mathrm{CH}_{2}, \mathrm{CSCH}_{2}\right), 34.4(\mathrm{CH}, \mathrm{C}-3), 25.2\left(\mathrm{CH}_{2}, \mathrm{HSCH}_{2}\right), 21.0\left(\mathrm{CH}_{3}, \mathrm{COCH}_{3}\right) ; \mathrm{HRMS}$ : $m / z \mathrm{C}_{18} \mathrm{H}_{23} \mathrm{O}_{5} \mathrm{~S}_{2}{ }^{+}[\mathrm{M}+\mathrm{H}]^{+}$calcd 383.0981, found $383.0983(\Delta=-0.38 \mathrm{ppm})$.

\subsection{Derivatives of Alkyne 114}

\subsubsection{Oxidation of 114 to Acid 120}

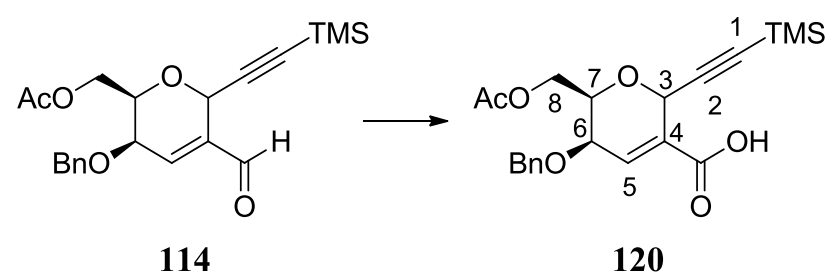

To a solution of aldehyde $114(51.8 \mathrm{mg}, 0.134 \mathrm{mmol})$ and resorcinol (7.3 $\mathrm{mg}, 0.066 \mathrm{mmol})$, in tert-butanol $(2.5 \mathrm{~mL})$ was added dropwise a solution of sodium chlorite $(59.7 \mathrm{mg}, 0.660 \mathrm{mmol})$ and sodium dihydrogen phosphate $(47.3 \mathrm{mg}, 0.394 \mathrm{mmol})$ in water $(1.25 \mathrm{~mL})$. After stirring overnight at room temperature, the reaction mixture was acidified with an aqueous solution of acetic acid $(10 \% \mathrm{v} / \mathrm{v}, 8 \mathrm{~mL})$. The cloudy solution was diluted with water $(10 \mathrm{~mL})$ extracted with ethyl acetate $(4 \times 8 \mathrm{~mL})$, and the combined organic phase washed with brine $(1 \times 8 \mathrm{~mL})$. The organic phase was then dried over anhydrous sodium sulfate, filtered through cotton wool, and the volatiles removed under reduced pressure. The pink-brown residue was purified via flash chromatography (silica gel, 5:1 petroleum ether:ethyl acetate) to afford acid $\mathbf{1 2 0}$ as a white solid contaminated with 2-hydroxy-1,4-benzoquinone. The impure product (120) was used directly in the next step. 
$(5 R, 6 R)-6$-(Acetoxymethyl)-5-(benzyloxy)-2-((trimethylsilyl)ethynyl)-5,6-dihydro-2Hpyran-3-carboxylic acid (120)

$\mathrm{R}_{f}=0.35$ (2:1, petroleum ether: ethyl acetate); $[\alpha]_{\mathrm{D}}^{22}-169.8\left(\mathrm{c} 0.27, \mathrm{CH}_{2} \mathrm{Cl}_{2}\right) ;{ }^{1} \mathrm{H}^{\mathrm{NMR}}(500$ $\mathrm{MHz}, \mathrm{CDCl}_{3}$ ): $\delta_{\mathrm{H}} 7.40-7.30$ (complex m, 5H, Bn), 7.13 (dd, J=4.9, $\left.1.3 \mathrm{~Hz}, 1 \mathrm{H}, \mathrm{H}-5\right), 5.34$ $(\mathrm{d}, J=1.2 \mathrm{~Hz}, 1 \mathrm{H}, \mathrm{H}-3), 4.70$ (d, $\left.J=11.8 \mathrm{~Hz}, 1 \mathrm{H}, \mathrm{CH}_{2} \mathrm{Ph}\right), 4.57$ (d, $\left.J=11.8 \mathrm{~Hz}, 1 \mathrm{H}, \mathrm{CH}_{2} \mathrm{Ph}\right)$, $4.44\left(\mathrm{dd}, J=15.8,7.8 \mathrm{~Hz}, 1 \mathrm{H}, \mathrm{H}-8_{\mathrm{A}}\right), 4.33-4.25$ (complex m, 2H, H-5, H-8B), 3.93 (dd, $J=$ 4.9, $2.4 \mathrm{~Hz}, 1 \mathrm{H}, \mathrm{H}-6), 2.09$ (s, 3H, $\left.\mathrm{COCH}_{3}\right), 0.15$ (s, 9H, Si( $\left.\left.\mathrm{CH}_{3}\right)_{3}\right) ;{ }^{13} \mathrm{C}$ NMR (126 MHz, $\left.\mathrm{CDCl}_{3}\right): \delta_{\mathrm{C}} 171.1\left(\mathrm{C}, \mathrm{COCH}_{3}\right), 168.0(\mathrm{C}, \mathrm{COOH}), 137.4(\mathrm{C}, \mathrm{Bn}), 135.6(\mathrm{CH}, \mathrm{C}-5), 133.3(\mathrm{C}$, C-4), 128.8 (CH, Bn), 128.4 (CH, Bn), 128.2 (CH, Bn), 100.2 (C, C-2), 91.9 (C, C-1), 71.9 $\left(\mathrm{CH}_{2}, \mathrm{Bn}\right), 71.1(\mathrm{CH}, \mathrm{C}-7), 67.2(\mathrm{CH}, \mathrm{C}-6), 63.8(\mathrm{CH}, \mathrm{C}-3), 63.6\left(\mathrm{CH}_{2}, \mathrm{C}-8\right), 21.0\left(\mathrm{CH}_{3}\right.$, $\left.\mathrm{COCH}_{3}\right)$, -0.1 $\left(\mathrm{CH}_{3}, \mathrm{Si}\left(\mathrm{CH}_{3}\right)_{3}\right)$; IR (Film from $\left.\mathrm{CDCl}_{3}\right)$ : v $\max 2960,1705,1371,1250,1045$, 844, 760, $699 \mathrm{~cm}^{-1}$; HRMS: $m / z \mathrm{C}_{21} \mathrm{H}_{26} \mathrm{O}_{6} \mathrm{SiNa}^{+}[\mathrm{M}+\mathrm{Na}]^{+}$calcd 425.1391, found $425.1382(\Delta$ $=2.12 \mathrm{ppm})$.

\subsubsection{Desilylation of 101 to make Terminal alkyne 121}

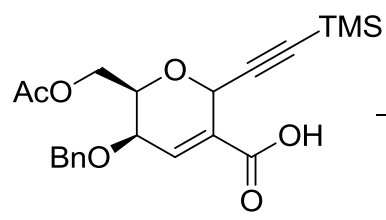

120

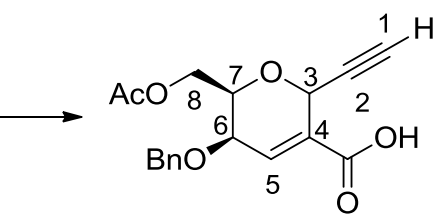

121

To a solution of impure $120(10.2 \mathrm{mg}, 0.025 \mathrm{mmol})$ in tetrahydrofuran $(0.5 \mathrm{~mL})$ at $0{ }^{\circ} \mathrm{C}$ was added tetra- $n$-butylammonium fluoride $(0.03 \mathrm{~mL}, 1 \mathrm{M}$ in tetrahydrofuran, $0.03 \mathrm{mmol})$. After stirring for $30 \mathrm{~min}$, the starting material had been consumed as determined via TLC analysis, and the mixture diluted with ethyl acetate. The resulting solution was filtered through a silica plug, and the silica washed with a $10 \%$ methanol in ethyl acetate solution. The volatiles of the filtrate were removed under reduced pressure. The resulting crude residue dissolved in acetic acid, loaded onto a silica gel column, and the column eluted with ethyl acetate. Removal of volatiles gave $\mathbf{1 2 1}$ as a white residue (5.5 $\mathrm{mg}$, 67\% over two steps).

(5R,6R)-6-(Acetoxymethyl)-5-(benzyloxy)-2-ethynyl-5,6-dihydro-2H-pyran-3-carboxylic acid (121)

$\mathrm{R}_{f}=0.72$ (Ethyl acetate); ${ }^{1} \mathrm{H}$ NMR (500 MHz, $\mathrm{CDCl}_{3}$ ): $\delta_{\mathrm{H}} 7.30$ (complex m, 5H, Ph-H), 7.06 (br s, 1H, H-5), 5.36 (br s, 1H, H-3), 4.65 (d, $J=11.7 \mathrm{~Hz}, 1 \mathrm{H}, \mathrm{CH}_{2} \mathrm{Ph}$ ), 4.49 (d, J = $11.4 \mathrm{~Hz}$, 
1H, $\mathrm{CH}_{2} \mathrm{Ph}$ ), 4.35 - 4.27 (complex m, 2H, H-8), 4.19 (br s, 1H, H-7), 3.85 (br s, 1H, H-6), 2.48 (br s, H-1), 2.05 (s, 3H, $\left.\mathrm{COCH}_{3}\right) ;{ }^{13} \mathrm{C} \mathrm{NMR}\left(150 \mathrm{MHz}, \mathrm{CDCl}_{3}\right): \delta_{\mathrm{C}} 172.8(\mathrm{C}, \mathrm{COOH}), 171.1$ $\left(\mathrm{C}, \mathrm{COCH}_{3}\right), 137.5$ (C, Bn), $133.2(\mathrm{CH}, \mathrm{C}-5), 128.7$ (CH, Bn), $128.24(\mathrm{CH}, \mathrm{Bn}), 128.18(\mathrm{CH}$, Bn), 80.0 (C, C-2), 74.6 (CH, C-1), $71.6\left(\mathrm{CH}_{2}, \mathrm{CH}_{2} \mathrm{Ph}\right), 71.1(\mathrm{CH}, \mathrm{C}-7), 67.2(\mathrm{CH}, \mathrm{C}-6), 63.6$ $(\mathrm{CH}, \mathrm{C}-3), 63.4\left(\mathrm{CH}_{2}, \mathrm{C}-8\right), 21.0\left(\mathrm{CH}_{3}, \mathrm{COCH}_{3}\right)$; HRMS: $m / z \mathrm{C}_{18} \mathrm{H}_{19} \mathrm{O}_{6}{ }^{+}[\mathrm{M}+\mathrm{H}]^{+}$calcd 332.1210, found $332.1206(\Delta=1.09)$. 
7. APPENDIX: NMR SPECTRA OF SELECTED COMPOUNDS 


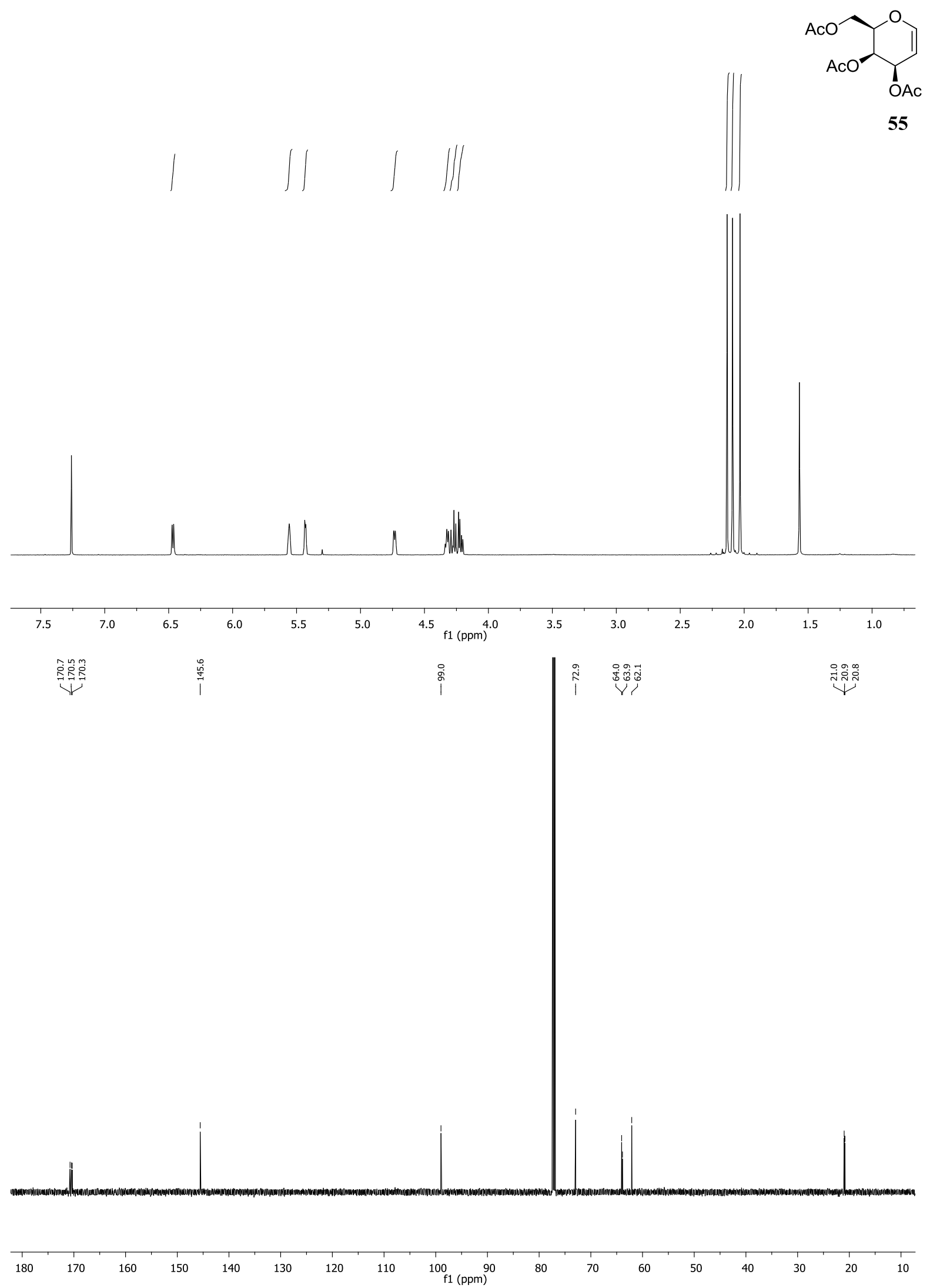

${ }^{1} \mathrm{H}(600 \mathrm{MHz})$ and ${ }^{13} \mathrm{C}(150 \mathrm{MHz})$ NMR spectra of 55 in $\mathrm{CDCl}_{3}$. 


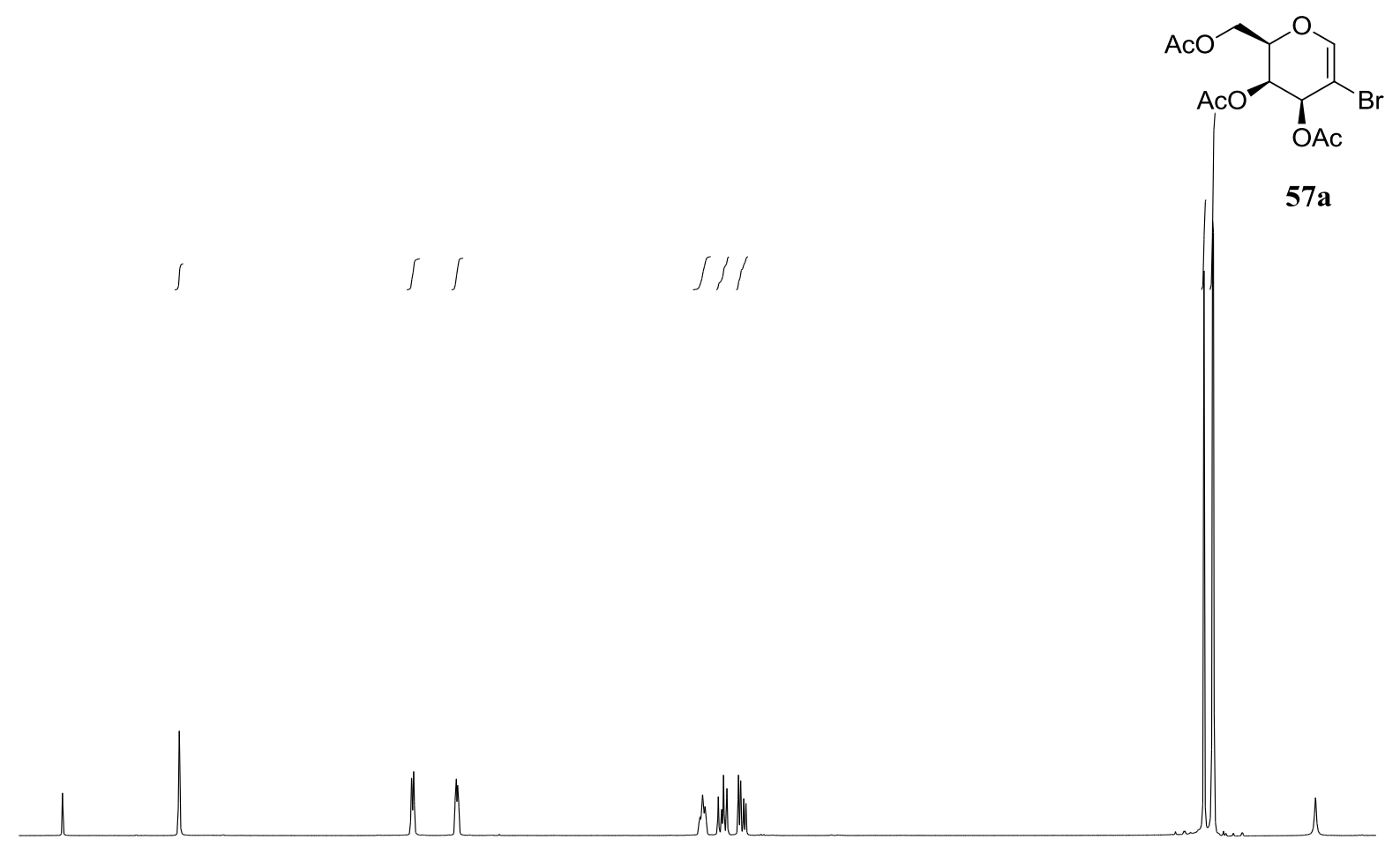

\begin{tabular}{lllllllllllllllllllllllllllllllllllll}
\hline 7.4 & 7.2 & 7.0 & 6.8 & 6.6 & 6.4 & 6.2 & 6.0 & 5.8 & 5.6 & 5.4 & 5.2 & 5.0 & 4.8 & 4.6 & 4.4 & 4.2 & 4.0 & 3.8 & 3.6 & 3.4 & 3.2 & 3.0 & 2.8 & 2.6 & 2.4 & 2.2 & 2.0 & 1.8 & 1.6 & 1.4
\end{tabular}
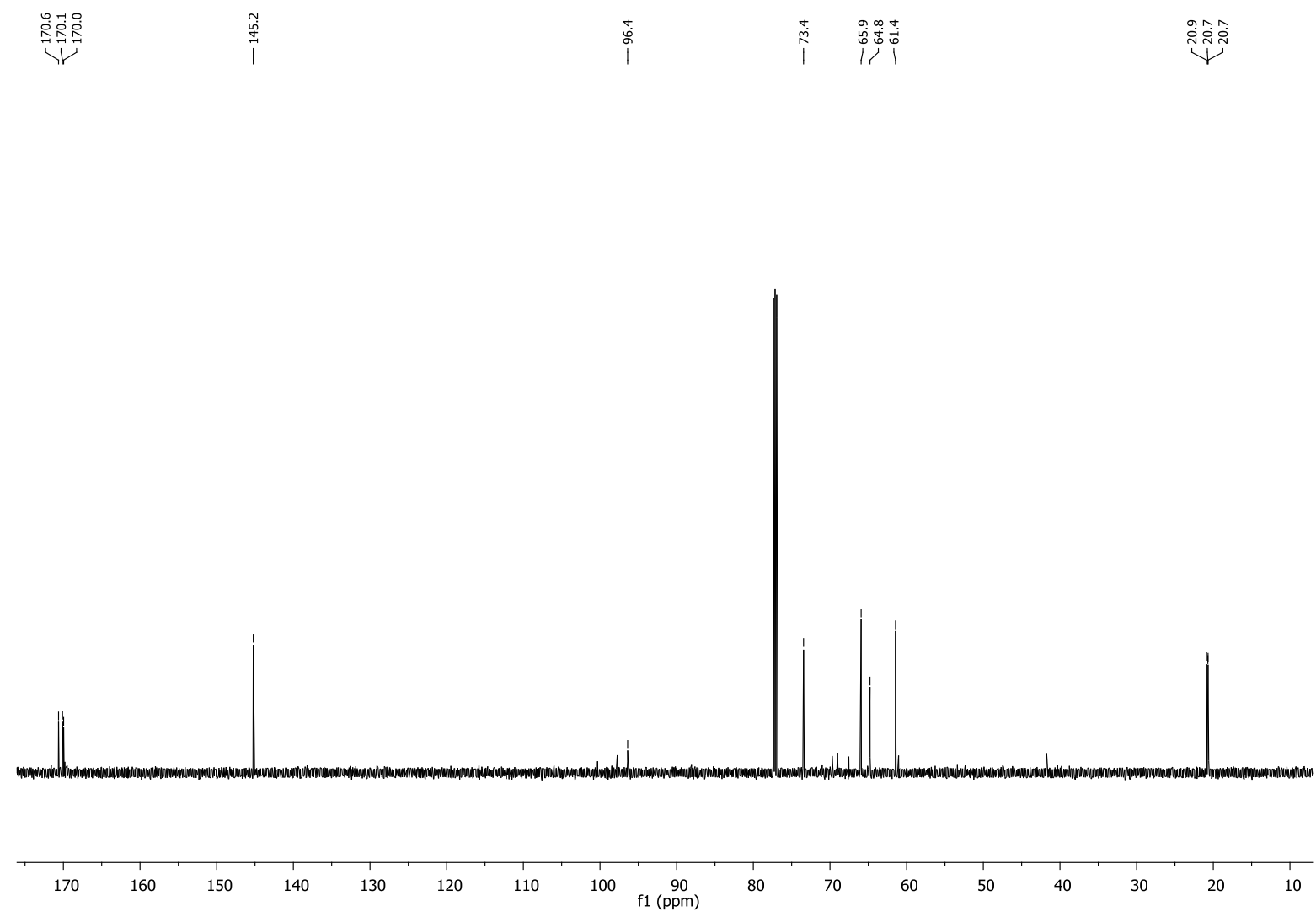

${ }^{1} \mathrm{H}(600 \mathrm{MHz})$ and ${ }^{13} \mathrm{C}(150 \mathrm{MHz}) \mathrm{NMR}$ spectra of 57a in $\mathrm{CDCl}_{3}$. 

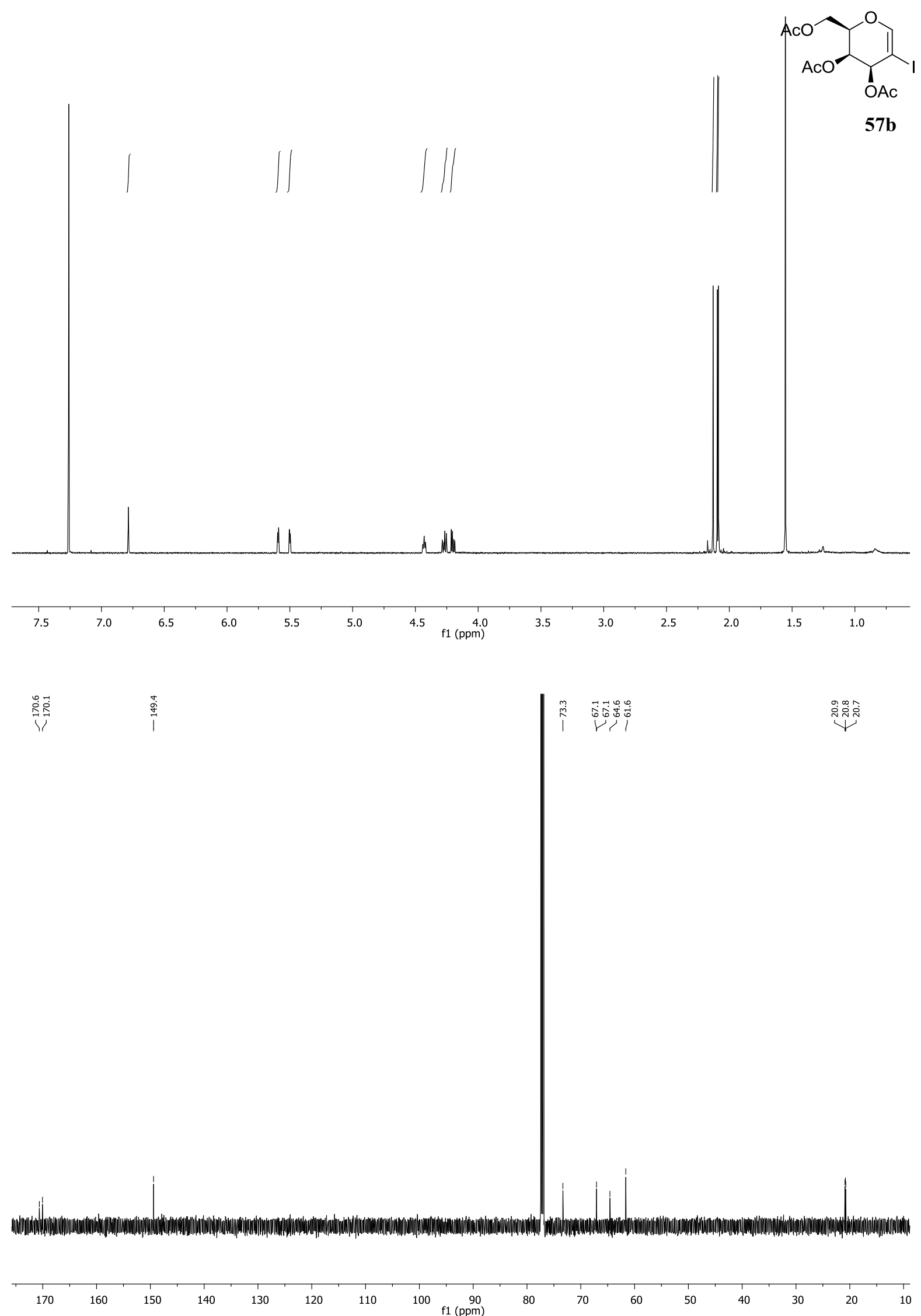

${ }^{1} \mathrm{H}(600 \mathrm{MHz})$ and ${ }^{13} \mathrm{C}(150 \mathrm{MHz}) \mathrm{NMR}$ spectra of $\mathbf{5 7 b}$ in $\mathrm{CDCl}_{3}$. 


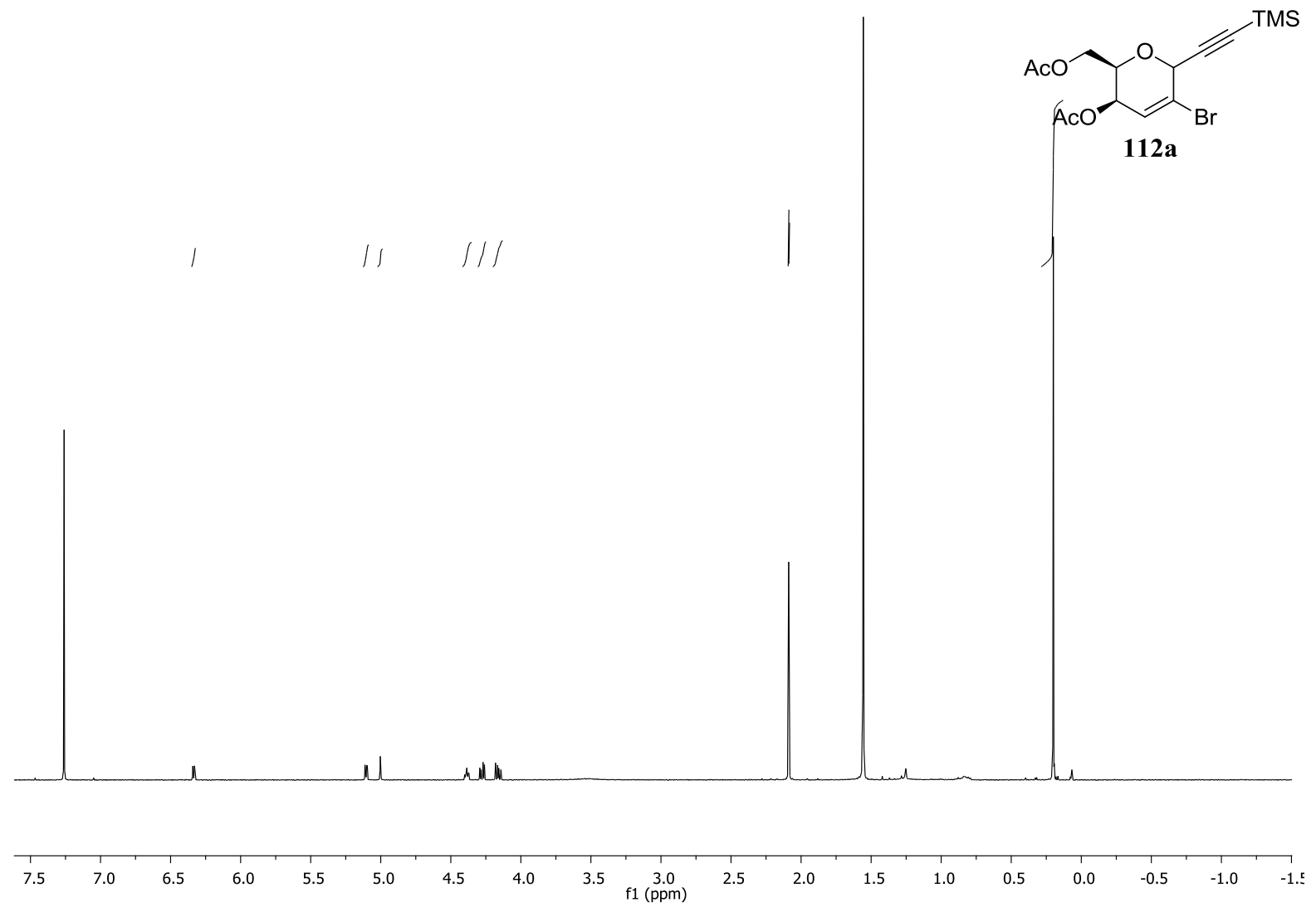

${ }^{1} \mathrm{H}$ NMR spectrum of $\mathbf{1 1 2 a}$ in $\mathrm{CDCl}_{3}(600 \mathrm{MHz})$. 

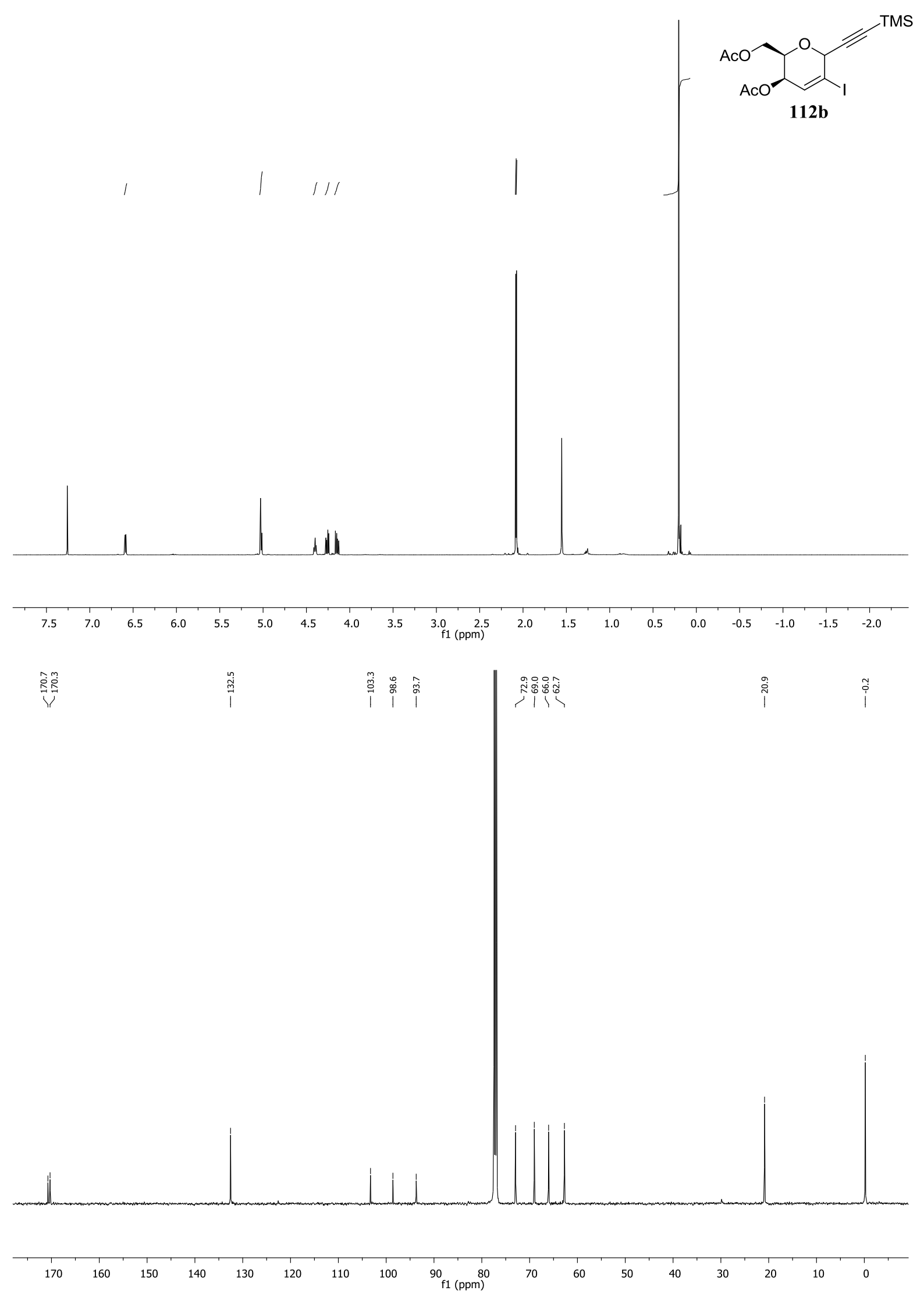

${ }^{1} \mathrm{H}(600 \mathrm{MHz})$ and ${ }^{13} \mathrm{C}(150 \mathrm{MHz})$ NMR spectra of $\mathbf{1 1 2} \mathbf{b}$ in $\mathrm{CDCl}_{3}$. 


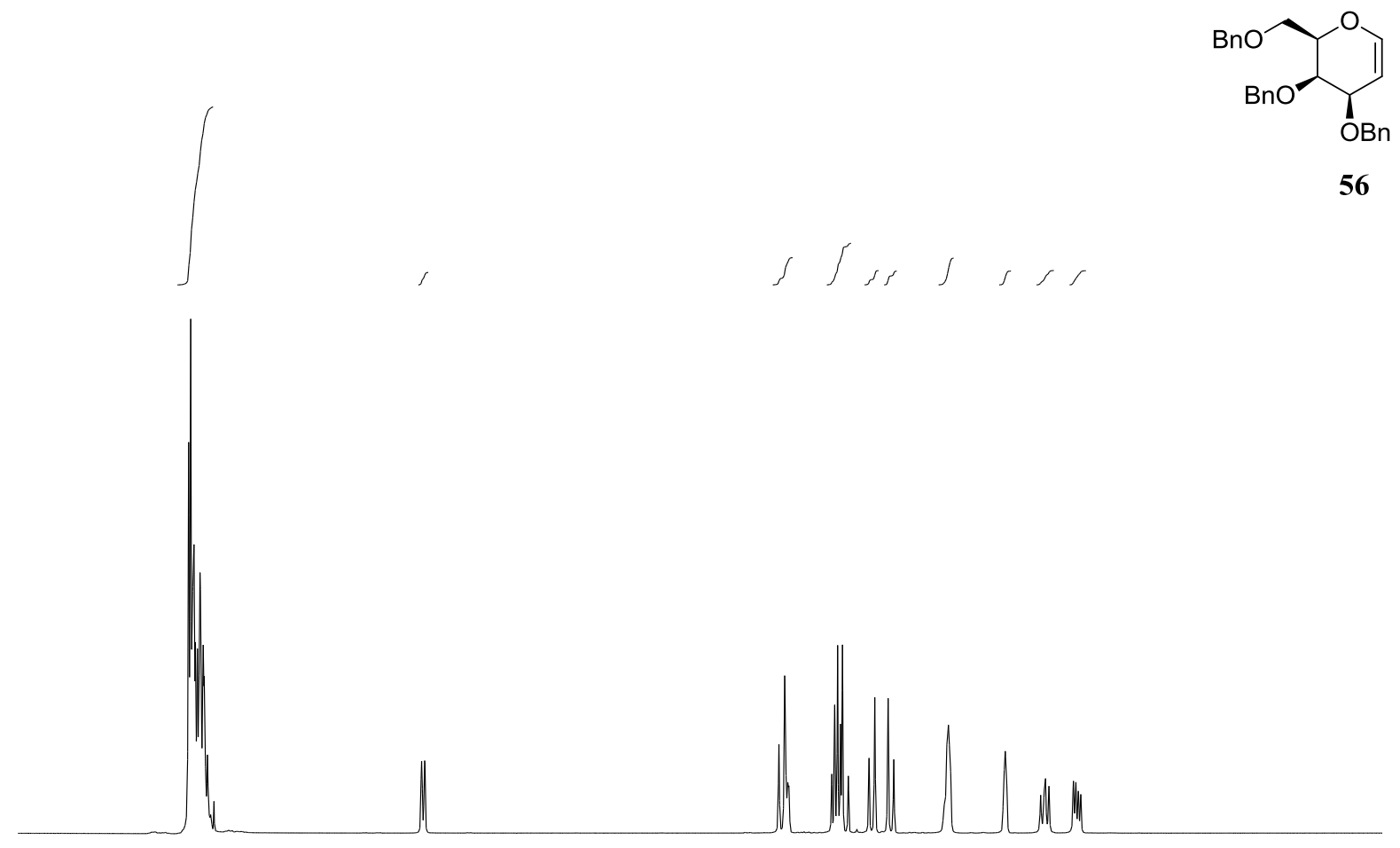

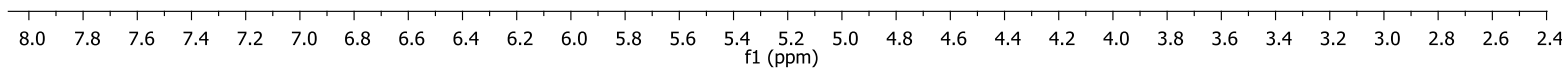

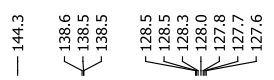

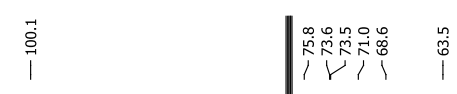

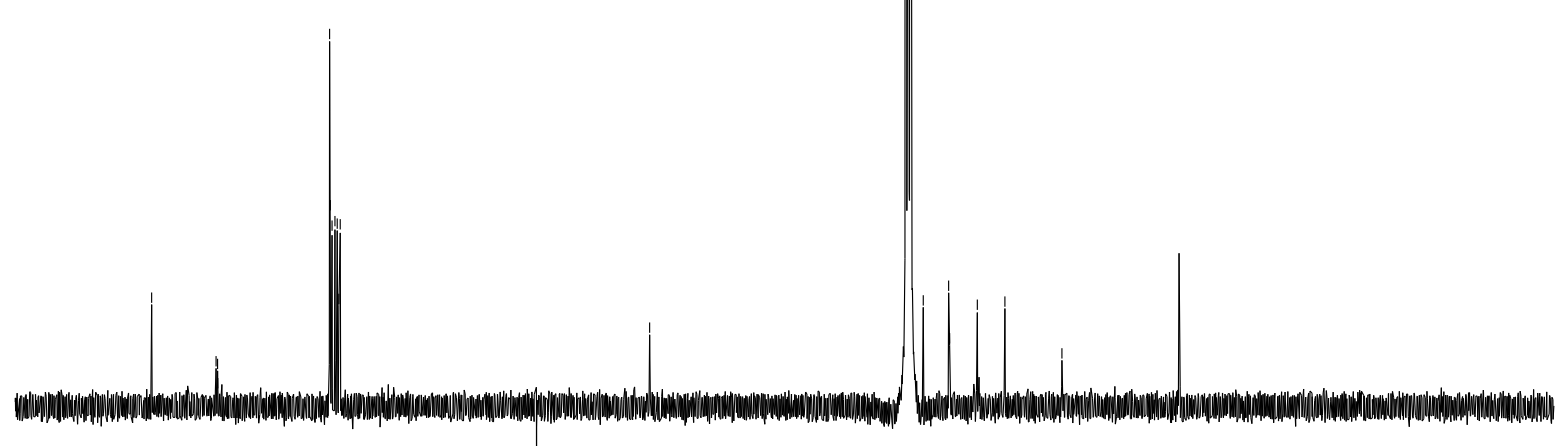

\begin{tabular}{llllllllllllllllllllllllllllllllllll}
\hline 155 & 150 & 145 & 140 & 135 & 130 & 125 & 120 & 115 & 110 & 105 & 100 & 95 & $\begin{array}{c}90 \\
\mathrm{f1}(\mathrm{ppm})\end{array}$ & 80 & 75 & 70 & 65 & 60 & 55 & 50 & 45 & 40 & 35 & 30 & 25 & 20
\end{tabular}

${ }^{1} \mathrm{H}(500 \mathrm{MHz})$ and ${ }^{13} \mathrm{C}(150 \mathrm{MHz})$ NMR spectra of 56 in $\mathrm{CDCl}_{3}$. 

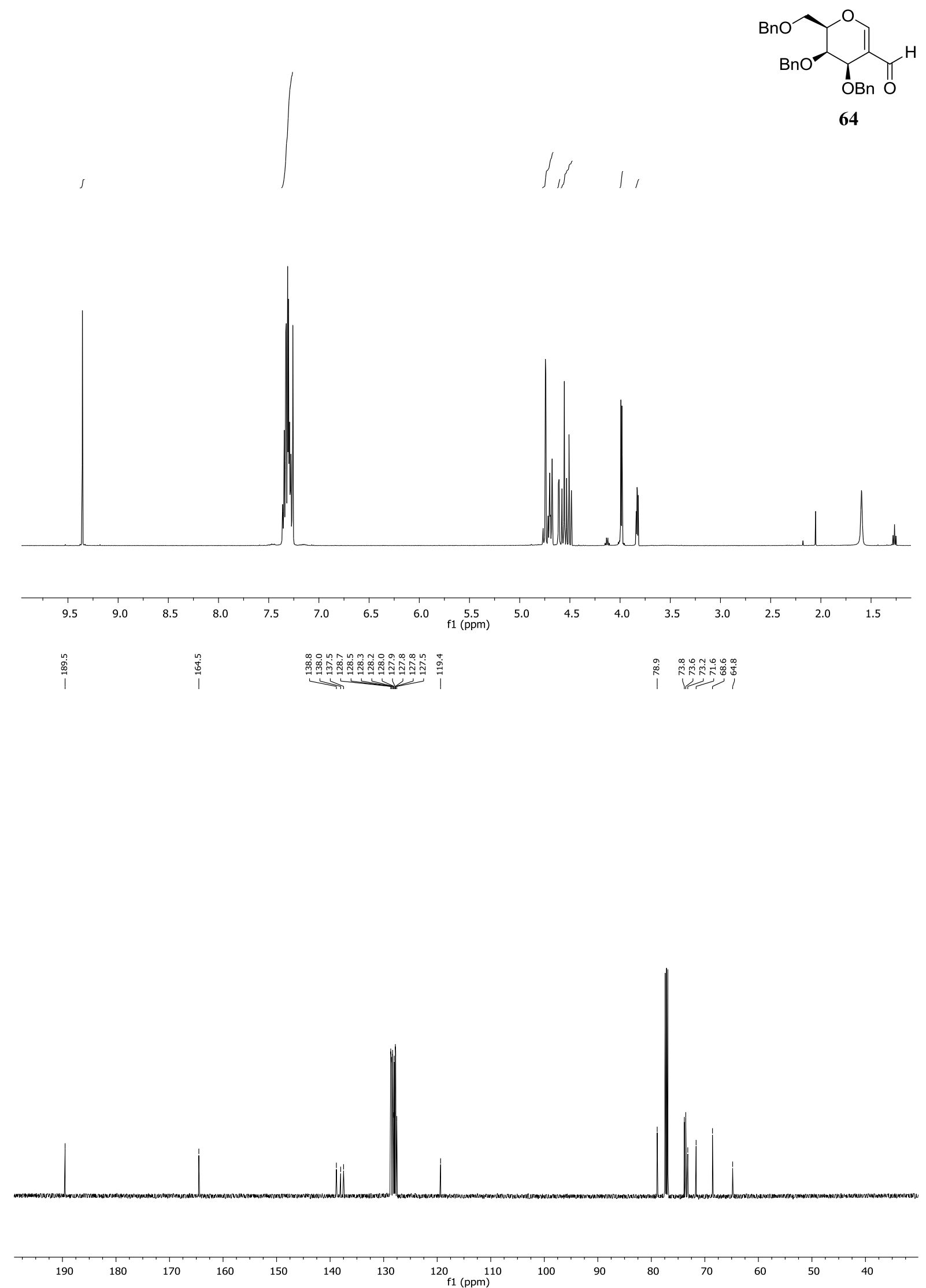

${ }^{1} \mathrm{H}(500 \mathrm{MHz})$ and ${ }^{13} \mathrm{C}(125 \mathrm{MHz}) \mathrm{NMR}$ spectra of 64 in $\mathrm{CDCl}_{3}$. 

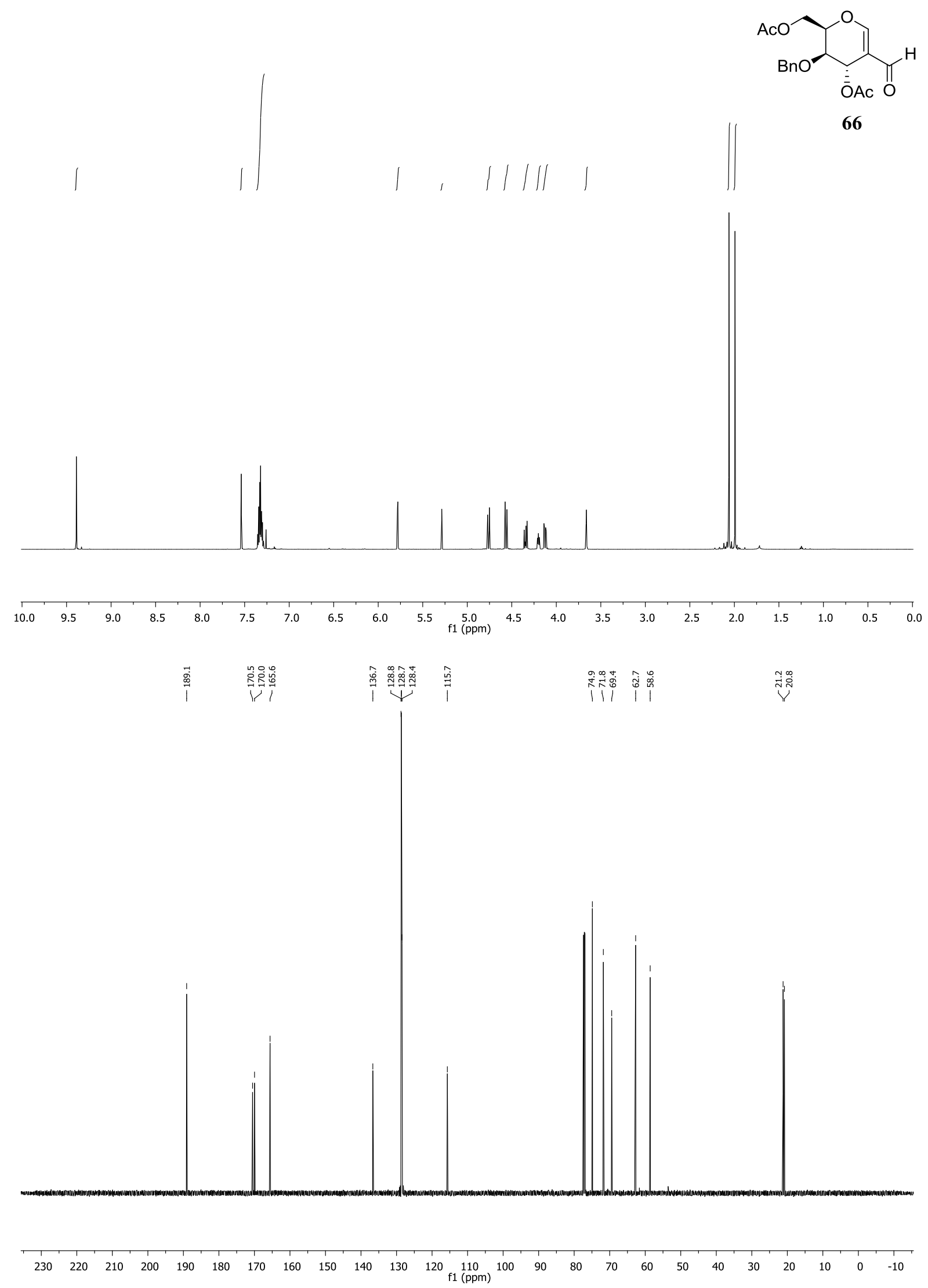

${ }^{1} \mathrm{H}(600 \mathrm{MHz})$ and ${ }^{13} \mathrm{C}(150 \mathrm{MHz}) \mathrm{NMR}$ spectra of 66 in $\mathrm{CDCl}_{3}$. 

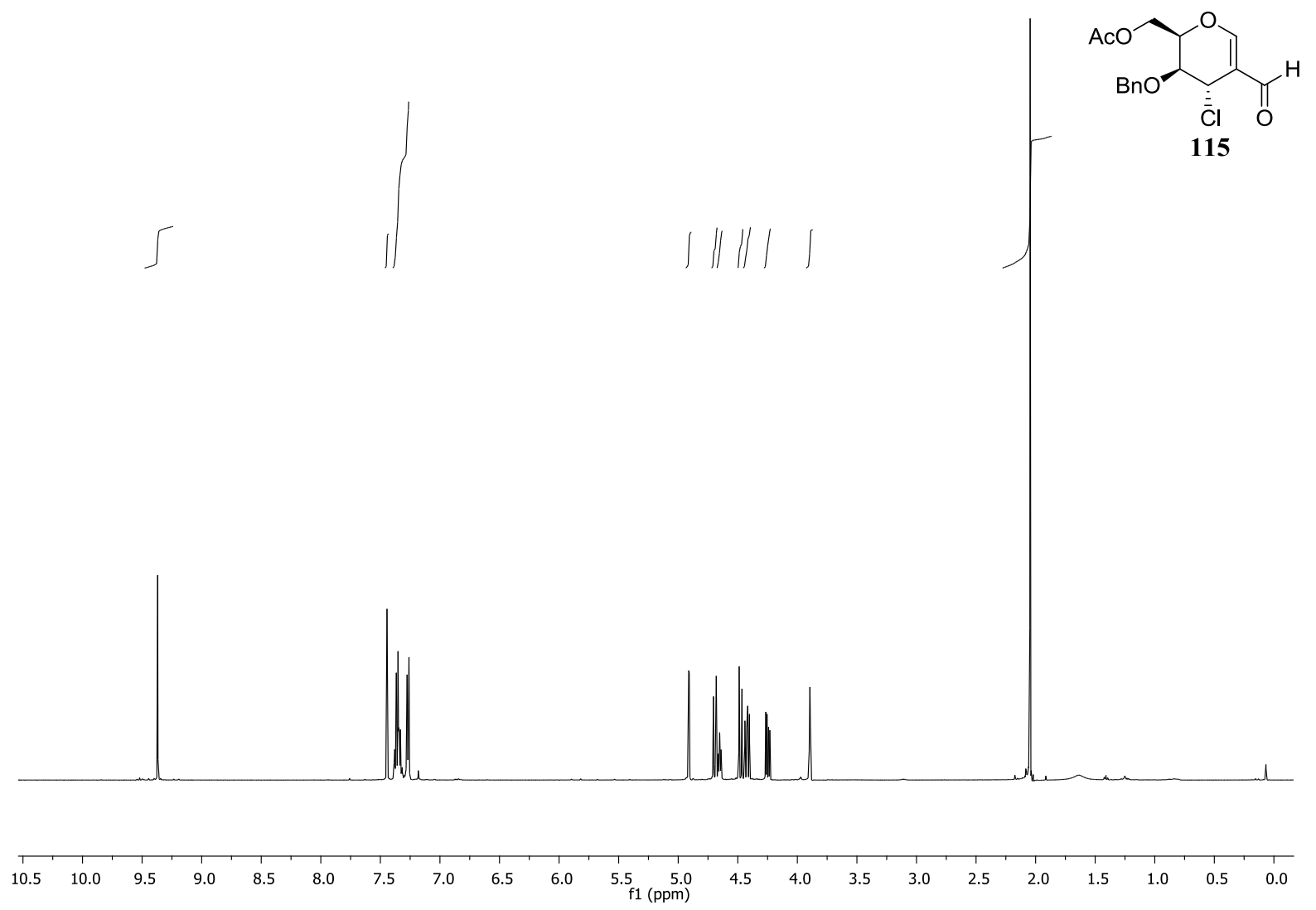

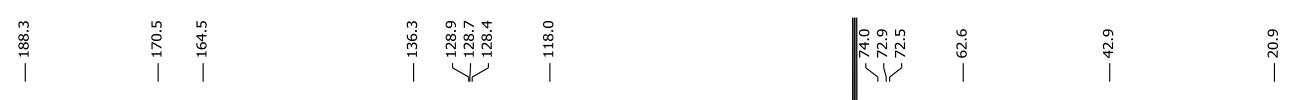

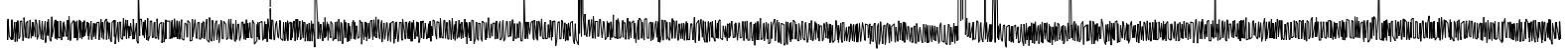

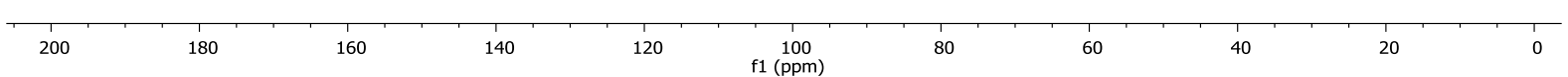

${ }^{1} \mathrm{H}(500 \mathrm{MHz})$ and ${ }^{13} \mathrm{C}(125 \mathrm{MHz}) \mathrm{NMR}$ spectra of 115 in $\mathrm{CDCl}_{3}$. 

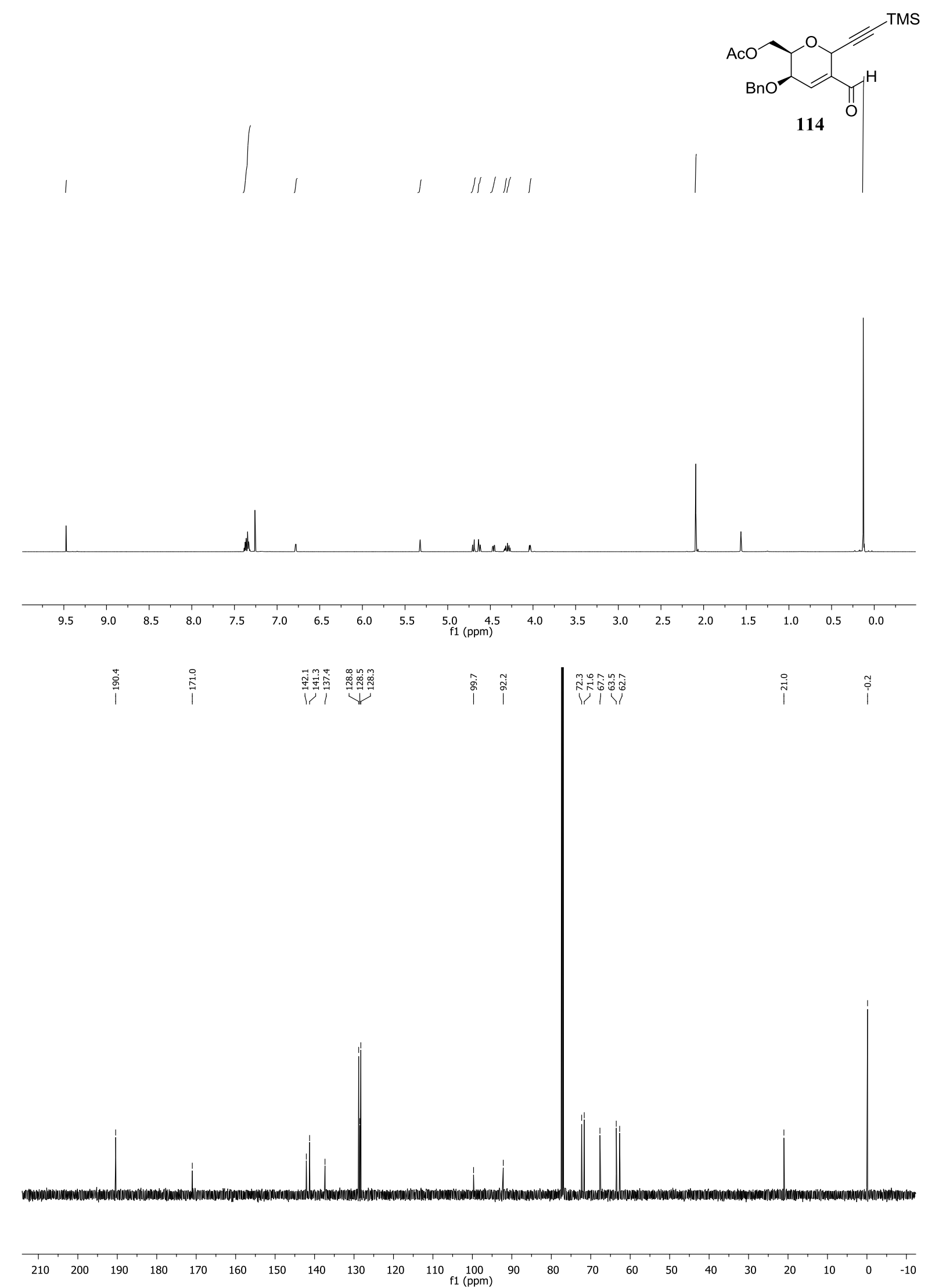

${ }^{1} \mathrm{H}(600 \mathrm{MHz})$ and ${ }^{13} \mathrm{C}(150 \mathrm{MHz})$ NMR spectra of 114 in $\mathrm{CDCl}_{3}$. 

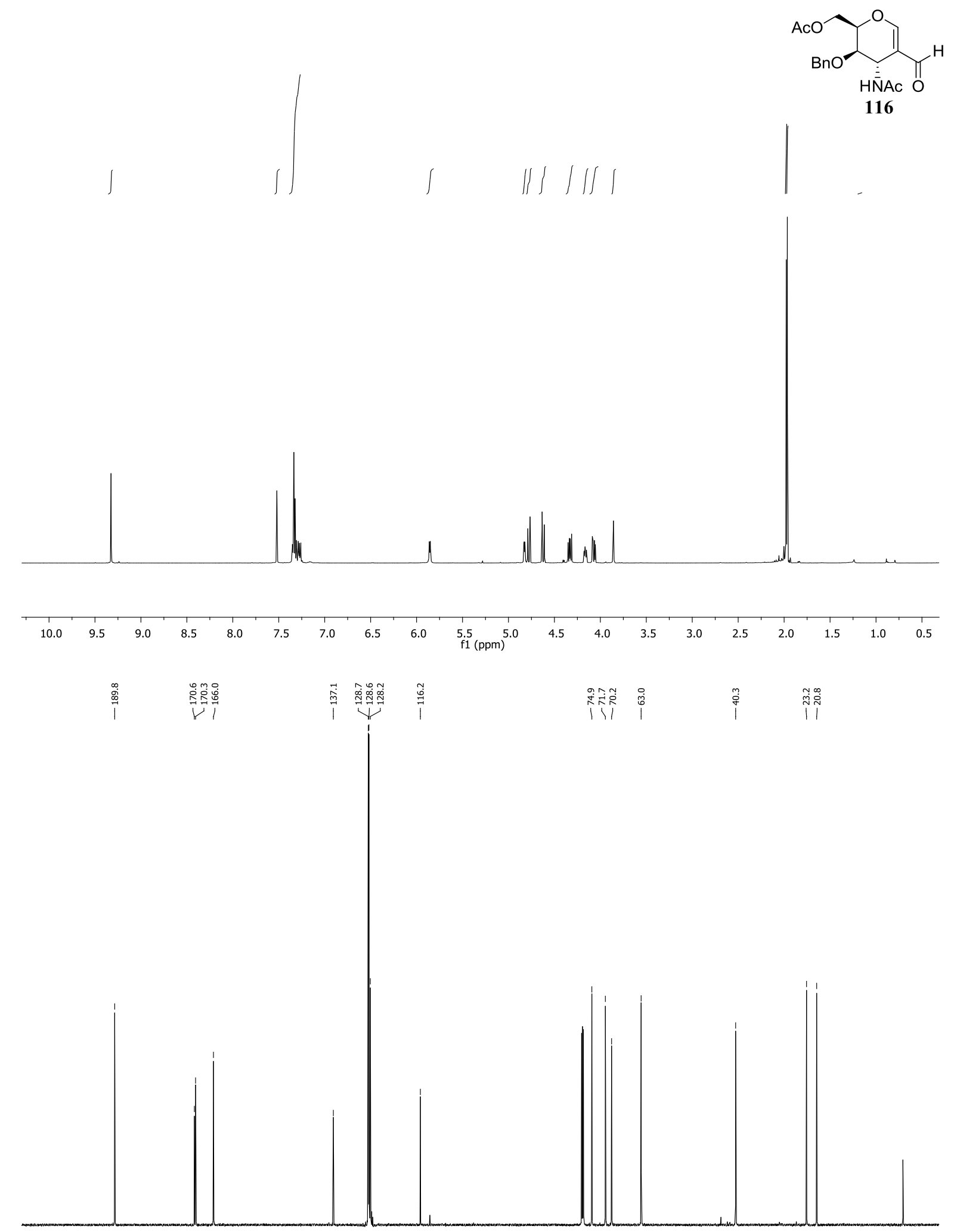

\begin{tabular}{llllllllllllllllllllllllll}
\hline 210 & 200 & 190 & 180 & 170 & 160 & 150 & 140 & 130 & 120 & 110 & 100 & 90 & 80 & 70 & 60 & 50 & 40 & 30 & 20 & 10 & 0 &
\end{tabular}

${ }^{1} \mathrm{H}(500 \mathrm{MHz})$ and ${ }^{13} \mathrm{C}(150 \mathrm{MHz})$ NMR spectra of 116 in $\mathrm{CDCl}_{3}$. 

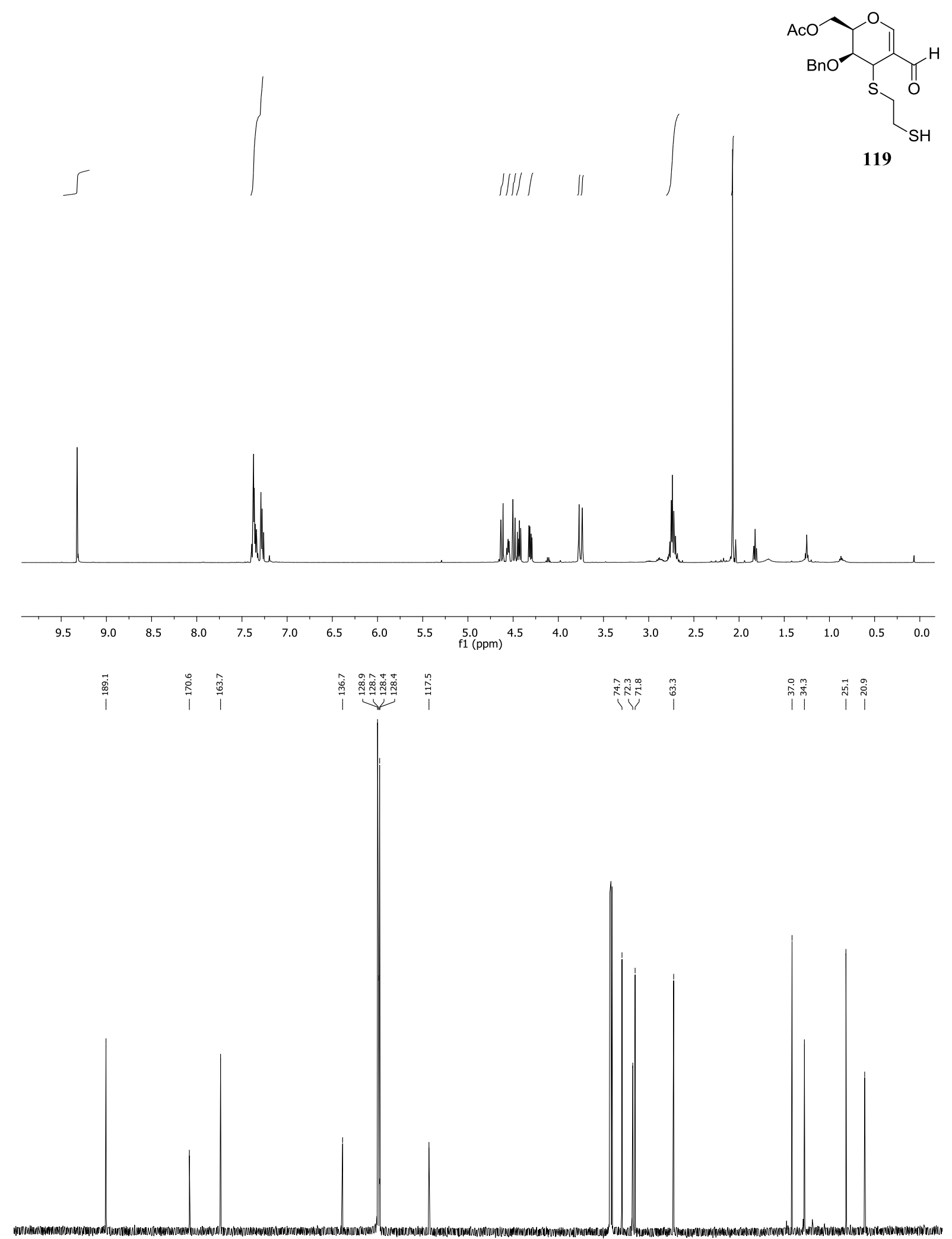

$200 \quad 180 \quad 160$ 140 $120 \mathrm{f} 1(\mathrm{ppm})^{100}$ 80 60 40 20 ${ }^{1} \mathrm{H}(500 \mathrm{MHz})$ and ${ }^{13} \mathrm{C}(125 \mathrm{MHz})$ NMR spectra of 119 in $\mathrm{CDCl}_{3}$. 

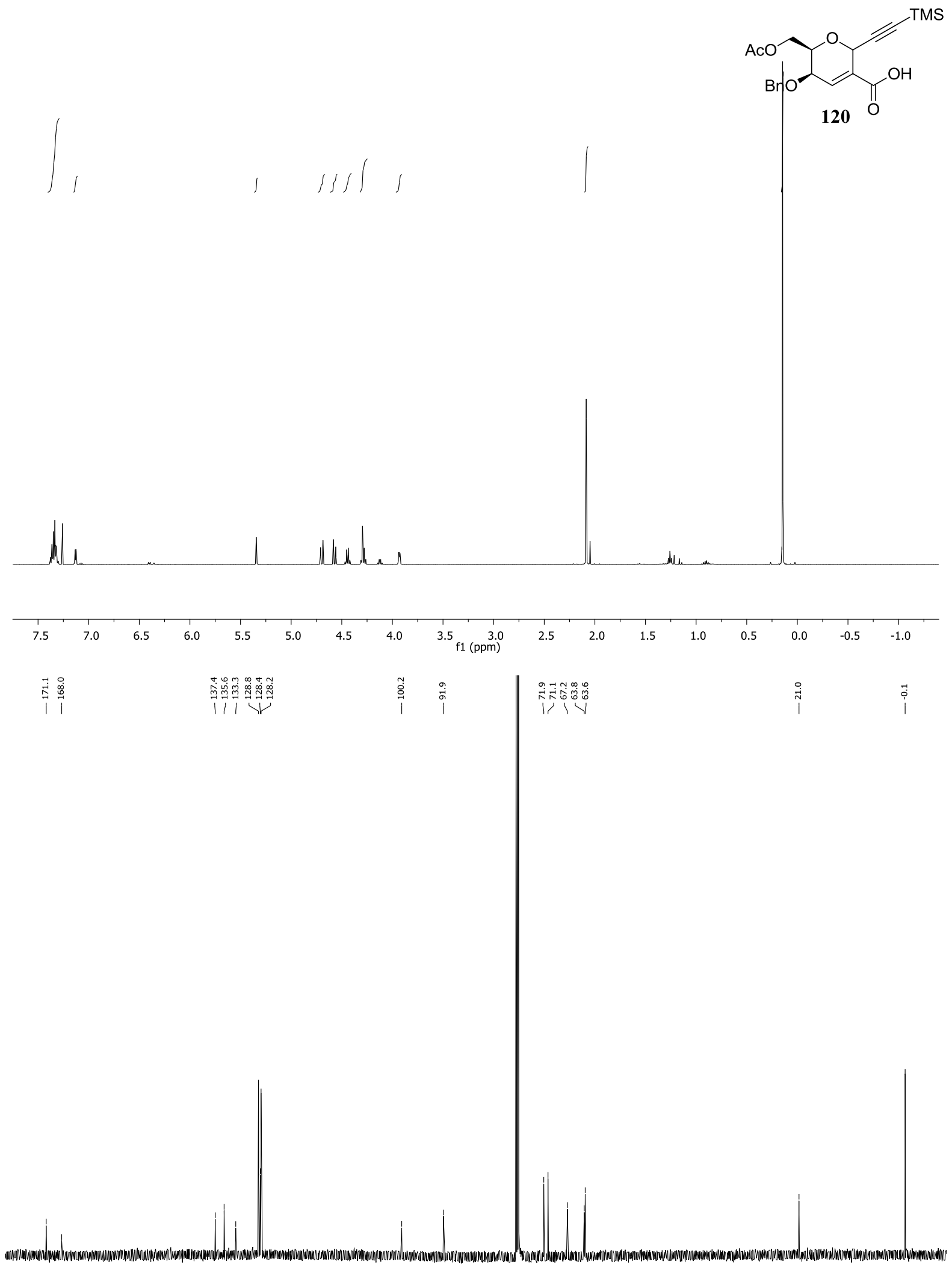

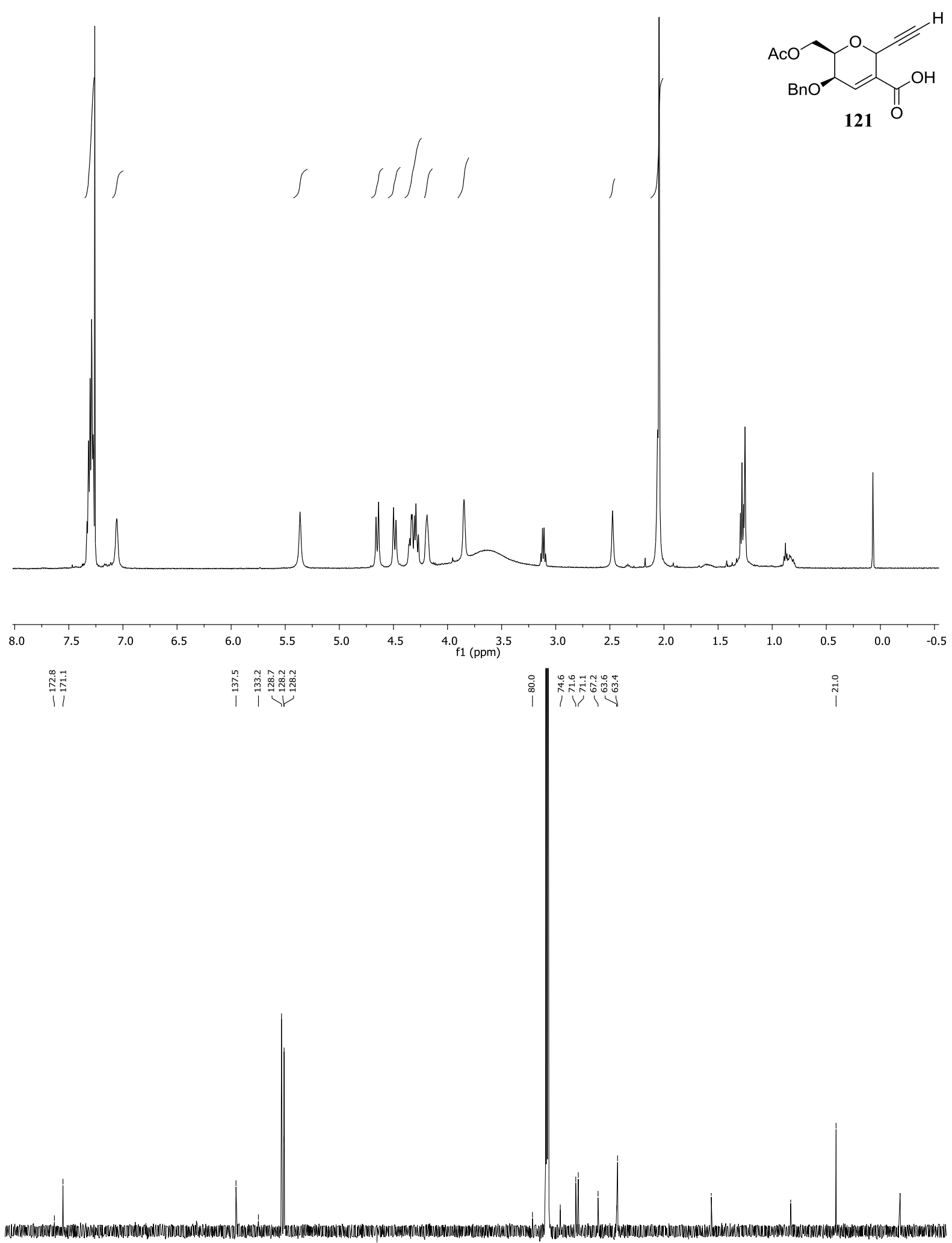

${ }_{180}^{160}$
${ }^{1} \mathrm{H}(500 \mathrm{MHz})$ and ${ }^{13} \mathrm{C}(150 \mathrm{MHz})$




\section{REFERENCES}

[1] K. T. Hayashi, K. Noguchi, Japanese Patent 10287679, 1998.

[2] X. Gao, B. B. Snider, J. Org. Chem., 2004, 69, 5517-5527.

[3] S. M. Dehm, K. Bonham, Biochem. Cell. Biol., 2004, 82, 263-274.

[4] J. Schlessinger, Cell, 2000, 100, 293-296.

[5] D. Hanahan, R. A. Weinberg, Cell, 2011, 144, 646-674.

[6] S. L. Teitelbaum, Science, 2000, 289, 1504-1508.

[7] O. Noazawa, T. Okazaki, N. Saki, T. Komurasaki, K. Hanada, S. Morimoto, Z.-X. Chen, B.-M. He, K. Mizoue, J. Antibiot., 1995, 48, 113-118.

[8] K. Krohn, M. Sohrab, T. van Ree, S. Draeger, B. Schulz, S. Antus, T. Kurtán, Eur. J. Org. Chem., 2008, 5638-5646.

[9] A. M. Stewart, K. Meier, B. Schulz, M. Steinert, B. B. Snider, J. Org. Chem., 2010, $75,6057-6060$.

[10] J. E. Harvey, R. J. Hewitt, K. K. Somarathne, World Patent WO/2015/084181, 2015.

[11] X. Gao, M. Nakadai, B. B. Snider, Org. Lett., 2003, 5, 451-454.

[12] R. J. Hewitt, J. E. Harvey, Org. Biomol. Chem., 2011, 9, 998-1000.

[13] K. K. Somarathne, Synthesis of highly funtionalised furo[3,4-b]pyrans: towards the fungal metalbolite (-)-TAN-2483B, PhD thesis, Victoria University of Wellington 2014.

[14] J. Riesterer, Synthesis of a new long chain ester-based analogue of (-)-TAN-2483B, MSc thesis, Victoria University of Wellington, 2015. 
[15] J. L. Pinedo Rivera, Synthetic development of (-)-TAN-2483B, a fungal metabolite with anticancer and anti-osteoporosis activity, MSc thesis, Victoria University of Wellington, 2015.

[16] C. Orme, Synthetic approaches towards the total synthesis of (-)-TAN-2483B; a lead as a novel kinase inhibitor, MSc thesis, Victoria University of Wellington, 2016.

[17] [a] Y. D. Vankar, T. Linker, Eur. J. Org. Chem., 2015, 7633-7642;

[b] A. A. Ansari, R. Lahiri, Y. D. Vankar, Arkivoc, 2013, 2, 316-362;

[c] A. M. Gómez, F. Lobo, C. Uriel, J. C. López, Eur. J. Org. Chem., 2013, 72217262.

[18] R. Ferrier, J. Chem. Soc., 1964, 5443-5449.

[19] C. Sun, Y. Fang, S. Li, Y. Zhang, Q. Zhao, S. Zhu, C. Li, Org. Lett., 2009, 11, 40844087.

[20] S. Dharuman, Y. D. Vankar, Org. Lett., 2014, 16, 1172-1175.

[21] [a] N. Ramesh, K. Balasubramanian, Tetrahedron Lett., 1991, 32, 3875-3878;

[b] N. G. Ramesh, Eur. J. Org. Chem., 2014, 689-707.

[22] R. E. Mewshaw, Tetrahedron Lett., 1989, 30, 3753-3756.

[23] J.-P. Lellouche, S. Koeller, J. Org. Chem., 2001, 66, 693-696.

[24] G. K. Rawal, S. Rani, N. Kumari, Y. D. Vankar, J. Org. Chem., 2009, 74, 5349-5355.

[25] T. Tsukiyama, S. C. Peters, M. Isobe, Synlett, 1993, 1993, 413-414.

[26] M. B. Tatina, A. K. Kusunuru, S. K. Yousuf, D. Mukherjee, Org. Biomol. Chem., 2014, 12, 7900-7903.

[27] J. Cossy, H. Rakotoarisoa, Synlett, 2000, 2000, 0734-0736. 
[28] B. S. Bal, W. E. Childers, H. W. Pinnick, Tetrahedron, 1981, 37, 2091-2096.

[29] K. S. Goh, C.-H. Tan, RSC Adv., 2012, 2, 5536-5538.

[30] S. Mahapatra, R. G. Carter, J. Am. Chem. Soc., 2013, 135, 10792-10803.

[31] B. M. Trost, J. T. Masters, F. Le Vaillant, J.-P. Lumb, J. Org. Chem., 2016, 81, 10023-10028.

[32] B. J. Marsh, D. R. Carbery, J. Org. Chem., 2009, 74, 3186-3188.

[33] B. Ren, M. Wang, J. Liu, J. Ge, X. Zhang, H. Dong, Green Chem., 2015, 17, 13901394.

[34] X. Xue, Z. Yin, X. Meng, Z. Li, J. Org. Chem., 2013, 78, 9354-9365.

[35] M. Julia, J.-M. Paris, Tetrahedron Lett., 1973, 14, 4833-4836.

[36] J. B. Baudin, G. Hareau, S. A. Julia, O. Ruel, Tetrahedron Lett., 1991, 32, 1175-1178.

[37] P. R. Blakemore, W. J. Cole, P. Kocienski, A. Morley, Synlett, 1998, 1998, 26-28.

[38] T. Okazoe, K. Takai, K. Utimoto, J. Am. Chem. Soc., 1987, 109, 951-953.

[39] [a] B. K. Shull, Z. Wu, M. Koreeda, J. Carbohydr. Chem., 1996, 15, 955-964;

[b] J. L. Regueira, C. R. Dantas, J. J. de Freitas, A. J. S. da Silva, J. R. Freitas Filho, P. H. Menezes, J. C. Freitas, Synthesis, 2016, 48, 1069-1078;

[c] S. B. Simelane, H. H. Kinfe, A. Muller, D. B. G. Williams, Org. Lett., 2014, $16,4543-4545$.

[40] R. Bukowski, L. M. Morris, R. J. Woods, T. Weimar, Eur. J. Org. Chem., 2001, 2697-2705.

[41] B. Tollens, Eur. J. Org. Chem., 1882, 15, 1635-1639. 
[42] B. Shanmugasundaram, A. K. Bose, K. K. Balasubramanian, Tetrahedron Lett., 2002, 43, 6795-6798.

[43] S. K. Sabui, P. Mondal, R. V. Venkateswaran, J. Chem. Res., 2002, 2002, 428-429.

[44] P. Levene, R. S. Tipson, J. Biol. Chem., 1931, 93, 631-644. 